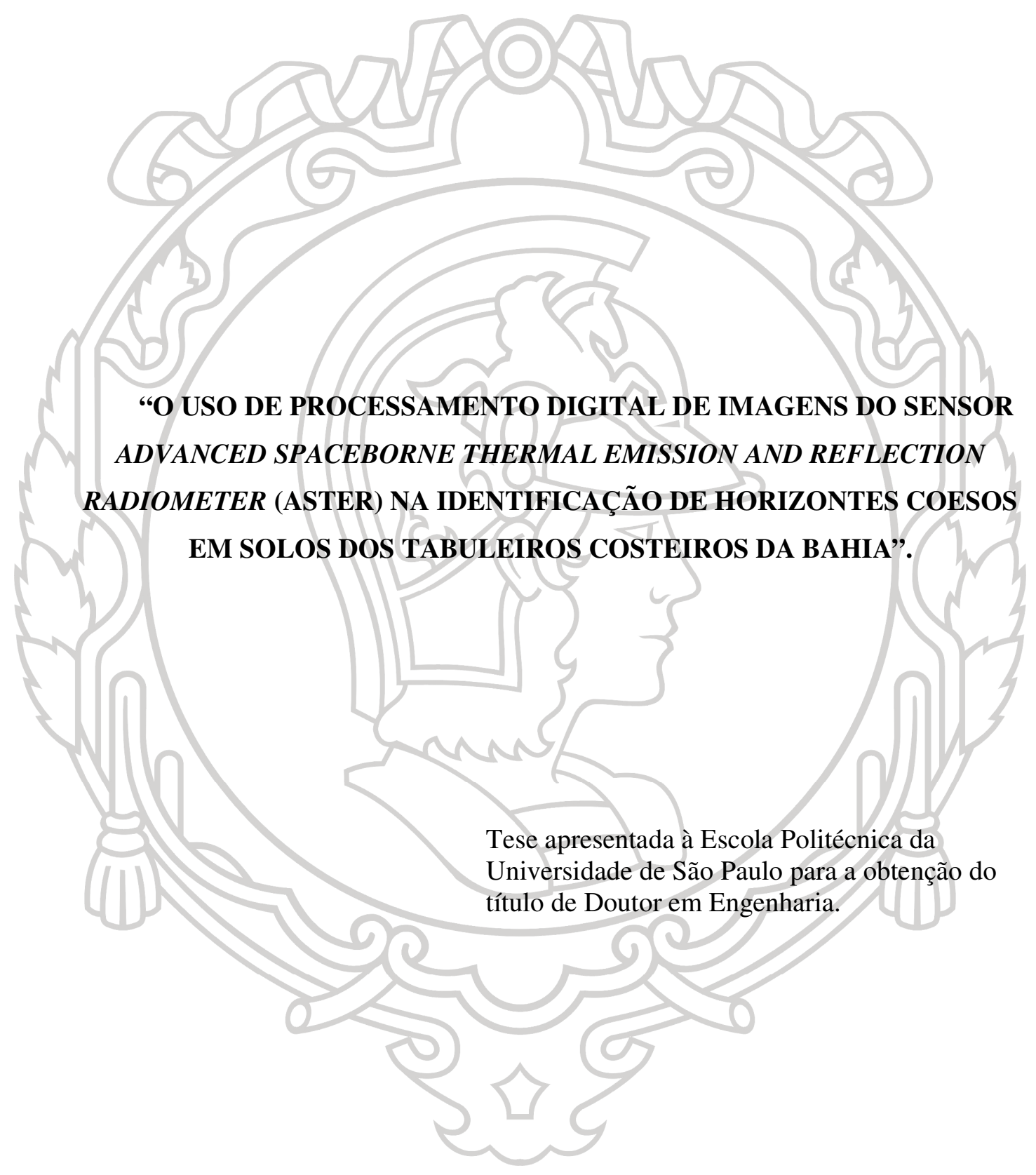

SÃO PAULO

2005 
ROSÂNGELA LEAL SANTOS

\section{“O USO DE PROCESSAMENTO DIGITAL DE IMAGENS DO SENSOR ADVANCED SPACEBORNE THERMAL EMISSION AND REFLECTION RADIOMETER (ASTER) NA IDENTIFICAÇÃO DE HORIZONTES COESOS EM SOLOS DOS TABULEIROS COSTEIROS DA BAHIA".}

Tese apresentada à Escola Politécnica da Universidade de São Paulo para a obtenção do título de Doutor em Engenharia.

Área de concentração:

Engenharia de Transportes

Orientador:

Prof. Dr. José Alberto Quintanilha.

SÃO PAULO

2005 
Este exemplar foi revisado e alterado em relação à versão original, sob responsabilidade única do autor e com a anuência de seu orientador.

São Paulo, 20 de Janeiro de 2006.

Assinatura do autor

Assinatura do orientador

SANTOS, ROSÂNGELA LEAL

O uso de processamento digital de imagens do sensor Advanced Spaceborne Thermal Emission and Reflection Radiometer (ASTER) na identificação de horizontes coesos em solos dos Tabuleiros Costeiros da Bahia / Rosangela Leal Santos - ed.rev. - São Paulo, 2005. 195 p.

Tese (Doutorado) - Escola Politécnica da Universidade de São Paulo. Departamento de Engenharia de Transportes.

1. Sensoriamento remoto 2. Processamento digital de imagens 3. Solos I. Universidade de São Paulo. Escola Politécnica. Departamento de Engenharia de Transportes II. t. 


\section{Dedicatória}

\section{Valéria Arlete Jun} Sandra Diana Socorro Risonete Wellison Áurea Lucedino Roberto Fabiana Elisangela Alessandra Neide Rosali Mariana Eduardo Olga Walquíria Washington Bayes Fernando Edvaldo Sofia Silvia

Ivy Luka Edson Simone Cidinha

Dani \& Pati Patrícia Zete Sara Conceição Cláudia (Margaret e Sousa) Renato Ricardo Celeste Elisa Danilo Tatti Jorgenes Daniel Oriana Agraci Adalberto César Josué Anaci Álvaro Zé Luis Gerardo Marilda Joselisa Odete Guiomar Zezé Augusto 


\section{Agradecimentos}

À Coordenação de Aperfeiçoamento de Pessoal de Nível Superior - CAPES pela Bolsa.

À UEFS, à direção do Departamento de Tecnologia, e a área de Geomensura, Geotecnia e Transportes, assim como todos os demais colegas, nas pessoas dos Professores Maria do Socorro Costa São Mateus, Washington Almeida Moura e João Carlos Batista Jorge, pela concessão do meu afastamento.

Ao Programa de Pós Graduação do Departamento de Engenharia de Transportes da Escola Politécnica da Universidade de São Paulo.

Ao meu orientador Prof. Dr. José Alberto Quintanilha por não ter desistido de mim.

À Copener Florestal (atual Bahia Pulp S.A.) pela concessão das informações dos solos referentes aos Projetos Altamira (I, II e III) bem como das cartas digitais da área, que foram utilizadas como verdade de campo.

Aos meus pais, que me deram a vida, e minha avó Guiomar, que me deu a direção e o ideal. Pelo pão e a poesia da minha vida.

Ao Prof. Dr. Lucedino Paixão Ribeiro, pelo amor à Ciência, ao Conhecimento e ao Trabalho, pela área de estudo e tudo mais que ele representou na minha vida acadêmica e na minha formação como pessoa e profissional.

À Prof. Dra. Risonete Batista, minha amiga-irmã que me fez relembrar dos meus sonhos e tomar uma decisão (além de ser a pessoa mais inteligente que eu conheço), e o não menos importante amigo-irmão Fernando Yamaguchi pelo tema ... e por Fernandinho em nossas vidas.

À minha amiga Valéria Assunção, por estar sempre ao meu lado, principalmente nos momentos mais difíceis e me dar total apoio e um gato. E minhas sinceras desculpas pelos momentos difíceis que a fiz passar... e pelo gato que eu perdi.

Aos meus fiéis amigos e colegas que seguraram a barra na minha ausência, principalmente a Professora Sandra Medeiros Santo, apesar de todas as agruras e dificuldades 
pelas quais passou, e a grande Prof. Dra. Rosali Fernandes, amiga que me suporta desde que tínhamos 3 anos de idade.

À minha mestra e amiga Prof ${ }^{a}$. Dra. Diana Hamburger por todo tempo, apoio, amizade e moedas brilhantes que ela me deu, e por combater ferozmente minha prosopopéia geográfica.

Ao meu amigo-irmão-gêmeo-siamês-separados-ao-nascer Eduardo Jun Shinohara. Entre nós não precisam palavras.

À Arlete Ohata pela alegria e amizade brilhante que iluminou meus dias mais negros e tornou minha vida aqui bem mais fácil.

Aos meus (espero ainda) amigos, José Roberto Rodrigues e Wellison Tatagiba de Araújo, pelos maravilhosos momentos que passamos juntos em busca do "café perfeito", no levantamento sistemático dos Shoppings Center da cidade e do corpus sano. A eles, pelos melhores momentos de descontração que passei.

À Elisangela Carneiro por ser quase eu.

Ao Prof. Dr. Edvaldo Simões, pelo exemplo e a palavra certa na hora certa.

Aos funcionários do PTR, Conceição, Edson, Cidinha, Simone, Sara, Flavinho, Arildo, Adalberto.

À minha fiel escudeira, Zete Nunes, que manteve o bom funcionamento da Estação.

Ao Sr. Edmundo Pereira pelas idas e vindas e a D. Cida pelos maravilhosos almoços dominicais ... e a ambos por me aceitarem em sua família e serem um exemplo de vida a ser seguido.

À Olga Iwai, pela calma presença constante e a Walquiria Fujii pelos e-mails.

À Neide Farran, minha primeira amiga por aqui, por seu sorriso e sincera amizade.

Aos que chegaram agora, mas que já se revelam para um grande futuro, e voltaram a fazer do Labgeo um lugar feliz: Alessandra Knopik, Mariana Giannotti e Patrícia Brito.

À Luka, Ivy, Cau, Cris, Cau_1, Cau_2, Paty e Dani.

À todos meus amigos e colegas que torceram por mim. 
"It can be the future. Buried deep within you, beneath the years of pain and anger, there is something beginning: the potential to make yourself a better man. That is what it is to be human: to make yourself more than you are."

Captain Jean-Luc Picard

(Star Trek, the New Generation - "Nemesis", 2003) 


\section{SUMÁRIO}

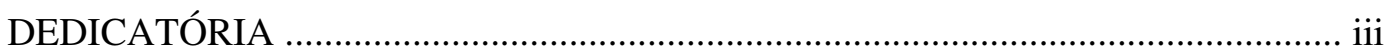

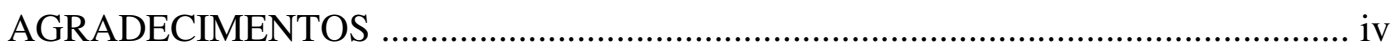

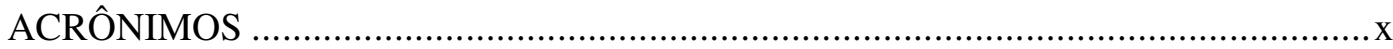

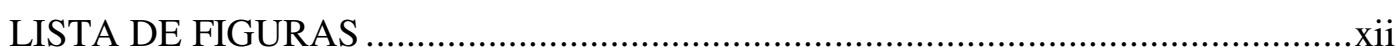

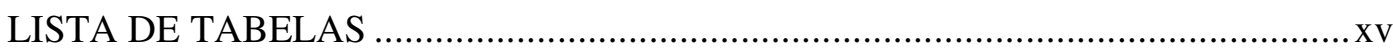

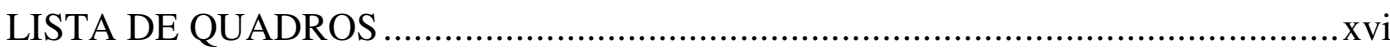

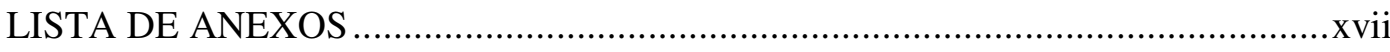

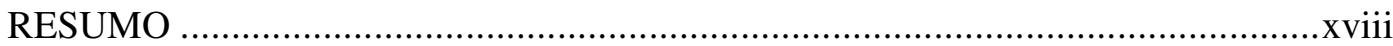

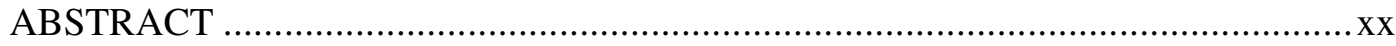

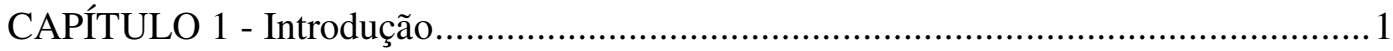

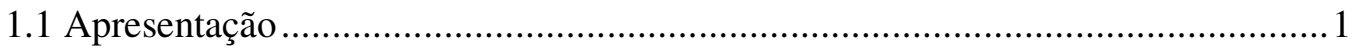

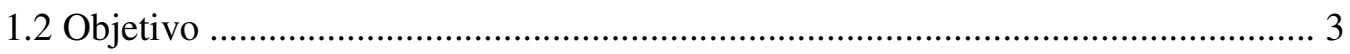

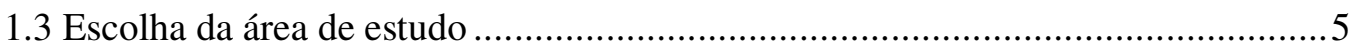

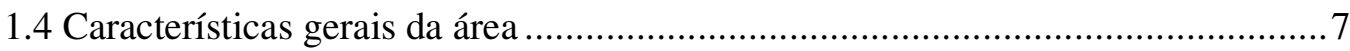

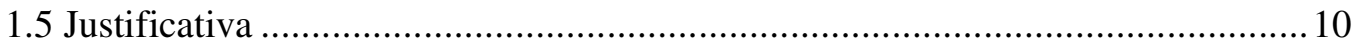

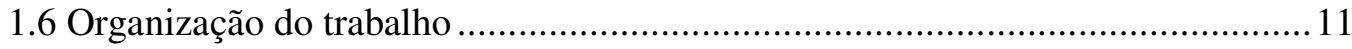

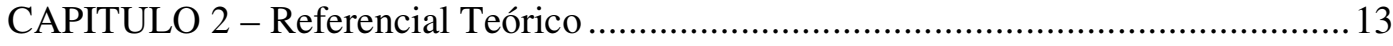

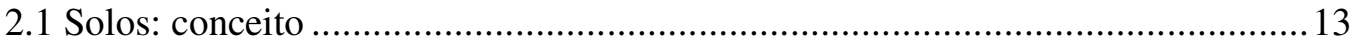

2.1.1 Os solos coesos dos Tabuleiros Costeiros................................................. 14

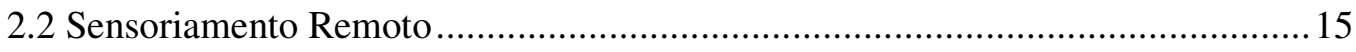

2.2.1 Autocorrelação e regularização em imagem de satélite............................... 15

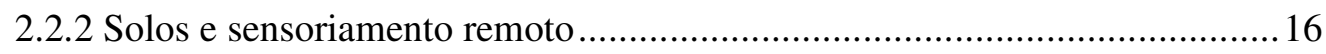

2.2.3 Os solos observados através dos sensores ópticos ................................... 18

2.2.4 O estado da arte do estudo dos solos através do sensoriamento remoto orbital

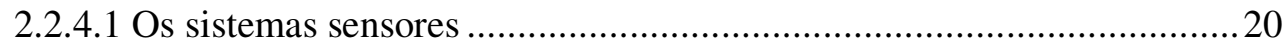

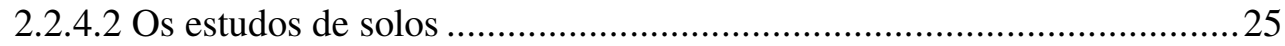

2.2.5 Fatores que influenciam a reflectância dos solos ...................................... 26

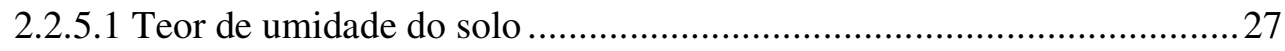

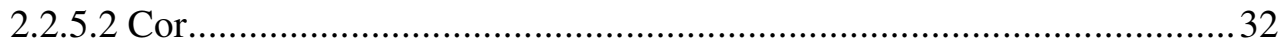

2.2.5.3 Composição mineralógica .......................................................... 33 


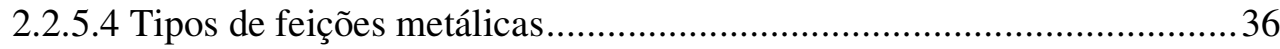

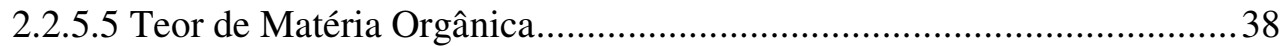

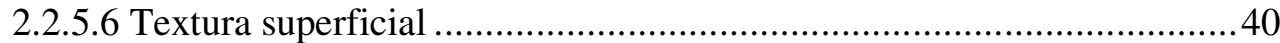

2.2.5.7 Tamanho e forma dos agregados ..................................................4

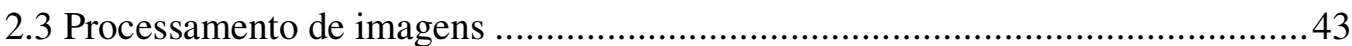

2.3.1 As técnicas exploratórias e de pré-processamento de imagens ....................44

2.3.1.1 As representações gráficas ...........................................................4 44

2.3.1.2 A análise de componentes principais ................................................45

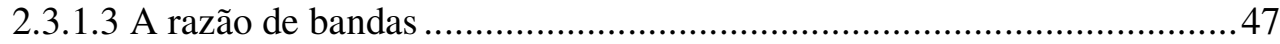

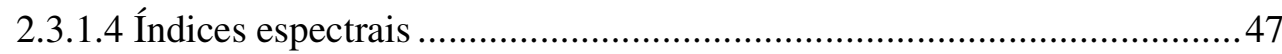

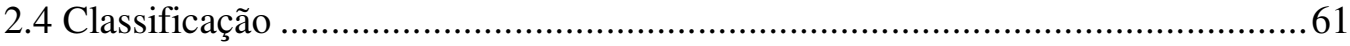

2.4.1 Problemas na classificação estatística de imagens de satélite.......................63

2.4.2 Erros na classificação de imagens de sensoriamento remoto........................64

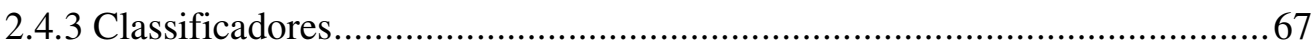

2.4.3.1 Os classificadores e os solos............................................................68

2.4.3.2 Estimador de Máxima Verossimilhança (Maxver) ..............................69

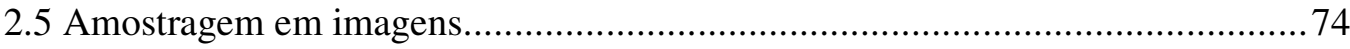

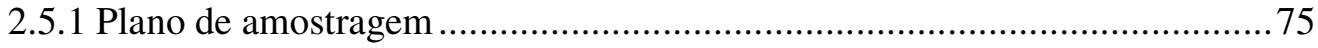

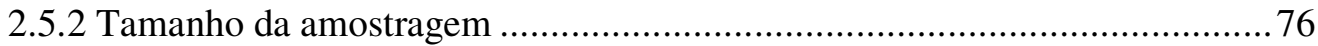

2.5.3 Número e dimensão dos polígonos amostrais ............................................77

2.6 Avaliação do desempenho da classificação ....................................................78

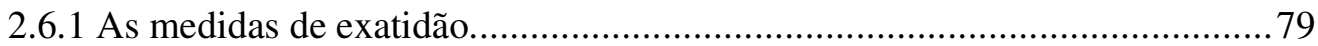

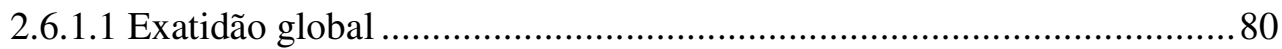

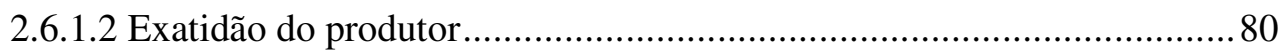

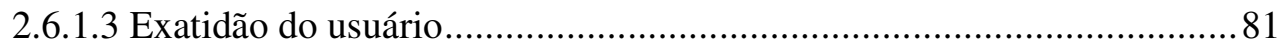

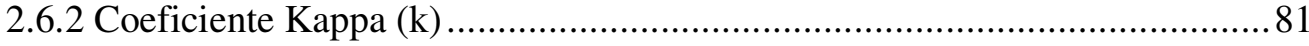

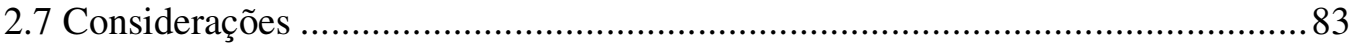

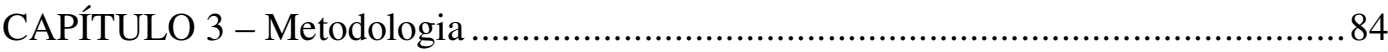

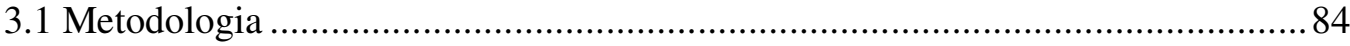

3.2 Material utilizado para o desenvolvimento do trabalho ...................................86

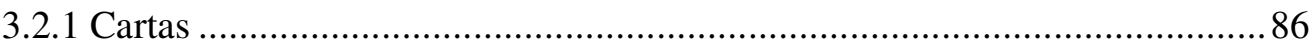

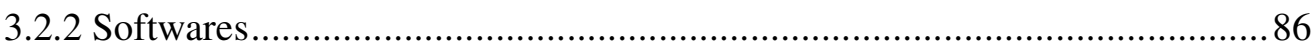

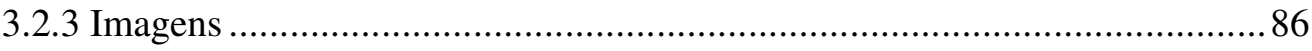

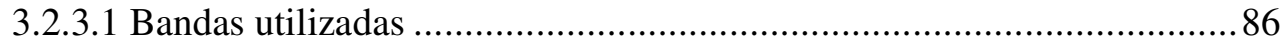




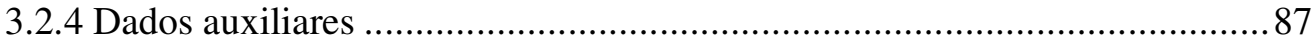

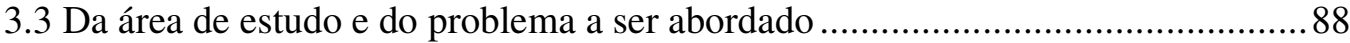

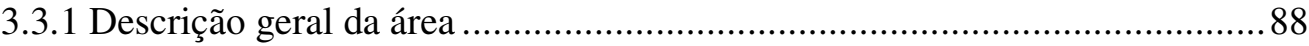

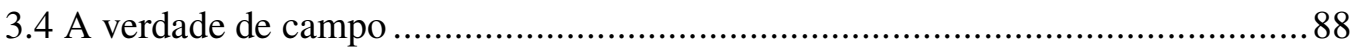

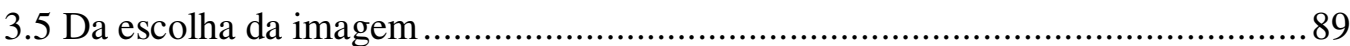

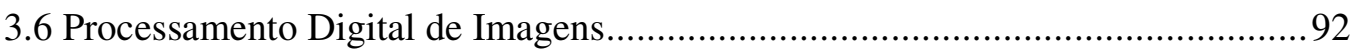

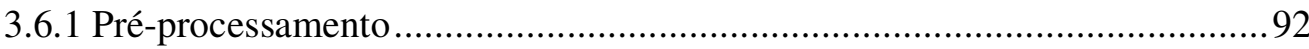

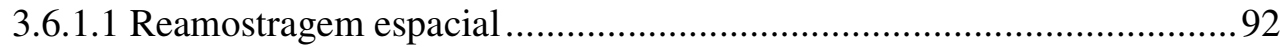

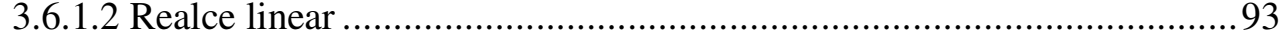

3.6.1.3 Análise exploratória dos dados ........................................................93

3.6.1.4 Análise de componentes principais....................................................94

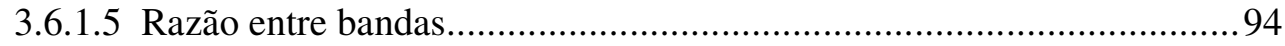

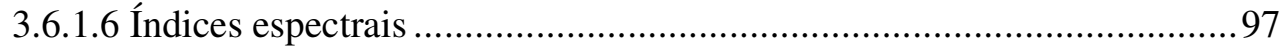

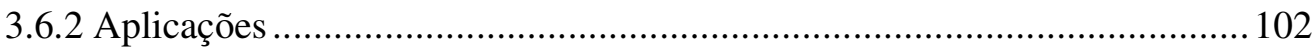

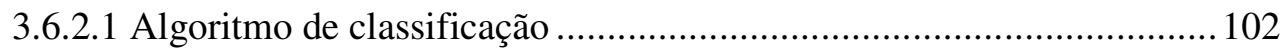

3.6.2.2 Amostragem para a classificação....................................................... 102

3.6.3 Avaliação do desempenho das diferentes técnicas de processamento..........110

3.6.3.1 O pré-processamento e a caracterização da área .................................. 110

3.6.3.2 Avaliação do desempenho da classificação........................................ 110

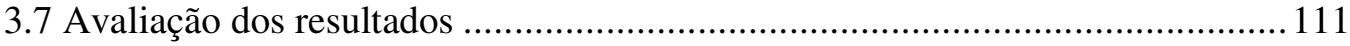

CAPÍTULO 4 - Resultados e Discussões ............................................................... 112

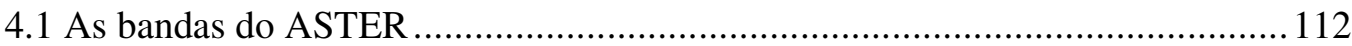

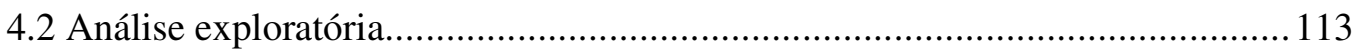

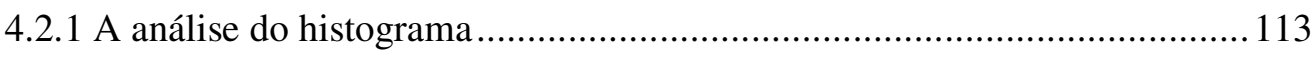

4.2.3 Diagramas de dispersão (scatterplot) .................................................. 115

4.2.4 Análise de bandas ............................................................................. 117

4.2.5 Caracterização das amostras das classes de solos (Verdade de Campo) .....119

4.3 Análise de Componentes Principais ............................................................. 122

4.3.1 A escolha da componente principal para estudos da umidade dos solos..... 129

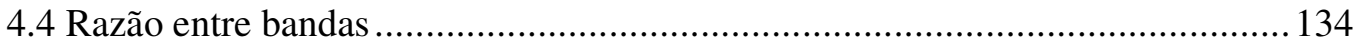

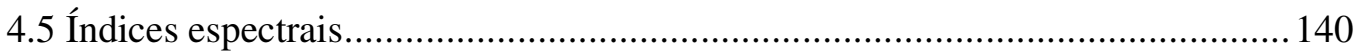

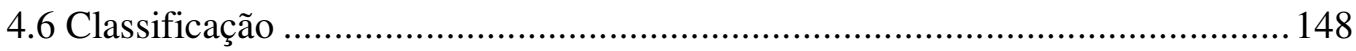

CAPÍTULO 5 - Conclusões e Recomendações ........................................................ 153

CAPÍTULO 6.0 - Referências Bibliográficas...................................................... 158 


\section{ACRÔNIMOS}

\begin{tabular}{|c|c|}
\hline $\mathrm{ACP}$ & Análise de Componentes Principais \\
\hline ASTER & Advanced Spaceborne Thermal Emission and Reflection Radiometer (Sensor) \\
\hline B & Brightness ou Brilho (Componente Tasseled-Cap) \\
\hline $\mathrm{CP}$ & Componente Principal \\
\hline \multicolumn{2}{|l|}{ Embrap } \\
\hline a & Empresa Brasileira de Pesquisa Agropecuária \\
\hline ENVI & Environment for Visualizing Image (Software) \\
\hline ETM+ & Enhanced Thematic Mapper Plus (sensor) \\
\hline FAO & Food and Agriculture Organization \\
\hline G & Greeness ou Verde (Componente Tasseled-Cap) \\
\hline HRV & Haute Résolution dans le Visible (sensor) \\
\hline HRVIR & Haute Résolution Visible et Infra Rouge (sensor) \\
\hline IR & Infrared \\
\hline IRS & Indian Remote Sensing Satellite (satélite) \\
\hline IV & Índice de Vegetação \\
\hline IVP & Infravermelho Próximo \\
\hline MODIS & Moderate Resolution Imaging Spectroradiometer (sensor) \\
\hline MS & MultiSpectral (sensor) \\
\hline MSS & MultiSpectral Scanner (sensor) \\
\hline NASA & National Aeronautics and Administration Space Agency \\
\hline ND & Número Digital \\
\hline NDMI & Normalized Difference Moisture Index \\
\hline NDVI & Normalized Difference Vegetation Index \\
\hline NIR & Near Infrared (Infravermelho Próximo) \\
\hline NOAA & National Oceanic and Atmospheric Administration \\
\hline $\mathrm{P}$ & Podzol (solo) \\
\hline PA & Podzólico Amarelo sem Coesão (solo) \\
\hline PAf & Podzólico Amarelo com Coesão (solo) \\
\hline
\end{tabular}




$\begin{array}{ll}\text { PAN } & \text { Panchromatic (sensor) } \\ \text { PC } & \text { Podzólico Acinzentado sem Coesão (solo) } \\ \text { PCf } & \text { Podzólico Acinzentado com Coesão (solo) } \\ \text { RGB } & \text { Red-Green-Blue (Vermelho-Verde-Azul) } \\ \text { RMSE } & \text { Root Mean Square Error (Erro Médio Quadrático) } \\ \text { SAVI } & \text { Soil Adjusted Vegetation Index } \\ \text { SPOT } & \text { Systéme Probatoire d' Óbservation de la Terre } \\ \text { Spring } & \text { Sistema de Processamento de Informações Georeferenciadas (Software) } \\ \text { SWIR } & \text { Shortwave Infrared } \\ \text { TIR } & \text { Thermal Infrared } \\ \text { TM } & \text { Thematic Mapper (sensor) } \\ \text { TTC } & \text { Transformação Tasseled-Cap } \\ \text { UM } & \text { Unidade Mínima } \\ \text { USDA } & \text { United States Department of Agriculture } \\ \text { USGS } & \text { United States Geological Survey } \\ \text { V } & \text { Vermelho } \\ \text { VNIR } & \text { Visible and Near Infrared } \\ \text { W } & \text { Wetness (Componente Tasseled-Cap) } \\ \text { Wetness } & \text { Umidade (Componente Tasseled-Cap) } \\ \text { WiFS } & \text { Wide Field Sensor (sensor) }\end{array}$




\section{LISTA DE FIGURAS}

Figura 1.1 - Localização da área de estudo no município de Esplanada (BA) ........................2

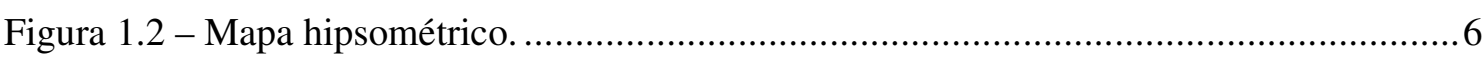

Figura 1.3 - Perfil esquemático das principais unidades geomorfológicas costeiras da Bahia.. 7

Figura 1.4 - Balanço Hídrico de Esplanada ...................................................................

Figura 2.1 - Interação do solo e das rochas com a energia solar........................................2

Figura 2.2 - Alteração da reflectância do solo pela presença da água. .................................29

Figura 2.3 - Variação da curva de reflectância de um solo em diferentes teores de umidade.. 29

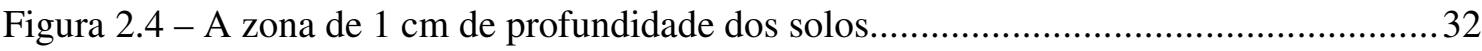

Figura 2.5 - Representação gráfica da transformação da componente principal .....................47

Figura 2.6 - Representação do NDVI como interação entre a radiação e a vegetação............53

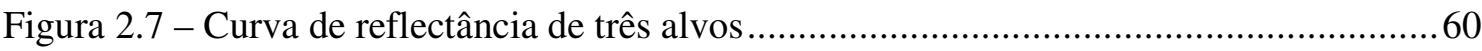

Figura 2.8 - Distribuição de classes no espaço amostral ...................................................... 70

Figura 2.9 - Intervalo de confiança indicando informação ............................................. 73

Figura 2.10 - Esquema de amostragem utilizados para determinação da acurácia.................75

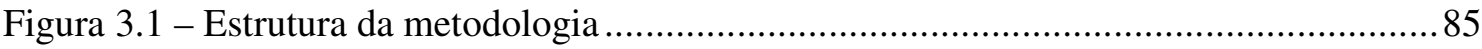

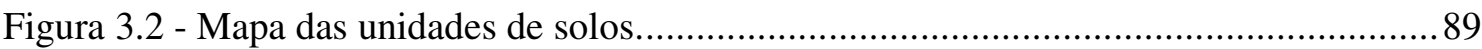

Figura 3.3 - Amostras de imagens ASTER (VNIR) e o problema da cobertura de nuvens ....90

Figura 3.4 - Amostragem histórica das melhores imagens Landsat 5 TM ..........................91

Figura 3.5 - Amostragem histórica das imagens do sensor Landsat 7 ETM ........................91

Figura 3.6 - Espectro obtido em laboratório de 4 solos com diferentes teores de água ...........95

Figura 3.7 - Distribuição das bandas do sensor ASTER no espectro eletromagnético...........96

Figura 3.8 - Diagrama metodológico de elaboração do Tasseled Cap .................................99

Figura 3.9 - Diagrama esquemático da relação do Brilho com o Verde e a Umidade............ 100

Figura 3.10 - Amostras coletadas para elaboração da Transformação Tasseled Cap ........... 102

Figura 3.11 - Imagem ASTER - cena completa, de 18/11/2002 ....................................... 105

Figura 3.12 - Determinação da área de amostragem e de classificação efetiva da imagem.. 107

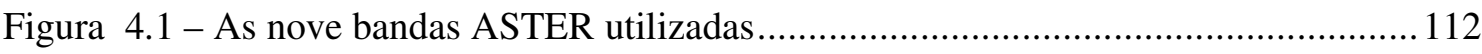

Figura 4.2 - Histograma original das imagens ASTER (Bandas 1-9) ................................. 115

Figura 4.3 - Distribuição das médias por banda, da cena de estudo.................................. 115

Figura 4.4 - Correlação entre os pares de bandas do sensor ASTER ( 1 a 9) ........................ 116

Figura 4.5 - Curvas de absorção de água, para diferentes teores de umidade. .....................118

Figura 4.6 - Composição colorida RGB (R:5-G:4-B:9) ............................................... 119 
Figura 4.7- Boxplot da distribuição das médias das classes de solos por bandas 120

Figura 4.8 - Boxplot da variância das classes de solo por banda 120

Figura 4.9 - Boxplot da média dos polígonos das classes de solos 121

Figura 4.10 - Boxplot da variância das classes 121

Figure 4.11 - Principais componentes das imagens do sensor ASTER (Bandas 1 a 9) 124

Figura 4.12 - Componente Principal 1 (CP1) 124

Figura 4.13 - Componente Principal 2 (CP2) ........................................................... 125

Figura 4.14 - Fatiamento “Arco íris” da segunda componente .......................................... 126

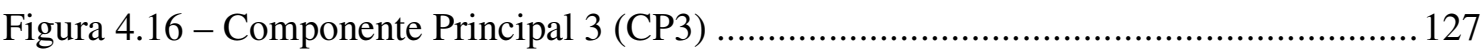

Figura 4.17 - Caracterização das feições extraídas da terceira componente......................... 128

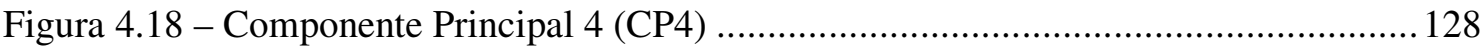

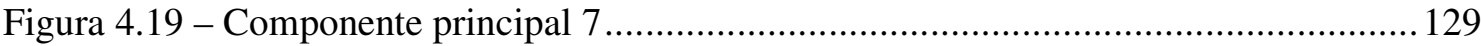

Figura 4.20 - Componente principal 7, com legenda em paleta bipolar............................. 130

Figura 4.21 - Fatiamento normal com 5 classes da sétima componente ........................... 131

Figura 4.22 - Componente principal 7 com fatiamento normal com 10 classes.................. 132

Figura 4.23- Fatiamento "Arco íris" da sétima componente ............................................... 132

Figura 4.24 - Variação das componentes principais considerando as diferentes condições de

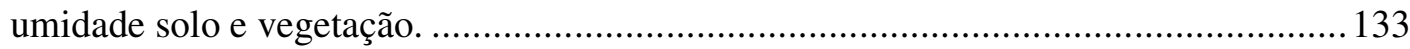

Figura 4.25 - Variação das componentes principais considerando as diferentes classes de solos da área de referência 134

Figura 4.26 - Razão entre as bandas VNIR x SWIR para diferentes condições de umidade de solo e vegetação.

135

Figura 4.27 - Razão entre as bandas SWIR mais significativas para a identificação do teor de água, para diferentes condições de umidade para solos e vegetação. 136

Figura 4.28 - Razão entre as bandas VNIR x SWIR para os solos em diferentes condições de umidade 136

Figura 4.30 - Imagem da razão entre bandas 3/8 139

Figura 4.31 - Gráfico comparativo dos índices espectrais para as diferentes condições de umidade do solo e vegetação. 140

Figura 4.32 - Conceito da linha do solo 141

Figura 4.33 - Variação do índice de Brilho segundo condições de umidade das amostras de solo. 142

Figura 4.34 - Variação do índice de Brilho segundo classes de solos 142 
Figura 4.35 - Gráfico comparativo dos índices espectrais para as diferentes condições de umidade do solo e vegetação. 144

Figura 4.36 - Variação dos índices espectrais segundo a classe de solos. 145

Figura 4.37 - Variação do índice de Umidade em solos com diferentes teores de umidade. 145 Figura 4.38 - Comparação dos resultados ente os índices NDMI e de Umidade para diferentes

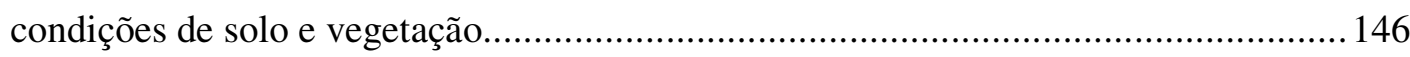

Figura 4.39 - Variação do NDVI segundo as condições de umidade dos solos. .................. 146

Figura 4.40 - Recorte de imagens dos índices espectrais com resultados mais significativos

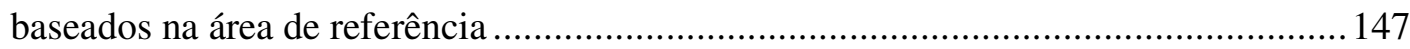

Figura 4.41 - Processo sumarizado de amostragem da área de referência. ......................... 148

Figura 4.42 - Polígonos amostrais no recorte da área útil da imagem a ser efetivamente

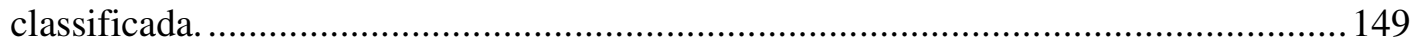

Figura 4.43 - Resultado da classificação MaxVer, com limiar de aceitação de 95\% ........... 150 


\section{LISTA DE TABELAS}

Tabela 1.1 - Pluviosidade Anual do Município de Esplanada (1999-2004) ........................... 8

Tabela 1.2 - Dados de Pluviosidade (P) em mm e Temperatura (T) em ${ }^{\circ}$ Celsius, referente ao município de Esplanada (Lat: $11^{\circ} 47^{\prime} /$ Long: $37^{\circ} 57^{\prime}$ - Alt: $181 \mathrm{~m}$ ), referente ao período

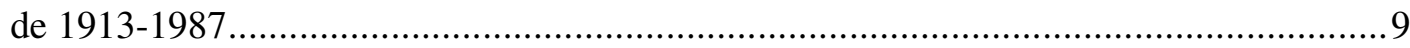

Tabela 3.2 - Razões de bandas entre as bandas VNIR e SWIR do sensor ASTER para

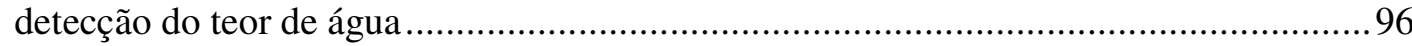

Tabela 3.3 - Área das unidades de solos: total, sob cobertura de nuvens e sombras e efetiva

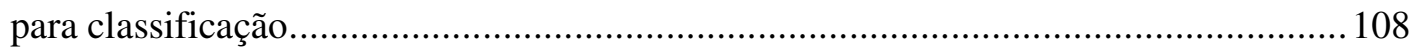

Tabela 3.4 - Área das Classes de Solos: total, sob cobertura de nuvens e sombras e efetiva

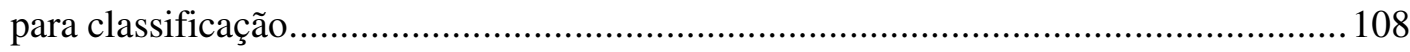

Tabela 3.3 Valores do Coeficiente Kappa e seu respectivo grau de concordância entre as amostras de uma classificação ................................................................................ 110

Tabela 4.1 - Resumo da performance do sensor ASTER ............................................. 113

Tabela 4.2 - Estatística descritiva das imagens ASTER (Bandas 1-9), da subcena de $1551 \mathrm{x}$ 1570 pixels - Esplanada (BA) 114

Tabela 4.3 - Estrutura de correlação da subcena 1551 x 1570 pixels, correspondente ao Município de Esplanada (BA) para as nove bandas do sensor ASTER 117

Tabela 4.4 - Componentes Principais: matriz de autovalores formado através da matriz de correlação. 123

Tabela 4.5.b - Exatidão do Produtor e Exatidão do Usuário para a Classificação Máxima Verossimilhança com limiar de aceitação de $95 \%$ 


\section{LISTA DE QUADROS}

Quadro 3.1 - Descrição das unidades de mapeamento de solos da área............................. 103

Quadro 3.2- Classificação das unidades dos solos segundo presença e tipo de horizonte coeso 104

Quadro 3.3 - Reclassificação das unidades de solo segundo a presença e o tipo de coesão .104 


\section{LISTA DE ANEXOS}

Anexo A - Dados climáticos do município de Esplanada/Bahia

Anexo B - Descrição do sensor ASTER

Anexo C - Tabela da Análise dos Componentes Principais

Anexo D - Tabelas de cálculo do Tasseled Cap

Anexo E - Descrição das unidades de solo da área de referência

Anexo F - Descrição da área de referência quanto às unidades de solo e seu recorte 


\section{RESUMO}

Os Tabuleiros Costeiros são unidades geomorfologicamente definidas, caracterizandose como formações sedimentares de topos aplainadas de grande extensão territorial, amplamente povoada, com intensa exploração econômica agropecuária, mas com a presença constante de restrições físicas ao uso agrícola, associadas à presença de solos com horizontes coesos em subsuperfície. A presença deste horizonte coeso reduz a profundidade efetiva dos solos, prejudicando a dinâmica da água no perfil e, principalmente, o aprofundamento do sistema radicular, reduzindo as taxas de infiltração de água, criando lençóis freáticos suspensos e que se desenvolvem particularmente sob os Latossolos Amarelos (Latossolos Amarelos) e os Argissolos Amarelos (Podzólicos Amarelos). Assim, a presença destes horizontes em áreas úmidas, pode ser associada a um maior teor de umidade nos solos, que pode ser captada pelo sensor.

Devido a sua natureza pedológica e sua localização em sub superfície e sua grande extensão, estes solos demandam grandes recursos para sua efetiva localização e mapeamento. A aplicação de técnicas de processamento digital de imagens nas imagens do sensor ASTER, um sensor experimental e pouco explorado, possibilita a redução de custos, empregados nos levantamentos exploratórios para localização destes horizontes coesos.

O principal objetivo deste trabalho foi submeter imagens obtidas através do sensoriamento remoto óptico orbital, do sensor ASTER, a diferentes técnicas de processamento digital de imagens, para assim identificar, reconhecer e caracterizar a presença dos horizontes coesos nos solos dos Tabuleiros Costeiros da Bahia, utilizando como critério identificador, o teor de umidade dos solos.

O trabalho foi desenvolvido numa área de aproximadamente $2.475 \mathrm{~km}^{2}$, onde está inserida uma área de referência de $29 \mathrm{~km}^{2}$, situada no município de Esplanada, onde predominam solos da mesma Classe (Podzólicos Amarelos e Acinzentados) mas diferenciados em unidades que possuem diversos graus de coesão, com textura que varia de arenosa a argilosa. Foi utilizada uma única cena ASTER, sob a qual foi extraída oitenta amostras para determinar a relação entre o teor de umidade dos solos e as diferentes técnicas de processamento digital de imagens. Foram realizadas vinte e seis técnicas de realce (análise componentes principais, Transformação Tasseled Cap, NDVI, NDMI, SAVI e vinte e uma razões entre bandas do sensor ASTER), além da aplicação de uma classificação supervisionada (método da máxima verossimilhança), com limiar de aceitação de $95 \%$. 
Os resultados demonstraram que a sétima componente principal é o melhor produto para mapear a presença dos horizontes coesos, por melhor identificar a umidade do solo; o NDMI, o SAVI e a Umidade obtida através da Transformação Tasseled Cap têm um comportamento similar entre si, mas com resultados menos evidentes e entre as razões entre as faixas espectrais testadas, os melhores resultados foram as razões entre as faixas 1 e 8 e entre as faixas 3 e 8 .

Palavras-chave: Processamento digital de imagens; Solos coesos; Sensoriamento remoto 


\section{ABSTRACT}

The Coastal Tableland are units geomorfologicaly defined, characterized by sedimentary formations of smoothed tops of great territorial extension, widely populated, with intense agricultural economic exploration, but with the constant presence of physical restrictions to agricultural use, that are associated to cohesion horizons in subsurface. The presence of this cohesion horizon reduces the soil's depth, harming the dynamics of the water in the profile and, mainly, the radicular system of depth, reducing the water infiltration rates and creating suspended sheets particularly under Yellow Latossol and Yellow Podzolic. Thus, the presence of these horizons in humid areas can be associated with higher moisture levels in the soils that can be caught by the sensor.

Due to its pedologic nature, sub surface and great extension location, these soil demand great resources for its effective localization and mapping. The application of techniques of image digital processing in the images of the ASTER sensor, an experimental and few explored sensor, turns possible the reduction of costs, used in the exploratory searches for the localization of these cohesion horizons.

The main objective of this work was to submit images obtained through the orbital optical remote sensed, of the ASTER sensor, the different image digital processing techniques, in order to identify, to recognize and to characterize the cohesion horizons soil of Coastal Tableland of Bahia, using as identification criteria, the soil moisture contents .

The work was developed in an area of $2.475 \mathrm{~km}^{2}$ approximately, where an area of reference of $29 \mathrm{~km}^{2}$ is inserted, situated in Esplanada city of, where soil of the same class prevail (Yellow and Grey Podzólicos) but differentiated in predominate units that possess diverse cohesion degrees, with texture that varies of sandy the loamy. An only ASTER scene was used, under which it was extracted eighty samples to determine the relationship between the the soil moisture contents and the different images digital images processing techniques. Twenty-six techniques of distinction had been carried through (principal components analysis, Tasseled Cap Transformation, NDVI, NDMI, SAVI and twenty bands ratio on the ASTER sensor bands), beyond the application of a supervised classification (Maximum Likelihood method), with threshold of $95 \%$ acceptance.

The results had demonstrated that the seventh principal component is the best product to map the cohesion horizons presence and to identify the soil moisture contents; the NDMI, the SAVI and the Wetness obtained through the Tasseled Cap Transformation have a similar 
behavior, but with less evidences relating the results and, the ratio bands tested, the best results had been those found between bands 1 to 8 and bands 3 to 8 .

Keywordss: Digital image processing; cohesion soil; remote sensing 


\section{CAPÍTULO 1 - Introdução}

\subsection{Apresentação}

O ecossistema dos Tabuleiros Costeiros estende-se desde o Amapá até o Rio de Janeiro, ocupando uma área de cerca de 20 milhões de hectares, dos quais metade encontra-se na Região Nordeste, correspondendo a cerca de $11 \%$ da área total dos Estados da Bahia (Figura 1.1). Esse ecossistema apresenta grande potencialidade para uso agrícola, principalmente para a produção de alimentos, devido à topografia plana a suavemente ondulada, que favorece a mecanização, e ao mercado consumidor que os grandes centros urbanos, localizados nos tabuleiros, representam. No entanto, os solos desse ecossistema apresentam várias limitações agrícolas como baixa fertilidade natural, aumento da acidez com a profundidade, caráter álico, baixa capacidade de troca de cátions (CTC), baixa saturação por bases e baixa capacidade de retenção de água. Entretanto, o maior problema dos Tabuleiros Costeiros é a presença de horizontes coesos. Este tipo de problema é bastante estudado em várias partes do mundo, onde se busca analisar o comportamento natural de um conjunto de solos que se tornam endurecidos quando secos, e friáveis quando úmidos, seja em seu conjunto, ocorrendo em todo o perfil, seja apenas no desenvolvimento de determinados horizontes ou camadas. No Brasil, os solos com esse comportamento são conhecidos como solos coesos ou solos com horizontes coesos. A presença deste horizonte coeso reduz a profundidade efetiva dos solos, prejudicando a dinâmica da água no perfil e, principalmente, o aprofundamento do sistema radicular, reduzindo as taxas de infiltração de água, criando lençóis freáticos suspensos e que se desenvolvem particularmente sob os Latossolos Amarelos (Latossolos Amarelos) e os Argissolos Amarelos (Podzólicos Amarelos).

O uso das técnicas de sensoriamento remoto pode auxiliar na identificação da presença destes solos com horizontes coesos. Com o advento de novos sensores de detecção de informações ambientais, a adoção de técnicas mais modernas de aquisição de dados tornam-se possíveis para os estudos pedológicos. Neste aspecto, o estudo do caráter espectral vem se destacando em uma série de trabalhos que demonstram a potencialidade na caracterização e discriminação dos solos.

Com a evolução dos sensores remotos, o aumento das capacidades de processamento e armazenamento computacional, a integração entre os dados provenientes do sensoriamento remoto com os de outras bases de dados, por exemplo através de sistemas de informações geográficas, podem ser utilizados com mais eficácia como um meio de facilitar os levantamentos, identificação e mapeamento das diferentes feições dos solos. 
Os sistemas em muito evoluíram desde a utilização inicial das fotografias aéreas na década de 40, passando pelos sensores orbitais multiespectrais da série Landsat (MSS, TM e ETM) e os da série Spot. Esses sensores, assim como tantos outros que surgiram no decorrer da década de 80 , com raras exceções, não possuíam uma boa performance para avaliar as diferentes feições dos solos, principalmente o teor de umidade. A partir do final da década de 90, ocorreu uma verdadeira "explosão" na área de inovação e melhoria de sistemas sensores, abrangendo as diversas resoluções, seja a espacial (IRS - 5.8m; Ikonos - 1m e 4m; Quickbird - 0.6m e 2.5m), ou a espectral (ASTER - 14 bandas; MODIS - 36; Hyperion - 220) . Estes sensores estão gerando uma grande quantidade de dados, que servem para diferentes aplicações em várias áreas de conhecimento, entre elas a pedologia.

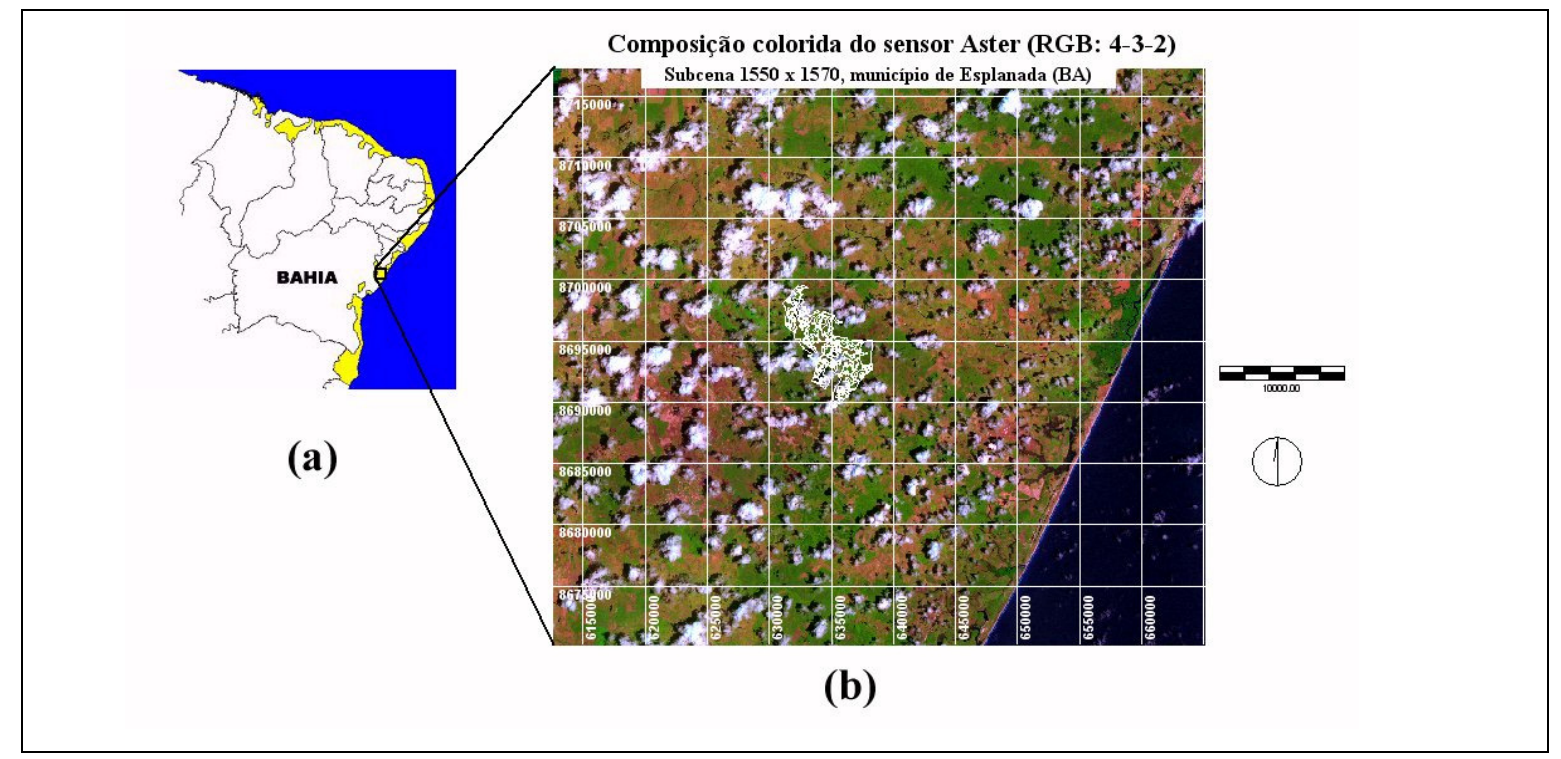

Figura 1.1 - Localização da área de estudo no município de Esplanada, Estado da Bahia. (a) Localização da area no Estado da Bahia, em relação à região Nordeste do Brasil. Em amarelo, a distribuição dos Tabuleiros Costeiros; (b) Imagem ASTER em composição colorida (RGB-432), na região central, em linhas brancas a verdade de campo

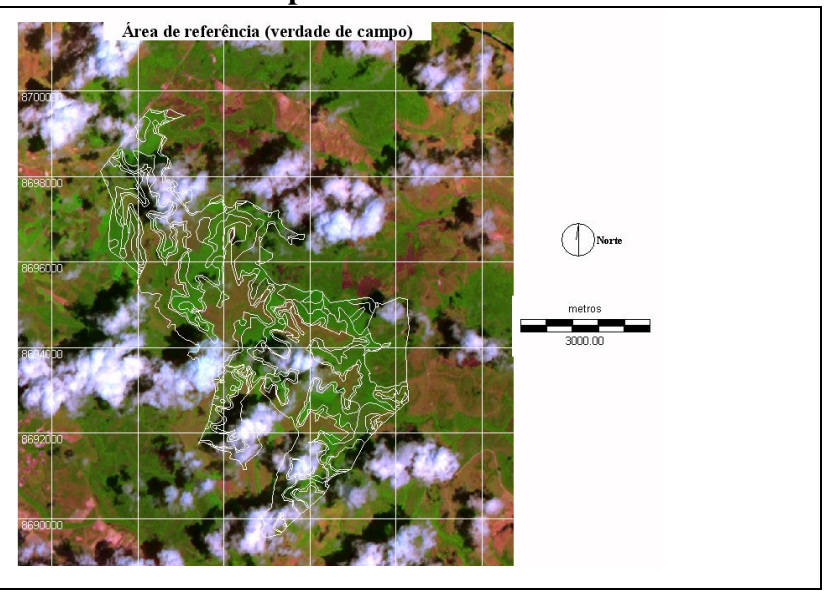

(c) Contorno da área da verdade de campo, em composição colorida ASTER (RGB: 4-32). 
Os solos, como objetos de estudos per si para o sensoriamento remoto, constituem-se em uma superfície natural, formada pela combinação heterogênea de vários elementos de diferentes composições, tamanho, forma e distribuição espacial. A combinação destes elementos pode ser descrita em termos de propriedades dos solos como: a classe textural, a composição mineralógica, o teor de matéria orgânica e a umidade. A camada do solo que está em contato com a atmosfera possui uma certa rugosidade, que pode ser devido à presença de agregados, sulcos provocados tanto pelo fluxo de água superficial, como pelo acúmulo de sedimentos depositados pela redução da energia de transporte da água de escoamento, crostas superficiais, ou efeito da ação humana, como aração e preparo dos solos para o plantio, seja de forma manual ou mecânica. Esta mesma interface pode também conter pedras, detritos de plantas e outros materiais e é onde se desenvolve a vida vegetal, em suas várias formas, desde as algas até as árvores, assim como as atividades agrícolas anuais que podem ter um impacto importante na estrutura da superfície. Por outro lado, seu uso e manejo podem apresentar dificuldades pelas propriedades físicas, químicas ou topográficas específicas destes solos, que são representadas tipicamente por uma ou mais classes de solos. Este é o caso da formação e desenvolvimento de horizontes coesos nos solos dos Tabuleiros da Região Nordeste do Brasil, que geralmente possuem vários problemas agronômicos a ele associados, tais como: restrição ao cultivo e aumento do impedimento físico para crescimento de raízes.

Toda esta complexidade de elementos em superfície apresenta uma certa orientação espacial, que são conhecidas tecnicamente como declividade e exposição da encosta. $\mathrm{O}$ conjunto destes fatores devem ser levados em consideração quando o objetivo é determinar e caracterizar o comportamento dos solos e de seus atributos, utilizando sistemas sensores como meio de obtenção de dados para análise.

\subsection{Objetivo}

Embora seja parte do objetivo deste trabalho utilizar os produtos de sensoriamento remoto óptico orbital para identificar, reconhecer e caracterizar a presença dos horizontes coesos nos solos dos Tabuleiros Costeiros da Bahia, que, em si já se constitui em uma inovação metodológica na solução de um problema tão espacialmente abrangente (10 milhões de hectares em todo o Nordeste e mais de 1 milhão de hectares somente no Estado da Bahia), quanto social e economicamente (mais de uma centena de municípios e uma população de mais de 2 milhões ${ }^{1}$ ), buscou-se ir além de uma das possibilidades de solução desta

\footnotetext{
${ }^{1}$ Fonte: Censo Demográfico 2000, IBGE
} 
problemática geral. Neste contexto, o principal objetivo deste trabalho baseou-se em um tripé composto pela metodologia, a técnica e o próprio objeto:

- Na metodologia foi a aplicação e avaliação de diferentes métodos já consagrados pela bibliografia e a adaptação de seu uso para a identificação dos horizontes coesos em solos dos Tabuleiros Costeiro;

- O técnico foi a seleção de um sensor óptico mais adequado ao estudo dos solos, no caso o ASTER, pouco utilizado, e com poucos trabalhos publicados, ao menos quando do início desta pesquisa, mas com grande potencialidade, especialmente nas suas bandas do infravermelho médio, pouco exploradas até hoje, na área de estudo dos solos e, menos ainda, no que se refere ao seu teor de umidade;

- O do objeto foi o próprio estudo dos solos através do sensoriamento remoto óptico, principalmente no que se refere ao seu teor de umidade, que encontra-se com uma grande defasagem bibliográfica, onde muito pouco foi feito nos últimos quinze anos.

O trabalho foi desenvolvido numa área de aproximadamente $2.475 \mathrm{~km}^{2}$, onde está inserida uma área de referência de $29 \mathrm{~km}^{2}$, situada no município de Esplanada, onde predominam solos da mesma Classe (Podzólicos Amarelos e Acinzentados) mas diferenciados em unidades que possuem diferentes graus de coesão, com textura que varia de arenosa a argilosa. A área de referência foi utilizada como nossa verdade de campo, e corresponde a uma área com mapeamento de solos detalhado, em escala 1:10.000, elaborado pela Copener Florestal Ltda., no período de 2001 a 2003, pelo método de levantamento pedológico convencional (Figura 1.1 (b) e (c)).

A questão básica deste trabalho pode ser descrita como: "Utilizando-se os dados do sensor ASTER analisados através de técnicas de processamento digital de imagens, haveria condições de se discriminar a presença dos solos com horizontes coesos e seus diferentes níveis de coesão dos solos e identificar e caracterizar os feições envolvidos, de tal forma que estes resultados pudessem auxiliar os levantamentos pedológicos?"

A hipótese a ser testada é a de que é possível discriminar os solos com horizontes coesos em seus diferentes níveis de coesão, através da variação do seu teor de umidade, que altera os valores da energia refletida e, conseqüentemente, a representação em níveis de cinza nas imagens orbitais.

A fisiografia geral da área de referência, como o relevo aplainado e a homogeneidade da vegetação, assim como as informações disponíveis (o mapeamento dos solos em escala 1:10.000), o levantamento bibliográfico abrangendo o conhecimento básico das propriedades 
ópticas dos elementos dos solos adquiridos e testadas ao longo dos últimos 50 anos, tanto em laboratório com controle de iluminação e da geometria da visada, como nos levantamentos de campo sob iluminação solar direta, possibilitou a escolha do método empregado, e a conseqüente escolha das técnicas de processamento digital de imagens, e a aplicação das técnicas de classificação supervisionada, do tipo pixel-a-pixel para a identificação das feições, permitindo caracterizar as diferentes unidades de solos.

A partir da escolha da metodologia de análise, buscando testar a hipótese levantada, o trabalho foi conduzido, tendo como principais objetivos específicos:

- Caracterização do comportamento espectral de solos em resposta às diferentes técnicas de pré-processamento aplicadas e sua correlação com os diferentes teores de umidade;

- Verificar o nível e o grau de separabilidade das unidades de mapeamento através das respostas específicas ao teor de umidade em sua caracterização espectral;

- Adaptar os índices espectrais (NDVI, SAVI, NDMI e Tasseled Cap) e suas respectivas interpretações ao teor de umidade dos solos e aos parâmetros do sensor ASTER.

- Avaliar a eficiência da metodologia empregada, através dos resultados da classificação, em relação ao mapa de solos utilizado como "verdade de campo".

O estudo dos solos através de produtos orbitais e processamento digital de imagens está em constante desenvolvimento, posto a grande variedade de fatores que interferem na formação complexa dos solos, assim como a constante melhoria e aperfeiçoamento dos instrumentos e sensores, e a constante necessidade de dados mais específicos e detalhados sobre sua funcionalidade. Utilizando o conhecimento acumulado ao longo das décadas, esperamos, com nosso trabalho, dar nossa pequena contribuição ao já extenso, mas ainda incompleto cabedal do sensoriamento remoto nas ciências pedológicas.

\subsection{Escolha da área de estudo}

Vários fatores foram considerados na escolha da área de estudo. O principal é que a área de Altamira (município de Esplanada) se constitui na área piloto do Projeto Tabuleiros Costeiros, num convênio UFBA/Embrapa-Solos, buscando solucionar os problemas decorrentes da existência de solos com horizonte coeso dos diferentes tipos de solos desta formação geomorfológica, de onde surgiu a hipótese da possibilidade de se identificar e localizar esta feição através de imagens de satélite. Associado a isso, o fornecimento de um mapeamento detalhado dos solos (escala 1:10.000) pela empresa Copener Florestal, 
contribuiu para a determinação de uma verdade de campo sobre a qual foi possível elaborar a classificação em condições de controle das variáveis da área (Figura 1.1 (b) e (c)).

A área de estudo possui baixa variação de altitude (Figura 1.2). Possui uma variabilidade climática paralela à linha do litoral em direção ao interior (direção oeste) com uma progressiva redução de pluviosidade. Os solos são profundos, com predomínio dos Latossolos e dos Podzólicos Amarelos.

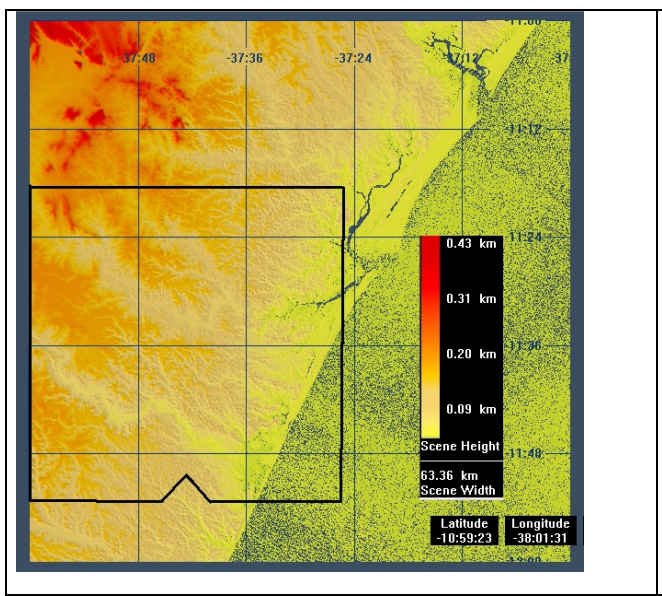

(a)

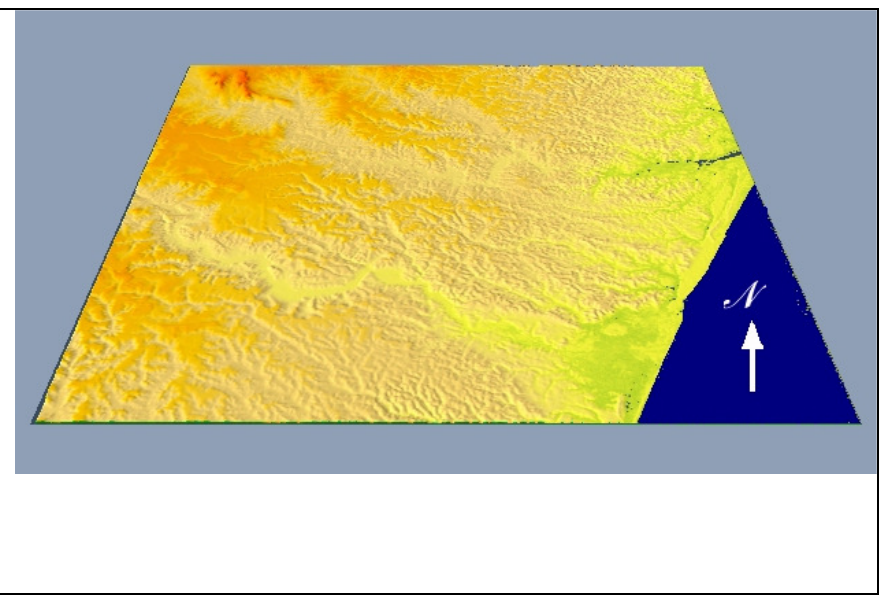

(b)

Figura 1.2 - Mapa hipsométrico, destacando a forma aplainada com baixas variações de altitude, típicas de deposições sedimentares. (a) Mapa hipsométrico; (b) Visada 3D da área selecionada (Foram utilizados os dados do SRTM).

A área da verdade de campo, concentrou-se na abrangência dos Projetos Altamira I, II e III, correspondendo a uma área de $29 \mathrm{~km}^{2}$, o que possibilitou um controle das variáveis dos solos. $\mathrm{Na}$ área de referência, a topografia é plana e os solos são profundos, com baixa fertilidade natural e reduzida capacidade de armazenamento de água (Figura 1.4 e 1.5(c)). Nestas áreas a altimetria varia apenas de 101 m à 135 m, e constitui-se numa monocultura de eucalipto (Eucaliptus sp).

O retângulo envolvente da área tem como coordenadas:

- Canto inferior esquerdo:

$$
\text { ○ } \mathrm{x}_{1}=612630 \mathrm{E}\left(\mathrm{MCF}=39^{\circ} \mathrm{W}\right) \quad \mathrm{y}_{1}=8670199 \mathrm{~N}
$$

- Canto superior direito

$$
\text { ○ } \mathrm{x}_{2}=665175 \mathrm{E}\left(\mathrm{MCF}=39^{\circ} \mathrm{W}\right) \quad \mathrm{y}_{2}=8717299 \mathrm{~N}
$$




\subsection{Características gerais da área}

Os Tabuleiros Costeiros ocorrem em uma faixa intermitente ao longo da costa, formando uma planície com elevações que variam de 30 a 150m acima do nível do mar, com grande potencial agrícola, sobretudo para culturas perenes. Possuem topografia plana e solos profundos com baixa fertilidade natural e reduzida capacidade de armazenamento de água (Figura 1.3).

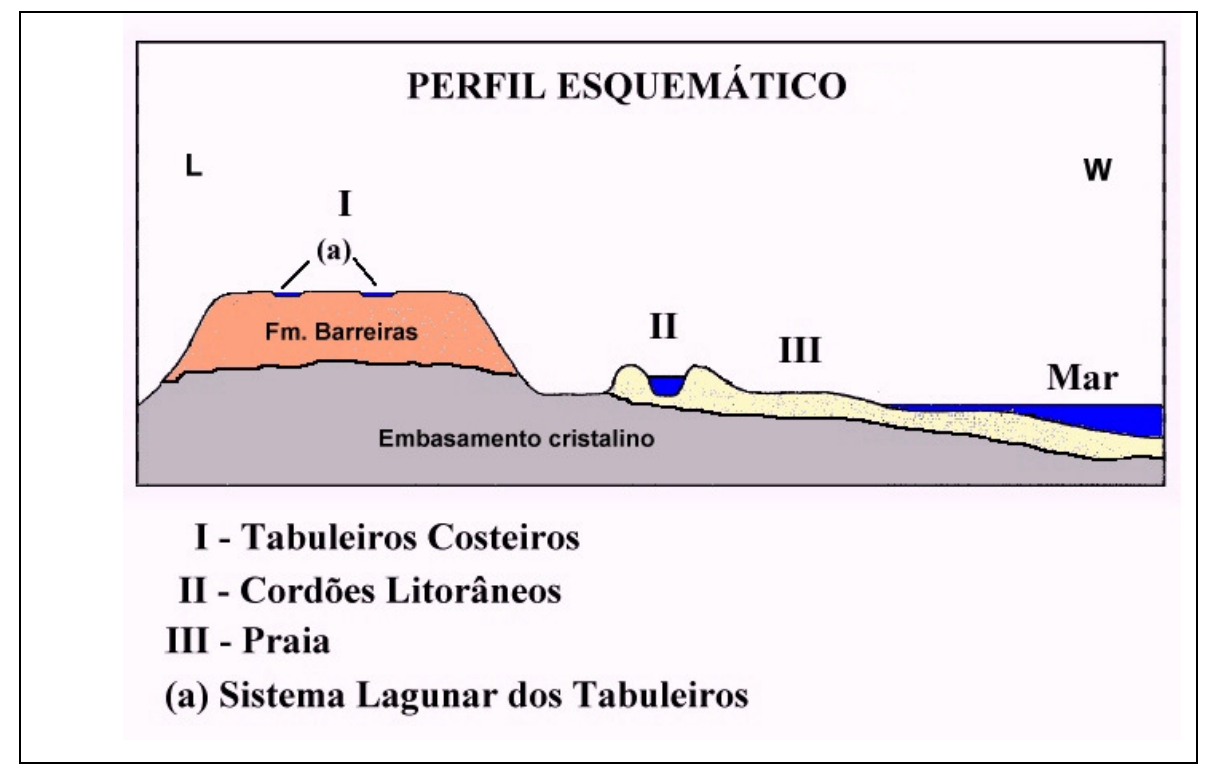

Figura 1.3 - Perfil esquemático das principais unidades geomorfológicas costeiras da Bahia.

Os Tabuleiros Costeiros constituem uma cobertura sedimentar terrígena continental de idade plio-pleistocênica, depositada por sistemas fluviais entrelaçados e associados a leques aluviais sobre o embasamento cristalino, e ocorrem ao longo de todo litoral brasileiro onde este recebe a denominação genérica de Grupo Barreiras. No Estado da Bahia, o Grupo Barreiras pode ser encontrado ao longo de toda a faixa costeira, com as ocorrências mais importantes nas regiões extremo sul e nordeste. Estas áreas são palco de marcante ocupação antrópica como atividades agro-pastoris e expansão do turismo. Estas atividades são potencialmente causadoras de desequilíbrio do meio ambiente, através de interferências no meio físico. Os sedimentos do Barreiras são também fonte importante de materiais de construção e de cerâmica, além de constituírem, em alguns locais, aqüíferos importantes, responsáveis pelo abastecimento de água de algumas cidades e vilarejos. A formação dos horizontes coesos nos solos desta formação estaria associada a processos pedogenéticos complexos, envolvendo tanto a idade e a composição do material pedogeneizado, a natureza 
ácida da matéria orgânica como as práticas agrícolas não conservacionistas comuns na região. Assim, a formação destes horizontes se associa a solos antigos, com elevado grau de intemperismo (Podzol, Podzólicos e Latossolos) em regiões planas, que facilitam a infiltração da água, com tradicional atividade agrícola que aceleraram os processos de formação de ácidos húmicos de baixa complexidade. No município de Esplanada, a precipitação anual média é de $1104 \mathrm{~mm}$, sendo que, de 1999 a 2004, a precipitação anual variou de 626mm (2001) à 1421mm (2000) (Tabela 1.1). Climatologicamente, o período chuvoso predominante concentra-se no quadrimestre abril-julho, com máximo em maio (Tabela 1.2), apesar da pluviosidade, em geral, ser bem distribuída durante todo o ano (Araújo e Rodrigues, 2000). Os principais sistemas causadores de chuva nesta região são os distúrbios de leste (ventos alísios de Sudeste, originados pelo Anticiclone Semifixo do Atlântico Sul), os sistemas frontais e os sistemas de brisa, sendo que este último atua durante todo o ano (Araújo e Rodrigues, 2000). Este aspecto garante uma constante nebulosidade na região, mesmo não se traduzindo em pluviosidade. Conseqüentemente a este fato, a elevada nebulosidade na região não se torna perceptível pela simples análise da média pluviométrica da região, como apresentado na Tabela 1.2, ou no seu Balanço Hídrico, expresso na Figura 1.4, o que caracteriza a área como região de passagem para as nuvens carregadas de umidade em direção ao interior do estado.

Tabela 1.1 - Pluviosidade Anual do Município de Esplanada (1999-2004)

\begin{tabular}{c|c}
\hline Ano & Precipitação $(\mathbf{m m})$ \\
\hline 1999 & 661,0 \\
\hline 2000 & 1421,3 \\
\hline 2001 & 626,1 \\
\hline 2002 & 1201,7 \\
\hline 2003 & 899,9 \\
\hline 2004 & 2 \\
\hline
\end{tabular}

Os Tabuleiros Costeiros, por sua própria organização fisiográfica, são pouco heterogêneos, tanto nos aspectos de relevo, quanto de uso e ocupação. Esta homogeneidade reduziu as variáveis ambientais e sua influência nos resultados da classificação, facilitando a interpretação dos dados produzidos pelos algoritmos de classificação, permitindo avaliar

\footnotetext{
${ }^{2}$ De 1 de Janeiro a 11 de Novembro de 2004
} 
melhor seus respectivos comportamentos e desempenho no processo de extração e mapeamento das feições em estudo.

Tabela 1.2 - Dados de Pluviosidade (P) em mm e Temperatura (T) $\mathrm{em}^{\circ}$ Celsius, referente ao município de Esplanada (Lat: $11^{\circ}$ 47'/ Long: $37^{\circ} 57^{\prime}$

- Alt: $181 \mathrm{~m})$, referentre ao período de 1913-1987

\begin{tabular}{c|c|c}
\hline Mês & $\mathbf{P}(\mathrm{mm})$ & $\mathrm{T}^{\mathbf{}} \mathrm{C}$ \\
\hline Janeiro & 51.2 & 25.3 \\
\hline Fevereiro & 66.6 & 25.5 \\
\hline Março & 102.4 & 25.4 \\
\hline Abril & 129.4 & 24.6 \\
\hline Maio & 170.9 & 23.5 \\
\hline Junho & 145.8 & 22.4 \\
\hline Julho & 143.6 & 21.5 \\
\hline Agosto & 90.2 & 21.3 \\
\hline Setembro & 61.8 & 22.3 \\
\hline Outubro & 56.8 & 23.5 \\
\hline Novembro & 73.1 & 24.5 \\
\hline Dezembro & 67.7 & 24.8 \\
\hline ANUAL & 1176.2 & 23.7 \\
\hline
\end{tabular}

Fonte (SUDENE, 2002)

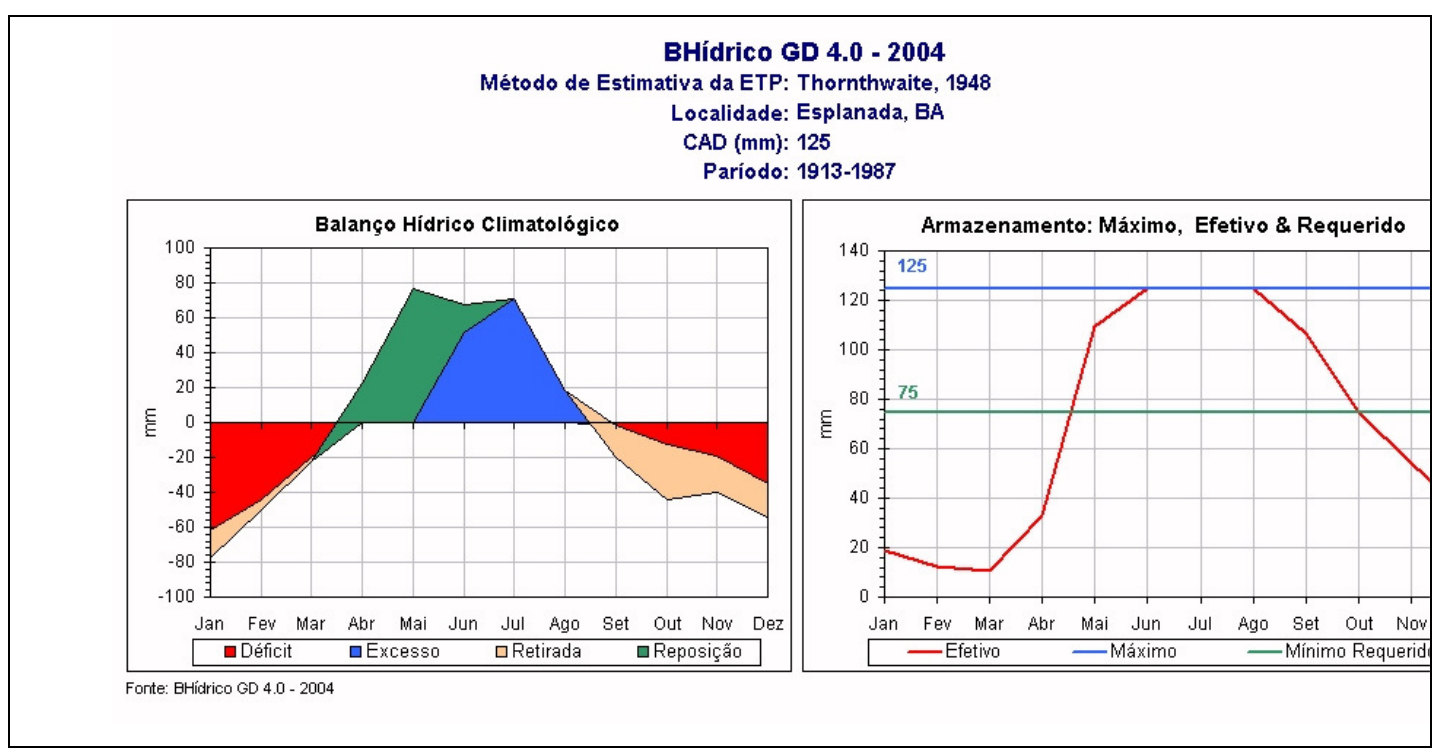

Figura 1.4 - Balanço Hídrico de Esplanada 


\subsection{Justificativa}

“Levantamento pedológico é um prognóstico da distribuição geográfica dos solos como corpos naturais, determinados por um conjunto de relações e propriedades observáveis na natureza" (Embrapa, 1999). Por meio do levantamento, identificam-se solos que passam a ser reconhecidos como unidades naturais, prevêem-se e delineiam-se suas áreas nos mapas, em termos de classes definidas de solos. As informações contidas num levantamento pedológico são essenciais para a avaliação do potencial e das limitações de uma área, constituindo-se numa verdadeira base de dados georrefenciadas para estudos de viabilidade técnico econômica de projetos e planejamento de uso, manejo e conservação de solos (FAO, 1975; Embrapa, 2001).

Os solos são a base de sustentação das atividades primárias de produção. Seu conhecimento é de fundamental importância para o desenvolvimento agrícola de qualquer região. Entretanto, no Brasil como um todo e na Bahia, em particular, existe uma grande deficiência de material cartográfico em escalas maiores. Esta deficiência, em grande parte é devida aos elevados custos de levantamento de campo, imprescindível para este tipo de trabalho. Por outro lado, os trabalhos que abrangem grandes extensões territoriais são antigos, datando das décadas de 70 e início de 80 (Embrapa, 1977; Brasil, 1985) e restringem-se a levantamentos exploratórios (1:1.000.000).

Segundo Nóbrega et al. (1992), a análise integrada da paisagem, relacionando principalmente as características de solo e de relevo com o uso da análise bi e tridimensional da cobertura pedológica, pode ajudar no mapeamento das zonas de riscos a erosão. Essa interpretação corrobora o empregado na França por Antoine (1977) em áreas suscetíveis aos riscos naturais, conhecidos ou previsíveis, identificados e hierarquizados conforme o grau de risco que cada tipo de uso e/ou ocupação pode promover.

Em função da dinâmica de desenvolvimento de equipamentos e programas de computador, envolvidos no processo de aquisição, armazenamento, manipulação e expressão de dados orbitais, muitas técnicas à disposição no mercado ainda não foram suficientemente testados e validados.

O problema da coesão dos solos por sua extensão espacial, localização e número de pessoas direta ou indiretamente afetadas por este problema, faz surgir a necessidade de buscas de soluções por diferentes caminhos e que apresentem soluções viáveis ou forneçam subsídios na busca destas soluções. 
Este trabalho, ao indicar as análises através do sensoriamento remoto, busca uma destas soluções viáveis, incorporando uma nova abordagem de estudo a um velho problema. Aliada a isso, a utilização de novos sensores, também muito pouco explorados para a área de solos, mas que apresenta grandes possibilidades, como no caso o sensor ASTER (Advanced Spaceborne Thermal Emission and Reflection Radiometer) com suas 14 bandas, incorporam uma nova metodologia a um antigo problema. Entretanto, o uso de imagens de satélites ópticos na região escolhida, pela descrição climática citada anteriormente, não se apresenta como uma tarefa fácil, principalmente pela freqüente e elevada cobertura de nuvens na área. A isto se deve a total ausência de trabalhos científicos utilizando esta metodologia nesta região. Mas em vez de se tornar mais uma dificuldade, abordamos o problema como mais um desafio a ser ultrapassado. Não se pode excluir todo um método e um conjunto de técnicas apenas pelas dificuldades apresentadas, mas buscar soluções para resolvê-las e avaliar a viabilidade de sua aplicação.

Assim, tanto as técnicas de pré-processamento, destacando as técnicas de realce, como as técnicas de processamento digital de imagens, seja pelos seus diversos processos e as respostas específicas aos diferentes algoritmos de classificação, ou diferentes produtos de plataformas orbitais, ainda não foram sequer testadas em relação a identificação dos horizontes coesos nos solos dos Tabuleiros Costeiros da Bahia.

Acima de tudo, a problemática local de coesão dos solos, típica dos Tabuleiros Costeiros, considerado um forte fator limitante às diferentes práticas de cultivo, exigem soluções urgentes e de âmbito mais geral, que os mapeamentos localizados, restritos a pequenas áreas de estudo.

\subsection{Organização do trabalho}

Este trabalho foi organizado da seguinte forma:

- No Capítulo 1 (Introdução), será apresentado o problema a ser resolvido, os objetivos do trabalho, a descrição geral da área e a justificativa da escolha do problema.

- No Capítulo 2 (Referencial Teórico) é realizada ampla revisão teórico-metodológica do estado da arte sobre o estudo dos solos e o sensoriamento remoto, partindo do conceito de solos e suas formas de classificação e representação até o embasamento teórico sobre o comportamento óptico dos solos e sua interação com o sensoriamento remoto, passando pelas diferentes linhas de abordagem e atuais pesquisas e seus resultados. 
- No Capítulo 3 (Metodologia) são apresentadas a metodologia escolhida e as técnicas que serão abordadas visando o uso do processamento digital de imagens, integrado ao sistema de informações geográficas para identificar os horizontes coesos nos diferentes tipos de solos.

- No Capítulo 4 (Resultados e Discussões) são apresentados os resultados obtidos e sua conseqüente discussão.

- No Capítulo 5 (Conclusões e Recomendações) são apresentadas as conclusões e as perspectivas futuras deste trabalho.

- No Capítulo 6 (Referências Bibliográficas) são apresentadas as referências citadas como a bibliografia de apoio utilizada.

Alguns desenvolvimentos que foram fundamentais para a realização deste trabalho, mas cujo detalhamento não são necessários para sua compreensão, foram colocados em anexos, na seqüência de sua solicitação pelo texto.

- Anexo A - Os dados climáticos do município de Esplanada/Bahia (Pluviosidade e Temperatura); o balanço hídrico (tabular)

- Anexo B - Descrição do sensor ASTER

- Anexo C - Tabela da Análise dos Componentes Principais

- Anexo D - Tabelas de cálculo do Tasseled Cap

- Anexo E - Descrição das unidades de solo da área de referência

- Anexo F - Descrição da área de referência quanto às unidades de solo e seu recorte 


\section{CAPITULO 2 - Referencial Teórico}

\subsection{Solos: conceito}

A importância dos solos para o ser humano é indiscutível, seja como a base material para o desenvolvimento das atividades econômicas, seja como o local de onde se retire nossa alimentação, abrigo e roupas, onde são erguidas nossas edificações, construções, monumentos e lares, ou onde andamos, trabalhamos, produzimos e vivemos. O solo possui diversos significados, dependendo do ponto de vista de quem o usa ou observa. Daí a tão grande variedade de conceitos sobre ele, dependendo do olhar de quem o vê. O solo pode ser diferentes coisas para diferentes pessoas: o agrônomo, o engenheiro civil e de minas, o agricultor, o pedólogo, o biólogo, o geógrafo ou o geólogo, cada qual com sua especificidade, cada qual com seu objetivo próprio. Daí a necessidade de primeiramente definirmos este objeto de estudo, para sabermos com que olhar o estamos observando.

No contexto deste trabalho, será adotado o conceito pedológico dos solos. O conceito de solos é bastante abrangente e sujeito a diferentes interpretações e conceituações, dependendo do especialista que o tome como objeto de estudo. Segundo o conceito aqui adotado, o solo é a porção superficial do regolito (rocha intemperizada), bioquimicamente decomposta, que é um produto combinado de forças destrutivas como sintetizadoras, podendo ser definido como o conjunto de corpos naturais, desenvolvido em material não consolidado e em matéria orgânica na imediata superfície da terra e que serve como ambiente natural para o crescimento vegetal, e possui propriedades conseqüentes dos efeitos climáticos e da matéria viva que atuam sobre o material original, tudo condicionado pela topografia num determinado período de tempo.

Os solos se distinguem do material subjacente pela presença de matéria orgânica, raízes de plantas, micro e macro organismos dos solos e horizontes. Deste modo, os solos não são apenas materiais litológicos inconsolidados, mas contêm produtos de intemperização e decomposição minerais e orgânicos, associados a água e ar, e possuem vários graus de consolidação, estrutura e camadas. As propriedades, referentes à concentração, organização, e interrelações entre todos os materiais dos solos afetam a reflexão da energia solar pelos solos (Irons et al., 1985).

A camada mais superficial dos solos, ou camada de aração, é a zona principal de desenvolvimento das raízes, camada de solo que armazena a maioria dos nutrientes e da água para os vegetais, como sofre os efeitos do cultivo, das arações e da calagem, é a camada de 
solo que mais reflete as condições físicas e químicas. Em geral, do ponto de vista prático a denominação solo refere-se a camada de superfície, ou camada de aração.

Neste trabalho, o solo é uma "coleção de corpos naturais, constituídos por partes sólidas, líquidas e gasosas, tridimensionais, dinâmicos, formados por materiais minerais e orgânicos, que ocupam a maior parte do manto superficial das extensões continentais do nosso planeta, contém matéria viva e podem ser vegetados na natureza, onde ocorrem" (Embrapa, 1999).

\subsubsection{Os solos coesos dos Tabuleiros Costeiros}

O caráter coeso ocorre em um horizonte pedogenético, adensado, muito duro ou extremamente duro, quando seco, e normalmente friável quando úmido, que se desmancha subitamente ao ser imerso em água (Jacomine, 2001), é característico de horizontes subsuperficiais ( $\mathrm{AB}, \mathrm{BA}$ e, ou, parte do $\mathrm{Bw}$ ou $\mathrm{Bt}$ ) e está relacionado com os sedimentos da Formação Barreiras, período Terciário, que constituem a unidade geomorfológica dos Tabuleiros Costeiros e que correspondem, na Bahia, a 11\% do seu território (IBGE, 1983).

Ribeiro (1991) definiu os horizontes que apresentam caráter coeso como: "horizontes muito duros e firmes, que não apresentam organização estrutural visível (são maciços), motivo pelo qual os grandes torrões se quebram em fragmentos de tamanhos menores e angulosos; apresentam uma macroporosidade geralmente ligada à atividade biológica (biovazios), sendo difícil a observação dos poros finos; no seu interior são raras as raízes observadas, mesmo assim, a grande maioria das que conseguirem penetrar nesses horizontes encontram-se mortas"

A origem dos horizontes com caráter coeso ainda não foi completamente esclarecida, porém se sabe que ocorre de forma natural e que pode estar associada a vários processos, tais como: perda do plasma argiloso das camadas superficiais do solo para as camadas subjacentes; forte instabilidade estrutural; presença de argila dispersa, assim como de outros agentes químicos, nos microporos, e adensamento por dissecação, proveniente da alteração da estrutura do solo pela alternância de ciclos de umedecimento e secagem (Ribeiro, 1986).

Mullins et al. (1987) ao apresentar explicação física para solos com esse tipo de comportamento, indica também vários problemas agronômicos a ele associados, como: restrição ao cultivo e aumento do impedimento físico para crescimento de raízes. Outros estudos também mostram a grande influência das propriedades físicas no comportamento desses solos (Cintra e Libardi, 1998; Giarola et al., 2003). 


\subsection{Sensoriamento Remoto}

De forma abrangente, o sensoriamento remoto é definido como "Utilização de sensores para aquisição de informações sobre objetos ou fenômenos sem que haja contato direto entre eles" (Jensen, 1986). Para este trabalho, utilizaremos uma definição mais específica que é o "Conjunto das atividades relacionadas à aquisição e a análise de dados de sensores remotos" (INPE, 2003)

A discussão foi limitada a dados digitais, coletados através de plataformas orbitais de sensores ópticos. Embora os levantamentos ambientais mais locais, ainda dependam da interpretação visual e manual de fotografias aéreas, o uso de imagens de satélite para analise regional é agora lugar comum e seu uso tende a aumentar cada vez mais como uma fonte de informação geográfica. Os produtos digitais do sensoriamento remoto representam muito mais que uma simples extensão da fotografia aérea convencional, requerendo fundamentalmente diferentes conceitos para a análise da superfície da terra (Everett e Simonett, 1976). Discutiremos a seguir, alguns problemas e questões referentes ao sensoriamento remoto por satélite óptico e o caso específico das aplicações no estudo dos solos.

\subsubsection{Autocorrelação e regularização em imagem de satélite}

A variação espacial observada na imagem de satélite é gerada pela convolução da variação intrínseca das propriedades eletromagnéticas na superfície com a amostragem de campo do sensor (Davis e Simonett, 1991). A variação da superfície pode ser categorizada como contínua (gradiente), discreta (mosaico), linear ou localizada (isto é, eventos extremamente intermitentes, processos pontuais). Isto também é importante para reconhecer o quanto o processo superficial que está sendo investigado é estacionário ${ }^{3}$, isto é, se os efeitos de $1^{\mathrm{a}}$ e $2^{\mathrm{a}}$ ordem são constantes, de modo que suas propriedades estatísticas não dependem da posição espacial absoluta e se o teste padrão da variação de superfície é aleatório, de contato ou regular (Davis e Simonett, 1991)

A maioria das superfícies naturais é não-estacionárias, isto é, os efeitos de $1^{\mathrm{a}}$ e $2^{\mathrm{a}}$ ordem não são constantes, quando ocorrem em áreas de grande extensão, podendo manifestar muitos diferentes tipos de variação dentro e entre diferentes escalas de medida.

\footnotetext{
3 A estacionariedade é um dos principais conceitos estatísticos que definem a estrutura espacial dos dados e se relacionam aos efeitos de $1^{\mathrm{a}}$ ordem (o valor esperado, isto é, a média do processo no espaço) e de $2^{\mathrm{a}}$ ordem (a covariância entre as áreas) (Câmara et al., 2002).
} 
Inferir a variação da superfície da variação espacial de um dado fenômeno através de dados de satélite não é um processo direto, posto que as radiâncias fornecidas pelos satélites são afetadas por fatores não-superficiais tais como a geometria sol-terra-satélite e as características atmosféricas.

Strahler et al. (1986) distinguiu dois diferentes modelos fundamentais quanto a resolução dos elementos: o modelo de Resolução-H, no qual elementos da cena são maiores se comparados a resolução da imagem; e o modelo de Resolução-L, no qual os elementos são menores que a área da resolução da imagem e não são individualmente detectáveis. A textura de uma imagem aumenta enquanto a definição da imagem se aproxima das dimensões de elementos da cena. Uma grande variância local pode ser problemática na classificação de imagens, a qual aumenta com a resolução espacial do sensor. No caso de Landsat, Spot ou ASTER, onde a definição do sensor se aproxima do tamanho de edifícios individuais ou de clareiras entre árvores, pode gerar confusão na classificação que irá produzir mapas de cobertura do solo ou de áreas urbanas. No caso dos solos, este aspecto se torna relevante porque este, como corpo natural, apresenta uma distribuição contínua e de variação gradual nas suas propriedades, raramente abrupta, enquanto seu modelo de representação, os mapas, nos quais nos baseamos como verdade terrestre, são entidades discretas.

No caso dos sensores de alta resolução como o Ikonos e o Quickbird, os problemas da classificação provem de outros fatores, principalmente da identificação e classificação dos tipos alvos, bem como o de algoritmos específicos para este nível de resolução espacial e radiométrica.

\subsubsection{Solos e sensoriamento remoto}

O conceito de utilizar dados multiespectrais para ajudar a separar diferentes grupos de solos não é novo. Os conhecimentos básicos das propriedades ópticas dos elementos dos solos foram adquiridos e testadas ao longo dos últimos 50 anos, tanto em laboratório com controle de iluminação e da geometria da visada, como nos levantamentos de campo sob iluminação solas direta (Galvão e Vitorello, 1996; Demattê at al, 2005).

$\mathrm{Na}$ maioria dos estudos sobre os solos e sua reflectância ou seu comportamento espectral, apenas a camada superior é considerada, ainda que, em laboratório, sejam testados amostras de camadas mais profundas e seus resultados possam ser interessantes, mas cujas repostas não são captadas pelos sistemas sensores orbitais (Curran et al., 1990) 
O uso do sensoriamento remoto para o levantamento dos solos, freqüentemente é utilizado nas regiões áridas, pois nestas condições tem-se minimizada a problemática da cobertura vegetal e sua interferência na resposta espectral dos solos. Weismiller et al. (1977) por exemplo, utilizou o Landsat MSS para mapear solos em Jasper County. Dwived (1985) utilizou o Landsat para generalizar solos e desenvolver um sistema de análise da paisagem em regiões áridas e semi-áridas, onde avaliou a limitação dos dados de campo. Entretanto, surgiram grande problemas ao se utilizar dados multiespectrais em áreas úmidas: primeiro, a freqüente (e densa) cobertura vegetal e em seguida a cobertura de nuvens que restringe o uso das imagens (Kornblau e Cipra, 1983; Wright e Birne, 1986).

Os usos das observações coletadas em plataformas orbitais sempre tentaram utilizar os dados coletados para demarcar unidades de paisagem e grandes grupos de solos, baseados principalmente na interpretação visual. Mas o estudo das características dos solos como tamanho dos grãos ou textura, inicialmente foram limitados à baixa resolução espacial, seguida pela resolução espectral inadequada às necessidades.

Normalmente, solos tropicais são altamente intemperizados, devido principalmente ao clima quente e úmido. Sua mineralogia é caracterizada por um número reduzido de componentes tais como a caulinita, óxidos e hidróxidos de ferro e alumínio, como os minerais mais frequentes na fração argila e quartzo nas frações silte e areia. As quantidades e proporções desses componentes minerais são muito úteis para classificação e para o manejo dos solos. O conhecimento dos espectros de reflectância desses componentes é muito importante para a utilização de espectroscopia de imageamento para aplicações nos estudos de solos (Baptista et al., 1998a).

Cabe destacar como problema, a elevada diferença entre os resultados obtidos em laboratório e os obtidos por medições em campo, devido as diferentes condições ambientais e procedimentos analíticos, onde as medidas obtidas em laboratório serem de 1.5 a 3 vezes mais elevadas que as medidas em campo. Estes resultados levaram Curran et al (1990) a concluir de modo extremo, não ser possível aplicar as conclusões obtidas em laboratório em estudo de solos sobre dados obtidos diretamente em condições de campo.

Apesar de tudo, estes estudos ainda deixam muitas lacunas, devido a amplitude da gama de variáveis envolvidas nas relações entre sensoriamento remoto e os solos. Dentre eles, a própria avaliação dos produtos dos sistemas sensores em tipificar as diferentes classes de solos.

Entretanto, poucos são os trabalhos que procuram caracterizar os solos em níveis categóricos mais detalhados utilizando os dados do TM Landsat, apesar de seu potencial 
comprovado por trabalhos nacionais e internacionais (Myers, 1975; Westin e Frazee, 1976; Myers, 1983; Agbu et al., 1990; Vettorazzi e Couto, 1990; Rocha, 1993; Nanni, 1995; Nanni e Rocha, 1997).

Além deste aspecto, a utilização do sensoriamento remoto tem grande potencial no complemento das informações necessárias para o melhor desenvolvimento agrícola junto à denominada agricultura de precisão (Moran et al., 1997; Embrapa, 2001).

\subsubsection{Os solos observados através dos sensores ópticos}

Observações remotas sobre a reflectância dos solos nas regiões do visível e do infravermelho do espectro eletromagnético são muito importantes por duas razões. Primeiro é a inegável, inexorável e inquestionável a presença dos solos sobre a superfície da terra. Mesmo sobre uma densa cobertura vegetal, uma parcela da radiação solar incidente consegue penetrar e atinge a camada superficial do solo. Os solos influenciam assim a reflectância da superfície da terra, sendo que esta influência aumenta em regiões de vegetação rara ou esparsa e dominante em áreas destituídas de vegetação (Irons et al., 1989). Além disso, muitos dos processos climáticos e biológicos da superfície envolvem a absorção e reflexão da radiação solar pelos solos.

A segunda razão para estudar a reflectância dos solos é pedológica. Pedologia é o estudo dos solos como um corpo natural tridimensional que resulta dos processos de intemperismo, que são condicionados pelo clima, biota e topografia, agindo sobre o material parental através do tempo (Brady, 1989). A pedologia inclui a descrição , caracterização quantitativa, classificação e mapeamento dos solos. Desde que as características da radiação refletida de um material é uma função das propriedades deste material, as observações da reflectância dos solos pode fornecer informações sobre as propriedades e estado dos solos. A mais conhecida aplicação deste conceito é a observação da cor dos solos para descrever e ajudar a classifica-los em categorias e classes.

Apesar das técnicas de sensoriamento remoto não poderem captar as características dos perfis dos solos, muitos dos seus parâmetros podem ser detectados através dela. Primeiro, a cor da superfície dos solos: este afeta a percentagem de insolação recebida pela superfície a qual é refletida de volta para o espaço. Solos arenosos secos podem ter um albedo de 37\%, contra solos escuros (alto teor de matéria orgânica) com um albedo aproximado de $8 \%$. Segundo, a rugosidade da superfície pode ser observada, não importa se este tenha sido criado pelas práticas de cultivo agrícola, ou seja inerente à própria estrutura natural dos solos, em 
ambos os casos, provocam o espalhamento da radiação incidente. Terceiro, a temperatura dos solos pode ser detectada pelos sensores termais. O principal fator que afeta as relações de temperatura de um solo é seu calor específico ou capacidade termal, isto é, a quantidade de calor necessária para aumentar a temperatura de uma dada substância de $15^{\circ} \mathrm{C}$ para $16^{\circ} \mathrm{C}$ comparada àquele mesma aumento de temperatura de uma massa de água do mesmo peso. Por exemplo, um solo mineral seco pode ter um calor específico de 0.20 mas com um teor de umidade de $30 \%$ sua capacidade aumenta para 0.38. Isto se tornará evidente pelo monitoramento do regime termal dos solos, isto é, suas variações anuais, sazonais e diárias, que fornecerão, evidências indiretas da variabilidade da umidade dos solos (Irons et al., 1989; Barret e Curtis, 1992).

\subsubsection{O estado da arte do estudo dos solos através do sensoriamento remoto orbital}

As informações relativas à reflexão da luz pelo solo estão entre as propriedades mais antigas e mais utilizadas em pedologia - a cor. Nos últimos anos (a partir de 1980) a espectroscopia de imageamento apresenta-se como a possibilidade de exploração dos dados de reflectância espectral de maneira mais completa. Essa exploração dos dados, e seu uso para a identificação e possível caracterização dos solos, através de produtos gerados por esses sistemas sensores, depende principalmente da compreensão das propriedades de reflectância dos solos e de suas relações com seus constituintes (Baptista e Madeira Netto, 2000). Segundo Dozier e Goetz (1989), a análise dos espectros de reflectância permite a identificação de minerais em solos e rochas por meio de feições de absorção. Assim, O espectro de reflectância dos solos varia devido a muitos fatores tais como cor, conteúdo mineralógico, tipo de cobertura, teor de umidade, textura, tamanho e arranjo dos grãos, tipo de material parental e relevo.

No Brasil, os trabalhos pioneiros sobre sensoriamento remoto e estudo dos solos, estão profundamente marcados pelo grupo de pesquisa do INPE (Instituto Nacional de Pesquisas Espaciais). Já em 1981, Valerio Filho et al. (1981) realizava uma revisão das técnicas de fotointerpretacao aplicadas ao levantamento de solos. Em 1986, realizam-se no Brasil os primeiros trabalhos buscando utilizar dados de sensoriamento remoto (produtos da série Landsat) para avaliar suas potencialidade na cartografia de solos (Valerio Filho et al, 1986). Os trabalhos específicos sobre avaliação e caracterização radiométrica dos solos tropicais brasileiros ganham destaque a partir dos trabalhos de Epiphanio et al.(1982), Epiphanio (1983), Formaggio et al (1988), destacando-se os estudos sobre o comportamento 
radiométrico dos latossolos sobre diferentes culturas, os quais evoluíram para a extração de informações de elementos dos solos (como teor de ferro e umidade) dos solos tropicais brasileiros (Formaggio et al, 2001). Estes estudos sobre os solos tropicais culminaram na caracterização do comportamento espectral dos solos de S. Paulo (Formaggio e Epiphanio, 1995; Epiphanio et al., 1996). A partir da década de 90, ocorre um aprofundamento da temática do estudo dos solos e dados de sensoriamento remoto, através principalmente do curso de pós-graduação em sensoriamento remoto do INPE, sendo desta fase os trabalhos de Gleriani (1995), Máximo (1997) sobre a influência da vegetação sobre a espectrometria dos solos, com imagens de radar, Demattê et al (2003) sobre a influência da matéria orgânica e do ferro no comportamento espectral dos solos (Máximo, 1997). Todos estes trabalhos iniciais serviram de base para uma caracterização espectral dos solos tropicais brasileiros, a ponto de se poder, enfim, estabelecer parâmetros para extração de informações dos solos (em particular óxido de ferro, umidade dos solos, argilo-minerais e matéria orgânica) através de curvas espectrais (Formaggio et al, 2001). Agindo como grupo disseminador, uma segunda geração de pesquisadores formada pelo INPE, se espalhou em diversos órgãos e instituições de pesquisa pelo país, contribuindo para o desenvolvimento do cabedal de conhecimentos sobre os solos e sensoriamento remoto. Dentre estes podemos citar os pesquisadores da Escola Superior de Agricultura Luiz de Queiroz (ESALQ), com os trabalhos de Demattê et al. (2003) sobre a avaliação de diferentes produtos do sensoriamento remoto para o mapeamento de solos, Fiorio (2002), sobre a utilização de dados radiométricos obtidos nos níveis terrestre e orbital na avaliação de solos. Também na Embrapa podemos citar os trabalhos desenvolvidos por Madeira Neto (Madeira Netto, 1991; Madeira Netto et. al, 1993; Madeira Netto, 1996; Madeira Netto et al, 1997), assim como os trabalhos de Baptista (Baptista et al, 1998; Baptista et al, 1999, Baptista et al, 2000).

\subsubsection{Os sistemas sensores}

Os estudos tradicionais de solos envolvem principalmente os espectrômetros ou radiômetros, onde podemos verificar um enorme acervo bibliográfico. Entretanto, os estudos envolvendo diretamente a identificação dos tipos de solos ou de suas propriedades, através de produtos orbitais, através das técnicas de processamento digital de imagens são muito difíceis pela própria natureza do objeto, haja vista a sobreposição de dados espectrais dos elementos da cobertura e/ou uso do solo. Dependendo do modo pelo qual os dados são adquiridos, estes podem apresentar informações indesejáveis "sobre outros fatores que podem mascarar as 
características que realmente deseja-se determinar" (Madeira Netto, 1996). Uma superfície rugosa e úmida pode apresentar alterações significativas na determinação de um índice relativo à matéria orgânica, por exemplo. A compreensão dessas interferências é importante para determinar a acurácia das predições por meio de dados espectrais.

Madeira Netto (1996) afirma que não existe, ainda, uma fórmula universal para analisar os dados espectrais de todos os tipos de solos. As relações definidas entre alguns componentes dos solos e características espectrais são normalmente válidas para uma gama de condições que devem ser definidas experimentalmente. Muitos estudos ainda serão necessários para a compreensão dos efeitos das interações espectrais dos diferentes componentes dos solos.

Dados espectrométricos, na faixa do visível e do infravermelho refletido, são obtidos da interação entre luz e a matéria de uma camada de solo muito fina de apenas alguns milímetros. Os pedólogos que usam dados espectrométricos, principalmente os obtidos de satélites, precisam entender como as propriedades dessa fina camada relacionam-se com toda a cobertura pedológica para derivar informação com real significado para a compreensão do solo (Madeira Netto, 1993; 1996).

Esta forte tendência do estudo das relações entre solos e o sensoriamento remoto através de espectrometria, ou a modelagem de apenas um atributo do solo através do sensoriamento remoto orbital, pode ser explicada por uma série de razões, as quais podem ser sumarizadas nas razões abaixo:

- A complexa natureza do solo, em seus diferentes níveis e singularidades;

- Seu conceito tridimensional;

- As características intrínsecas ao mapeamento convencional dos solos;

- A resolução dos atributos de solos;

- O complexo conjunto de elementos inter-relacionados que respondem pela caracterização dos solos;

- A dificuldade de modelagem destes elementos e sua conversão em atributos perceptíveis e mapeáveis à nível orbital.

Os recentes avanços na tecnologia de sensores remotos têm possibilitado a aquisição de dados de melhor resolução espectral do que os atualmente coletados por sensores como, por exemplo, aqueles a bordo dos satélites Landsat 7 e SPOT 4. Como exemplo, em dezembro de 1999, foi lançado pela NASA o satélite Terra do programa EOS (Earth Observing System). 
Esse satélite possui cinco instrumentos, dentre os quais o ASTER (Advanced Spaceborne Thermal Emission and Reflection Radiometer), do qual falaremos mais detalhadamente posteriormente, e o MODIS (Moderate Resolution Imaging Spectroradiometer) com 36 bandas, posicionadas nas faixas espectrais do visível e infravermelho próximo $(0.4-2.5 \mu \mathrm{m})$ e infravermelho termal $(8.0-15.0 \mu \mathrm{m})$, mas com o problema, para o estudo dos solos, que seria sua baixa resolução espacial $(250 \mathrm{~m})$.

Também não podemos, frente às características espectrais tão peculiares dos solos, deixar de citar os novos satélites hiper-espectrais, os quais, em teoria, teriam a sensibilidade espectral adequada para detectar os elementos característicos e específicos que definem as diferentes classes de solos. Podemos afirmar que, a partir das atuais mudanças verificadas no campo do sensoriamento remoto, com o espantoso aumento das resoluções espaciais e espectrais e das novas alternativas de resolução radiométrica, está área está se transformando, destacando-se a espectrometria de imageamento, quando utiliza sensores hiper-espectrais, e que passa a representar o estado da arte do sensoriamento remoto na faixa ótica, ainda que os princípios dessa técnica tenham sido estabelecidos na década de 1980 e tornados operacionais apenas em 1990 (Madeira Netto e Baptista, 2000).

De pixels representando a ocorrência de diferentes tipos de alvos na cena, pode-se extrair um espectro de reflectância diretamente da imagem em um nível de resolução espectral mais próximo do existente em condições de laboratório (Green et al., 1998). Quanto maior o número de bandas, melhor é a reconstituição de bandas de absorção espectral que podem ser usadas para identificação de alguns materiais na cena, incluindo a indicação, na imagem, da presença de minerais espectralmente dominantes nos espectros de solos. Embora a resposta espectral do solo seja influenciada por vários fatores que atuam em conjunto (matéria orgânica, óxidos de ferro, fração de argila, umidade), a reflectância de certos minerais, em alguns intervalos espectrais, se sobrepõe à do solo, o que possibilita a sua identificação remota através de dados de alta resolução espectral. Como exemplo, feições espectrais típicas do mineral caulinita em $2.2 \mu$ m podem ser também observadas nos espectros de laboratório de Alissolos, Latossolos e Cambissolos (Valeriano et al., 1995; Formaggio et al., 1996; Galvão et al., 1997; Demattê e Focht, 1999).

Dos satélites hiper-espectrais hoje em operação, podemos citar o Hyperion com seus 220 canais espectrais num intervalo de 0.357 à $2.576 \mu \mathrm{m}$, com uma resolução espacial de 30m, e uma faixa de imageamento padrão com $7.7 \mathrm{~km}$ de largura e $42 \mathrm{~km}$ de comprimento. Entretanto, poucos trabalhos são realizados, principalmente visando o estudo dos solos. Dos 
poucos trabalhos utilizando este satélite no Brasil, a maioria deles se refere a estudos de uso/cobertura do solo (Pizarro e Fernandes, 2003) e vegetação (Espírito Santo, 2003). Acreditamos contudo, que estes estudos tendem a aumentar a partir de agora.

Embora seja um sensor aerotransportado, cabe aqui destacar os trabalhos que estão sendo realizados com o AVIRIS (Airborne Visible InfraRed Imaging Spectrometer). Este é o único sensor óptico que fornece imagens calibradas referentes a um espectro de radiância de 224 bandas contíguas, cada uma com um intervalo de $10 \mathrm{~nm}$, com comprimento de onda abrangendo o intervalo de 400 à $2500 \mathrm{~nm}(0.4$ à $2.5 \mu \mathrm{m})$. A resolução espacial deste sensor depende da altura em que o dado é coletado $\left(4 \mathrm{~m}^{2}\right.$, quando, a aeronave sobrevoa à $4 \mathrm{~km}$ de altitude), aliando assim a alta resolução espectral a uma elevada resolução espacial. Muitos trabalhos têm sido realizados utilizando-se os produtos AVIRIS, com aplicação específica para estudo dos solos, como determinação da caulinita e outros argilo-minerais em solos tropicais (Baptista, 2001; Baptista et al., 2000), a composição mineralógica dos solos (Pizarro et al., 2001; Galvão et al, 2001) e o teor de matéria orgânica (Henderson, 1992).

Então, todas estas mudanças fornecem novos instrumentos de mensuração e novas alternativas a serem exploradas, principalmente na área dos solos, onde os antigos sensores orbitais disponíveis possuíam atuações limitantes e restritivas.

Para este trabalho, escolhemos o sensor ASTER, um dos sensores a bordo da Plataforma Terra, por suas características de resolução, tanto espectrais como espaciais, assim como os poucos trabalhos realizados utilizando este sensor, ao menos durante o início deste estudo e, em particular, os aplicados aos solos. Entretanto, freqüentemente iremos nos referir aos sensores dos satélites Landsat (MSS, TM e ETM), posto que a maioria dos trabalhos publicados, assim como o desenvolvimento de metodologias e suas aplicações foram realizadas tendo por base as imagens por eles produzidas.

\subsection{O Landsat}

As imagens produzidas pelos satélites da série Landsat são as que possuem maior quantidade de material publicado. Isto se deve a uma série de fatores, sendo os mais importantes o seu preço e a política de distribuição adotada.

$\mathrm{Na}$ sua concepção, voltada basicamente para estudos regionais (escalas iguais ou menores a 1:50.000), determinado pela sua resolução espacial, espectral e radiométrica, acabou por especificar os principais padrões de análise e quase toda base conceitual experimental existente e ainda hoje em vigor, do sensoriamento remoto óptico. 
Para maiores detalhes sobre os satélites da série Landsat e seus sensores ver Goward et al. (2001), NASA (2004) e USGS (2004).

Assim, devido a grande quantidade de estudos disponíveis, nas mais diferentes áreas, os resultados de experimentos obtidos com as imagens Landsat ainda são uma referência para qualquer trabalho de pesquisa em sensoriamento remoto.

\subsection{O ASTER}

Dentre estes novos produtos citamos os da plataforma Terra, com o ASTER, lançado em 1999. É o satélite de mais elevada resolução espacial da plataforma Terra, funcionando como a lente de "zoom" dos outros instrumentos da plataforma Terra (MODIS -250 de resolução espacial; e o CERES - 1km) sendo a versão equivalente, embora melhorada, dos sensores da série Landsat para esta plataforma (Abrams et al., 2002).

Este sensor cobre uma larga região do espectro, perfazendo um total de 14 bandas, sendo 4 canais visíveis e infravermelho próximo, com $15 \mathrm{~m}$ (sendo a banda 3 repetida com visada diferente para formar a visada interferométrica); 6 bandas no infra-vermelho médio com 30 m de resolução espacial e 5 bandas no termal, com 90m de resolução espacial e uma resolução radiométrica de 12 bits. Por sua distribuição de faixas espectrais, muito mais que sua resolução espacial, em especial as do infra-vermelho médio, apresenta grandes possibilidades a serem exploradas para o estudo dos solos.

O ASTER pode ser considerado como um sensor ainda muito pouco estudado, mesmo com suas reconhecidas vantagens em relação a outros sensores ópticos disponíveis no mercado, inclusive o custo, como os dos sensores da série Landsat. Quanto ao aspecto de sua baixa utilização e poucas publicações, só podemos especular: por ser projetado com bandas similares ao Landsat, os usuários preferiram continuar trabalhando com produtos oriundos de uma plataforma já conhecida; outro fator seria justamente suas propriedades diferenciadoras, como as diferentes resoluções espaciais de acordo com sua posição no espectro eletromagnético; o grande número de bandas no infra-vermelho médio (canais SWIR); suas quatro bandas termais (TIR) com sua resolução radiométrica de 12 bits. Outro fator seria a baixa divulgação e pouco conhecimento deste produto, aliado à relativa dificuldade de aquisição dos dados.

Os poucos trabalhos realizados utilizando-se os produtos ASTER, se contrapõem a alta qualidade e a grande variedade de seus produtos, seu baixo custo, e todas as possibilidades de combinações possíveis entre eles. A maioria dos trabalhos realizada com o ASTER foi 
justamente aqueles que se referiam a calibração ou descrição do equipamento (Tovinkere et al., 1993; Yamaguchi et. al., 2001; Jacob et. Al., 2002; Abrams, 2000), sobre as potencialidades da imagem termal (Crowley e Hook, 1996; Gillies et al., 1997; Hook et al., 2003; Liang, 2001) e sobre interferometria e modelagem 3D (Welch et al, 1993; Tonooka, 2001; Toutin, 2002). Nos trabalhos referentes a aplicações de recursos naturais destacam-se apenas os trabalhos voltados à geologia (Fujizada et al., 1998; Hellman e Ramsey, 2001; Ogawa et al., 1999; Oppenheimer, 1996; Pieri et al., 1995; Ramsey e Dehn, 2002). Entretanto, para as demais área muito poucos trabalho foram realizados, destacando-se alguns artigos sobre gelo (Kargel e Kieffer, 1995; Bishop et al, 2000; Wessels et al.,, 2002) , monitoramento urbano (Stefanov e Christensen, 2001; Stefanov et al, 2001; Netzband e Stefanov, 2003); ecossitema florestal (Nemani et al, 1993); uso do solo (Carlson e Arthur, 2000; Arthur et al, 2000, Saito et al., 2001; Francelino et al., 2003). Sobre trabalhos específicos sobre os solos, na bibliografia especializada, nacional e internacional, pudemos encontrar trabalhos referentes a atributos específicos dos solos, como a salinidade (Al-Khaier, 2003), a relação com a topografia (Levin et al, 2004), o uso de técnicas de fusão de imagens para uma melhor diferenciação visual (Vani e Sanjeevi, 2002), a avaliação do teor de umidade dos solos em áreas secas (Carlson et al., 2001; Nemani et al, 1993), a relação da reflectância do solo no infra-vermelho $(8-14 \mu \mathrm{m})$ com o tamanho das partículas constituintes do solo, e o uso de índices espectrais e razões de bandas para identificação de argilo-minerais (Yamaguchi e Naito; 2003; San et al, 2004).

As imagens do ASTER, assim, de apresentam como um produto inovador, relativamente pouco estudado, embora venha aumentando as publicações cientificas com seus produtos, principalmente nos dois últimos anos, e que apresenta grandes potencialidades ainda pouco exploradas. Acreditamos que sua configuração espectral se adequa ao estudo dos solos e possibilita ao menos, a diferenciação dos tipos de coesão encontrados nas diferentes unidades de solo.

\subsubsection{Os estudos de solos}

A maioria dos trabalhos hoje desenvolvidos, como os citados anteriormente, utilizando exclusivamente sensores orbitais no estudo dos solos se referem a aplicação de imagens de sensoriamento remoto orbital para identificação de solos em regiões áridas e semi-áridas (Karavanova et al, 2004). Esta prática se deve a baixa cobertura vegetal, algumas vezes inexistente, possibilitando leituras espectrais diretamente da superfície do solo exposto. 
Desde o início, a cobertura vegetal se revelou um forte obstáculo à análise do comportamento espectral dos solos, mascarando as repostas específicas da superfície dos solos. Devido a isso, tem-se uma grande concentração de trabalhos em área áridas ou semiáridas (Murray-Darling Basin Ministerial Council, 1999; Moran et al, 1998, Al-Khaier, 2003), onde a cobertura vegetal é muito pouca ou mesmo inexistente. Em geral, verifica-se uma forte tendência atual de investigar um único parâmetro para o estudo dos solos, como o teor de umidade (Sano, 1997; Sana et al, 1998; Roberts, 1998; Moran, 2000), a cor dos solos (Galvão et al., 1997; Post et. al., 2000) ao teor de materia orgânica (Henderson et al., 1992), teor de ferro (Kampf e Schwertmann, 1983; Frasier et al., 1995; White et. al., 1997), ou o tamanho dos grãos constituintes das camadas superficiais.

Apesar de tudo, estes estudos ainda deixam muitas lacunas, devido a amplitude da gama de variáveis envolvidas nas relações entre sensoriamento remoto e os solos.

Embora para alguns autores a integração de dados seja um grande problema a ser enfrentado (Bourrough, 1991; Davis e Simonett, 1991) a análise conjunta de dados geográficos que podem variar na estrutura, na data de aquisição, na resolução e no nível de pré-processamento ou interpretação humana pode fornecer um novo fôlego para a análise dos solos através do sensoriamento remoto. Estes diferentes dados, oriundos de diferentes produtos, associados ao avanço verificado nos últimos 5 anos, com a inserção de novos satélites que apresentaram mudanças radicais quanto às resoluções espaciais, espectrais e radiométricas, criaram uma nova perspectiva de abordagem para o problema metodológico do estudo dos solos através de sensoriamento remoto, o qual pretendemos, neste trabalho, explorar.

Acreditamos que com o surgimento dos novos métodos, ligados as novas tecnologias e aprimoramento de novas ferramentas, assim como de novos algoritmos, tende a abrir todo um novo campo ainda não explorado.

\subsubsection{Fatores que influenciam a reflectância dos solos}

A reflectância dos solos é uma função da sua composição física e química (Bowers e Hanks, 1965). Apesar de termos vários trabalhos de solos realizados com os dados de sensoriamento remoto orbital, particularmente agora, com os novos sensores de elevada resolução espectral, como o ASTER e o MODIS, a maior parte dos trabalhos ainda hoje é desenvolvida em laboratório. 
Em geral, a reflectância dos solos é baixa, mas aumenta monotonicamente com o comprimento de onda do visível para o infra-vermelho (Curran et al., 1990). Na maioria dos estudos sobre a reflectância dos solos, ou seu comportamento espectral, apenas os horizontes superficiais são considerados, posto a característica dos sensores ópticos de imagear a luz refletida da superfície (Figura 2.1).

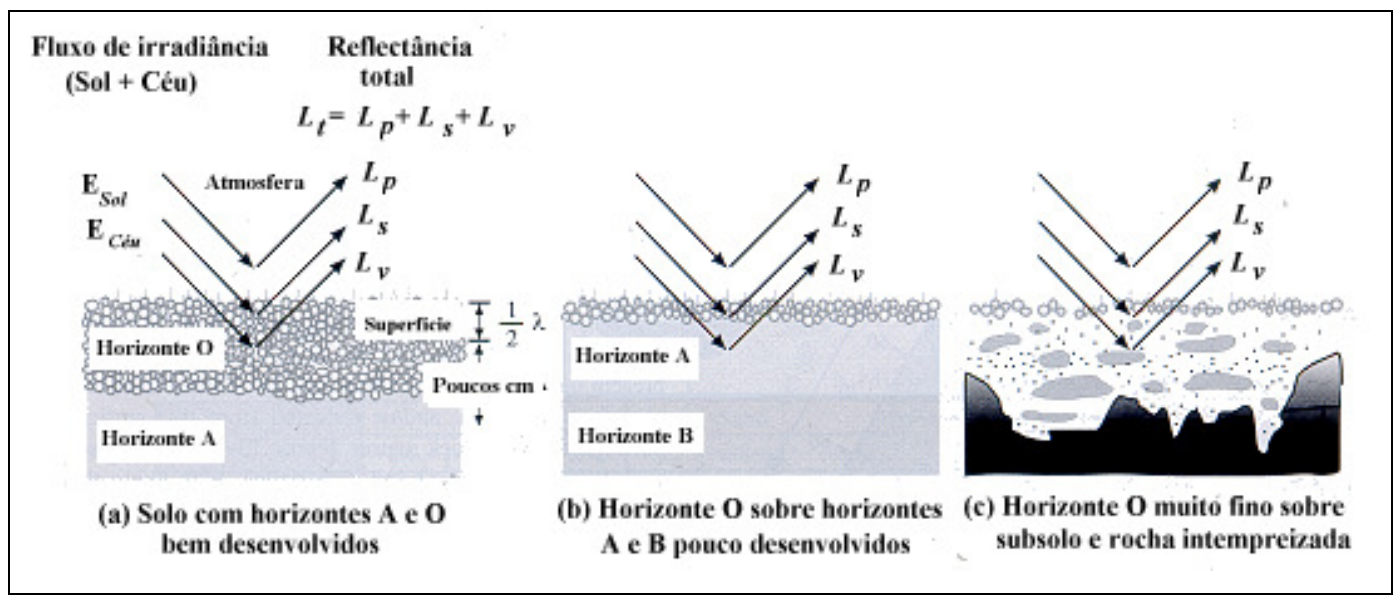

Figura 2.1 - Interação do solo e das rochas com a energia solar. Os solos e as rochas recebem irradiância do Sol $\left(E_{S o l}\right)$ e da atmosfera $\left(E_{C e ́ u}\right)$. A radiância total emitida pela matriz solo/rocha para o sensor remoto é uma função da radiância de uma indesejada dispersão atmosférica $\left(L_{p}\right)$, uma substancial quantidade de radiância refletida ou dispersada $\left(L_{s}\right)$ da camada superficial da matriz solo/rocha (aproximadente $1 / 2$ profundidade do comprimento de onda), e uma pequena parte da radiância volumétrica da subsuperfície $\left(L_{v}\right)$ e uma parte muito pequena da radiância oriunda do substrato solo/rocha. (Jensen, 2000)

Neste ítem discutiremos o comportamento da reflectância dos solos em suas principais variáveis, destacando a influência do teor de umidade, principal variável a ser abordada neste trabalho. Entretanto, faremos uma revisão geral das principais variáveis que influenciam o comportamento espectral dos solos, das quais podemos destacar: cor; composição mineralógica; tipo de feições metálicas; teor de matéria orgânica; textura superficial; tamanho e forma dos agregados.

\subsubsection{Teor de umidade do solo}

Um dos objetivos da aplicação do sensoriamento remoto na agricultura é para determinar as propriedades biofísicas e estimar as condições da cobertura vegetal e da superfície dos solos. Estes aspectos assumem particular relevância durante os diferentes estágios de desenvolvimento da planta, pois os solos e as plantas, tanto refletem como emitem sinais que são medidos pelas plataformas de sensoriamento remoto. Nestas condições, o conhecimento da extensão da cobertura vegetal tanto quanto das condições da superfície dos 
solos (seco, úmido, rugoso, etc) torna-se necessário para que se possa utilizar, de forma efetiva, as informações obtidas à partir dos satélites, associadas a modelos do crescimento das plantas, as condições determinantes da vegetação e a determinação do balanço de energia tal como o fluxo de calor dos solos e a transferência do calor latente (Bauer, 1985; Huete e Warrick, 1990).

Medidas de umidade do solo diretamente do espaço são muito difíceis, especialmente com sensores ópticos. A temperatura de superfície e as condições da vegetação podem ser usadas para inferir alguma coisa sobre a umidade. Isto é mais freqüente em sensores com bandas no TIR (Thermal Infrared), principalmente com $4.10-4.25 \mu \mathrm{m}$ e de $13.00 \mu \mathrm{m}$ a 15.40 $\mu \mathrm{m}$ (CEOS, 1995). A precisão é determinada, na maioria das vezes pela homogeneidade da superfície observada. Diversos autores estudaram o efeito de umidade na reflectância do solo (Bowers e Hanks, 1965; Bedidi et al., 1992; Madeira Netto, 1993; 1996).

A influência da água no solo na reflectância da superfície do solo é complexa e possui muitos fatores envolvidos. A adição de água em uma amostra de solo seco introduz um componente extra na absorção o qual depende das características ópticas dos solutos contidos e da tensão superficial por eles formados. Muitos esforços foram feitos para incluir a água do solo como um parâmetro simples na modelagem do solo, muito embora sem sucesso (Huete e Warrick, 1990; Jackson e Huete, 1991).

O teor de água no solo tem forte influência na composição da energia emitida e reflexiva da superfície do solo (Figura 2.2). O maior efeito da água adsorvida na reflectância dos solos é a redução da energia refletida, a qual possui o mesmo comportamento ao longo do espectro, com exceção apenas do comprimento de onda centrado em $1.45 \mu \mathrm{m}$ e $1.9 \mu \mathrm{m}$, que responde por sua pronunciada absorção à água, onde se observa a mais pronunciada redução da reflectância pela umidade do solo (Bower e Hank, 1965; Reginato et al, 1977). A redução da reflectância é proporcional à espessura do filme de água ao redor da partícula do solo a qual pode então ser relacionado ao status de energia da água de adsorbância (Crist e Cicone, 1984). Outros autores tem relatado o comportamento do teor de água gravimétrica com base no volume e no peso (Planet, 1970; Musick e Pelletier, 1986). 


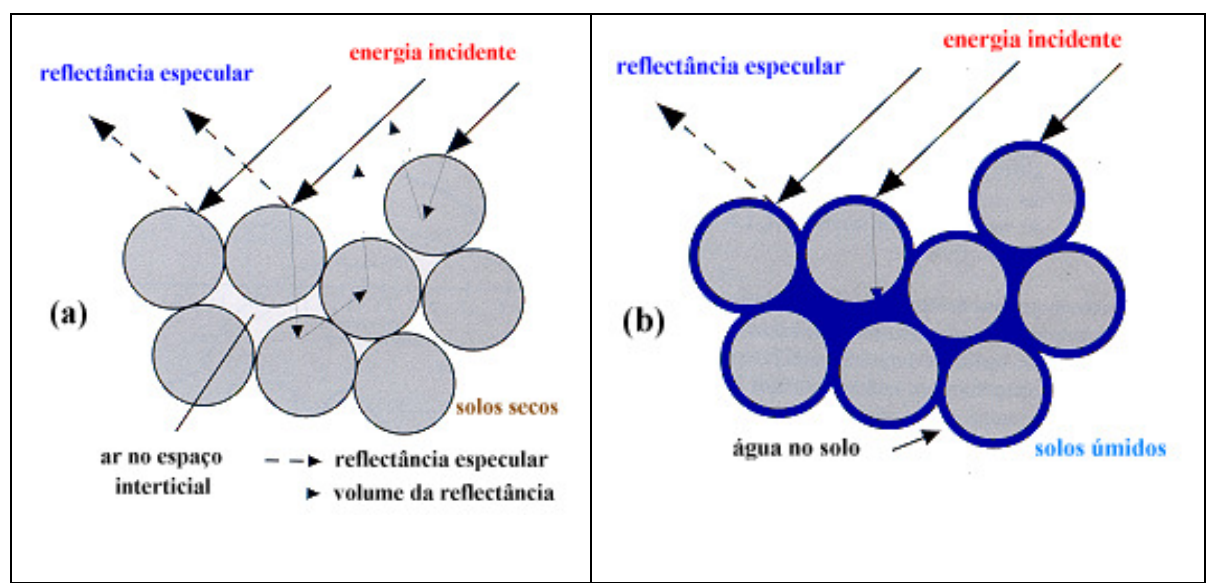

Figura 2.2 - Alteração da reflectância do solo pela presença da água. (a) Solos secos; (b) Solos úmidos. (Fonte: Jensen, 2000)

No trabalho pioneiro de Bowers e Hanks (1965), ao relacionar em um gráfico a relação entre o diâmetro da partícula com a umidade em diferentes comprimentos de onda, demonstraram haver uma relação linear entre o diâmetro da partícula e o teor de umidade (Figura 2.3). Bowers e Hanks (1965) afirmaram que a reflectância global diminui quase linearmente com conteúdos crescentes de umidade do solo. Porém, para solos que apresentam bandas de absorção fortes, como os lateríticos, os efeitos de umidade dependem do comprimento de onda, da posição e da intensidade das bandas de absorção dos minerais (Bedidi et al., 1992; Bedidi e Cervelle, 1993).

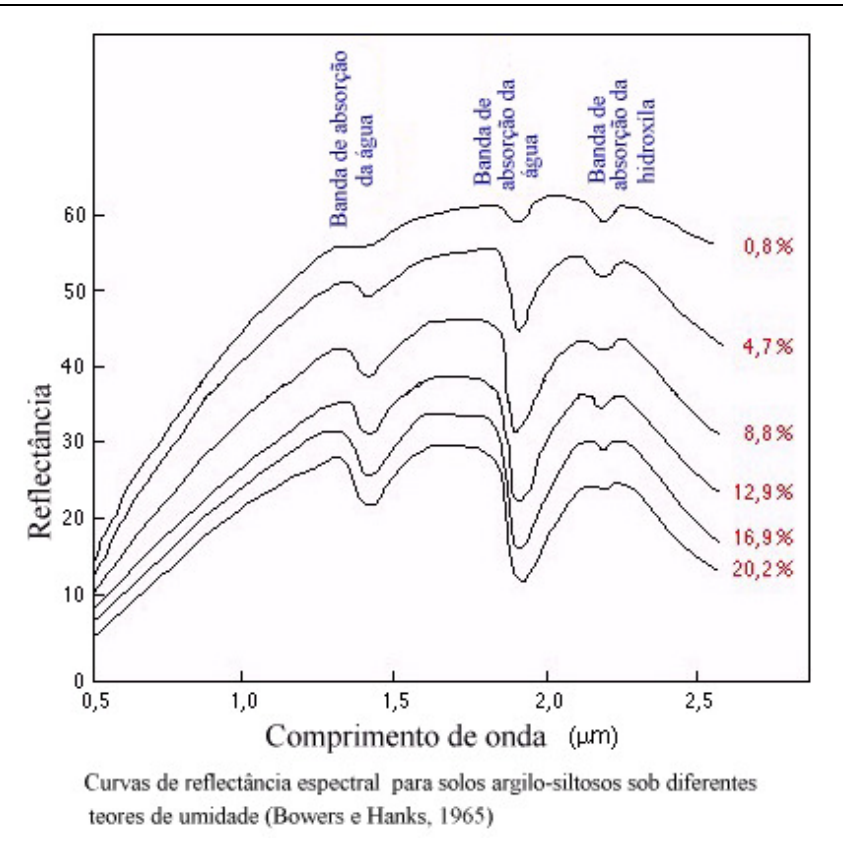

Figura 2.3 - Variação da curva de reflectância de um solo em diferentes teores de umidade 
A umidade afeta a reflectância do solo por causa das bandas de absorção da água em $0.76 \mu \mathrm{m}, 0.97 \mu \mathrm{m}, 1.19 \mu \mathrm{m}, 1.45 \mu \mathrm{m}$ e $1.94 \mu \mathrm{m}$ e $2.73 \mu \mathrm{m}$ e provoca diminuições na intensidade de reflectância ao longo de todos os intervalos espectrais (Curcio e Petty, 1951 apud Madeira Netto, 1996).

Bedidi et al. (1992) realizaram um estudo sobre os efeitos da umidade nas características espectrais de solos lateríticos. Esses autores afirmaram que a modificação das propriedades espectrais de um solo quando umedecido depende de seus componentes minerais. O comportamento espectral devido a variações de umidade é mais complexo para estes solos pela presença dos sesquióxidos que produzem feições entre $0.4 \mu \mathrm{m}$ e $0.7 \mu \mathrm{m}$. Qualquer material que contenha substância absorvedora deve induzir variações de reflectância semelhantes na região visível do espectro quando é umedecido (Bedidi et al., 1992).

A cor também é afetada pela umidade: ocorre uma mudança do matiz para o vermelho quando têm-se altas taxas de umidade e uma diminuição sistemática da pureza. A variação da cor é devida à variação de reflectância que depende do teor de água e de sua distribuição no sistema de porosidade macro e micro do solo; essa distribuição é fixada pela textura a pela estrutura do solo (Bedidi et al., 1992).

Devido ao fato de a água ser transparente na faixa do visível, só se muda o índice de refração médio pelo ar que penetra nos solos secos e pela água que entra nos solos saturados. Essa variação no índice de refração médio induz mudanças nos espectros de reflectância que dependem da existência, da localização e da intensidade das bandas de absorção (Bedidi et al., 1992).

A absortância dos diferentes componentes minerais dos solos determina a contribuição para a reflectância total: a reflectância aumenta com o índice de refração médio e diminui quando os minerais são altamente absorvedores, considerando-se que o componente especular comporta-se de modo oposto. O predomínio de um desses dois componentes rege o comportamento da reflectância total (Bedidi et al., 1992).

Não se pode menosprezar a estreita relação entre as propriedades espectrais e o comportamento pedoídrico dos solos que deve ser quantificada, principalmente, pela redução do albedo observado e, simultaneamente, pelas medidas de reflectância espectral para diferentes taxas de umidade (Bedidi et al., 1992). Essa relação pode ser usada para medir parâmetros pedoídricos, como o potencial hídrico e derivar aplicações de sensoriamento remoto para agricultura e ciência de solo. 
Um trabalho relativamente recente foi o realizado por Muller e Duchamps (2001) que buscou modelar as alterações na reflectância devido a umidade em solo exposto, em condições reais de campo, através de dados obtidos por sensores Spot aerotransportados.

Um dos trabalhos mais completos sobre o monitoramento da água no solo através de imagens digitais de sensores ópticos orbitais (no caso, o Landsat) foi realizada por Huete e Warrick (1990). A análise da água do solo é difícil de ser analisada devido a presença da cobertura vegetal. Huete e Warrick (1990) sugeriram o uso dos parâmetros espectrais de análise termal, brilho e NDVI, para avaliação da umidade do solo, desde que estes são sensíveis aos solos secos. Também propuseram o uso do SAVI (Soil-adjusted vegetation index - índice de vegetação ajustado ao solo) para minimizar as variações espaciais e temporais do comportamento espectral dos solos para uma possível determinação das condições de umidade. Devido a toda esta complexidade da dinâmica da água na superfície do solo seco e a variabilidade de suas propriedades, o teor de água na superfície dos solos tornase muito difícil de ser determinada através de sensores ópticos como o Landsat ou através de seus indicadores.

Cabe aqui destacar que a maioria dos estudos desenvolvidos sobre a umidade dos solos foram realizadas em condições de laboratório. Alguns dos problemas encontrados na delimitação do teor de umidade em campo, originam-se na variação espacial e na natureza dinâmica dos processos de secagem dos solos sobre as condições de campo e suas variações diurnas que interferem diretamente na radiação refletida e emitida (Jackson et al, 1973).

Por mais úmido que esteja os solos, em condições de elevada evaporação, os solos úmidos podem ter suas superfícies secadas rapidamente, onde as medidas ópticas são feitas. Jackson et al (1973) apresentam exemplos de um rápido processo de secagem dos solos da superfície como um resultado do movimento bidirecional da água, isto é, a água que fica até $1 \mathrm{~cm}$ da superfície dos solos pode se mover para cima (evaporação) enquanto a água situada abaixo de $1 \mathrm{~cm}$ pode se mover para baixo (Figura 2.4).

Como o processo de secagem dos solos é espacialmente não-uniforme, pode, o mesmo solo, situado na mesma área, ser encontrado em diferentes níveis de umidade e este irá produzir diferentes respostas que serão captadas como diferentes níveis de energia refletida e será registrada pelo imageamento de satélite (Huete e Warrick, 1990). Como durante a geração do pixel ocorre uma integração espacial do sinal, o pixel gerado irá ser interpretado erroneamente como um solo com níveis intermediários de água. Como a complexidade do fluxo de água nos solos ocorre como uma função da profundidade, em conjunto com 
superimposição da variabilidade espacial e temporal, torna-se muito difícil correlacionar funcionalmente a energia refletida com a umidade da superfície/subsuperfície.

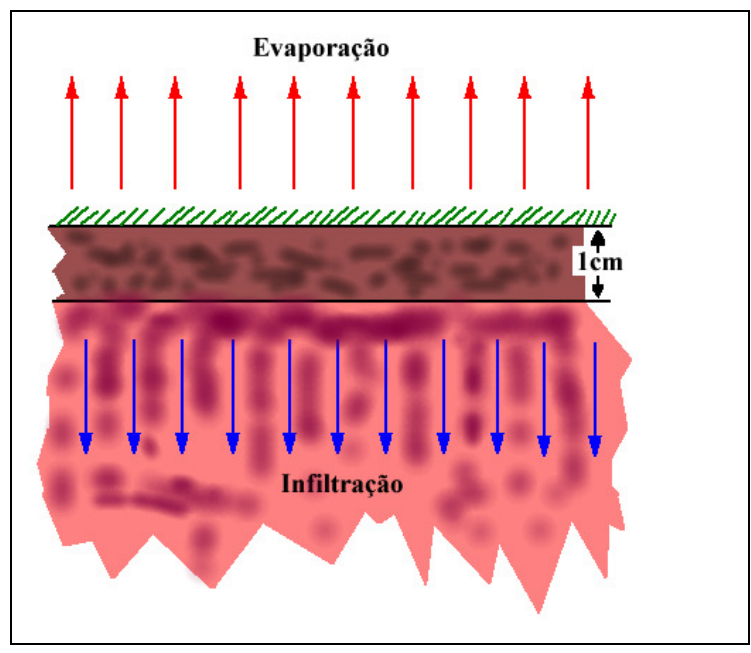

Figura 2.4 - A zona de $1 \mathrm{~cm}$ de profundidade dos solos e que é efetivamente imageada pelo sensor, pode ter suas características de teor de umidade rapidamente modificadas, tanto pelo processo de evaporação (climático) como da infiltração (granulometria e textura dos solos), passando rapidamente de um estado úmido para seco.

Investigações focadas nas bandas ópticas tem tentado estimar o teor de água pela variação da reflectância da folha, seja através de dados espectrais brutos ou índices sintéticos (razão entre bandas ou transformação Tasseled Cap). Cohen (1991) estabeleceu que os efeitos da deficiência hídrica podem se manifestar de muitas maneiras, como pela alteração na área foliar e na arquitetura das folhas, afetando assim, a resposta espectral da cobertura de modo significativo. Como resultado, os índices de vegetação para determinar a deficiência hídrica nas folhas, são muito limitados (Verbesselt et al., 2002)

Muitos dos índices de vegetação podem ser usados com o NDVI que tem a vantagem que seu valor para vegetação seca (não-vegetação) é zero e que maximiza o contraste do "Verde" (Greenness) para fins de análise (Prince, 1991; Prince e Goward, 1995; Cohen, 1991). Daí o estudo dos solos estar intrinsecamente associado ao estudo da vegetação e utilizar destas mesmas técnicas para inferir o teor de umidade dos solos.

\subsubsection{Cor}

As chaves de interpretação de cores para as imagens de satélite tem que ser elaboradas especificamente para cada área, sendo sua validade restrita a zonas poucas extensas e agroecologicamente homogêneas.

A cor do solo é o fator de correlação mais importante nos estudos iniciais do solo, sendo sua importância destacada na chave de classificação dos solos, no terceiro nível categórico. 
A cor é um fator que se destaca, em particular quando se trabalha com o espectro visível. Nas áreas secas, que exibe um grande parcela de solo exposto,as cores diferentes podem ser facilmente observadas, principalmente através de sistema IHS. Na composição falsa cor, a diferenciação de cores é pouco pronunciada.

Trabalhos de campo demonstram, entretanto, que nem toda cor diferenciada pelos sensores do satélite corresponde aos limites dos solos, podendo ser alterados pela presença de elementos superficiais como, por exemplo, acúmulo de areia resultante da deposição nos processos de transporte da erosão superficial dos solos. Por outro lado, também áreas com idênticas cores de reflectância apresentam solos diferentes (Christiansen, 1986).

Analisando as bandas do Spot, Wright e Birne (1986) sugeriram o uso de bandas do visível para identificar pela cor, a diferentes tipos de solo. Entretanto eles destacam que o teor de umidade é problemático para este procedimento, pois a presença de umidade altera estes valores.

\subsubsection{Composição mineralógica}

Assume-se que o efeito da composição de diferentes minerais na reflexão pode ser descrito através do peso médio do coeficiente de absorção dos componentes individuais.

Em 1970, Hunt e Salisburry publicaram o resultado de exaustivas medidas de reflectância em amostras de minerais puros de vários tamanhos de partículas.

A composição mineral dos solos afeta seu espectro de reflectância. O aumento da reflectância ocorre do visível para o infra-vermelho próximo - com bandas de absorção em torno de $1.4 \mu \mathrm{m}$ e $1.9 \mu \mathrm{m}$ relacionado ao aumento da umidade dos solos. No espectro de reflectância dos solos, estes solos úmidos desenvolverão curvas paralelas. A umidade dos solos tem um efeito igual sobre o espectro e sobre a razão de bandas espectrais. As bandas espectrais do vermelho e do infravermelho próximo são independentes da umidade dos solos.

A linha correspondente ao solo, no espectro de reflectância dos solos, caracteriza o tipo de solo, define os índices de vegetação e corrige a reflectância do dossel das plantas do efeito das propriedades ópticas dos solos. Esta linha do solo também representa a relação entre a reflectância dos solos no vermelho e no infravermelho próximo.

A temperatura de superfície e as condições da vegetação podem ser usadas para inferir alguma coisa sobre a umidade. Isto é mais freqüente em sensores com bandas no termal, principalmente com 4.1-4.25 $\mu \mathrm{m}$ e 13.0 e $15.4 \mu \mathrm{m}$ (CEOS, 1995). Todos os sensores que 
apresentam estas bandas têm uma resolução espacial muito baixa. Mas é a única forma de se obter uma descrição geral da umidade do solo na paisagem. A precisão é determinada, na maioria das vezes pela homogeneidade da superfície observada. Poderia se testar o uso das bandas TIR do sensor ASTER, principalmente devido a sua maior resolução espacial e a sua maior descriminação em número de bandas espectrais (6)

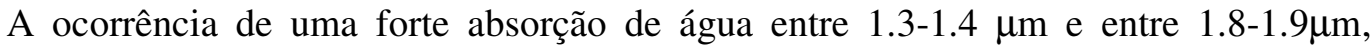
denota que o solo reage muito intensamente aos "processos vibratórios", indicativos da presença de moléculas de água, dissassociada da estrutura mineral, em alguma forma. Entretanto, os instrumentos dos satélites devido a localização e largura de suas bandas não são aptos para detectar esta característica. Pode ocorrer também uma curva de absorção em 1.3$1.4 \mu \mathrm{m}$ sem a presença da curva de $1.8-1.9 \mu \mathrm{m}$. Neste caso, isso seria decorrente da presença de grupos de $\mathrm{OH}$ diferentes da água

As bandas entre 2.0 e $2.5 \mu \mathrm{m}$ são muito valiosas para a detecção de características dos solos. Estas indicariam o dobramento da estrutua $\mathrm{X}-\mathrm{OH}$ (sendo $\mathrm{X}=\mathrm{Al}$ ou $\mathrm{Mg}$ ), próximo à $2.2 \mu \mathrm{m}$ ou $2.3 \mu \mathrm{m}$, os quais podem ser observados na banda 7 do Landsat TM, e no conjunto de bandas SWIR do ASTER, correspondendo às Bandas 6, 7 e 8. Normalmente os sensores dos satélites não monitoram as bandas de absorção de água, então vamos dizer que os instrumentos dos satélites com bandas entre $1.1 \mu \mathrm{m}$ e $2.6 \mu \mathrm{m}$ seriam interessantes para detectar $\mathrm{OH}, \mathrm{H}_{2} \mathrm{O}, \mathrm{CO}, \mathrm{POH}$ característicos. Poderíamos sugerir que, no futuro, os instrumentos tivessem sensores correspondentes as duas últimas bandas nesta região do espectro. Da maioria dos satélites pesquisados, apenas o sensor OPS, montado sobre o JERS1 (agora inoperante) oferecia muitas possibilidades, tanto por ter um elevado número de bandas como por possuir uma resolução espacial de $21 \mathrm{~m}$.

O ASTER (EOS-AM1) se apresenta como uma boa alternativa. O MODIS poderia ser uma alternativa, mas como os dois são da EOS-AM1, prefere-se o ASTER por te uma resolução espacial maior (ver Anexo B)

\subsection{Caulinita $\left(\mathrm{AI}_{2} \mathrm{SiO}{ }_{5}(\mathrm{OH})_{4}\right)$}

A caulinita é o argilo-mineral mais freqüentemente encontrado nos solos tropicais. Ela é formada nos solos pelo intemperismo ou ainda nas rochas pela alteração hidrotermal de aluminossilicatos, particularmente, o feldspato, ou ainda como constituinte de rochas sedimentares. Seu espectro de reflectância tem feições características na região do infravermelho refletido (Hunt e Salisbury, 1970; Hunt et al., 1973). 
Hunt et al. (1973) consideraram que a intensidade da feição da caulinita a $2.2 \mu \mathrm{m}$ está associada às duas camadas dioctaédricas da estrutura do mineral. A banda de absorção fraca da água próxima a $1.9 \mu \mathrm{m}$ indica a presença de água molecular absorvida e não água constitucional, como ocorre, por exemplo, na montmorillonita ((AI, Mg) $)_{-3} \mathrm{Si}_{4} \mathrm{O}_{10}(\mathrm{OH})_{2}$ . $\left.\mathrm{nH}_{2} \mathrm{O}\right)$.

Lindberg e Snyder (1972 apud Hunt et al., 1973) apresentaram vários espectros de reflectância difusa nas faixas do visível e do infravermelho próximo de vários minerais de argila. Apresentaram, também, espectros de minerais de argila desidratados e reidratados e concluíram que pode existir correlação entre as feições dos espectros obtidos com as dos espectros de água molecular e qualquer diferença entre esses espectros é devida a água na estrutura de argila. Hunt et al. (1973) salientaram que muitas dessas feições agudas resultam de vibrações do $\mathrm{OH}$ estrutural em vez de água molecular, podendo-se notar facilmente essas diferenças pela presença da feição a $1.9 \mu \mathrm{m}$.

Essa feição em $1.9 \mu \mathrm{m}$ envolve a vibração de dobramento da ligação H-O-H e, na ausência de água molecular, é devida, quase na sua totalidade, ao processo vibracional da hidroxila estrutural (Hunt et al., 1973), como ocorre na caulinita. A feição da água próxima a $1,9 \mu \mathrm{m}$ só é fraca quando as bandas de absorção da hidroxila são muito mais intensas e quando é devida à água molecular absorvida (Hunt et al., 1973). Entretanto, como dito anteriormente, os sensores dos satélites normalmente não foram preparados para monitorar as bandas de absorção de água, o que significa dizer que esta feição não pode ser avaliada pelos sensores orbitais comuns.

Entretanto, a caulinita apresenta um pico de máxima reflectância a $2.225 \mu \mathrm{m}$ e uma

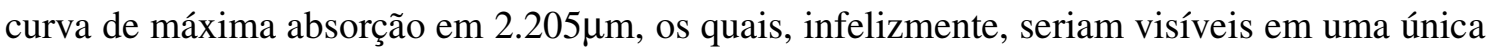
banda, a banda 6 do satélite ASTER.

\subsection{Gibsita $\left(\mathrm{Al}_{2} \mathrm{O}_{3} 3 \mathrm{H}_{2} \mathrm{O}\right)$}

Os solos que foram sujeitos a pronunciada alteração como os latossolos situados em antigas superfícies de erosão, sempre apresentam elevados teores de gibsita em sua composição. Em vários casos representa o mineral mais importante da fração argila (Baptista et al., 1998).

A gibsita é um hidróxido de $\mathrm{Al}$ triidratado, apresentando fórmula $\left(\mathrm{Al}_{2} \mathrm{O}_{3} 3 \mathrm{H}_{2} \mathrm{O}\right)$ e um dos principais componentes de depósitos de bauxita formados por intemperismo tropical de rochas com silicato de alumínio. Raramente, forma-se em regiões de baixas temperaturas. 
Junto com os outros dois minerais (diásporo e boehmita) que formam a bauxita, é um mineral formador de minério de alumínio (Hunt et al., 1971).

A gibsita, assim como a caulinita, apresenta feições espectrais devido às vibrações das hidroxilas. Assim, apresenta as bandas de absorção de $1.4 \mu \mathrm{m}$ decorrente das vibrações moleculares da hidroxila, a de $1.9 \mu \mathrm{m}$ resultante da vibração de dobramento de $\mathrm{H}-\mathrm{O}-\mathrm{H}$ na ausência de água molecular, e a correspondente ao alongamento do $\mathrm{OH}$ e as curvaturas de ligação do $\mathrm{Al}-\mathrm{OH}$ a $2.2 \mu \mathrm{m}$.

Assim, no caso da gibsita, somente as feições decorrentes da vibração molecular originárias do grupo $\mathrm{OH}$ podem ser observadas, sendo a primeira a $1.55 \mu \mathrm{m}$, que pode ser avaliada na banda 5 do Landsat TM, e a de $2.3 \mu \mathrm{m}$, que pode ser avaliada nas bandas 7, do Landsat TM e nas bandas 8 e 9 do ASTER.

Assim como a caulinita, a gibsita também possui uma banda de máxima absorção ocorrendo em $2.265 \mu \mathrm{m}$ a qual poderia ser observada na banda 7 do ASTER.

\subsubsection{Tipos de feições metálicas}

A maioria das feições metálicas é absorvida na parte visível do espectro. Este fato pode ser monitorado na maioria dos instrumentos existentes com sensores de diferenciar mais de 3 bandas. Assim, dos satélites mais conhecidos, hoje em operação somente o MODIS, com 7 bandas no visível seria bom para a diferenciação dos solos com base em seu conteúdo metálico.

\subsection{Goetita (FeOOH) e Hematita (Fe2O)}

Goetita $(\mathrm{FeOOH})$ e Hematita $\left(\mathrm{Fe}_{2} \mathrm{O}_{3}\right)$ são as mais freqüentes ocorrências de minerais de ferro férrico $\left(\mathrm{Fe}^{3+}\right)$ encontrados em solos tropicais. Eles resultam da oxidação do ferro presente como $\mathrm{Fe}^{2+}$ em minerais primários nos processos de formação de solos. A predominância de um ou de outro está relacionada a fatores pedogenéticos e à compreensão de sua ocorrência é de grande importância nos estudos dos solos tropicais.

Várias feições na curva espectral são atribuídas a presença de ferro (Ben-Dor et al. 1999), sendo que de uma maneira geral a Goetita apresenta maior reflectância que a Hematita. A presença de óxidos de ferro no solo influencia o comportamento da curva espectral principalmente na região do visível e infravermelho próximo diminuindo o albedo conforme aumenta seu teor no solo. As feições típicas que ocorrem na região de $0.9 \mu \mathrm{m}$, são atribuídas a 
presença de óxidos de ferro sendo mais intensas quanto mais elevados forem seus teores no solo (Dalmolin et. al, 2002).

O uso de novas técnicas provenientes da evolução do uso dos novos sensores, como os hiperspectrais, possibilita realizar separações mais precisas entre a Goetita e a Hematita, pois os usuais classificadores espectrais apresentam dificuldades para separar feições de absorção próximas e semelhantes devido à alta correlação entre as feições. A dificuldade aumenta quando essas apresentam-se misturadas, como a Goetita e Hematita, que geram feições intermediárias. Para esses minerais e suas misturas a identificação pode ser melhor determinada pela posição da banda central de absorção como a proposta por Carvalho et. al. (2001) utilizando dados do Aviris, pois que no intervalo entre $0,46 \mu \mathrm{m}$ e $0,62 \mu \mathrm{m}$ as feições de absorção do $\mathrm{Fe}^{+3}$ são bem definidas.

Esses sesquióxidos de ferro apresentam-se diferenciados por meio de suas feições espectrais, principalmente no visível e no infravermelho próximo.

Sherman e Waite (1985) demonstraram as principais transições eletrônicas de campo cristalino na faixa do visível e do infravermelho próximo da Hematita e da Goetita.

\subsection{Relação Hematita/Goetita}

Madeira Netto et al. (1997) propuseram índices baseados na reflectância na faixa do visível para determinação dos teores de Hematita e Goetita de solos lateríticos, por meio de dados multiespectrais do sensor TM do landsat 5 para a região de Brasília.

Para determinação do índice de Hematita, Madeira Netto et al. (1997) apresentaram a seguinte equação:

$$
I_{H m}=1000 \frac{T M 3}{T M 1 . T M 2} \quad \text { (Equação 2.1) }
$$

Onde $\mathrm{I}_{\mathrm{Hm}}$ é o índice proporcional ao conteúdo de Hematita dos solos; TM 1, TM2 e TM3 são respectivamente as bandas 1, 2 e 3 do sensor TM do Landsat 5 (Madeira Netto et al., 1997).

O índice férrico utilizado para estimar a razão Hematita/(Hematita + Goetita) é apresentado pela Equação :

$$
I_{F e}=\frac{S T M 3-S T M 2}{S T M 3+S T M 2} \quad \text { (Equação 2.2) }
$$


Onde $\mathrm{I}_{\mathrm{Fe}}$ é proporcional aos teores de Hematita relativos ao total dos óxidos de ferro livres (Hematita mais Goetita); STM2 e STM3 são respectivamente as bandas 2 e 3 do sensor TM do Landsat 5 simuladas com base na convolução dos espectros (Madeira Netto et al., 1997).

\subsubsection{Teor de Matéria Orgânica}

É sabido que a matéria orgânica contida nos solo influencia significativamente a reflectância espectral, interferindo nos levantamentos de solos realizados por sensoriamento remoto. O principal problema é que a cobertura vegetal, os resíduos de lavoura, padrões de cultivo, umidade do solo afetam seriamente o espectro de reflectância do solos (Gausman et. al., 1975, 1977; Huete et al., 1985).

A Matéria Orgânica do solo (MO) é um termo genérico para uma mistura complexa de substâncias de carbono com características físicas e químicas variáveis. Normalmente, é classificada em três categorias amplas: humina, ácidos fúlvicos e ácidos húmicos (Vieira, 1988; Moniz, 1975). A proporção dessas combinações nos solos pode variar, sensivelmente, e depende dos fatores de formação tais como as condições climáticas, os organismos vivos que os originaram, a composição dos materiais inorgânicos do solo, entre outros (Flaig et al., 1975).

A Matéria Orgânica é o quarto fator que influencia nas propriedades ópticas dos solos. A Matéria Orgânica pode indiretamente afetar o comportamento espectral, baseando na alteração que a mesma pode provocar na estrutura dos solos e na capacidade de retenção de água. Altos teores de Matéria Orgânica nos solos pode produzir interferências no espectro nas bandas características de minerais como o Mn e o Fe.

Karmanov (1968) afirmou que as propriedades espectroscópicas dos solos são afetadas, principalmente, pelo acúmulo de substâncias húmicas escuras responsáveis pela redução do coeficiente de brilho. As substâncias húmicas escuras ocasionam um matiz brunado-acinzentado no solo o que tenderia a aproximar a coloração do acromático, resultando em uma redução dos coeficientes de cor .

Galvão et al. (1997) demonstrou que, para os solos tropicais brasileiros, a transição nos horizontes superficiais é caracterizada principalmente pela troca de inclinação das curvas de reflectância, como um resultado direto da redução de matéria orgânica (M.O.) e da migração das argilas do horizonte A para B. Embora os sensores mais utilizados (Landsat 
TM) possa caracterizar o albedo e a inclinação espectral dos solos, possivelmente um sensor de resolução espectral maior para caracterizar as bandas de absorção dos solos seria mais adequado.

Galvão e Vitorello (1998) afirmaram que a MO é o principal componente responsável pela redução da reflectância na faixa de 0.6 a $0.75 \mu \mathrm{m}$ e que a presença de mais que $1,7 \%$ de MO bloqueia as características espectrais do ferro, induzindo a uma redução maior que $40 \%$ na correlação entre o conteúdo total de ferro $\left(\mathrm{Fe}_{2} \mathrm{O}_{3}\right)$ e a reflectância.

Depois da remoção da MO por meio de tratamento químico, os solos apresentaram veios ligeiramente avermelhados e são mais saturados e mais luminosos que as amostras sem tratamento. As amostras tratadas apresentaram aumento significativo da reflectância (mais que 100\%). Segundo Galvão e Vitorello (1998) o resultado geral da remoção de MO foi o aumento de albedo e um aplainamento na forma dos espectros.

Após o tratamento de remoção da $\mathrm{MO}$, o aumento nos valores dos atributos de cor e na profundidade das bandas de absorção ao redor de $0.9 \mu \mathrm{m}$ é menos acentuado em solos com conteúdo de $\mathrm{Fe}^{2} \mathrm{O}^{3}$ maior que $10 \%$ por causa da presença de outros materiais opacos (Galvão e Vitorello, 1998).

Quando o teor de ferro está próximo de zero, a reflectância aumenta para o intervalo de 0.4 a $2.5 \mu \mathrm{m}$.Para solos com um teor alto de óxidos de ferro e nenhum mineral opaco, a eliminação da matéria orgânica aumenta a reflectância nos comprimentos de onda abaixo 0.6 $\mu \mathrm{m}$ e diminuiu para o restante do espectro. Para solos ricos em materiais opacos (magnetita e ilmenita) a reflectância diminui em quase todo o espectro após a remoção da matéria orgânica (Madeira Netto, 1993; 1996).

Palacios-Orueta e Ustin (1998), utilizando análises estatísticas de componentes principais, afirmaram que os sensores aero-transportados e de plataforma orbital permitem a detecção espectral e a quantificação dos óxidos de ferro e da matéria orgânica dos solos. Os autores enfatizaram que as variabilidades produzidas pelos teores de ferro e pela matéria orgânica encontram-se resumidos na segunda e terceira componentes.

A matéria orgânica não apresenta bandas características de absorção, mas influencia no albedo e na forma do espectro de reflectância geralmente provocando aumento na resposta espectral quando a mesma é removida do solo (Dematte e Garcia, 1999; Galvão e Vitorello, 1998).

De acordo com Clark (1999), o melhor instrumento para monitorar a matéria orgânica deveria ter bandas em torno de 1.7, 2.3 e $3.4 \mu \mathrm{m}$. Preferencialmente as bandas de 1.7 e 3.4 
$\mu \mathrm{m}$, devido a ocorrência de possíveis confusões com os minerais da banda de $2.3 \mu \mathrm{m}$. Somente dois sensores, dos quais só um operativo hoje, atenderiam a estas especificações: o

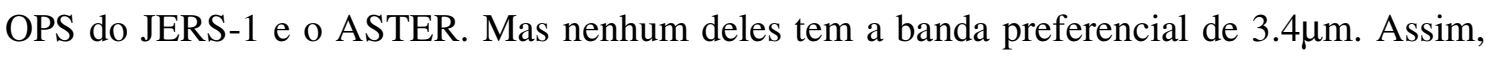
poderia se buscar observar a redução da reflectância nas bandas 2 e 3 do Landsat TM e na banda 1 do ASTER, ou a redução geral da reflectância, decorrente da presença do ferro em todas as bandas em geral, correspondentes ao intervalo de 0.4 a $2.5 \mu \mathrm{m}$.

\subsubsection{Textura superficial}

A superfície do solo exposto é definida como uma combinação de segmentos de superfície intrínseca do solo como do não-solo, estruturado em uma incerta distribuição e orientação espacial.

Assim, segundo Cooper e Smith (1985), somente as variações na reflectância se originam nas feições microscópicas do solo (cujo maior tamanho é ainda pequeno a ponto das irregularidades geradas na superfície poderem ser negligenciadas), são considerados.

Uma superfície de solo exposto tem uma certa rugosidade que é diferente geometricamente das outras superfícies do solo com cobertura. Uma superfície de solo exposto tem tantas rugosidades geometricamente diferentes quanto as superfícies de solo exposto existam.

Também os elementos do não-solo como fragmentos de rochas de diversos tamanhos (cascalhos, seixos, matacões, etc), são indivíduos desta categoria, tanto quanto a declividade e a exposição da superfície também compõe este elemento.

A textura do solo (rugosidade) também afeta as propriedades ópticas dos solos. A luz é capturada e/ou desviada na superfície rugosa das partículas grosseiras, de maior granulometria. Por exemplo, se o Ferro e o silte estão presentes a reflectância é muito maior do que se o material dos solos fosse de textura fina e seca. Variações na reflectância dos solos ocorrem onde tem-se uma troca na distribuição de áreas de luz e sombras com áreas de superfície rugosa. Este fator é importante no domínio do infravermelho termal e do microondas.

Madeira Netto ( 1993) baseou-se nas feições de absorção da caulinita e da gibsita para determinar a textura para os latossolos. Esses minerais são os principais componentes da fração argila desses solos e portanto apresentam boa correlação entre a soma desses minerais e o teor de argila. 
As feições espectrais da caulinita e da gibsita estão integradas na banda TM7 e na banda TM5 não havendo nenhuma feição específica relacionada aos minerais da fração argila que ocorrem na maioria dos latossolos. Madeira Netto (1993) propôs uma relação para expressar o teor de argila (Equação 3) .A análise de regressão linear de 52 amostras mostrou correlação significativa entre a relação (TM5 -TM7/TM5 + TM7) e teor de argila, com um erro inferior a $5 \%$ e um coeficiente de correlação $r=0.80$.

$$
I T .(S T M)=\frac{S T M 5-S T M 7}{S T M 5+S T M 7}
$$

Onde IT x (STM) é o índice proporcional à textura dos solos; STM5 corresponde à banda 5 simulada por meio de convolução dos espectros obtidos em laboratório; e o STM7 = a banda 7 simulada.

Solos mais argilosos apresentam-se mais inclinados na porção do espectro de 1.5 a 2.5 $\mu \mathrm{m}$, enquanto os solos mais arenosos, apresentam uma menor inclinação. Como a banda TM5 cobre o intervalo de 1.55 a $1.75 \mu \mathrm{m}$ que não apresenta feições de argilo-minerais, e a banda TM7, o de 2.08 a $2.35 \mu \mathrm{m}$, apresentando as feições dos principais argilo-minerais encontrados nos solos tropicais, a relação proposta por Madeira Netto (1993) ressaltaria as variações texturais dos solos.

\subsubsection{Tamanho e forma dos agregados}

A estrutura superficial das partículas e dos agregados também é um elemento que interfere na reflexão superficial dos solos. A superfície natural dos solos consiste de um conjunto de partículas e agregados que raramente podem ser agrupados em uma classe de partículas do mesmo tamanho. As propriedades ópticas de um agregado de partículas, formados por elementos granulométricos de diferentes classes de tamanho, mas que, se assemelham ao comportamento da partícula de menor tamanho.

Uma grande quantidade de luz é ricochetada e absorvida pelas partículas e este aspecto depende do tamanho destas partículas. Uma partícula grande tem um grande caminho interno onde os fótons podem ser absorvidos de acordo com a lei de Beers. É a reflexão das superfícies e as imperfeições internas que controlam o ricocheteamento (scaterreing). Em uma partícula pequena, tem-se, proporcionalmente, mais superfície de reflexão comparada ao 
comprimento do caminho que o fóton irá percorrer internamente, ou, em outras palavras, a razão superfície/volume é uma função do tamanho da partícula.

Entretanto, no infra-vermelho termal o efeito do tamanho da partícula é muito mais complexo, onde a tendência de retorno das emissões são comumente observadas.

Podemos indicar então que, para se poder analisar o efeito do tamanho das partículas na reflectância dos solos, seria interessante ter-se, ao menos, uma banda entre 0.4 e $3.0 \mu \mathrm{m}$ para detectar a redução da reflectância com o aumento do tamanho da partícula. A tendência de retorno da emissão seria melhor observada numa banda menor que $6.5 \mu \mathrm{m}$ e uma banda em torno de $9.5 \mu \mathrm{m}$.

Em 1965, Bowers e Hanks publicaram o resultado de um estudo sobre o efeito do tamanho da partícula na reflectância em diferentes comprimentos de onda no intervalo óptico, em amostras de caulinita e bentonita. Este trabalho tornou-se referência para todos os posteriores.

Simmons (1972) apresentou uma teoria geral do efeito do tamanho de partícula na reflectância, por meio de equação que mostra uma relação inversa entre eles. A explicação para esse comportamento reside no fato de que os materiais mais finos apresentam uma superfície mais plana com menos porosidade para capturar a luz incidente.

Os trabalhos experimentais de Bowers e Hanks ( 1965) que estudaram a reflectância da caulinita e da bentonita e Orlov (1966) de agregados de solo confirmaram essa teoria. Este autor propôs uma relação exponencial entre o tamanho da partícula e a reflectância. Para partículas maiores que $2 \mathrm{~mm}$ de diâmetro não há praticamente nenhuma variação na reflectância e a equação seguinte (Equação 2.4) explica seus resultados:

$$
\mathrm{R}=\mathrm{k} 10^{-\mathrm{nd}}=\mathrm{R}_{\mathrm{a}} \quad \text { (Equação 2.4) }
$$

Onde $\mathrm{R}$ é a reflectância; $\boldsymbol{d}$ é o diâmetro do agregado; $\boldsymbol{R} \boldsymbol{a}$ é a reflectância dos agregados sobre os quais não há nenhum efeito adicional devido ao tamanho da partícula; $\boldsymbol{k} \mathrm{e}$ n são constantes que dependem de tipo de solo (Orlov, 1966).

A presença dos óxidos férricos e o porquê de a banda de absorção diminuir rapidamente de intensidade ocorre por causa do aumento da superfície em relação ao volume, em virtude do pequeno tamanho dos grãos, resultando na maior proporção dos limites do grão em que os efeitos de campo cristalino são diferentes e resultam na redução da junção magnética e a força de absorção, portanto, é reduzida. Outros óxidos férricos provavelmente 
apresentam efeitos semelhantes. Espectros de reflectância de óxidos de ferro apresentam bandas de absorção mais fortes à medida que muda significativamente o tamanho dos grãos (Morris et al., 1985).

A partir do exposto, podemos afirmar que a reflectância espectral dos solos é uma função complexa da composição e estrutura da camada superficial. O coeficiente de reflectância depende do teor de umidade, da matéria orgânica, dos óxidos de ferro, assim como do tamanho e composição dos agregados.

\subsection{Processamento de imagens}

Processamento digital de imagem é a manipulação numérica da imagem digital e é composta por 3 etapas: pré-processamento, realce e classificação. O pré-processamento se refere ao processamento inicial dos dados brutos para calibrar a radiometria de uma imagem, corrigir distorções geométricas e remover ruídos. A natureza da particularidade do préprocessamento é fortemente dependente do sensor, pois o pré-processamento objetiva remover qualquer característica indesejável da imagem produzida por este. As imagens corrigidas são então submetidas aos processos de realce ou classificação, ou ambos (Schowengerdt, 1983).

O realce de imagens produz uma nova imagem, em geral, uma imagem realçada para auxiliar a interpretação visual. Esta imagem realçada deve ser mais facilmente interpretada que a imagem original. $\mathrm{O}$ realce pode ser de diferentes tipos como o realce de contraste ou o realce de cor,

Já a classificação de imagens conduz o processamento digital de imagens a um passo além para substituir a etapa de interpretação visual pela tomada de decisão quantitativa. A saída de um processo de classificação é um mapa temático, no qual cada pixel da imagem original foi classificado em um dos muitos "temas" ou classes. Embora a intenção da classificação seja fazer o processo de mapeamento o mais quantitativo possível, a participação do usuário e sua integração ao processo é um parte vital para o efetivo sucesso do procedimento (Schowengerdt, 1983; Jensen, 1995)..

Embora o pré-processamento, realce e classificação possam ser considerados tópicos distintos, como foi discutido anteriormente, existe entre eles, na prática, muita interação. Por exemplo, algumas técnicas de pré-processamento, tal como eliminação de ruídos podem também ser consideradas como técnicas de realce. Algumas técnicas de processamento, tais como razão de bandas espectrais são úteis, tanto para produzir imagens realçadas como 
aperfeiçoar classificações. Por último, a precisão da classificação pode ser aperfeiçoada pelas etapas tanto de pré-processamento como de realce.

Devido a similaridade funcional de muitas das técnicas utilizadas pelo processamento e pelo realce de imagens, pode se utilizar simplesmente o termo processamento de imagens para inclui tanto o pré-processamento como o realce (Schowengerdt, 1983). O termo classificação de imagem incluirá as técnicas que são utilizadas para produzir mapas temáticos à partir da imagem.

No caso particular dos solos, as etapas de processamento, em particular as técnicas de realce (índices espectrais) são as mesmas utilizadas para a identificação de outras feições de uso e cobertura do solo. No presente trabalho iremos utilizar algumas das técnicas básicas de análise de imagem, a qual apresentamos em seguida, dando uma breve descrição de sua funcionalidade e princípios teóricos envolvidos, assim como os trabalhos mais relevantes publicados, começando com as técnicas exploratórias (análise de histograma, boxplot e diagrama de dispersão), em seguida técnicas de realce e transformação de imagem (Análise de componentes principais, razão de bandas, índices espectrais e transformação de Tasseled Cap) e por fim, o processamento propriamente dito, com a classificação de imagens.

\subsubsection{As técnicas exploratórias e de pré-processamento de imagens}

A primeira etapa de qualquer atividade de processamento de imagens é a análise exploratória de dados. O termo análise está relacionada a parte do tratamento onde existe uma descrição da informação presente na imagem. Esta parte é também chamada de parametrização e é nela que várias medidas quantitativas (parâmetros) são identificadas, e utilizadas para descrever diferentes informações dentro de uma imagem. Esta técnica tem como objetivo maior obter um conhecimento primário dos processos que se expressam através dos dados. A análise exploratória de dados usa os dados como uma "janela" para identificar as características das feições e traçar um quadro genérico do processo que gerou estes mesmos dados e avaliar seu comportamento.

\subsubsection{As representações gráficas}

O primeiro passo para qualquer análise espacial é a visualização do evento em estudo através de gráficos e mapas.

Gráficos como os histogramas e boxplots permitem uma análise rápida e robusta da distribuição das variáveis que serão utilizadas através do conjunto de unidades de análise 
observadas. Os boxplots são diagramas de caixa (Tukey, 1990), que identifica graficamente a posição da mediana e da média da distribuição; a altura da caixa (ou Box) representa o intervalo interquartílico $\left(1^{\circ}\right.$ e $\left.3^{\circ}\right)$, uma linha pontilhada engloba 1,5 vezes o intervalo interquartílico a partir do centro, e os traços horizontais representam os valores atípicos (outliers) da distribuição (StatSci, 1993), como pode ser observado nas Figuras 4.7 à 4.10. Com estas informações, pode-se traçar o perfil da totalidade da distribuição dos níveis de cinza em cada banda e seu comportamento estatístico geral.

Os gráficos de espalhamento de pontos (scatterplots) também são muito úteis para a avaliação bivariada evidenciando as correlações entre as variáveis, possibilitando a seleção daquelas mais adequadas para análise multivariada. Estes métodos não são específicos da análise espacial mas devem fazer parte da análise exploratória dos dados.

\subsubsection{A análise de componentes principais}

Análise de componentes principais (ACP) é uma das técnicas estatísticas mais aplicadas em sensoriamento remoto para descobrir quais conjuntos de variáveis, na forma de subconjuntos coerentes, são relativamente independentes uma das outras. Como em sensoriamento remoto as bandas são altamente correlacionados está técnica é amplamente aplicada na identificação destas correlações e reduzir um grande conjunto de variáveis para um conjunto mais significativo, com um conjunto menor de variáveis, e assim poder reduzir a dimensionalidade dos dados utilizados. Outra aplicação importante, a qual foi também utilizada neste trabalho é a capacidade de separar feições específicas em cada uma das componentes geradas, como a variação do albedo da cena (Componente 1) e vegetação (Componente 2).

A análise de componentes principais consiste em reescrever as variáveis originais em novas variáveis denominadas componentes principais, através de uma transformação de coordenadas no espaço de atributos. A transformação das coordenadas pode ser considerada um processo trivial quando feito usando matrizes e pode ser feita de diversas maneiras conforme o interesse, embora possua algumas especificidades. Esta operação está disponível em diversos softwares de processamento de imagens especializados. Cada componente principal é uma combinação linear de todas as variáveis originais. Por exemplo, na imagem ASTER, como foram utilizados 9 canais ou bandas (variáveis), após a transformação, obtevese nove componentes principais na forma de imagens. Cada uma destas componentes 
principais, por sua vez, foi escrita como uma combinação linear das nove imagens originais. Nestas combinações, cada imagem (variável) terá uma importância ou peso diferente.

Duas são as características das componentes principais que as tornam mais efetivas que as variáveis originais para a análise do conjunto das amostras (Prado et all., 2002): (a) as variáveis podem guardar entre si correlações que são suprimidas nas componentes principais. Como as componentes principais são ortogonais entre si, cada uma delas traz uma informação diferente das outras, sendo elas excludentes entre si devido a eliminação da correlação existente entre as imagens originais ; e (b) a segunda característica importante é decorrente do processo matemático-estatístico de geração de cada componente que maximiza a informação para cada uma das coordenadas que estão sendo criadas (Figura 2.5). As variáveis originais (imagens) têm a mesma importância estatística, enquanto que as componentes principais têm importância estatística decrescente, devido a concentração da variância. As primeiras componentes principais são tão mais importantes que em alguns casos, correspondem a 99\% de toda a informação do conjunto de variáveis. Assim, pode-se observar que a análise de componentes principais: (1) podem ser analisadas separadamente devido à ortogonalidade, servindo para interpretar o peso das variáveis originais na combinação das componentes principais mais importantes; (2) podem servir para visualizar o conjunto da amostra apenas pelo gráfico das duas primeiras componentes principais, que detêm maior parte da informação estatística.

Simplificando, o principal objetivo da análise de componentes principais é a obtenção de um pequeno número de combinações lineares (componentes principais) de um conjunto de variáveis, que retenham o máximo possível da informação contida nas variáveis originais. $\mathrm{O}$ processamento da análise de componentes principais pode ter partida na matriz de variâncias e covariâncias ou na matriz de correlação entre bandas.

A técnica de ACP é amplamente utilizada tanto para análise nos produtos do sensor ASTER, assim como na análise dos solos e/ou de elementos de sua composição mineralógica (Apan et al., 2002; Ninomiya, 2002; Rowan e Mars, 2002; Mah, 2003; Azurra et al., 2003) voltado a redução da dimensionalidade dos dados e avaliar a contribuição dos solos para a classificação. 


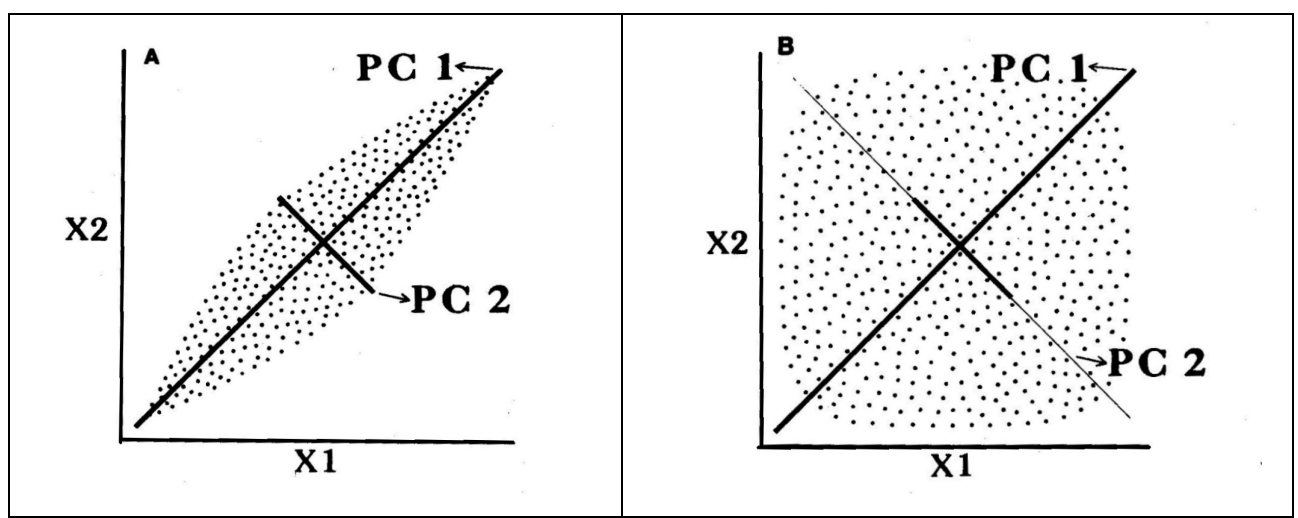

Figura 2.5 - Uma representação gráfica da transformação da componente principal e a transformação da componente principal invertida, em duas bandas hipotéticas, X1 e X2, mostrando a redução na contribuição da variância pela segunda componente PC2 (a) e o efeito da equalização da variância pelo realce do contraste nas duas componentes (b)

Fonte: Williams, Jr., 1983

\subsubsection{A razão de bandas}

A razão de bandas é um processo pelo qual os valores do brilho ${ }^{4}$ do pixel em uma banda são divididos pelos valores do brilho do pixel correspondente em outra banda de forma a criar uma nova imagem na saída do processo. Estas razões podem realçar ou atenuar certos atributos (bruma, topografia, etc) encontrados numa imagem, dependendo das características espectrais de cada uma das bandas escolhidas, caracterizando determinadas feições da curva de assinatura espectral de alguns alvos.

A técnica de razão de bandas é bastante utilizada, principalmente no ASTER para identificar elementos específicos dos solos, como descrito anteriormente, onde foram desenvolvidos índices para identificação de elementos como caulinita, montomorilonita, ferro, cor, etc (Yamaguchi, 1987; Chavez et al., 1989; Yamaguchi e Naito, 2003; San et al., 2004).

\subsubsection{4 Índices espectrais}

O ecossistema terrestre apresenta um comportamento óptico muito complexo devido à sua própria dinâmica, inerente ao crescimento vegetativo, assim como a própria deterioração dos processos, que são comandados pela dependência temporo-espacial tanto das propriedades climáticas como dos solos (Leeuwen e Huete, 1996). Na escala do subpixel, a dispersão múltipla e a interação entre os componentes verdes das plantas, assim como dos

${ }^{4}$ O "brilho" (tonalidade) de um pixel que constitui a imagem é proporcional ao valor digital (número digital ou Digital Nunber) registrado pelo sensor, e que equivale ao nível de reflectância dos alvos de superfície. 
componentes não ativos fotossinteticamente (como a serrapilheira ou plantas no estado senescente) e o solo, determinam a reflectância espectral obtida pelos sensores.

O índice espectral é a integração de duas ou mais bandas espectrais, segundo procedimento determinado, cuja finalidade é realçar as características de determinado objeto ou atributo da imagem em relação aos demais elementos que compõem a cena (Moreira, 2001). Os índices espectrais são os métodos primários utilizados para gerar informações para caracterizar o caráter biofísico da planta. Por sua vez a correlação entre os fatores biofísicos e a reflectância espectral é influenciada pela largura e posição que as bandas ocupam no espectro eletromagnético (Price et al, 2002) (Vide Anexo 2 - Características do Sensor ASTER). Daí o uso dos índices espectrais para gerar essas informações ser indiscutível, seja em escala regional ou local, pois estes índices foram desenvolvidos para realizar avaliação qualitativa e quantitativa da cobertura vegetal, utilizando medidas espectrais.

Como o índice espectral é uma transformação ortogonal dos dados multiespectrais, ele é um processo similar a análise de componentes principais (ACP). O índice espectral define a transformação do eixo para representar um padrão espectral específico de interesse, enquanto a ACP determina a transformação dos eixos matematicamente, para maximizar a variância do dado espectral. A ACP pode ser usada para reduzir a dimensionalidade dos dados multiespectrais sem reduzir significativamente a informação fornecida. A interpretação visual para discriminar as feições de superfície para possibilitar seu mapeamento, podem ser realçadas pela composição colorida da imagem das maiores componentes. Entretanto, seu significado não é ainda muito claro em muito dos casos. Como o resultado da ACP é dependente da cena, os seus coeficientes de transformação mudam de cena para cena. Por outro lado, os índices espectrais utilizam coeficientes de transformação pré-determinados, sendo possível conhecer o significado físico dos resultados de transformação dentro de um certo limiar, os quais são mais facilmente interpretados pelo intérprete.

Entretanto, os índices espectrais os quais são expressões matemáticas da reflectância espectral para qualificar e quantificar as respostas, tanto da vegetação como dos componentes do solo, são afetados de diferentes modos pela presença destes ruídos na estrutura dos parâmetros biofísicos (índice de área foliar, radiação ativa da fração fotossintética absorvida, fitomassa verde, cobertura vegetal, brilho do solo, teor de umidade - da planta e do solo). A relação entre os índices espectrais e os parâmetros biofísicos foram descritos por vários pesquisadores (Tucker, 1979; Asrar et al, 1984; Prince, 1991; Huete e Jackson, 1987; Leeuwen e Huete, 1996). 
As resposta dos índices espectrais são afetadas por vários elementos, desde que a resposta espectral é uma complexa mistura de vegetação, da média de brilho do solo em todas as bandas de sensor (soil brightness) e o brilho do solo em cada faixa do espectro (soil color), de efeitos ambientais, sombra e umidade. Além disso, estes índices são afetados pela variância temporo-espacial da atmosfera (Bannari et al., 1995).

$\mathrm{Na}$ escala das folhas, a concentração de pigmento nas folhas (clorofila e carotenóides), o teor de água nas folhas e suas estruturas causam variações na absorção , transmitância e reflectância das folhas (Tucker, 1980; Leeuwen e Huete, 1996). Os pigmentos das folhas, nas folhas verdes e saudáveis, causa uma forte absorção da irradiância e resulta numa baixa reflectância e transmitância nas partes visíveis do espectro $(0.4$ a $0.7 \mu \mathrm{m})$. O infravermelho próximo (NIR) é minimamente absorvidos pelas folhas verdes. As propriedades da reflectância e transmitância do NIR são, na maioria das vezes uma função da estrutura das folhas (estrutura do mesófilo, espessura da folha, existência de pelos ou espinhos) e, em menor extensão, do teor de umidade das folhas (Tucker, 1980; Leeuwen e Huete, 1996).

A partir do NIR, ocorre uma drástica redução ( 4\%) na absorção das folhas verdes, sendo elas inertes para as bandas do infravermelho médio (SWIR) (Tucker, 1978, 1979; 1980; Gates et al., 1965; Wooley, 1971). Como a absortância é muito baixa no NIR, o mecanismo de espalhamento aumenta a reflectância neste comprimento de onda (Tucker, 1978; 1979; 1980), enquanto que a transmitância diminui com a espessura das folhas.

Estas mudanças na correlação entre fatores biofísicos e a reflectância espectral podem ser muito abruptas na passagem de uma dada região de comprimento de onda para a seguinte, à partir da porção visível do espectro. Este aspecto enfatiza a importância das propriedades da largura e posição da banda selecionada quando se utiliza dados do sensoriamento remoto espectral para caracterizar as condições biofísicas (Price et al, 2002).

É de considerável importância a direção da drástica mudança de relacionamento entre os alvos e seu comportamento em relação às bandas de uma região de comprimento de onda para outra, em particular nas posições do visível, do infravermelho próximo e médio (ondas curtas) que é a base para a identificação específica dos alvos. Este aspecto enfatiza a importância da própria largura da banda e seleção da sua posição quando utilizar dados espectrais de sensoriamento remoto para caracterizar condições biofísicas (Price et al, 2002).

Existem vários tipos de índices espectrais, sendo os mais comuns os utilizados para a identificação e diferenciação da vegetação e sua massa foliar, sendo o mais comum deles o NDVI - Normalised Difference Vegetation Index (Tucker et al., 1985; Nogi et al., 1993). Em geral, os índices de vegetação são apenas uma razão entre o canal vermelho e o infra- 
vermelho próximo (Jackson, 1983). A maioria destas razões são relações que eliminam efeitos de sombreamento, por realçar a diferença de reflectância entre duas faixas de imagem. Remoção da sombra e albedo através dos índices de vegetação pode oferecer melhorias na qualidade da classificação (Huemmrich, 1996,; Qi et al., 1995).

São inúmeros os índices espectrais também utilizados para análise mineralógica e composição litológica, como os propostos por Yamaguchi (1987), utilizando as bandas SWIR do sensor OPS do Jers-1, os quais podem ser adaptados para as bandas SWIR do ASTER. Em trabalho posterior, Yamaguchi e Naito (2003) propuseram a adaptação da transformação de Tasseled Cap para o ASTER, assim como índices para identificação da alunita, caulinita, montmorilonita e calcita. Estes índices são amplamente utilizados para imagens ASTER, principalmente para a diferenciação da alunita/caulinita (San et al., 2004; Ninomiya, 2002; Rowan e Mars, 2002).

Outros índices foram aplicados sobre as imagens ASTER para identificação de óxidos de ferro (Azurra et al., 2003; Ninomiya, 2002; Rowan e Mars, 2003 )

\subsection{Indices de Vegetação (IV)}

Os índices de vegetação foram concebidos com a finalidade de ressaltar a resposta espectral da vegetação em função do fechamento de seu dossel sobre o solo (Huete e Jackson, 1991). Uma das vantagens do uso de índices de vegetação é a obtenção de uma banda com significado físico, ou seja, o índice de vegetação é um número altamente correlacionado com a fitomassa verde e com o grau de cobertura do solo por vegetação verde (Jardim-Lima e Nelson, 2003).

Numerosos trabalhos são encontrados na literatura com relação aos índices espectrais de vegetação e a correlação entre os dados de sensoriamento remoto e suas propriedades biofísicas (Tucker, 1979; Asrar et at., 1989; Gao et al., 2000).Muitos trabalhos foram focados no desenvolvimento e na comparação dos índices de vegetação. Perry e Lautenschlager (1984) compararam vinte índices de vegetação e concluíram que a maioria deles eram funcionalmente equivalentes. Coppin e Bauer (1994) sugeriram que os índices de vegetação podem ser agrupados em três categorias principais, denominadas de "Brilho", "Verde" e "Umidade"

\footnotetext{
5 Preferimos utilizar a forma substantiva em português, em detrimento da tradução literal para a forma adjetiva, posto que estas acarretam um "desconforto acústico", além de um confronto à gramática da língua portuguesa. Estes termos, literalmente seriam traduzidos

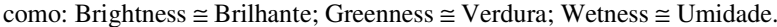


Os índices de vegetação se baseiam no princípio físico de que o sinal é atribuído a absorção da luz vermelha incidente pela clorofila da planta e a reflexão da radiação infravermelho próximo incidente nas folhas das plantas. Cada banda é um indicador do montante de vegetação. Entretanto, a contribuição ao sinal das componentes não-florestadas tais como os solos e a massa de ar, e as janelas atmosféricas podem contribuir para gerar valores maiores do que realmente são (Jackson et al, 1983). Um índice de vegetação ideal deveria ser altamente sensível à vegetação e insensível às mudanças do solo e somente levemente influenciado pelos caminhos da radiância na atmosfera. Entretanto, a maioria dos índices espectral de vegetação não cumpre integralmente com estes critérios.

Em áreas parcialmente cobertas por vegetação, os índices de vegetação são utilizados para extrair o montante da biomassa das plantas (ou LAI - Leaf Área Index; \% de cobertura etc), sem levar em conta as condições superficiais dos solos. Entretanto, a resposta subjacente dos solos, provoca sérios problemas nos resultados dos índices espectrais, decorrentes tanto dos tipos dos solos como do teor de água (Huete et al, 1985; Shabanov et al., 2005). Dentre eles, destaca-se a variação do brilho do solo no Índice da Vegetação pela Diferença Normalizada [NDVI $=(\mathrm{NIR}-$ Vermelho $) /(\mathrm{NIR}+$ Vermelho $)]$ : este problema é tal que o escurecimento da superfície do solo (presença de umidade) resulta em um valor elevado no índice, para uma mesmo montante de vegetação. Isto sugere que os índices de vegetação poderiam responder à diferentes estágios de umidade do solo, tanto quanto ao cultivo, encrostamentos, compactação ou salinização.

Huete (1988) apresentou um índice de vegetação ajustado ao solo (Soil-Adjusted Vegetation Index $:$ SAVI $=($ NIR-Vermelho $) /($ NIR + Vermelho $)+L)$ para minimizar os efeitos relacionados ao brilho do solo, considerando as interações solo $\mathrm{x}$ vegetação como de "primeira ordem", pelo uso de uma variável "L" usada como termo de ajuste do solo.

Como a assinatura espectral da vegetação se caracteriza pela intensa absorção da radiação eletromagnética na região do vermelho (devido à clorofila) e intensa reflexão na faixa do infravermelho (NIR) próximo (causada pela estrutura foliar), é comum o uso de razões de bandas, correspondentes a estas faixas do espectro, nos estudos de vegetação.

Segundo Crosta (1992), esta é a base para o desenvolvimento dos Índices de Vegetação, que envolvem divisão, soma e diferença entre bandas espectrais.

É muito difícil determinar qual o melhor índice. O critério utilizado para avaliar seu desempenho tem dois desdobramentos: a) o baixo ruído que afeta o julgamento de acordo com o nível de significância e sua correlação com os dados da verdade de campo; b) a linearidade de suas relações com os parâmetros biofísicos. O primeiro critério pode ser objeto 
para a acurácia dos dados da verdade de campo, mas na comparação com a significância da correlação,a acurácia pode ter uma importância secundária. O segundo critério é também importante por causa das relações lineares que ajudam na simplificação dos algoritmos de sensoriamento remoto e supera a acurácia na recuperação dos parâmetros de superfície (Roujean e Breon, 1995; Goel e Qin, 1995).

Os índices espectrais de vegetação podem ser estruturados de diferentes formas: podem ser baseados em combinações lineares, em simples razões ou serem transformações ortogonais de várias bandas espectrais. Neste trabalho foram escolhidos e analisados quatro deles, para avaliar suas respectivas funcionalidades e potencialidades como indicadores de umidade dos solos. São eles o NDVI, o NDMI, o SAVI e Tasseled Cap.

\subsection{NDVI (Normalized Difference of Vegetation Index)}

O mais comum e conhecido índice de vegetação é o NDVI (Normalized Difference of Vegetation Index - Índice de vegetação da diferença normalizada). Este índice foi assim designado pela primeira vez por Rouse et al (1973), embora o conceito já tivesse sido discutido por Kriegler et al (1969).

\section{NDVI $=\frac{\text { NIR }- \text { Vermelho }}{\text { NIR }+ \text { Vermelho }} \quad$ (Equação 2.5)}

O Índice de Vegetação da Diferença Normalizada (Normalized Difference Vegetation Index NDVI) é um índice muito simples, resultante da diferença normalizada entre a reflectância do infravermelho próximo e a reflectância do vermelho (Figura 2.6)

É uma transformação não linear da razão da reflectância entre o infravermelho próximo e o vermelho e foi desenvolvido para realçar o sinal da vegetação em condições de baixa biomassa.

O NDVI é o índice de vegetação mais freqüentemente utilizado. Ele foi primeiramente descrito por Rouse et al (1973). Numerosos estudos posteriores têm demonstrado a forte correlação entre o NDVI e a produtividade primária da planta, da biomassa e do índice de área folia (Leaf Área Index - LAI). (Tucker et al, 1985, 1986; Running, 1990; Justice et al, 1998) 


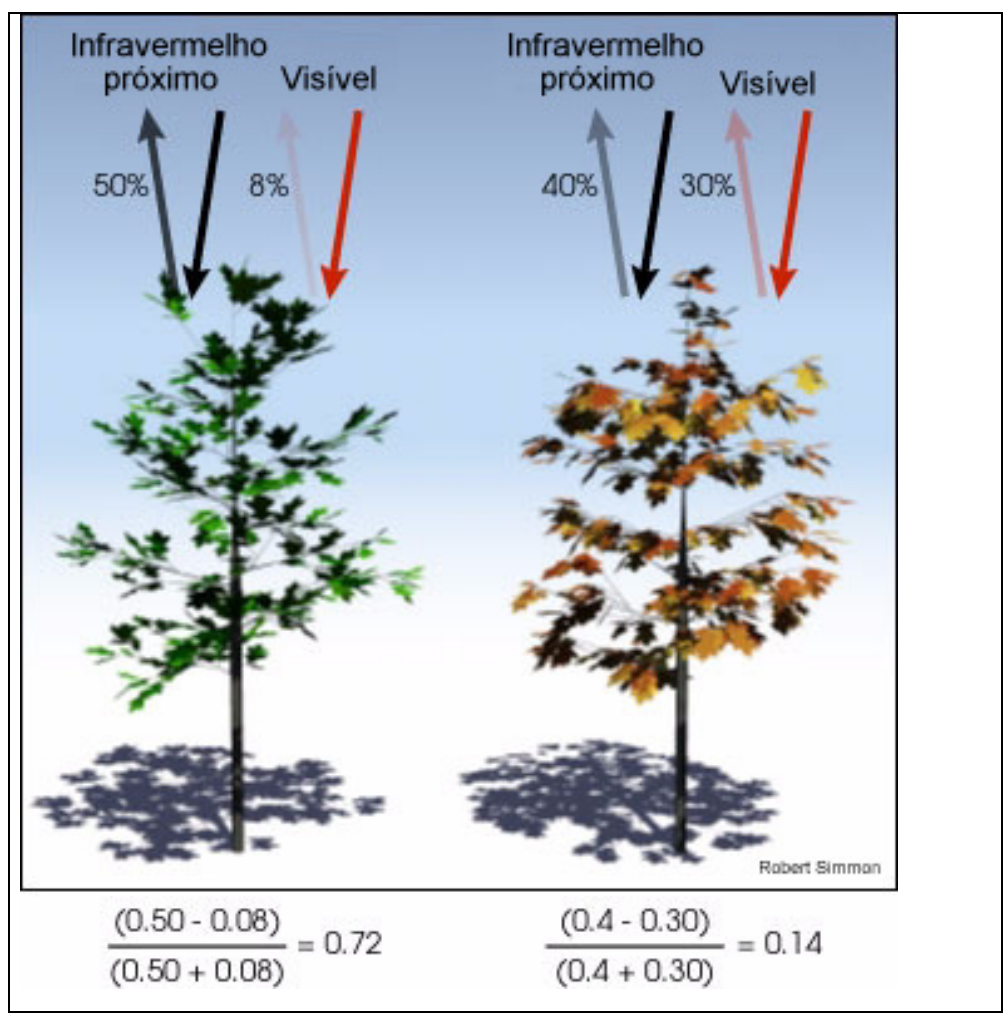

Figura 2.6 - Representação do NDVI como interação entre a radiação e a vegetação. NDVI é calculado a partir da diferença entre a radição visível (vermelho) e da infravermelha próxima (NIR), refletida pela vegetação. Uma densa vegetação verde (a) absorve a maior parte do comprimento de luz visível e reflete a maior parte da radição infravermelha próxima. Áreas com vegetação escassa ou senescente (b), reflete mais luz do espectro visível e absorve mais radiação NIR. Os valores na figura são representativos de valores atuais (de uma floresta boreal, Canadá), mas estes valores podem variar muito mais em áreas mais densas e com diferentes espécies. (Fonte: NASA, 2000. Ilustração por Robert Simmon).

Índices que utilizam razões entre o vermelho e o infravermelho são sensíveis às mínimas respostas da biomassa, acentuando o realce deste alvo. Segundo Qi et al, 1995, o NDVI é extremamente sensível a vários fatores externos, principalmente a geometria da iluminação, propriedades ópticas do solo abaixo do dossel e efeitos atmosféricos. Como resultado, os índices que utilizam esta razão, freqüentemente saturam em elevada biomassa como nas áreas de floresta. A saturação ocorre quando o NDVI não mais responde a variação da biomassa verde. Estudos revelam que o NDVI apresenta muito pouca variação sob cobertura com baixa reflectância no vermelho (0.02 a 0.05) embora a reflectância do NIR varie acima do dobro destes valores (Huete et al, 1997). Este problema tem sido parcialmente atribuído a alta sensibilidade da absorção da clorofila no intervalo do vermelho, a qual satura 
rapidamente em coberturas florestais muito fechadas. Várias soluções foram propostas para a modificação do NDVI, entre elas, substituir a banda vermelha pela verde; utilizar uma banda do infravermelho médio; utilizar índices de vegetação mais lineares. O uso do NDVI com a banda verde, terá, segundo Gitelson (1997) cinco vezes mais sensibilidade à concentração de clorofila que o NDVI com a banda vermelha. Outros autores tem utilizado as bandas 5 e 7 do TM para discriminar os diferentes tipos de vegetação, tanto a estrutura da cobertura (dossel) quanto as condições de elevada biomassa.

Numerosos tentativas de melhorar a performance do NDVI foram realizadas, principalmente através da troca de bandas, dentre elas, substituir a banda 3 pela banda 5 , que se justificaria pela esta refletir mais fortemente o solo exposto que a banda 3 e sofrer menos interferência de elementos atmosféricos além de estar relacionada com informações do conteúdo hídrico da massa foliar.

Entretanto, Huete et al (1997) mostram que os resultados destes procedimentos são insignificantes. Que o NDVI fica saturado em florestas, não importando a banda (se verde ou infravermelho médio). Estas bandas adicionais não resultam em uma maior sensibilidade na equação do NDVI. Em contraste, o SAVI e o EVI (Enhanced Vegetation Index) continuam sensíveis às variações da reflectância do NIR, assim como o GVI (Green Vegetation Index) que também não satura e mantem-se sensíveis às variações de reflectância na densa floresta.

A sensibilidade do NDVI para o solo visível, abaixo do dossel e os afeitos atmosféricos, entre outros, tem gerado um crescente desenvolvimento de novos índices, tal como o SAVI (Soil adjusted Vegetation Index - Huete, 1988). Variações do brilho do solo tem forte influência sobre o NDVI, o que é indesejável quando se procura saber apenas o grau de cobertura verde. O relacionamento entre as reflectâncias do NIR e do vermelho, variando do escuro ao claro, é geralmente linear, ou seja, o solo sempre cai ao longo de uma linha no plano cartesiano definido pelas reflectâncias das duas bandas, NIR e vermelho. Na medida em que qualquer destes solos é coberto com vegetação a posição do pixel se afasta perpendicularmente desta linha do solo.

\subsection{SAVI(Soil adjusted Vegetation Index)}

O SAVI (Huete, 1988) está entre um grupo de índices de vegetação que medem ou aproximam a distância entre o pixel e a linha do solo $^{6}$, assim retirando os efeitos dos solos

\footnotetext{
${ }^{6} \mathrm{O}$ conceito de linha do solo foi analisado utilizando-se de um modelo de reflectância do solo. A linha do solo é uma relação linear entre a reflectância do solo exposto observado em dois comprimentos de onda diferentes. Ele também pode ser definido como um modelo de transferência de energia no qual a reflectancia foi
} 
claros e escuros. O SAVI é uma técnica utilizada para minimizar a influência do brilho do solos sobre os índices espectrais de vegetação, envolvendo os comprimentos de onda do vermelho (V) e do infravermelho próximo (NIR).

O SAVI - Soil Adjusted Vegetation Index (Índice de vegetação ajustado ao solo) incorpora um fator fixo $(\boldsymbol{L})$ que representa a linha do solo, para o cálculo da vegetação (Huete, 1988; Qi et al., 1994). Estes trabalhos mostram que a incorporação deste fator, representando a influência conhecida do solo, fornece uma melhor detecção da vegetação, independente da condições de variação de umidade dos solos e das condições de vegetação (Cleavers, 1988).

$$
S A V I=\frac{N I R-\text { Vermelho }}{\text { NIR }+ \text { Vermelho }+L}(1+L)
$$

Quando L=0, o SAVI é igual ao NDVI. Segundo Huete (1988), o valor do coeficiente L escolhido deve ser tão menor quanto mais densa for a vegetação. Para efeitos práticos, ele indica três fatores de ajuste preferíveis: $\mathrm{L}=0$ para análises com vegetação de baixa densidade de cobertura; $\mathrm{L}=0,5$ para vegetação com densidade para vegetação com densidade intermediária, e $\mathrm{L}=0,25$ para altas densidades. $\mathrm{O}$ autor considera $\mathrm{L}=0,5$ o melhor fator de ajuste para reduzir razoavelmente os efeitos de solos com diferentes valores de brilho.

Numerosos índices de vegetação foram desenvolvidos para caracterizar a cobertura vegetal. A maioria destes índices utiliza a reflectância ou radiância da cobertura vegetal no vermelho e no infravermelho próximo (NIR) em forma de razão (como diferença normalizada ou razão de um índice) (Tucker, 1979), ou uma combinação linear (índices de vegetação perpendicular - Richardson e Wiegang, 1977). Estes índices foram determinados por serem bem correlacionados com vários parâmetros da vegetação, incluindo área da folha verde, biomassa, \% da cobertura verde, produtividade e atividade fotossintética (Huete, 1988).

A turbidez da atmosfera e os diferentes substratos dos solos agem como fatores limitantes na determinação destes resultados. A turbidez da atmosfera geralmente inibe medidas confiáveis da vegetação e pode atrasar a detecção de uma possível deficiência na

separada em componentes de dispersão único e múltiplos. O conceito de linha do solo é robusto sob todo o domínio do espectro óptico no que se refere à configuração das fontes e rugosidade da superfície mas falha no domínio do infravermelho médio sob condições de variação do teor de umidade. Este modelo não explica os efeitos da variação da rugosidade da superfície nem seu teor de umidade nos parâmetros do modelo. O tipo de solo aparenta ser o principal fator na variação dos parâmetros da linha do solo (Huete, 1988). 
cobertura vegetal (Jackson, 1983). Efeitos não corrigidos da atmosfera podem gerar problemas em estudos multitemporais onde respostas induzidas pelas variações atmosféricas geram interpretações errôneas sobre o desenvolvimento da vegetação.

O solo, por sua vez, exerce considerável influência no espectro da vegetação com cobertura parcial e no cálculo dos índices de vegetação. A influência do brilho do solo exposto foi notado em numerosos estudos onde, para um dado percentual de vegetação, o substrato de solos escuros resultam em valores de índices tão elevados quanto a razão dos índices de vegetação (RIV=NIR/Red) ou o índice de vegetação pela diferença normalizada $(\mathrm{NDVI}=(\mathrm{NIR}-\mathrm{Red}) /(\mathrm{NIR}+\mathrm{Red})=(\mathrm{RIV}-1) / \mathrm{RIV}+1)$ foram usados como medidas de vegetação (Elvidge e Lyon, 1985; Huete et al., 1985). Huete et al (1985) também encontraram um oposto a influência do brilho do solo no índice de vegetação perpendicular tal que o brilho do solo resultasse em valores elevados dos índices para uma dada cobertura incompleta da vegetação. Então, nas áreas onde se tem consideráveis valores de brilho no solo, com toda a complexidade de sua resposta espectral resultante de diferença de umidade, variações de rugosidade, sombras, teor de matéria orgânica, a resposta dos índices é induzida tanto pelo solo como pelos valores da vegetação.

Huete (1987) afirmou que o sinal refletido dos solos é inseparável do da vegetação. O componente do solo tornou o índice de vegetação "solo-dependente" devido à magnitude variada com as propriedades reflectivas do solo subjacente. Huete encontrou que a sensibilidade dos índices de vegetação para a resposta dos solos subjacente aumenta enormemente em áreas com níveis de cobertura intermediária $( \pm 50 \%)$. Em áreas com pouca cobertura não existe vegetação suficiente para gerar um espalhamento do sinal refletido do solo; enquanto que nas áreas densamente recobertas por vegetação, o solo não possui sinal suficientemente forte e distinto para emergir da cobertura vegetal para ter significância. Um nível intermediário de vegetação, entretanto, significa dispersão e transmissão de fluxo do NIR através da cobertura vegetal, produzindo um sinal espectral do solo, refletido tão forte quanto a assinatura espectral da vegetação (Huete, 1988).

Wallace e Campbel (1989) afirmaram que os índices originados de uma dada análise podem se tornar rapidamente inadequados em um contexto diferente. Price et al (1992) encontrou que a transformação Tasseled Cap (Crist e Cicone, 1984) não discrimina de forma mais significativa do que os dados brutos (não transformados) do Landsat TM. A conclusão era que o uso do índice de vegetação ajustado ao solo (SAVI) em regiões semi-áridas pode ser bem mais apropriado devido ao grande montante de solo exposto comparado à vegetação 
associada à área de estudo. Qi et al (1995) encontrou alguns índices de vegetação, entretanto, estes analisavam apenas uma única informação biofísica.

Cabe aqui destacar o trabalho de Gao et al (2000) que buscou analisar o sinal da vegetação pura separando-a das "contaminações de fundo". Os resultados mostraram que nestas condições o NDVI tem uma relação assinótica com os parâmetros biofísicos, enquanto que, para o SAVI tem pouco efeito. Demonstrou também que os valores do NDVI foram uniformes sob diferentes tipos de cobertura vegetal, enquanto o SAVI era muito mais afetado por estas alterações. Se por um lado trabalhos deste tipo servem para caracterizar parâmetros biofísicos da cobertura vegetal, por outro afirmam a presença constante deste "ruído de fundo" provocado pelo solo e suas propriedades ópticas, reforçando a necessidade de se aprofundar os estudos deste componente, sem a qual a modelagem eficiente para o estudo da cobertura vegetal sempre será incompleta. Por outro, reforça que é possível desenvolver um estudo de solos, apesar da cobertura vegetal, através da modelagem deste "ruído de fundo".

Elvidge e Chen (1994) compararam índices espectrais (cinco razões e duas transformações) para avaliar o percentual de cobertura verde. Segundo eles, os resultados podem ter uma elevada imprecisão devido aos efeitos adversos das variações de "fundo" sendo que o NDVI é muito mais sensível a estes efeitos que o SAVI, onde estes efeitos são reduzidos. Segundo os autores, a única forma de reduzir a interferência de fundo nos índices espectrais e aumentar a resolução espectral.

\subsection{NDMI}

O NDMI (Normalized Difference Moisture Index - Ìndice de Umidade da Diferença Normalizada) é um dos muitos índices derivados do NDVI, sendo, entretanto, uma relação entre o NIR e a primeira das bandas do infravermelho médio ou ondas curtas (SWIR).

\section{$N D M I=\frac{B a n d a 3-B a n d a 4}{B a n d a 3+B a n d a 4} \quad$ (Equação 2.7)}

O uso da banda SWIR está relacionada ao fato desta possuir mais informação sobre a estrutura da vegetação (Harler e Ahern, 1986). Por outro lado, Nemani et al (1993) aplicou o fator de correção SWIR para o NDVI, para provar a relação entre o NDVI e o índice de área foliar (LAI). Embora poucos estudos de vegetação tenham aplicado o NDMI, muitos deles 
utilizaram a razão SWIR/NIR ou NIR/SWIR a qual é muito similar ao NDMI (Cohen e Fiorella, 1998; Fiorella e Ripple, 1993).

Hunt e Rock (1989) encontraram que a razão SWIR/NIR era linearmente correlata ao teor de água foliar, sendo esta específica para cada espécie, possuindo cada uma delas uma equação de regressão específica. Fiorella e Ripple (1993) relataram que a razão NIR/SWIR era altamente correlacionada à umidade $\left(\mathrm{r}^{2}=0.97\right)$ e tinha mais alta correlação com a idade da vegetação do que os índices do Tasseled Cap.

Hardinsky et al (1983) relata que o NDMI era altamente correlacionada com o teor de umidade da cobertura vegetal e mais próximo ainda das mudanças de biomassa da planta e suas deficiências hídricas que o NDVI.

\subsection{Tasseled Cap}

A análise dos dados obtidos por sensoriamento remoto orbital requer a síntese das informações contidas nas muitas bandas espectrais discretas em informações que podem ser associadas com características físicas das classes da cena. Este processo pode ser dividido em três partes: (1) compreender as relações entre as bandas espectrais para as classes de interesse da cena; (2) comprimir as "n" bandas espectrais de informações em um número de feições manipuláveis e; (3) extração de características físicas da cena à partir das feições específicas. O NDVI ou a razão de bandas são exemplos de técnicas que desenvolvem parcialmente estas funções: eles são baseados nas interações espectrais conhecidas da cobertura da vegetação verde, gerando uma limitada compressão do volume de dados, e são mais diretamente associadas com os atributos da cena do que os dados originais. A ACP também fornece redução do volume dos dados, mas apresenta maiores obstáculos para uma interpretação física correspondente às feições, mas como é uma técnica "cena-dependente", apresenta sérias limitações para comparações temporais (entre datas) e espaciais (entre as cenas). A Transformação Tasseled Cap desempenha estas três funções (compreender as relações espectrais entre as bandas espectrais e as classes da cena, compressão de dados , interpretação física da cena a partir das feições).

A Transformação Tasseled Cap (TTC) foi desenvolvido por Kauth e Thomas (1976) para melhorar a detecção de colheitas agrícolas. A TTC é uma transformação linear que resulta na rotação dos eixos das imagens originais em novos eixos que estão diretamente correlacionados com as características físicas da vegetação. A transformação foi inicialmente derivada para dados Landsat MSS, onde a TTC transforma ortogonalmente os 4 canais 
originais do sensor MSS num novo espaço com 4 dimensões: Brilho, Verde, Amarelo (componente da vegetação seca) e um quarto eixo, relacionado aos efeitos atmosféricos (bruma). Geralmente os dois primeiros componentes contem a maior parte da informação espectral da imagem (95\% a 98\%) (Jensen, 1996; Santos, 2003). Crist e Cicone (1984) estudaram a TTC em imagens Landsat TM e estimaram os coeficientes da transformação para aquele sensor. A TTC quando aplicada aos dados captados pelo sensor TM, manifesta a presença de uma terceira componente, a Umidade, intimamente relacionada com a informação adicional que o sensor TM capta da região do infravermelho médio, quando comparado ao sensor MSS. Deste modo, uma imagem TM apresenta 3 variações principais: Brilho, que reflete toda a variabilidade espectral da imagem; Verde, que indica o contraste ente as bandas visíveis e infravermelho médio, e; Umidade, que está relacionada com o conteúdo de água do solo e da vegetação (Santos, 2003). Com o lançamento do Landsat 7 , com o novo sensor ETM+, foi necessário realizar novos ajustes aos coeficientes (Brilho, Verde e Umidade) para realizar corretamente a Transformação Tasseled Cap (Huang et al., 2002).

A Transformação Tasseled Cap (TTC) é amplamente utilizada no mapeamento e monitoramento da vegetação (Cohen et al, 1995; Collins e Woodcock, 1996; Fiorella e Ripple, 1993; Jin e Sader, 2005). Esta transformação não somente fornece um mecanismo de redução de volume de dados com mínima perda de informação mas suas feições espectrais podem ser diretamente associadas a importantes parâmetros físicos da superfície do solo (Crist e Cicone, 1984; Crist e Kauth, 1986; Crist et al, 1986).

A TTC é uma fonte de idéia para técnicas de processamento dentre elas: (a) é uma transformação de preprocessamento linear que isola o desenvolvimento "Verde", "Umidade" e "Brilho" do solo, além de permitir a redução da dimensionalidade dos dados; (b) o uso de elementos de padrões mensuráveis específicos da estrutura do TTC para estimar e corrigir interferências atmosféricas e os efeitos da umidade; (c) os dados contidos nas bandas relativos ao comportamento espectral dos alvos, podem ser associados à características físicas das classes da cena (Kauth e Thomas, 1976).

A TTC orienta o plano de dados de tal forma que as duas feições que são definidas sejam diretamente relacionadas com as características físicas da cena. A primeira feição, o Brilho , é o somatório de todas as bandas e é definida na direção da variação principal da reflectância dos solos. Então, esta primeira feição mede o brilho dos solos ou o total da reflectância. A segunda feição, o Verde é o contraste entre o NIR e o Visível (VIS). O grande espalhamento da radiação infravermelha resultante da estrutura celular da vegetação verde e a 
absorção da radiação visível pelos pigmentos das plantas (ex.: clorofila) combinam-se para produzir um alto valor de "Verde" para alvos com alta densidade de vegetação verde, o qual a curva de reflectância achatada dos solos são expressos por um baixo valor de Verde (Figura 2.7).

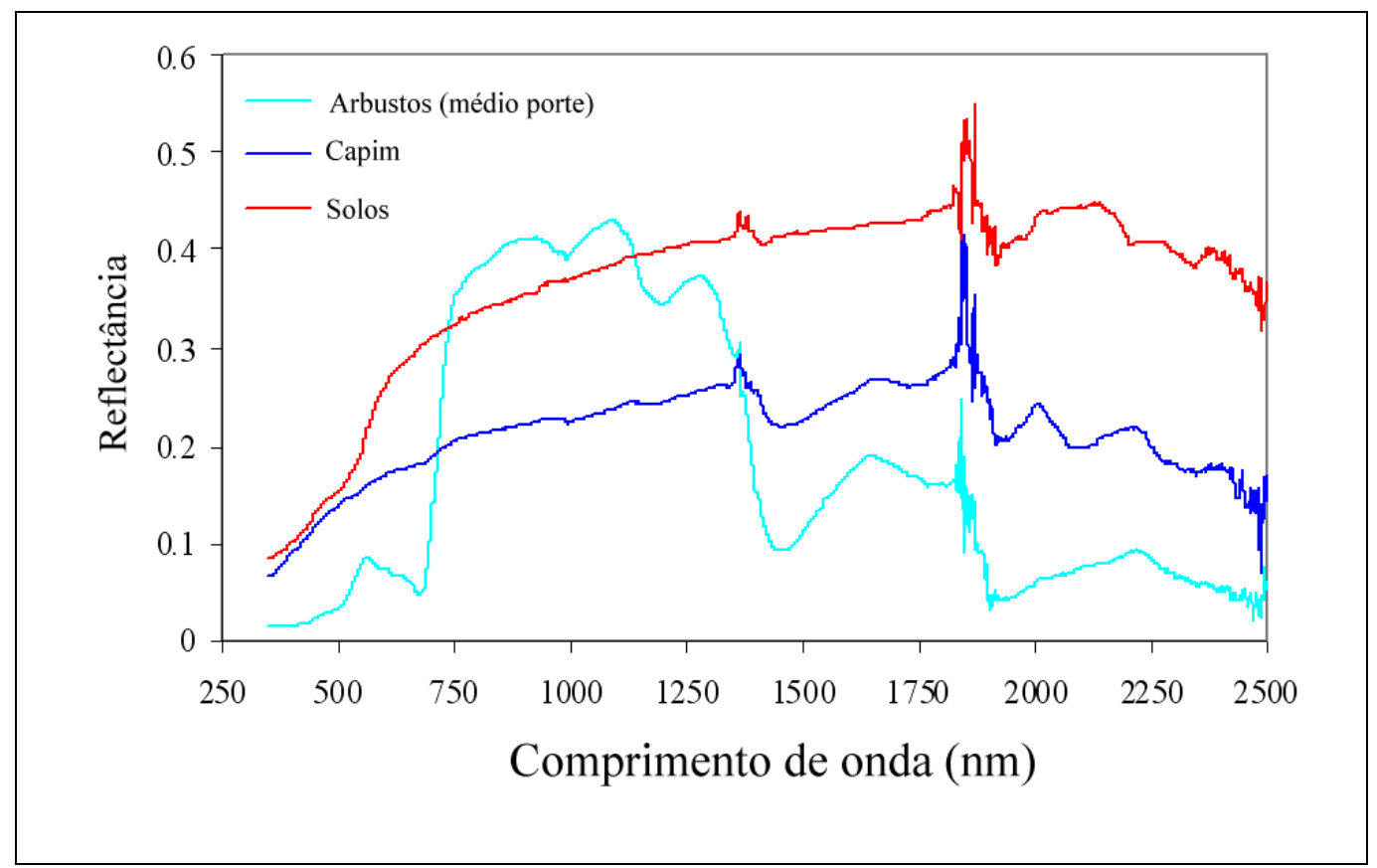

Figura 2.7 - Curva de reflectância de três alvos: arbustos de porte médio, capim e solo, no intervalo de abrangência do sensor ASTER (Fonte: Sandvig, 2003)

A terceira feição, denominada inicialmente de Amarelo (Kauth e Thomas, 1976; Jackson, 1983) e posteriormente de Umidade (Crist e Cicone, 1984) foi originalmente definida na direção espectral para corresponder à vegetação senescente, mas posteriormente foi redefinida para servir como diagnóstico da bruma atmosférica (Kauth et al, 1979).

Como uma transformação linear (rotação) o TTC preserva as relações euclidianas dos dados brutos, mas captura tipicamente $95 \%$ ou mais do total da variabilidade em 2 feições verdadeiramente interpretáveis. Por outro lado, ela é uma transformação invariável (independente de cena) e pode ser então interpretada uma vez que os dados foram normalizados para efeitos externos, tal como nível de bruma ou geometria de visada e iluminação. Estas características resultam em uma ampla aceitação e consequiente uso desta transformação para sensores tradicionalmente conhecidos, mas há necessidade de se analisar sua estrutura e funcionamento para os novos satélites.

A idéia básica Tasseled Cap, como a proposta por Kauth e Thomas (1976) é de que uma diferença específica de pesos numa combinação linear, do infravermelho e dos canais 
visíveis do Landsat mediriam o crescimento da vegetação. Entretanto, qualquer "índice de vegetação verde" tal como o índice de vegetação perpendicular (PVI), a diferença normalizada, a razão Infravermelho/Vermelho, etc, podem ser utilizadas para esta finalidade. O que se destaca nesta técnica, em particular para este estudo, é a componente de terceiro nível, inicialmente chamada de "Amarelo" e posteriormente de "Umidade". Na verdade, as imagens do Landsat MSS para a qual foi desenvolvida inicialmente, ou do ASTER, para o qual desenvolvemos coeficientes específicos e que utilizamos neste trabalho, não medem a "secura" per se, mas apenas refletem as condições de reduzida atividade fotossintética da área foliar causada pelo estresse hídrico (Thompson e Wehmanen, 1980).

Embora os índices espectrais sejam conhecidos por sua característica de "cenaindependente", e estes possam indistintamente ser utilizados em toda parte do mundo, têm-se algumas restrições a este conceito. Todos os cálculos dos índices do Tasseled Cap foram desenvolvidos e aplicados sobre amostras da América do Norte, inclusive os índices espectrais litológicos, desenvolvidos sobre as bandas SWIR do ASTER, por Yamaguchi e Naito (2003). Como a geração do primeiro índice espectral (Brilho) se baseia na reflectância dos solos, a aplicação de um índice desenvolvido em um único país pode não corresponder às características de reflectância dos solos locais, comprometendo o valor do primeiro índice e, consequientemente, de todos os demais (Mather, 1999). Soma-se a isso as condições de iluminação e atmosféricas, que afetam diretamente as bandas do sensor e que afetam diferentemente os coeficientes obtidos (Gleriani et al., 2003).

\subsection{Classificação}

Classificação é o agrupamento de objeto em classes baseado em suas similaridades com respeito a uma ou mais variáveis, sendo que a discriminação é a determinação dos objetos para uma classe pré-definida baseada nas propriedades do objeto, sendo que ambas utilizam critérios diagnóstico bem definidos, os classificadores. O objetivo da maioria das aplicações em sensoriamento remoto é para descriminar e pré-determinar, através de mapas, as informações das classes a serem encontradas no campo, comumente com a ajuda de agrupamentos estatísticos ou métodos discriminantes.

A literatura sobre sensoriamento remoto, freqüentemente se refere à análise de agrupamento (clustering), como classificação não-supervisionada e a análise discriminante como classificação supervisionada. Existe uma enorme quantidade de bibliografia sobre este assunto, que vem sendo desenvolvida desde a década de `60, dos quais podemos, só para citar 
alguns, indicar Moik (1980) Haralick e Fu (1983), Richards (1986), Langley (2001), Tso e Mather (2001).

A classificação não-supervisionada envolve o agrupamento de pixels individuais em classes espectrais baseados nos valores de reflectância medidos nos canais originais ou já transformados e/ou modificados em relação a uma dada função. As classes espectrais são então relacionadas às informações das classes identificadas no campo (isto é, as categorias de uso e/ou cobertura do solo) pelo analista, que se baseia nas observações de campo ou na interpretação de fotografias aéreas, determinando assim a rotulagem dos objetos (Lillesand e Kiefer, 1994).

Na classificação supervisionada, os pixels são determinados pelas classes identificadas pelas informações de campo, já conhecidas previamente, através de uma função discriminante baseada na observação das propriedades espectrais das classes de informação em um conjunto de amostras de treinamento previamente selecionadas. As funções discriminantes estatísticas incluem os estimadores de máxima verossimilhança, onde o vetor de média espectral e a matriz de covariância das amostras de treinamento são analisados para serem a fonte da informação comparativa (para serem a base de comparação para a realização da classificação), e os estimadores Bayesianos, onde a função de densidade da probabilidade (FDP) da classe de informação (classe de referência) é assumida para ser conhecida a piori e amostras de treinamento são utilizadas para refinar a FDP para obter uma função discriminante $a$ posteriori. Outra forma de discriminação é o reconhecimento de padrão sintático, o qual utiliza estruturas de decisão hierárquicas e regras gramaticais para reconhecer as classes de informação, baseadas no conjunto de feições primitivas de cada classe (Haralick e Fu, 1983).

Alguns conceitos de classificação combinam métodos supervisionados e nãosupervisionados, usando a classificação não-supervisionada para gerar classes de treinamento com funções da densidade da probabilidade normal multivariada que são, subseqüentemente utilizadas no procedimento supervisionado (Richards, 1986; Giacinto e Roli, 2001). Outro conceito híbrido é o cluster "dirigido", que implica a determinação inicial dos clusters espectrais ou "pooling" baseado na estatística das classes de treinamento (Peterson e Running, 1989).

Neste trabalho, optamos por utilizar a classificação supervisionada, principalmente pela existência de uma verdade de campo conhecida e de boa qualidade, representado por um mapa de solos digital, em escala 1:10.000. 


\subsubsection{Problemas na classificação estatística de imagens de satélite}

$\mathrm{Na}$ classificação estatística, os objetos geralmente são classificados baseando-se nas variáveis mensuráveis que são relevantes às classes de informação, assumindo que as características das classes se regem por determinados modelos probabilísticos. Por exemplo, dados sobre a abundância de espécies de plantas são utilizados para classificar amostras de vegetação em tipos de vegetação. Em sensoriamento remoto, porém, as propriedades eletromagnéticas da superfície são substitutas para propriedades pertinentes das classes de informação como uso da terra, tipo de solos, vegetação e assim por diante (Robinove, 1981). Este tipo de relação de substituição é fortemente dependente da cena porque as classes de informação não possuem sinais eletromagnéticos únicos (Hoffer, 1978). Normalmente a classe de informação pertence a uma única feição do meio ambiente como, por exemplo, tipo de cultura. A assinatura espectral para aquele tipo específico de cobertura, variará com alterações do solo (como umidade, profundidade, textura), assim como também com o estágio de desenvolvimento da cultura, iluminação, atmosfera, etc. A correção atmosférica e a retificação radiométrica, para normalizar as mudanças de iluminação reduzem, de forma não desejada, a variação da assinatura. As razões de bandas e as transformações espectrais como as transformações de Kauth - Thomas Tassled Cap ajudam a isolar a variação da reflectância relacionada às plantas (Kauth e Thomas, 1976). A acuracidade da classificação também pode ser melhorada utilizando-se imagens multi-temporais. Por exemplo, o uso de perfis multitemporais para melhorar o reconhecimento de culturas em diferentes estágios de desenvolvimento, baseando-se nas especificidades fenológicas das espécies culturais (Hall e Badhwar, 1987). Na análise final, porém, as variações locais e regionais nos processos físicos e biológicos e as condições médias de transferência radioativa específica da cena, que tem sempre um forte componente local, constituem-se em elementos empíricos para a classificação estatística de imagens de satélite.

Uma segunda preocupação com a classificação de imagens de satélite, quando aplicada à superfície da terra, relaciona-se a uma discussão anterior, quanto ao tipo de análise adotada: se orientada-a-objeto ou orientada-a-dados. Os sistemas de classificação evoluem pela interação entre as necessidades humanas e suas capacidades de estruturar as informações disponíveis. Um sistema de classificação ideal descreve tanto o nome das classes como o critério utilizado para distingüi-las umas das outras, onde uma classificação seria tanto independente da escala como dos meios utilizados para coletar as informações (se imagem de satélite, fotografias aéreas, pesquisa de campo, ou uma combinação destas). 


\subsubsection{Erros na classificação de imagens de sensoriamento remoto}

Após o processo de classificação torna-se necessária a avaliação da exatidão da classificação, ou seja, é necessário se determinar quão bom é o resultado da classificação em relação à realidade. O método de avaliação da exatidão de classificação depende da disponibilidade de dados de campo. Um dos métodos mais simples expressa a exatidão da classificação através da razão entre a área total de cada classe obtida na imagem em relação à área total da classe determinada em campo ou em fotografias áreas sem levar em conta a localização das classes (matriz de contingência).

A forma mais utilizada para representar a exatidão de classificação é a comparação do mapa derivado da imagem com um mapa de referência a partir da utilização de uma matriz de erro, também conhecida como matriz de confusão que é uma tabela de contingência (Dozier e Strahler, 1983).

Conforme Story e Congalton (1986), a maneira mais comum para expressar a precisão, tanto de imagens quanto de mapas, está na declaração da porcentagem da área de mapa que foi corretamente classificada quando comparada com dados de referência ou "verdade de campo", denominada Exatidão Global. Esta declaração normalmente é derivada de uma contraparte da classificação correta gerada por amostragem dos dados classificados, e expressa na forma de matriz de erro ou de confusão. Jensen (1986) sugeriu que a análise comparativa da precisão específica local, através da matriz de erro, pode fornecer métodos mais eficientes para comparar a precisão de mapeamentos de uso da terra que uma simples comparação de precisão através de uma estimação global.

Entretanto, Gong e Howarth (1990) utilizaram o índice Kappa (K) como uma medida de precisão importante a ser associada à matriz de erro, por representá-la inteiramente, isto é, considerando todos os elementos da matriz e não apenas aqueles que se situam na diagonal principal, como acontece com o índice de Exatidão Global (a ser detalhado no item 2.6.1.1) .

Foody (1992) ressaltou que o grau de concordância por chance poderia estar sendo superestimado, pelo fato de incluir também a própria amostragem, e que por conta disso a magnitude de Kappa não refletiria a concordância presente na classificação. Tal fato gerou um outro índice para a medição da precisão de classificação, definido por Ma e Redmond (1995) como índice Tau (T). 
Para um conhecimento mais profundo sobre os métodos de avaliação da exatidão de mapeamento consultar (Fidalgo, 1995) onde se encontra uma ampla revisão teórica sobre assunto, bem como exemplos práticos.

Um dos problemas enfrentados para a avaliação da exatidão de classificação é a disponibilidade de informações de campo. Idealmente, todas as informações de campo deveriam ser obtidas simultaneamente à aquisição das imagens de satélite. $\mathrm{Na}$ prática, entretanto, isto nem sempre é possível devido ao elevado custo e muitas vezes às dificuldades de acesso. Estes custos elevados podem ser justificados quando as informações de campo se referem a variáveis que se modificam rapidamente com o tempo, como é o caso da composição dos corpos d'água, umidade do solo etc. Quando, entretanto, o objeto de estudo é o uso da terra, culturas agrícolas, unidades geológicas, a simultaneidade da aquisição não é um requisito rígido.

Existem dois métodos básicos de amostragem de dados de campo visando a avaliação da exatidão das informações extraídas de imagens. Um dos métodos é o de amostragem direcionada, que pode variar desde a aquisição minuciosa de medidas em talhões até a inspeção aérea da região em estudo.

Este método apresenta três vantagens:

- baseia-se no conhecimento do pesquisador e em sua capacidade de escolher locais mais representativos para amostragem;

- as áreas amostrais podem ser localizadas rapidamente em função do acesso;

- é um método rápido; a

- principal desvantagem deste tipo de aquisição de dados é que ela pode ser tendenciosa, e portanto, com pouca validade estatística.

O método de amostragem probabilístico envolve a seleção objetiva de pontos amostrais sobre toda a área de estudo e envolve:

- definir o número de amostras necessárias para se estabelecer não só a exatidão de classificação, mas também o seu nível de confiança;

- definir o tamanho da área amostrada em função da resolução espacial da imagem e da exatidão de localização dos pixels no terreno;

- definir as variáveis ambientais a serem medidas. 
A junção destes dois métodos irá gerar a amostragem casual estratificada, que é um método probabilístico, utiliza o conhecimento do pesquisador e dá a mediada de erro, sendo, esta a mais urtilizada.

De qualquer modo, a comparação das classes da imagem com as classes na superfície são fundamentais para a determinação da acurácia da classificação.

A divergência entre os resultados obtidos das classes da imagem com as classes da superfície podem se originar de várias razões:

- Má qualidade dos registros dos dados do satélite para o sistema de coordenadas cartográficas;

- Má qualidade dos registros dos dados da superfície para o sistema de coordenadas cartográficas;

- Separação espectral inadequada das amostras de treinamento;

- Inadequação do classificador, estatístico ou contextual;

- Classificação inadequada para análise das classes pelas amostras de classificação/amostras de teste;

- Desagregação espacial de uma feição da superfície em várias classes espectrais;

- Pixels misturados ou efeitos de borda.

Deve se notar também, que é muito difícil de se obter amostras suficientemente grandes e imparciais dos locais de teste para se medir com precisão a acuracidade do mapa temático (Congalton, 1988). Também, em muitas aplicações, a classificação parcial (erros em classes específicas contabilizando-se os erros de omissão e de comissão) e a distribuição espacial dos erros podem ser tão importante quanto a precisão global.

A experiência tem mostrado que as classificações de imagem são freqüentemente parciais, que as taxas de erro quase sempre diferem sistematicamente entre as classes de informação, e que os erros raramente (ou nunca) são aleatoriamente distribuídos (Congalton, 1988). Estes tipos de distribuição de erro podem ser muito difíceis para modelar analiticamente e podem acarretar em sérias conseqüências em um sistema de decisão ou modelagem espacial (Anselin, 1989). 


\subsubsection{Classificadores}

A classificação de imagens permite sintetizar a variabilidade e complexidade inerente a uma paisagem num número limitado de agrupamentos (clusters) os quais atribuímos valores de classes. A classificação de imagens de sensoriamento remoto é tradicionalmente realizada através de métodos estatísticos clássicos (classificadores K-NN, bayesianos), mas também existem desenvolvimentos de aplicação com redes neurais e árvores de decisão. No geral, a escolha do classificador adequado pode se tornar algo muito mais complexo do que se imagina. Um excelente trabalho de comparação experimental entre algoritmos de diferentes naturezas e arquiteturas para classificação de imagens de sensoriamento remoto foi apresentado por Serpico et. al (1996). Nestes experimentos, a pesquisa mostra claramente que não existe uma superioridade explicita de um algoritmo sobre outro na classificação de imagens de sensoriamento remoto. A performance dos classificadores depende basicamente das características da imagem considerada e dos esforços aplicados na fase de "design" do algoritmo utilizado, como a escolha da arquitetura do classificador, a adequação e aperfeiçoamento dos parâmetros de aprendizagem, entre outros (Giacinto et al., 2000)

Podemos então afirmar que o melhor classificador será aquele mais adequado ao seu objetivo, ao tipo de dado, às características da imagem e a escolha correta dos parâmetros.

Os conceitos bayesianos são aplicados quando a informação à priori dos problemas é combinada com a evidência dos dados, dando a probabilidade à posteriori das soluções. As predições são realizadas pela integração sobre as distribuições à posteriori.

O treinamento dos algoritmos bayesianos não é algo simples ou fácil de fazer, posto serem eles não muito manipuláveis para análise, entretanto, eles compartilham uma estrutura comum que é simples e bastante manipulável. O algoritmo supervisionado da máxima verossimilhança pode ser incluído nesta classe e ser denominado de classificador bayesiano, como originalmente no trabalho de Duda e Hart (1973). O método de armazenamento (agrupamento) é uma simples análise probabilística para cada classe; esta análise contem a probabilidade condicional de cada valor do atributo dado a classe, bem como a probabilidade (ou frequiência básica) das classes. A estrutura destes dados tem um poder representacional aproximado, como uma percentagem, se estamos descrevendo uma simples fronteira de decisão através da instância espacial. Cada vez que o algoritmo encontra uma nova instância, é reformulada a probabilidade dos dados armazenados para com a classe específica.

Próximo a ordem da instância do treinamento, nem a ocorrência de erros de classificação tem efeitos neste processo. Numa instância de teste, numa classificação não- 
supervisionada, o classificador usa uma função de avaliação para ordenar as diversas alternativas de classes, baseadas no resumo de suas probabilidades, e assinalar a instância para a classe com a mais alta pontuação.

Tanto a função de avaliação como o sumário descritivo usado pelos classificadores bayesianos assume que as feições são estatisticamente independentes. Apesar deste fato não ser muito realista na maioria dos domínios naturais, existem poucas evidências conclusivas de que o algoritmo se comporte mal, em comparação com outros métodos indutivos. Entretanto, não há estudos que examinam a extensão com que ocorre a violação da suposição anterior sobre a degradação da performance dos algoritmos bayesianos.

$\mathrm{Na}$ análise dos dados pelo método baysesiano, a quantificação da incerteza é modelada como a distribuição da probabilidade e a inferência é representada pela elaboração das probabilidades condicionais à posteriori para as variáveis de interesse não observadas e assumindo-se o à priori como verdade (Lampinem e Vehtari, 2001). Maiores referências sobre a análise de dados bayesianos pode ser encontrada em Berger (1985) Bernardo e Smith (1994) e Gelman et al. (1995).

Apesar de tudo, Clark e Niblett (1989) afirmam que o uso dos classificadores bayesianos é extremamente prático. Consideram que sua performance e resultados são as mais sofisticadas nos diversos domínios de aplicação, devido a uma elaborada estrutura técnica.

Não queremos afirmar a superioridade dos classificadores bayesianos, mesmo que apenas destacando que sua performance, aplicada a uma diversidade de domínios é muito mais eficaz quando comparada a outros algoritmos conhecidos, mas que seu comportamento é menos ambíguo e mais consistente quando submetido a uma análise mais profunda e cuidadosa.

O conceito bayesiano aborda que a análise estatística deve ser encarada condicionalmente, ou seja, os dados observados devem ser tratados como conhecidos. No presente caso de estudo esta é uma verdade, desde que a análise será realizada sobre a verdade de campo, previamente conhecida. E este classificador se mostra mais que adequado.

\subsubsection{Os classificadores $e$ os solos}

O uso de classificadores de imagens digitais para identificação de tipos de solos sempre foi complexa. Desde Wright e Birnie (1986), utilizando imagens Spot, com classificadores baseados em análise de regressão múltipla. Em 1981, Thompson utilizou a classificação supervisionada na região de Brazos County (Texas) na determinação efetiva do uso dos dados 
Landsat na separabilidade das unidades de solos e reporta que obteve um máximo de precisão de $42 \%$ na classificação para separar "famílias" de solos e também destacou que o método supervisionado e não supervisionado obtiveram aproximadamente o mesmo resultado.

O uso específico de classificação digital de imagens do Landsat para identificação e tipos de solos foi realizado por Kornblau e Cipra (1983), utilizando técnicas automatizada de reconhecimento de padrões, que usam tanto classificação não-supervisionada (clustering) como supervisionada (máxima verossimilhança). Entretanto, conseguiram apenas uma precisão de $47 \%$ na melhor tentativa, com o método supervisionado.

Em 1986 Wright e Birnie utilizaram imagens Spot para identificar tipos de solos utilizando também um classificador de máxima verossimilhança.

Assim, dos numerosos algorítmos de classificação disponíveis, os classificadores de máxima verossimilhança são os mais utilizados em classificação supervisionada aplicada aos solos, uma vez que apresentam uma base teórica bastante desenvolvida (Bolsted, 1992), são de fácil implementação, apresentaram os melhores resultados (Kornblau e Cipra, 1983; Yamaguchi, 1987; Yamaguchi e Noito, 2003). Estes algoritmos baseiam-se na estatística paramétrica das assinaturas espectrais e serão os utilizados neste trabalho.

\subsubsection{Estimador de Máxima Verossimilhança (Maxver)}

Para a predição e avaliação de tendências é necessário ter o conhecimento dos componentes de variância e da covariância das observações. Vários são os métodos estudados para solucionar estas questões mas um deles se destaca pela ampla utilização e robustez no tratamento de diferentes situações, como um dos algoritmo iterativo mais eficientes: o estimador de máxima verossimilhança - Maxver (Hardley e Rao, 1967; Oliveira, 2003).

O princípio do classificador Maxver é baseado na inferência da máxima verossimilhança, a qual é muito atraente, em parte, devido a sua grande simplicidade.

O método da máxima verossimilhança consiste em maximizar a função de densidade de probabilidade, em relação aos efeitos fixos e aos componentes de variâncias dos efeitos aleatórios, como os encontrados em uma cena durante a classificação. Esse método é iterativo e fornece sempre estimativas positivas de componentes de variância. Existem alguns problemas no uso deste estimador devido ao fato deste não considerar a perda dos graus de liberdade resultante da estimação dos efeitos fixos do modelo (Oliveira, 2003). 
$\mathrm{Na}$ estimação por máxima verossimilhança assume-se que os dados seguem uma distribuição multivariada Gaussiana com função de probabilidades conjuntas (Mardia e Marshall, 1984).

Se assumirmos que $X_{11}, \ldots, X_{1 n 1}$ e $X_{21}, \ldots, X_{2 n 2}$ são amostras aleatórias das distribuições $N\left(\theta_{1}, \sigma_{2}^{2}\right)$ e $N\left(\theta_{2}, \sigma_{2}^{2}\right)$ respectivamente e que as amostras são independentes. Podemos comparar as médias populacionais estimando a diferença $\beta=\theta_{1}-\theta_{2}$. A estimação é baseada na diferença entre médias amostrais, isto é, $\bar{X}_{1}-\bar{X}_{2}$ que é o estimador de máxima verossimilhança de $\beta$.

Dos métodos de classificação pixel a pixel, o método da máxima verossimilhança é o mais comum assim como a técnica mais robusta de estimação de parâmetros, considerando a ponderação das distâncias entre as médias dos pixels das classes, e acaba por utilizar para isto uma base estatística relativamente complexa.

Crósta (1992) cita "para que a classificação por Máxima Verossimilhança seja precisa o suficiente, é necessário um número razoavelmente elevado de pixels para cada conjunto de treinamento, número esse preferencialmente acima de uma centena".

Neste método os conjuntos de treinamento (determinados pelo classificador) definem o diagrama de dispersão das classes e suas distribuições de probabilidade, considerando a distribuição de probabilidade Gaussiana para cada conjunto de treinamento.

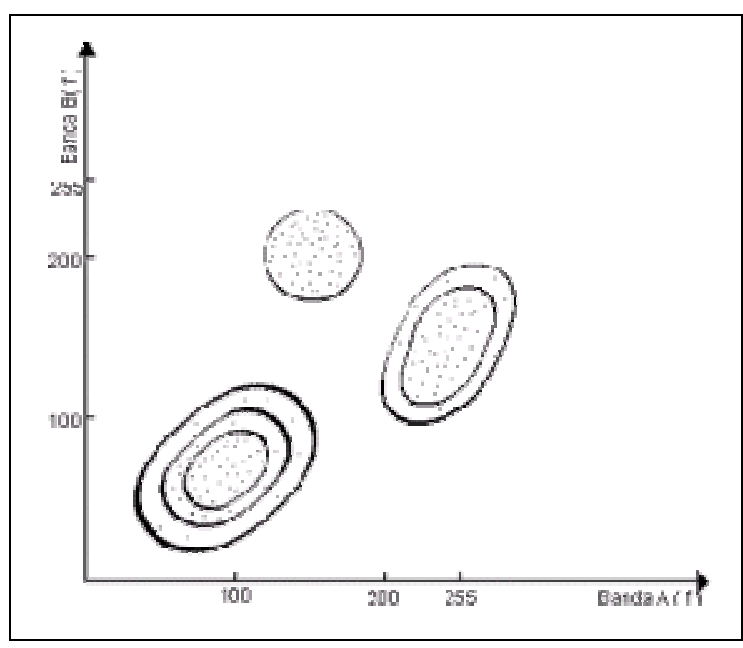

Figura 2.8 - Distribuição de classes no espaço amostral na classificação Maxver (Crosta,1992)

Os contornos ao redor de cada classe, segundo Crósta (1992) "podem ser entendidos como a probabilidade de existir um pixel naquele conjunto de treinamento com uma determinada combinação de DN's" (Figura 2.8). 
Em suma o Método da Máxima Verossimilhança (Maxver) calcula a variância e a correlação dos padrões de resposta espectral para classificar um pixel desconhecido. Os contornos equiprobabilísticos são baseados em valores limites e no caso de áreas sobrepostas, utilizam probabilidades "a priori" ou fatores de ponderação.

Fonseca (1996) comenta que "para diminuir a confusão entre as classes, ou seja, reduzir a sobreposição entre as distribuições de probabilidades das classes, aconselha-se a aquisição de amostras significativas de alvos distintos e a avaliação da matriz de classificação das amostras."

O Maxver utiliza a matriz de dados (bandas) com os valores das diversas variáveis descritivas e a indicação das classes (amostra de treino) e produzem uma regra de decisão que pode ser aplicada a novos dados (de classes desconhecidas). Para além da matriz de dados podem aceitar outros argumentos que diferem de classificador para classificador, aceitando um vetor de probabilidades a priori para cada classe e, por omissão, estimam esse vetor a partir da matriz de dados. Ele é um classificador paramétrico, pois assume a distribuição normal para cada uma das classes em cada uma das bandas, através da qual calcula os parâmetros de média e matriz de covariância (Jensen, 1986) - que computa as probabilidades de um determinado pixel pertencer a cada uma das classes determinadas na fase de treinamento, associando-o em seguida, à classe a qual ele apresenta a maior probabilidade. Sendo que a distribuição de cada uma das classes no espaço de atributos é determinada pelas amostras.

Pode-se dizer também que o Maxver é um "tomador de decisão" (Tso e Mather, 2001), onde :

$$
\underline{X} \in w_{i} \text { se } p\left(\underline{X} / w_{i}\right) P\left(w_{i}\right)>p\left(\underline{X} / w_{k}\right) P\left(w_{k}\right), i \neq k,
$$

(Equação 2.8)

Onde:

- $\quad$ wi $_{\mathrm{i}}$ ão as classes

- $\underline{X}=(\mathrm{x} 1, \mathrm{x} 2, \ldots \mathrm{xp})$ é o vetor de observações no espaço de atributos por pixel

- $\quad \mathrm{P}\left(\mathrm{w}_{\mathrm{i}}\right)$ são as probabilidades a priori de ocorrência de cada classe;

- $\mathrm{p}\left(\underline{\mathrm{X}} \backslash \mathrm{w}_{\mathrm{i}}\right)$ são as funções densidade de probabilidade de cada classe (ou suas estimativas):

- $\left(\underline{m}_{\mathrm{W}}\right) \mathrm{i}$ é o vetor de médias das classes:

- a matriz de variância-covariância $S_{i}$ de cada classe 
Sendo uma probabilidade condicional, este classificador ou "tomador de decisão" tem por finalidade atribuir um grupo de pixels a uma classe $\mathrm{w}_{\mathrm{i}}$ baseada na probabilidade condicional (Equação 2.9):

$$
p\left(X / w_{i}\right)=\frac{P\left(\underline{\left.X e w_{i}\right)}\right.}{P\left(w_{i}\right)}
$$

(Equação 2.9)

Ou seja, $\underline{X}$ pertence a classe $w_{i}$ se a probabilidade $\mathrm{P}\left(\underline{X} / w_{i}\right)$ for a maior para qualquer outra classe $w_{j} \neq w_{i}$.

Entretanto, para a aplicação do Maxver são necessários alguns parâmetros, sendo o mais importante deles, a determinação do intervalo de confiança.

\subsection{Intervalo de confiança}

O intervalo de confiança é um intervalo centrado na estimativa pontual, cuja probabilidade de conter o verdadeiro valor do parâmetro é igual ao nível de confiança. Um ponto estimado, por ser um único ponto, por si só não fornece informação sobre a precisão e a confiabilidade da estimativa. Uma alternativa para relatar um único valor, capaz de retratar o parâmetro que está sendo estimado, é calcular e relatar o intervalo inteiro de valores plausíveis - um intervalo de estimativa ou intervalo de confiança. (Devore, 2000).

Um intervalo de confiança é sempre calculado inicialmente pela escolha de um nível de confiança, a qual é medida o grau de confiabilidade do intervalo.

Os níveis de confiança mais freqüentemente utilizados são os de $90 \%, 95 \%$ e $99 \%$.

Um intervalo de confiança com nível de confiança de 95\% implica que 95\% de todas as amostras podem estar no intervalo que inclui $\mu$ (média), ou qualquer que seja o parâmetro estimado, e somente 5\% de todas as amostras poderão ser conferidas a um intervalo errôneo.

Quanto maior o nível de confiança, mais fortemente nós acreditamos que o valor do parâmetro que é estimado encontra-se dentro do intervalo. A informação sobre a precisão de um intervalo estimado é fornecida pela largura deste intervalo. Se o nível da confiança for elevado e o intervalo resultante for estreito, pode-se afirmar que o nosso conhecimento do valor do parâmetro é razoavelmente preciso. Um intervalo de confiança muito largo, por outro lado, passa a mensagem de que há muita incerteza sobre o valor que estamos estimando. A Figura 2.9, mostra intervalos de confiança de $95 \%$ para as médias das amostras para uma dada classe. Na Figura 2.9 (a), a largura dos intervalos sugere o conhecimento preciso sobre $\mu$, enquanto a Figura 2.9 (b) sugere um largo intervalo de valores plausíveis. 


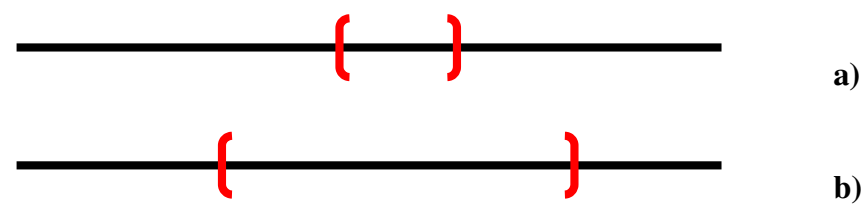

Figura 2.9 - Intervalo de confiança indicando informação precisa (a) e imprecisa (b) sobre $\mu$. (Montgomery e Runger, 2003)

\subsection{Nível de confiança, precisão e escolha do tamanho da amostra.}

Por quê estabelecer um nível do intervalo da confiança de $95 \%$ quando é possível assumir um nível de $99 \%$ ? Porque o preço a pagar pelo alto nível de confiança é a largura (Extensão) do intervalo. Porque um intervalo de 95\%, segundo as normas das probabilidades e suas propriedades básicas (ver Devore, 2000 e Montgomey e Runger, 2003), se estende $1,96 . \sigma / \sqrt{n}$ para cada lado de $\boldsymbol{x}$, sendo a largura total de 2(1,96). $\sigma / \sqrt{n}=3,92 \cdot \sigma / \sqrt{n} 2$. De forma similar, a largura de um intervalo de $99 \%$ é $2(2,58) \cdot \sigma \sqrt{n}=5,15 \cdot \sigma / \sqrt{n} 2$. Isto é, tem-se mais confiança num intervalo de $99 \%$ precisamente porque ele é mais largo. Quanto mais elevado o grau de confiança desejado, mais largo o intervalo resultante. De fato, o único intervalo de confiança de $100 \%$ para $\mu$ é $(-\infty, \infty)$, mas que não nos fornece nenhuma informação, porque, apesar da amostragem, nós sabemos que ele cobre todo o intervalo de $\mu$.

Se nós pensarmos da largura do intervalo como uma especificação da sua precisão ou exatidão, o nível da confiança (confiabilidade) do intervalo está relacionado inversamente com a sua precisão.

Uma estimativa do intervalo com elevada confiança pode ser imprecisa nos pontos extremos do intervalo por estes estarem muito distantes um do outro, visto que um intervalo preciso pode envolver uma confiabilidade relativamente baixa.

Assim, não se pode dizer inequivocadamente, que um intervalo de $99 \%$ deve ser preferido a um de $95 \%$, pois o ganho na confiabilidade envolve uma perda na precisão.

Uma estratégia atraente é especificar o nível desejado da confiança e a largura do intervalo e a partir daí, determinar então o tamanho de amostra necessário (Devore, 2000). 


\subsection{Amostragem em imagens}

Um plano de amostragem descreve o modo como as amostras de pixels são selecionadas de uma imagem no sentido de caracterizar as classes temáticas de interesse. $\mathrm{O}$ tamanho da amostra é importante em termos de acurácia (ou exatidão) com a qual se obtém as estimativas dos parâmetros estatísticos que descrevem estas classes. Tanto o plano de amostragem como o tamanho da amostra são importantes na determinação da acurácia do mapa temático derivado de dados de sensoriamento remoto (Tso e Mather, 2001). Pode-se obter amostras tanto de observações em campo, como de mapas ou fotografias aéreas. Se as características da classe sofrem influência de mudanças temporais, deve se tomar cuidado para que a amostra represente adequadamente o estado temporal do fenômeno observado. Se a área de interesse é grande, então pode não ser possível obter amostras estatisticamente válidas pela resolução temporal do satélite. Quando as nuvens são um problema, a logística da amostragem é realizada com mais dificuldade por ser preciso saber sobre o número de passagens do satélite que serão necessárias para obter uma imagem sem nuvens (Tso e Mather, 2001).

Os dados amostrais são classificados em dois tipos: dados de treinamento e dados de teste. As amostras de treinamento são utilizadas nos métodos de classificação supervisionada de reconhecimento de padrões para ensinar ao classificador as principais características de cada classe. Segundo Campbel (1987) o número de amostras observacionais tem uma relação direta com o intervalo de confiança da acuracidade estimada da classificação e, em particular, com os parâmetros estatísticos estimados utilizados. Por exemplo, estimativas do vetor de média e matrizes de variância-covariância das classes individuais são requeridas para o classificador de máxima verossimilhança. Também deve haver uma quantidade mínima de amostras que são atribuídas a cada classe, para assegurar-se de que cada uma delas esteja representada corretamente. As amostras-teste são utilizadas para determinar a acuracidade da classificação. Estas amostras somente são utilizadas quando o mapa temático já está pronto. As amostras-teste são então categorizadas, utilizando-se o mesmo procedimento com o qual foi gerado o mapa temático. A comparação da rotulação para cada elemento amostral das amostras-teste dada pelo classificador e o rótulo fornecido pelo usuário permite uma avaliação da exatidão conseguida pelo classificador. Onde não é possível adquirir amostras-teste então o uso de validação cruzada se apresenta como uma possível solução (Mata et al, 2004).

Alguns autores descrevem suas amostras-teste como "verdade-de-campo". Isto é um mal entendido e uma descrição incorreta, posto que ela é válida apenas para a categoria de 
análise para a qual foi criada, assim como para a escala do trabalho e a resolução espacial do satélite, sendo, portanto, uma verdade parcial, em função do objeto de estudo e do instrumento, no caso o sensor, de análise. Como errar é humano, presume-se que este aspecto do comportamento humano se estenda ao conjunto de amostras-teste e às amostras do treinamento. Entretanto, alguns erros encontrados em mapas temáticos não podem ser apontados como causados pela falha do classificador, mas podem ser resultado da má colocação de alguns elementos das amostras-teste, ou uma identificação falha dos seus atributos.

\subsubsection{Plano de amostragem}

Os diversos tipos de planos de amostragens são descritos na literatura (Congalton, 1991; Borak e Strahler, 1999; Congalton e Green, 1999). Congalton (1988) sugeriu que tanto a amostragem aleatória simples como a amostragem aleatória estratificada geralmente fornece resultados satisfatórios. Congalton e Green (1999) tem uma visão mais ampla, mas destacam que a alocação das amostras é tão importante quanto o plano de amostragem (Figura 2.10).

Figura 2.10 - Esquema de amostragem utilizados para determinação da acurácia

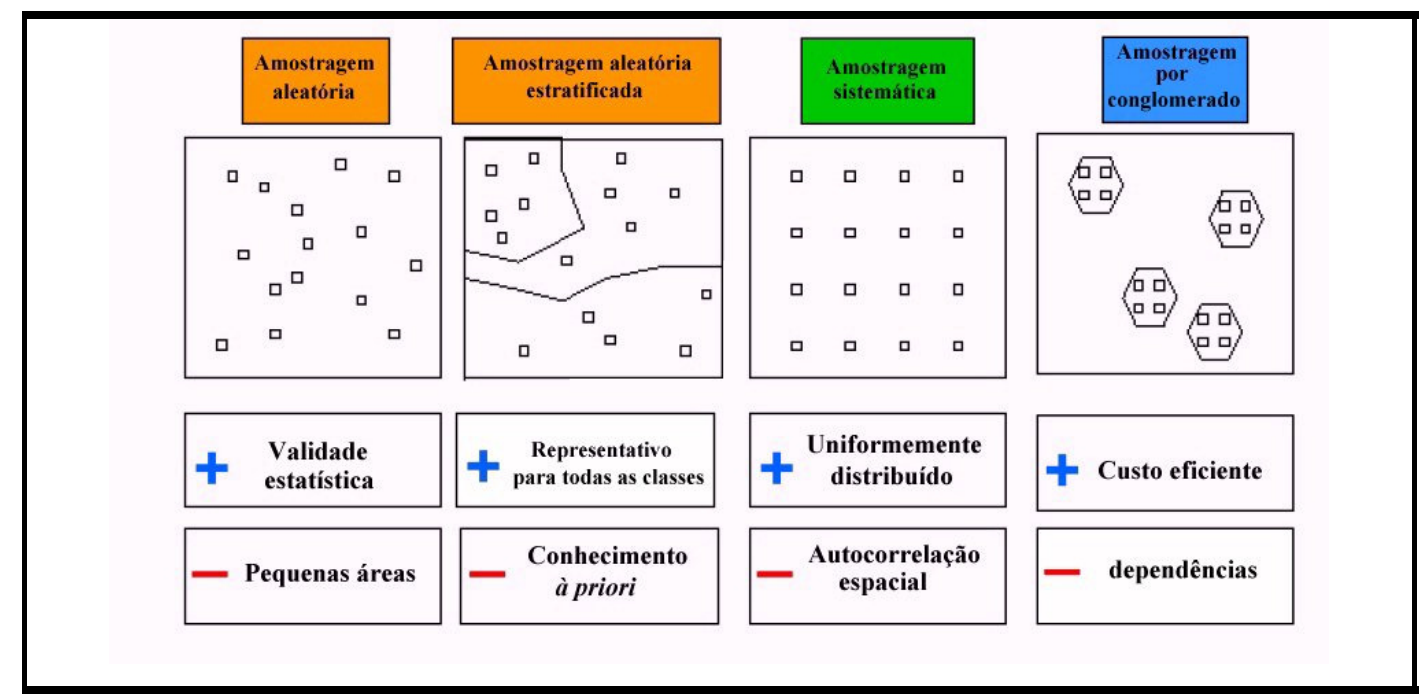

Fonte: Banko, 1998. Adaptado por Santos, 2005. 
Atkinson $(1991,1996)$ nota que as regras de amostragem estatísticas padrão não se aplicam em dados espaciais porque as posições no espaço estão em posições fixas e seus atributos são consequentemente autocorrelacionados. Ele mostra que a distância de amostragem ótima varia com a natureza do alvo, sendo da ordem de $100 \mathrm{~m}$ para áreas com vegetação. Para os solos, entretanto, a distância de amostragem ótima é a mais elevada resolução espacial obtida do instrumento.

Em um plano de amostragem aleatório, os pixels amostrados são escolhidos aleatoriamente na imagem. O termo "sem reposição" significa que nenhum pixel foi selecionado duas vezes. Apesar deste conceito ser muito fácil de ser aplicado, isso pode não ser sempre possível na prática, porque algumas classes pequenas podem ser omitidas. Entretanto, se o número de amostras selecionadas não forem suficientemente grande, algumas classes de informação podem ser sub- ou sobre- amostradas.

Segundo a bibliografia geral, a amostragem aleatória estratificada simples deve ser preferida (Brogaard e Olafsdottir, 1997), onde se pode escolher muitas subáreas para cada classe espalhadas pela imagem, e executar a amostragem em cada uma destas subáreas.

\subsubsection{Tamanho da amostragem}

O tamanho da amostra é um assunto muito discutido e analisado por diversos autores (Hord e Brooner, 1979; Hay, 1979; Mather, 1999). Mather (1999), sugere uma regra empírica na tentativa-e-erro, onde o número de pixels de treinamento por classe deve ser, no mínimo, trinta vezes o número de bandas. Esta regra é baseada na noção que, em estudos univariados, o tamanho de uma amostra de trinta vezes ou mais é considerado "grande". Esta regra pode ser modificada para indicar que o tamanho da amostra, por classe, deva ser, ao menos, de trinta vezes o número de parâmetros estimados. Outros autores indicam a utilização de modelos teóricos de distribuição de dados para predizer o tamanho da amostra a ser adquirida, levando em conta o nível especificado de acuracidade a ser alcançado (Congalton, 1991), como por exemplo, o método baseado na distribuição multinomial (Congalton e Green, 1999).

O tamanho da amostra necessária para medidas estatisticamente válidas da acurácia da classificação não é o único critério que deve ser considerado. Classificadores baseados em estatística requerem que certos parâmetros estejam estimados corretamente. No caso do classificador de Máxima Verossimilhança (Maxver), estes parâmetros são o vetor de média e a matriz de variância-covariância de cada classe. O tamanho da amostra está relacionado ao número de feições (dimensionalidade no espaço de feições ou atributos) e, como observado 
anteriormente, como a dimensionalidade dos dados aumenta para um tamanho de amostra fixo, então a precisão das estimativas destes parâmetros se torna mais baixo, conduzindo a perda de eficiência do classificador (Tso e Mather, 2001). Isto é conhecido como fenômeno de Hughes. Para dados de baixa dimensionalidade, a sugestão de Mather (1999) é que havendo um tamanho mínimo de 30 vezes o número de bandas se obterá resultados satisfatórios na maioria dos casos. Entretanto, com o crescente aumento da dimensionalidade dos dados (exemplo dos dados hiperespectrais), então o tamanho da amostra requerida será extremamente grande, o que irá requerer algum método de redução de dimensionalidade tal como uma transformação ortogonal ou o uso de métodos de seleção de feições.

Estas observações são dirigidas para o uso e classificadores estatísticos, os quais (no caso, o Maxver) operam definindo um modelo da distribuição dos dados, tal como a distribuição normal multivariada, para então estimar os parâmetros do modelo dos dados do treinamento. Este assunto foi discutido em profundidade por El-Sheik e Wacker (1980), Hseih e Landgrebe (1998) e Raudys e Pikelis (1980).

\subsubsection{Número e dimensão dos polígonos amostrais}

Como a classificação utilizada neste trabalho será a classificação supervisionada, cabe aqui discutir mais detalhadamente o problema das amostras.

A coleta das amostras constitui-se numa fase crítica para o processo de classificação supervisionada. Na bibliografia são raras as indicações que auxiliem o analista de imagens de satélite na escolha de um critério específico de amostragem. As regras mais citadas na bibliografia são regras obtidas através de "tentativa-e-erro", a partir das experiências específicas de cada pesquisador na aplicação da técnica em sua área de estudo. Em geral, se determina que o número de píxels em cada classe deve depender do número de variáveis consideradas, em particular o número de bandas da imagem. Por exemplo, Swain e Davis (1978) indicam que o tamanho da amostra deve conter pixels entre 10 a 100 vezes o número de bandas. Para Mather (1999), como já discutido no item anterior, este número deve ser de trinta vezes o número de bandas (Tso e Mather, 2001). Outros autores, como Fitzpatrick-Lins (1981) e Congalton $(1988 ; 1991)$ utilizam modelos teóricos de distribuição de dados para predizer qual o tamanho da amostra necessário, de acordo com o nível exigido de acuracidade.

Em geral, o número de amostras é um ponto de equilíbrio entre o esforço para minimizar os custos de trabalho de campo e a necessidade mínima de um tamanho de amostra 
que possua representatividade e significância estatística. Em geral, quanto maior o número da amostra, maior a sua confiabilidade (Dicks e Lo, 1990). Dependendo do objetivo do trabalho e da precisão exigida, o tamanho da amostra é calculada por diferentes métodos. A regra empírica proposta por Congalton (1991), recomenda um mínimo de 50 amostras por classe. Banko (1998) diz que um valor entre 75 e 100 amostras (pixels) por classe é uma boa definição empírica. Estes valores proporcionam medidas suficientes em cada estrato de classe para cálculos posteriores, em especial para a matriz de erros e o índice Kappa.

Os resultados teóricos existentes supõem a independência dos elementos da amostra. Esse pressuposto é habitualmente violado em classificação de imagens pelas seguintes razões: a) existem fortes restrições impostas pelo custo de obtenção da informação de terreno; b) os elementos da amostra, em teoria, devem ser pixels puros e portanto devem pertencer a áreas de terreno nas quais essa hipótese é aceitável; e c) é geralmente mais fácil marcar polígonos (conjunto espacialmente conexo de pixels) na imagem do que pixels individuais. Dado que os pixels de um mesmo polígono estão correlacionados espacialmente considera-se que a "dimensão efetiva" (no que se pode considerar o número de graus de liberdade numa análise estatística inferencial) aumenta progressivamente mais lentamente com o aumento da dimensão dos polígonos. No entanto essa progressão não está quantificada (Fitzpatrick-Lins, 1981).

$\mathrm{Na}$ área de estudo deste trabalho, entretanto, a "verdade de campo" é suficientemente detalhada para ter uma resolução espacial melhor que a imagem, onde as unidades de solos estão suficientemente detalhadas para possibilitar uma generalização posterior das unidades em classes de estudo. Como as unidades de solos são obtidas através de uma metodologia que envolve vários critérios distintos e variáveis não escalonáveis em sensoriamento remoto, onde o critério espectral, representado pelo nível de cinza não pode abstrair, a hipótese do "pixel puro" não será levada em consideração.

\subsection{Avaliação do desempenho da classificação}

Uma das formas mais simples e completa de avaliar os resultados de um classificador é através da designada matriz de erro ou matriz de confusão. Segundo Lillesand e Kiefer (1994), na maioria dos estudos de classificação, a exatidão do resultado é avaliada por meio da matriz de erros de classificação (também chamada de tabela de contingência). Essa representação é adequada quando se considera um número baixo ou moderado de classes. 
A matriz de confusão é uma tabela de dupla entrada na qual as colunas representam a realidade (as classes a que efetivamente pertencem às observações amostrais) e as linhas as classes previstas pelo classificador (ver Tabela 2.1). Cada célula do interior da tabela contém um valor $\mathrm{x}_{\mathrm{ij}}$, igual ao número de observações da classe $i$ classificadas pelo classificador na classe $j$. As observações da diagonal principal $\left(\mathrm{x}_{\mathrm{ii}}\right)$ são portanto as observações corretamente classificadas. Para além desses valores absolutos podem representar-se nas margens da matriz os valores de precisão relativos para cada classe e a precisão global do classificador para a mostra na célula inferior direita.

Existem dois valores de precisão para cada classe. $\mathrm{O}$ valor de precisão no mapa corresponde à proporção das observações que o classificador afeta à classe e que pertencem realmente a essa classe. $\mathrm{O}$ valor de precisão do classificador corresponde à proporção das observações que pertencem de fato à classe e que o classificador afeta a essa classe. Por exemplo, se uma classe tiver precisão do mapa de $40 \%$ e precisão do classificador de $80 \%$, então isso significa que se se construísse um mapa com base nesse classificador apenas $40 \%$ dos pixels da classe indicada no mapa pertenceriam efetivamente a essa classe e que $80 \%$ dos pixels dessa classe no terreno seriam corretamente representados no mapa.

Uma questão fundamental na apreciação dos valores da matriz de erro é a relação existente entre as observações que são usadas para treinar o classificador (e que constituem as amostras de treinamento) e as observações usadas para construir a matriz de confusão e avaliar a precisão do classificador (amostra de teste). Se ambas as amostras estiverem correlacionadas então os valores de precisão serão sobre-estimados. A situação extrema é aquela em que se usa mesma amostra para construir o classificador e a matriz de erro. A estimativa de precisão obtida nesse caso designa-se precisão aparente e pode atingir valores muito superiores ao verdadeiro valor de precisão do classificador para os dados analisados.

\subsubsection{As medidas de exatidão}

Várias características sobre o desempenho da classificação são expressas pela matriz de erro, cuja função é determinar o nível de exatidão da classificação. A principal delas é avaliar os erros de omissão e de comissão Os erros de omissão (ou exclusão) ocorrem quando um pixel não é atribuído à classe à qual pertence. Os erros de comissão (ou inclusão) ocorrem quando um pixel é atribuído a uma classe à qual não pertence. 
Tabela 2.1 - Matriz de erros de omissão e comissão

\begin{tabular}{|c|c|c|c|c|c|c|c|c|c|}
\hline \multicolumn{8}{|c|}{ Classes reais (i) } & \multirow[b]{2}{*}{ Total } & \multirow[b]{2}{*}{ Erro de Comissão } \\
\hline $\begin{array}{c}\text { Classes } \\
\text { geradas pelo } \\
\text { classificador } \\
\text { (j) }\end{array}$ & 1 & 2 & 3 & 4 & 5 & $\ldots$. & $\mathrm{n}$ & & \\
\hline 0 & $x_{01}$ & $x_{02}$ & $x_{03}$ & $x_{04}$ & $x_{05}$ & $x_{0 j}$ & $x_{0 n}$ & $\Sigma_{X_{0+}}$ & $\left(\Sigma_{X_{0+}}-x_{0 i}\right) / \Sigma_{X_{0+}}$ \\
\hline 1 & $x_{11}$ & $x_{12}$ & $x_{13}$ & $x_{14}$ & $x_{15}$ & $x_{1 j}$ & $x_{1 n}$ & $\Sigma X_{1+}$ & $\left(\Sigma_{X_{1+}-} X_{11}\right) / \Sigma_{X_{1+}}$ \\
\hline 2 & $x_{21}$ & $x_{22}$ & $x_{23}$ & $x_{24}$ & $x_{25}$ & $x_{2 j}$ & $x_{2 n}$ & $\Sigma_{X_{2+}}$ & $\left(\Sigma_{X_{2+}-} X_{22}\right) / \Sigma_{X_{2+}}$ \\
\hline 4 & $x_{41}$ & $x_{42}$ & $x_{43}$ & $x_{44}$ & $x_{45}$ & $x_{4 j}$ & $x_{4 n}$ & $\Sigma_{X_{4+}}$ & $\left(\Sigma_{X_{4+}-} X_{44}\right) / \Sigma_{X_{4+}}$ \\
\hline 5 & $x_{51}$ & $x_{52}$ & $x_{53}$ & $x_{54}$ & $x_{55}$ & $x_{5 j}$ & $x_{5 n}$ & $\Sigma_{X_{5+}}$ & $\left(\Sigma_{X_{5+}}-X_{55}\right) / \Sigma_{X_{5+}}$ \\
\hline .... & $x_{i 1}$ & $x_{i 2}$ & $x_{i 3}$ & $x_{i 4}$ & $x_{i 5}$ & $x_{i j}$ & $x_{\text {in }}$ & $\Sigma_{X_{i+}}$ & $\left(\Sigma_{X_{i+}-} X_{i i}\right) / \Sigma_{X_{i+}}$ \\
\hline $\mathrm{N}$ & $x_{n 1}$ & $x_{n 2}$ & $x_{n 3}$ & $x_{n 4}$ & $x_{n 5}$ & $x_{n j}$ & $X_{n n}$ & $\Sigma_{X_{n+}}$ & $\left(\Sigma_{X_{n+}}-X_{n n}\right) / \Sigma_{X_{n+}}$ \\
\hline Total & $\Sigma_{X_{+1}}$ & $\Sigma \Sigma_{+2}$ & $\Sigma X_{+3}$ & $\Sigma_{X+4}$ & $\Sigma_{X+5}$ & $\Sigma \Sigma_{+j}$ & $\Sigma_{X_{+n}}$ & $\Sigma_{X_{++}}$ & \\
\hline
\end{tabular}

Fonte: Iwai e Quintanilha, 2005

Onde:

$x_{i i}=$ número de observações corretamente classificada;

$x_{+i}=$ número total de observações na classe i;

$x_{i+}=$ número total de observações atribuídas à classe;

$\mathrm{D}=\sum_{\mathrm{i}=1}^{\mathrm{n}} \mathrm{X}_{\mathrm{ii}}=$ soma total dos valores da diagonal principal

$x_{++}=$soma total das células da matriz de erro;

$x_{i j}=$ número de observações da classe $\mathrm{j}$ atribuída à classe $\mathrm{i}$;

$\mathrm{x}_{0+}=$ número total de observações não classificadas em nenhuma das classes pré-definidas;

$\left(\Sigma x_{1+}-x_{11}\right) / \Sigma x_{1+=} \%$ de pixels observados erroneamente atribuídos à classe 1 .

$\left(\Sigma x_{+1}-x_{11}\right) / \Sigma x_{+1}=\%$ de pixels observados da classe 1 erroneamente atribuídos às outras classes

\subsubsection{Exatidão global}

A exatidão global é a proporção de todos os pixels de referência que foram classificados corretamente. É calculada dividindo-se o número total de pixels corretamente classificados (a soma dos elementos ao longo da diagonal principal) pelo número total de pixels de referência. A exatidão global gera uma medida total, não informando sobre quais classes foram melhor classificadas.

\subsubsection{Exatidão do produtor}

A exatidão do produtor é a medida de erro de omissão e indica a probabilidade de um pixel de determinada cobertura terrestre dos dados de referência ser corretamente classificado. Esta exatidão é o resultado da divisão do número de pixels corretamente classificados em 
cada classe (diagonal principal) pelo número total de pixels na coluna correspondente (número de conjunto de pixels de treinamento usados para aquela classe).

\subsubsection{Exatidão do usuário}

A exatidão do usuário é uma medida de erro de comissão e indica a probabilidade de um pixel classificado em uma dada classe, realmente pertencer àquela cobertura terrestre. Esta exatidão é o resultado da divisão do número de pixels correspondente classificados em cada classe (diagonal principal) pelo número total de pixels na linha correspondente (número total de pixels que foram classificados naquela classe).

Todos os elementos não contidos na diagonal da matriz representam erros de omissão ou de comissão. Cada erro representa uma omissão da classe correta e uma comissão para uma classe incorreta. Através da matriz de erro, podem ser avaliados vários índices de exatidão, como: global, do usuário e do produtor. Estes serão detalhados a seguir, assim como seus métodos de cálculo.

Um índice alternativo usado para avaliar a qualidade da classificação, em relação à realidade e/ou verdade de campo é o coeficiente Kappa.

\subsubsection{Coeficiente Kappa (k)}

Ao interpretar a exatidão de classificação, até mesmo a atribuição arbitrária de pixels pode produzir percentagens de valores corretos na matriz de erro. Na realidade, tal tarefa arbitrária poderia gerar um resultado de classificação aparentemente bom (Lillesand e Kiefer, 1994). A matriz de confusão permite o cálculo de vários índices de precisão. O mais conhecido e indicado para classificações de imagens por representar toda a matriz de confusão é o coeficiente Kappa (Congalton, 1991; Noguchi, 2004). Este índice considera todos os elementos da matriz de confusão, ao invés de somente utilizar os elementos da diagonal, como ocorre com a maioria dos índices. O caso ideal ocorre quando o resultado do índice $\mathrm{k}$ aproxima-se de 1 .

O coeficiente Kappa foi proposto originalmente por Cohen (1960), para o caso de dois avaliadores ou de dois métodos, razão pela qual é freqüentemente conhecido como Kappa de Cohen, e foi generalizado para o caso de mais de dois avaliadores por Fleiss, pelo qual às vezes é conhecido também como índice Kappa de Fleiss. 
O coeficiente Kappa determina a concordância esperada a posteriori, excluindo o efeito de erros aleatórios. O coeficiente Kappa poderá ser obtido através da seguinte fórmula (Pontius, 2000):

$$
K=\frac{P_{o}-P_{c}}{1-P_{c}}
$$

ou seja,

$$
K=\frac{N \sum_{i=1}^{M} X_{i i}-\sum_{i=1}^{M} X_{+1} X_{i+}}{N^{2}-\sum_{i=1}^{M} X_{i} X_{+i}}
$$

Onde:

$$
P_{0}=\sum_{i=1}^{M} X_{i i}
$$$$
P_{C}=\sum_{i=1}^{M}\left(X_{i+} X_{+i}\right)
$$

$\mathrm{N}=$ Total de observações

$\mathrm{M}=$ Total de classes ou

é a concordância observada

É a concordância esperada, em que $X_{i+}$ são os elementos pertencentes a uma determinada classe e $\mathrm{X}_{+1}$ os elementos classificados numa determinada classe de objeto

Os valores desse índice são inferiores aos valores de precisão global pois traduzem o ganho de precisão relativamente a uma distribuição aleatória dos indivíduos pelas classes. Se por um lado a utilização do índice Kappa apresenta algumas vantagens (o estimador correspondente tem uma distribuição de probabilidade conhecida, sob certas hipóteses, o que permite a realização de testes de hipóteses ao desempenho do classificador quando se dispõe de uma única matriz de confusão), por outro lado, parece-nos que o valor da estimativa de Kappa não é tão facilmente interpretável como o da precisão global (que é a estimativa da probabilidade de um indivíduo ser corretamente classificado pelo estimador).

Para o caso de concordância perfeita, o valor de Kappa será 1; se a concordância observada for igual a esperada o Kappa vale 0; e no caso da concordância do valor observado ser inferior ao esperado o índice Kappa é menor que zero.

Landis e Koch (1977) propuseram valores de graus de concordância em função do índice Kappa (Tabela 2.2): 
Tabel 2.2 - O índice Kappa e o valor do grau de concordância

\begin{tabular}{c|c}
\hline Kappa & Grau de concordância \\
\hline$<0$ & Sem concordância \\
\hline $0-0,2$ & Insignificante \\
\hline $0,2-0,4$ & Baixo \\
\hline $0,4-0,6$ & Moderado \\
\hline $0,6-0,8$ & Bom \\
\hline $0,8-1$ & Muito bom \\
\hline
\end{tabular}

Fonte: Landis e Koch (1977)

\subsection{Considerações}

Assim, de posse deste conteúdo teórico, passaremos agora a discutir a metodologia e seus recursos, empregados na solução do problema proposto. 


\section{CAPÍTULO 3 - Metodologia}

\subsection{Metodologia}

Neste capítulo será apresentada a metodologia adotada para o desenvolvimento da classificação dos dados da área de estudo, assim como os materiais utilizados. Este capítulo foi organizado considerando-se os seguintes procedimentos:

- Definição e descrição da área de estudo

- Obtenção da verdade de campo

- Escolha da imagem

- Processamento digital de imagens

○ Preprocessamento

- Análise e caracterização preliminar das imagens

- Razão de bandas

- Análise de componentes principais

- İndices espectrais

- NDVI

- SAVI

- NDMI

- Transformação Tasseled Cap

- Amostragem

○ Processamento

- Definição das técnicas de classificação

- Análise e definição da área a ser classificada

- Determinação da amostragem da classificação

- Aplicações

- Amostragem

- Classificação

- Matriz de erro

- Comparação dos resultados dos processamentos

- Avaliação dos resultados 


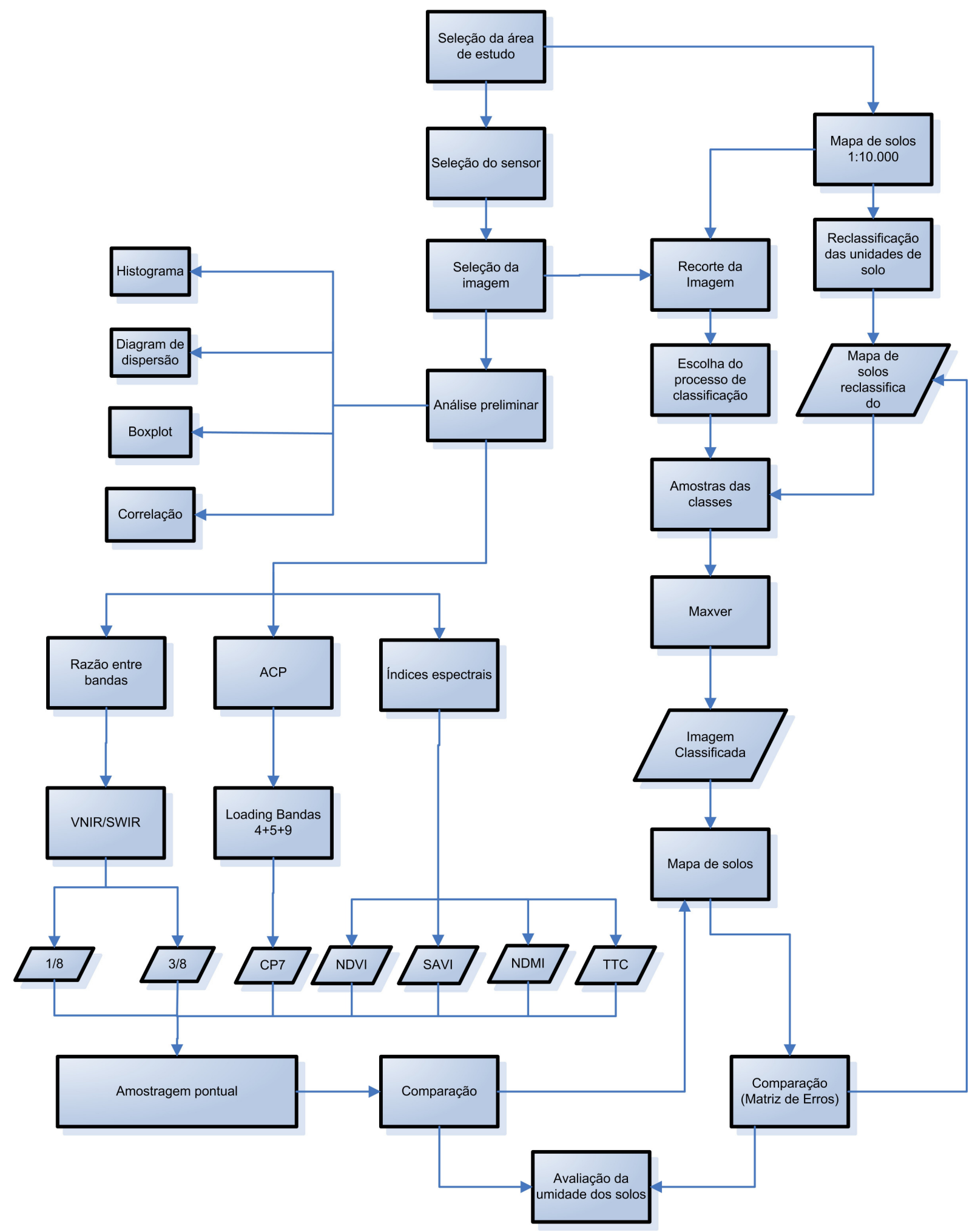

Figura 3.1 - Estrutura da metodologia 


\subsection{Material utilizado para o desenvolvimento do trabalho}

Durante o desenvolvimento deste trabalho, foram utilizados os seguintes recursos materiais, cujo uso será discutido no decorrer do texto.

\subsubsection{Cartas}

Neste trabalho foram utilizados 2 tipos de cartas:

- Carta topográfica 1:100.000 (Esplanada - SUDENE, 1976)

- 03 cartas de solos 1:10.000 (Copener Florestal, 2001 a 2004), correspondentes aos projetos Altamira I, II e III.

\subsubsection{Softwares}

Os softwares utilizados foram o Spring (INPE), nas suas versões 3.6.3 e 4.1, o Idrisi 3.2 (Clark Lab. Co), o ENVI (RSI) 4.0, o Minitab 14 (Minitab Inc.) e o Harvard Graphics 3.0, para as diferentes etapas de análise exploratória, pré-processamento e processamento.

\subsubsection{Imagens}

Foi utilizada uma única cena ASTER (Advanced Spaceborne Thermal Emission and Reflectance Radiometer) de aproximadamente $60 \mathrm{~km}$ x $60 \mathrm{~km}$, recobrindo uma área do Município de Esplanada, dos Tabuleiros Costeiros do Litoral Norte da Bahia, que foi selecionada como local de estudo. A imagem foi adquirida em 18 de novembro de 2002 e recobre uma extensa área de silvicultura. As imagens foram compostas pelas bandas VNIR (Visible and Near Infrared - Visível e Infra-Vermelho Próximo) e SWIR (Shortwave Infrared - Infra-vermelho), correspondendo às bandas espectrais de 1 a 9. Também foram utilizadas algumas das imagens transformadas, obtidas através da razão de bandas, índice de vegetação e componentes principais. Não foram utilizadas as bandas infravermelho termais do ASTER (TIR - Thermal Infrared: 10 a 14), devido a sua baixa resolução espacial (90m).

\subsubsection{Bandas utilizadas}

O sensor ASTER foi projetado para, além de discriminar os alvos tradicionais de cobertura do solo (vegetação, água, solo exposto, urbano) também discriminar importantes feições argilo-minerais constituintes da camada superficial intemperizada onde vivem as plantas, ou seja, os solos. A identificação destas feições é realizada principalmente através das bandas do infravermelho médio (SWIR), em particular das bandas 5 a 9. 
A banda 1 (verde) foi escolhida para captar o pico de reflexão da clorofila e a banda 2 (vermelho), para coincidir com a banda de absorção da clorofila. Embora a resposta espectral das bandas visíveis seja controlada primariamente pelo pigmento das plantas, a resposta obtida pelo infravermelho próximo (Banda 3) é controlado principalmente pela camada do mesófilo das folhas. A banda 4 possui o pico de absorção da água de $1.45 \mu \mathrm{m}$. A banda 5 possui o pico de absorção da hidroxila, além de se situar entre duas bandas de absorção de água. As bandas 6, 7, 8 e 9 são associadas a absorção específica de alguns filossilicatos e carbonatos, como a caulinita, a montmorilonita e a calcita, por exemplo (Yamaguchi e Naito, 2003).

A Banda 1 e a Banda 2, sendo bandas do visível, são claramente afetadas pelo efeito da dispersão atmosférica, sendo que a Banda 2 menos que a Banda 1. As áreas com vegetação mostram-se marcadamente contrastadas e de comportamento semelhante nas bandas do visível, devido à reflexão e à absorção pela clorofila e outros pigmentos, em maior proporção na Banda 2 que na Banda 1. As áreas com solo exposto ou vegetação senescente mostram uma resposta muito mais contrastada na parte do espectro visível. Na banda 3 (infravermelho próximo) a vegetação verde demonstra uma reflectância mais elevada que qualquer outro tipo de cobertura do solo. As bandas 4 e 5 mostram claramente o padrão de variabilidade dos solos nas áreas sem vegetação. As bandas de 5 a 9 mostram feições de absorção características dos minerais filossilicatos e carbonatos na região de $2.1 \mu \mathrm{m}$ a $2.4 \mu \mathrm{m}$. Mas, no geral, as bandas são visualmente muito semelhantes, principalmente as bandas de 5 a 9 .

Tabela 3.1 - Características das bandas do sensor ASTER utililizadas

\begin{tabular}{l|c|c}
\hline \multicolumn{1}{c|}{ BANDA } & COMPRIMENTO DE ONDA $(\boldsymbol{\mu m})$ & RESOLUÇÃO ESPACIAL \\
\hline B1 (Verde) & $0.52-0.62$ & $15 \mathrm{~m}$ \\
\hline B2 (Vermelho) & $0.63-0.69$ & $15 \mathrm{~m}$ \\
\hline B3 (Infravermelho próximo) & $0.78-0.86$ & $15 \mathrm{~m}$ \\
\hline B4 (Infravermelho) & $1.6-1.7$ & $30 \mathrm{~m}$ \\
\hline B5 (Infravermelho) & $2.145-2.185$ & $30 \mathrm{~m}$ \\
\hline B6 (Infravermelho) & $2.185-2.2225$ & $30 \mathrm{~m}$ \\
\hline B7 (Infravermelho) & $2.235-2.285$ & $30 \mathrm{~m}$ \\
\hline B8 (Infravermelho) & $2.295-2.365$ & $30 \mathrm{~m}$ \\
\hline B9 (Infravermelho) & $2.36-2.43$ & $30 \mathrm{~m}$ \\
\hline
\end{tabular}

\subsubsection{Dados auxiliares}

Os dados auxiliares utilizados neste estudo foram: o mapa de uso do solo (cobertura vegetal) realizado através de interpretação visual e informação da idade da gleba de plantio; a 
precipitação nos 15 dias anteriores à tomada da imagem e a temperatura média diária (SEI, 2004), para a elaboração do respectivo balanço hídrico (para estabelecer os teores de água do solo, quando da tomada da imagem). A necessidade destes dados pode ser explicada pela forte resposta espectral da cobertura vegetal, que interfere na obtenção da resposta específica dos solos, mas que, por outro lado, devido a sua homogeneidade, pelo caráter da silvicultura, permitiu estabelecer um padrão normalizador destas respostas conforme o explicado no item 2.4.1.4.1. O teor de umidade, por outro lado é, diretamente, o indicador da presença e do nível de coesão dos solos, sendo assim importante reconhecer o nível de umidade relativa dos solos quando da tomada da imagem.

\subsection{Da área de estudo e do problema a ser abordado}

Para o uso do sensoriamento remoto, numa área de topografia plana, com cobertura homogênea concluiu-se que o critério de teor de umidade do solo seria a variável ambiental que melhor expressaria a presença dos horizontes coesos dos solos de tabuleiros, devido a sua forte interferência na permeabilidade do solo, onde a velocidade de infiltração é condicionada pela presença e tipo de horizonte coeso, conforme explicado no item 2.1.1.

\subsubsection{Descrição geral da área}

A área de estudo localiza-se na folha topográfica "Esplanada" (1:100.000) SC-24-Z-CVI (IBGE, 1985), e corresponde a uma área total de aproximadamente $2.473 \mathrm{~km} 2$ (Figura 1.1(b)).

\subsection{A verdade de campo}

Assumiu-se como verdade de campo o mapa de solos elaborado pelos métodos convencionais (fotointerpretação, trabalho de campo, tradagens, recolhimento de amostras, análises físico-químicas), na escala 1:10.000, realizada pela empresa proprietária da área (Copener Florestal, 2001 a 2003) (Figura 3.2) 


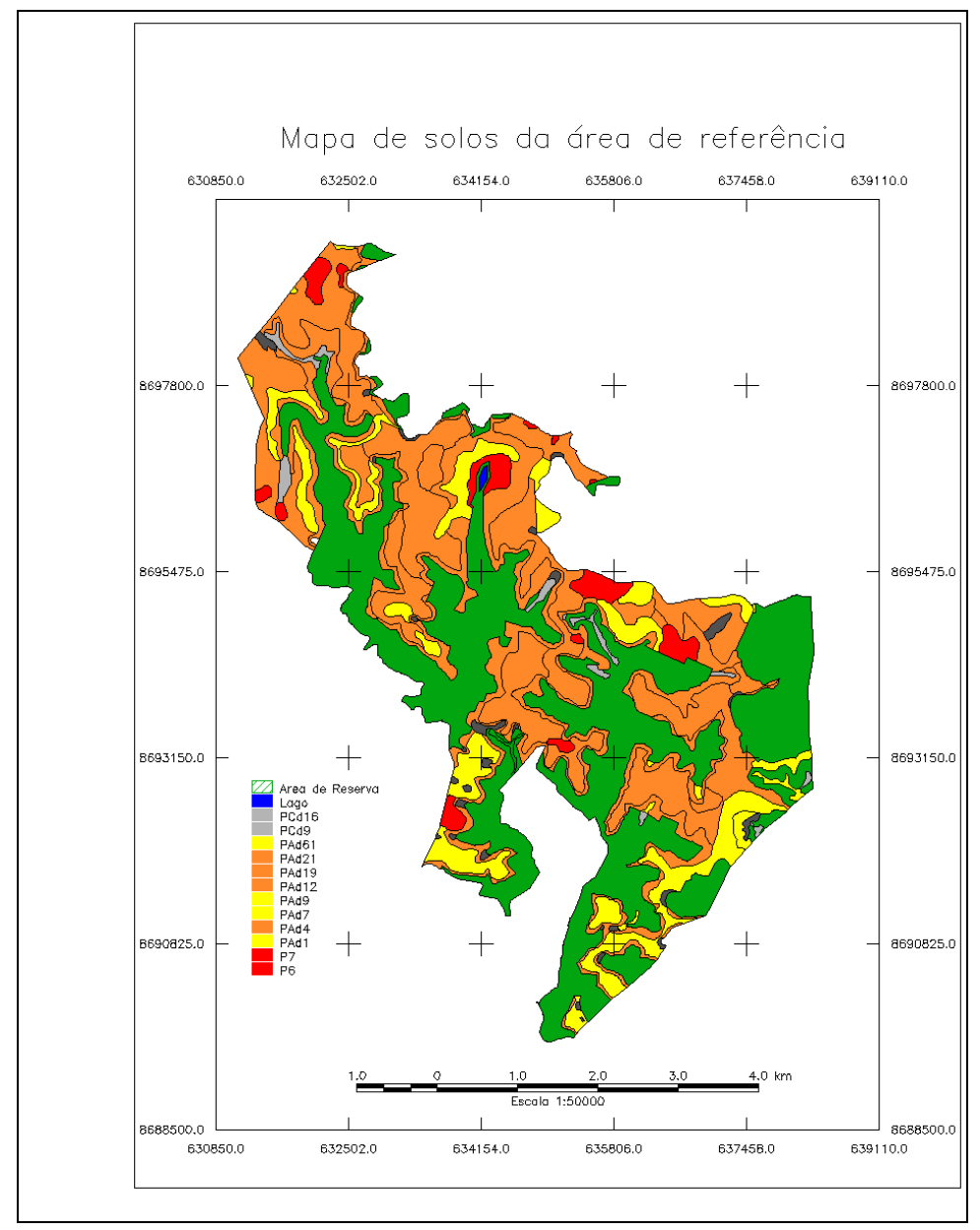

Figura 3.2 - Mapa das unidades de solos (descrição da legenda e das unidades de solo no Quadro 3.1 e 3.2)

\subsection{Da escolha da imagem}

A escolha do sensor ASTER, como já discutido no Capítulo 2, apoiou-se principalmente na inovação das características da resolução espectral e das diferentes resoluções espaciais. Assim, uma vez escolhido o sensor, a próxima etapa foi a obtenção da imagem nos arquivos da Earth Observing System Data Gateway. Nesta etapa apresentou-se um problema característico das regiões litorâneas das baixas latitudes, que é a intensa cobertura de nuvens na região, durante todo o ano, agravado pelo período reduzido de funcionamento do sensor (a partir de 1999) e o ciclo de La Niña, que foi responsável por um período com umidade acima do normal na região (Figura 3.3). Entretanto, esta área sempre apresentou problemas de cobertura de nuvens, como constatado através de pesquisa de arquivos de imagens Landsat TM 5 e ETM 7 (de 1986 até dezembro de 2004), que possui uma maior abrangência temporal de arquivos. (Figuras 3.4e 3.5) 
Figura 3.3 - Amostras de imagens ASTER (VNIR) demonstrando o problema da cobertura de nuvens

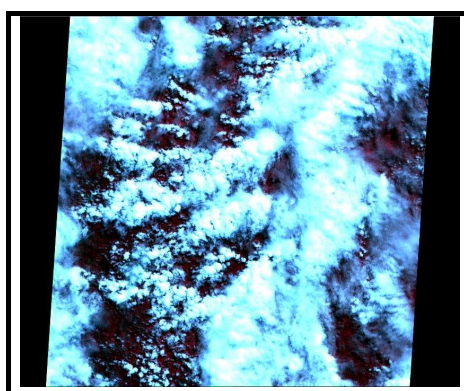

$24 / 08 / 2000$

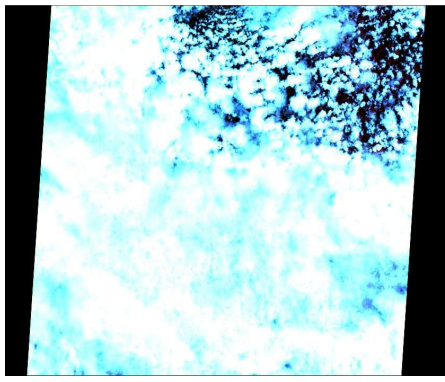

$09 / 11 / 2002$

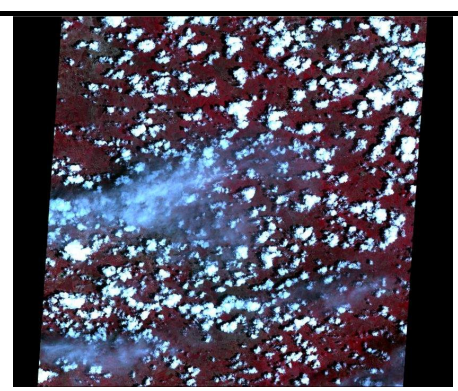

$15 / 01 / 2001$

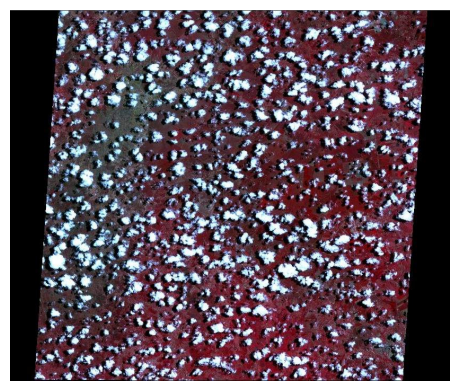

$11 / 10 / 2003$

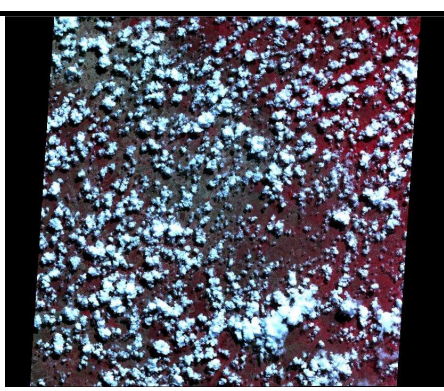

$21 / 04 / 2001$

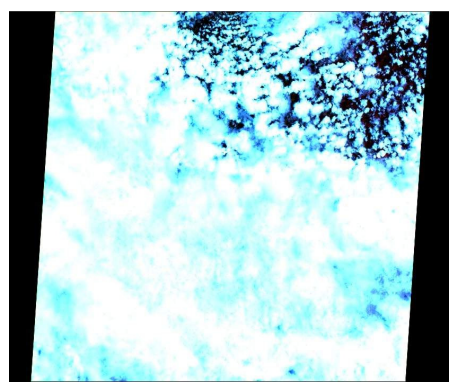

$09 / 11 / 2003$

A imagem selecionada foi uma única cena completa, de 02/12/2002. Fez-se um recorte de 4980x4200 pixels (VNIR), correspondente a um perímetro da área de estudo mais abrangente. A escolha desta imagem baseou-se no critério de que era a imagem que possui a menor cobertura de nuvens sobre a área escolhida (Figura 3.3). Optou-se por trabalhar com as imagens VNIR e SWIR. Entretanto, devido às diferentes resoluções espaciais de acordo com a faixa do espectro (VNIR: 15m; SWIR 30m), as imagens VNIR foram reamostradas espacialmente, alterando sua resolução espacial de $15 \mathrm{~m}$ para $30 \mathrm{~m}$, sendo esta a resolução padrão adotada para os processamentos executados, exceto para a Transformação Tasseled Cap, onde optou-se por trabalhar com a resolução de $15 \mathrm{~m}$, conforme será detalhado posteriormente (3.6.1.6.4). Assim, a área original foi modificada, passando a ter $1551 \times 1570$ pixels (colunas x linhas), na resolução de 30m. 
Figura 3.4 - Amostragem histórica das melhores imagens Landsat TM 5, apresentando a problemática constante da cobertura de nuvens para a área de estudo (1986 a 2004)

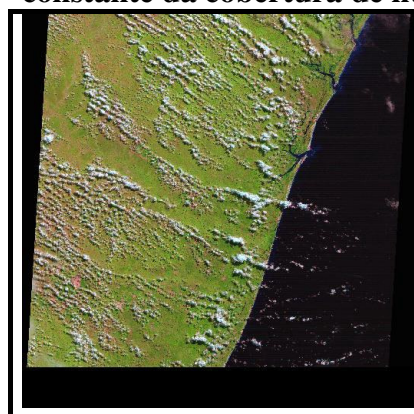

$22 / 05 / 1986$

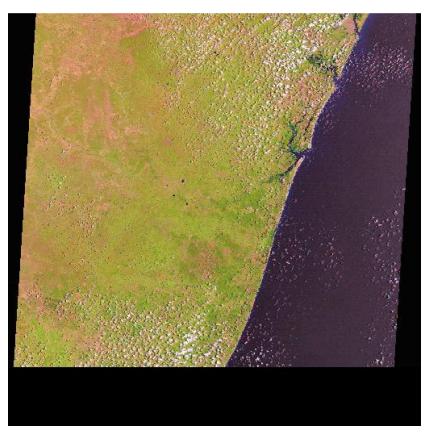

$17 / 10 / 1999$

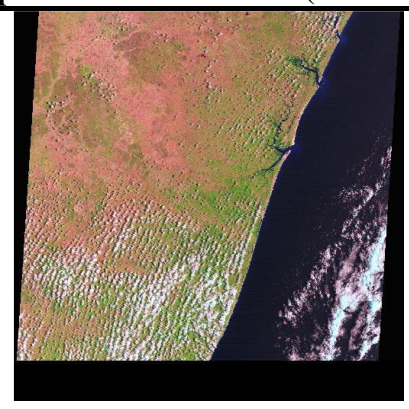

$13 / 02 / 1991$

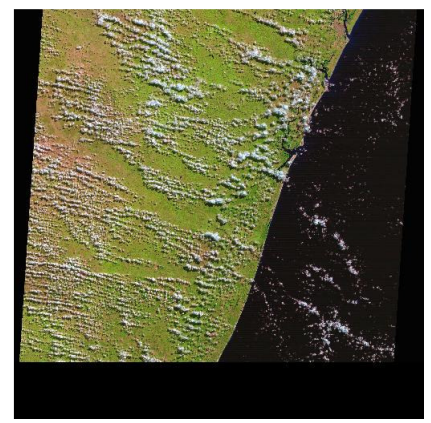

$08 / 07 / 2003$

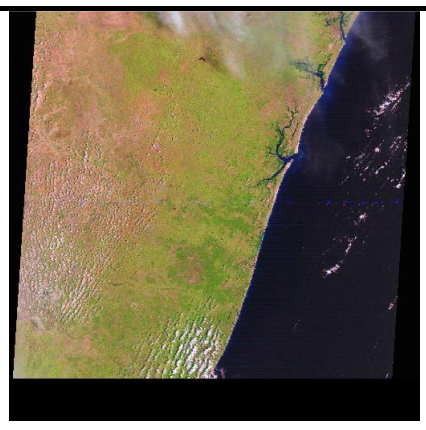

$09 / 12 / 1995$

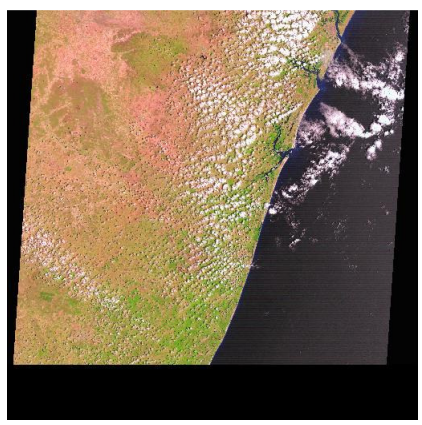

$01 / 12 / 2004$

Figura 3.5 - Amostragem histórica das melhores imagens do sensor Landsat ETM 7, apresentando a problemática constante da cobertura de nuvens para a área de estudo (2000 a 2003)

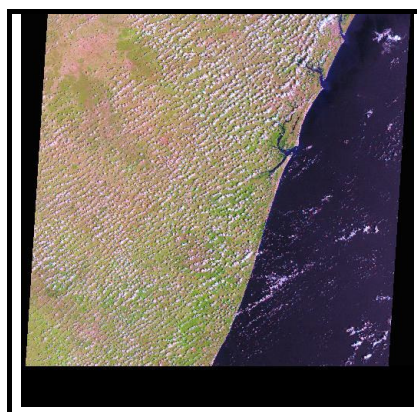

$30 / 12 / 2000$

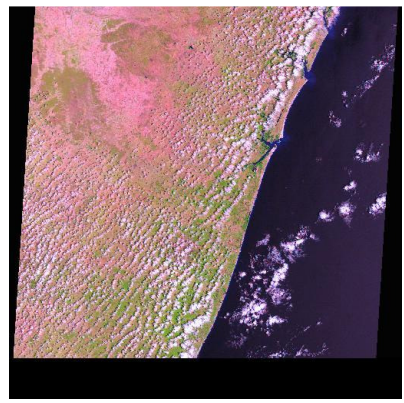

$05 / 01 / 2003$

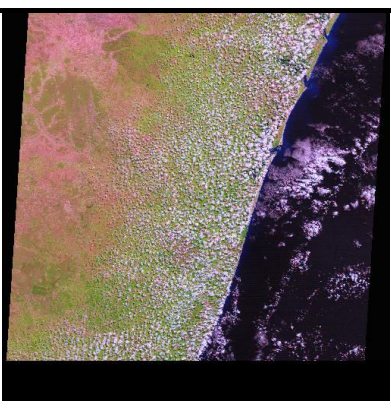

$07 / 05 / 2001$

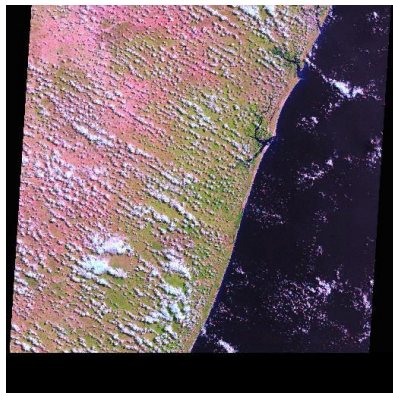

$26 / 03 / 2003$

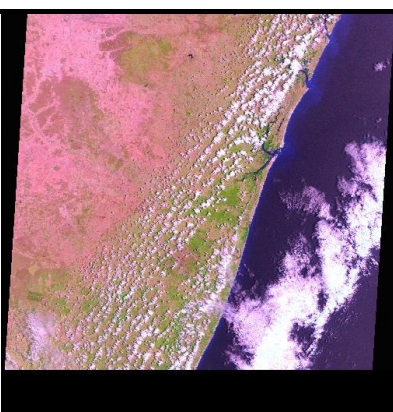

$02 / 11 / 2002$

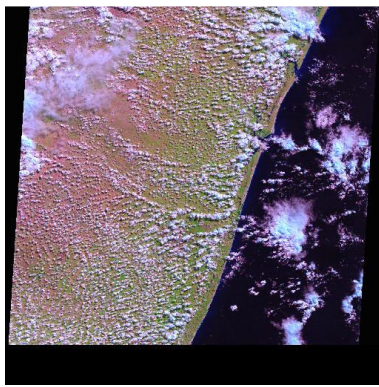

$13 / 05 / 2003$ 


\subsection{Processamento Digital de Imagens}

Este sub-ítem descreve as etapas metodológicas e os procedimentos técnicos, especificamente do processamento digital de imagem que foram divididos em 3 etapas que, embora separadas, ocorreram de forma interativa no decorrer do processo: pré-processamento, amostragem e processamento propriamente dito (classificação).

\subsubsection{Pré-processamento}

O grande aumento de informação advinda dos sensores multi e hiperespectrais, provenientes do aumento das resoluções espaciais, espectrais e radiométricas, têm aumentado substancialmente o volume de dados e sua complexidade, ambos considerados obstáculos ou dificultadores para uma extração eficiente das informações contidas nos dados. Como resultado, numerosos métodos são empregados, sejam novos ou já comprovadamente testados há muito tempo, visando a transformação destes dados, derivando feições que são mais fáceis de serem manipuladas (menos volume) ou mais fáceis de serem interpretadas (menos complexas). Destes métodos, podemos destacar a diferença e a razão de bandas, a análise de componentes principais e o Tasseled Cap e outras tantas combinações lineares de bandas que são aplicadas sobre os dados multiespectrais, com diferentes graus de sucesso.

Nesta etapa foi realizada a preparação da imagem inicialmente com a reamostragem espacial, necessária porque o ASTER apresenta resoluções espaciais diferentes para cada região espectral (15m - VNIR; 30m - SWIR). Em seguida realizou-se a análise exploratória dos dados. Com estas informações, foi possível realizar a correção atmosférica e transformação do número digital (ND) em reflectância relativa, necessária para a elaboração do Tasseled Cap. Logo após, aplicou-se nas imagens as técnicas de pré-processamento de realce, visando destacar um ou mais aspectos ou atributos de classes específicos da imagem, no caso particular, ao teor de umidade dos solos. As técnicas utilizadas podem ser agrupadas em 3 categorias: as razões, as técnicas de transformação (Tasseled Cap e Análise de Componentes Principais) e as razões das diferenças normalizadas (NDVI, SAVI e o NDMI).

\subsubsection{Reamostragem espacial}

As 14 bandas espectrais do ASTER não possuem a mesma resolução espacial: a região do visível e do infravermelho próximo (VNIR), correspondendo às bandas 1, 2 e 3, possuem resolução de 15 metros. As bandas do infravermelho médio (bandas 4 a 9 - SWIR) possuem resolução espacial de 30m. As imagens do infravermelho termal (TIR), correspondentes às 
bandas 10 à 14, que não foram utilizadas neste trabalho, possuem resolução espacial de 90m, além de terem uma resolução radiométrica de 12 bits, ao contrário das demais que são de 8 bits. A maioria dos métodos de processamento de imagem necessita que os pixels tenham o mesmo tamanho para todas as bandas, devido que as operações aritméticas se baseiam no tamanho da célula da matriz (imagem). Assim, para processar as imagens, foi necessário alterar o tamanho da resolução de pixels de regiões espectrais diferentes. Foram feitas duas alterações: na primeira, os pixels das imagens do VNIR foram reamostradas de $15 \mathrm{~m}$ para $30 \mathrm{~m}$. As imagens com pixels com $30 \mathrm{~m}$ foram utilizadas na maioria dos processamentos, inclusive a classificação. Uma segunda reamostragem foi realizada, onde os pixels do SWIR, de $30 \mathrm{~m}$, foram reamostrados para $15 \mathrm{~m}$. Estas imagens foram utilizadas na Transformação Tasseled Cap (TTC) do ASTER. Como para este processamento foi necessário realizar uma operação de realce linear nas imagens, devido a influência da bruma atmosférica nos canais visíveis, além de transformar os dados para reflectância relativa para normalizar o resultados para as duas regiões espectrais, preferiu-se então reamostrar todas as imagens para $15 \mathrm{~m}$ devido a importância das informações contidas nos canais visíveis neste processamento.

\subsubsection{Realce linear}

Para a elaboração do TTC, transformaram-se os números digitais (ND) das imagens para valores de reflectância relativa. É necessário transformar os dados do ND em reflectância por 2 motivos: devido a interferência da atmosfera nos dados do espectro visível (canais 1 e 2); e pela recomendação metodológica (Crist, 1985) para haver uma uniformização dos resultados (San et al., 2004). Entretanto, este procedimento não era indispensável, posto se estar trabalhando apenas com uma cena de uma única data, mas preferiu-se assim proceder para uniformizar o resultado e remover os possíveis efeitos atmosféricos, comum nos canais visíveis, principalmente na área de estudo que possui elevada nebulosidade (Crist, 1985).

Para isto, utilizou-se uma técnica bastante simples, com a aplicação de um realce linear ("stretch") como proposto por Crane (1971). Subtraiu-se, de cada banda, o valor mínimo do ND e, em seguida, dividiu-se pelo valor máximo. Os valores mínimos e máximos foram indicados pelos valores de cada histograma.

\subsubsection{Análise exploratória dos dados}

A primeira etapa do trabalho foi a análise exploratória dos dados, necessária para conhecer e caracterizar cada uma das bandas quanto à freqüência e distribuição dos níveis de 
cinza das imagens, das amostras e das classes selecionadas, com suas respectivas médias e variâncias e outros parâmetros estatísticos importantes para se conhecer o comportamento da(s) amostra(s) e, posteriormente referenciar a análise dos resultados. A análise exploratória dos dados foi aplicada tanto nas imagens, como nos dados tabulares gerados no decorrer do processamento. As técnicas exploratórias utilizadas foram a construção e a análise de histogramas, boxplots, e diagramas de dispersão, além das características estatísticas básicas (valor mínimo, máximo, média, desvio padrão, variância).

\subsubsection{Análise de componentes principais}

A primeira das técnicas utilizadas foi a análise de componentes principais (ACP), considerada uma das técnicas mais valiosas no processamento digital de imagens, seja como análise exploratória dos dados, que se apresenta como o melhor extrator de características lineares conhecidas, seja na redução da dimensionalidade dos dados. Essa transformada, também conhecida como transformada de Hotelling e por expansão de Karhunen-Loève, é amplamente utilizada pela comunidade de reconhecimento de padrões como teorema espectral (Jain et al., 2000).

Através da ACP avaliou-se a correlação entre bandas, e identificou-se a contribuição de cada uma delas na formação das componentes, podendo-se assim, descobrir quais as bandas mais importantes para a visualização dos aspectos dos solos, assim como quais elementos descartar na composição. A partir desta análise, selecionou-se a componente que tivesse suas cargas mais significativas formadas pelas bandas selecionadas para analisar os solos e avaliar suas potencialidades para identificar os diferentes teores de umidade dos solos.

A ACP foi realizada com as bandas ASTER de 1 a 9, com resolução espacial de 30m, utilizando-se a matriz de correlação das bandas.

\subsubsection{Razão entre bandas}

Nesta seção, foram geradas razões entre as bandas do ASTER buscando uma combinação satisfatória para análise do teor de água nos solos. Em particular, testou-se a premissa de que a razão das bandas 1, 2 e 3 (VNIR) para com as bandas 4, 5, 6, 7, 8, e 9 (SWIR) e, especificamente da banda 4 com a 5, aumentam com o teor de água (Curcio e Petty, 1951; Musick e Pellitier, 1986).

A aplicação da razão entre bandas nos estudos de teor de umidade dos solos baseia-se no fato de que a razão de bandas entre o visível e o infra-vermelho próximo ou de ondas 
curtas tende a aumentar com o teor de água, assim como a razão entre o infravermelho próximo e o infravermelho médio (SWIR). A análise do levantamento bibliográfico, juntamente com os dados obtidos na análise exploratória, indica as razões de bandas a serem exploradas.

O método da razão entre bandas requer que as bandas respondam diferentemente ao aumento do teor de umidade. Como o teor de água diminui a reflectância em todos os comprimentos de onda, torna-se necessário então, o uso de um grande contraste nesta taxa de redução. A reposta para o teor de umidade é muito similar no visível e no infravermelho próximo até aproximadamente $1.3 \mu \mathrm{m}$. Então, a resposta da razão entre as bandas desta região espectral é descartada como indicadora do teor de umidade (Reginato et al, 1977; Musick e Pellitier, 1986). A forte absorção da luz pela água na região espectral acima de $1.3 \mu \mathrm{m}$ (Curcio e Petty, 1951) sugere que o contraste, utilizando-se os comprimento de ondas acima de $1.3 \mu \mathrm{m}$ devem responder ao teor de umidade. O pico de absorção da água em $1.45 \mu \mathrm{m}$ e $1.95 \mu \mathrm{m}$ responde mais fortemente ao teor de água no solo (Bowers e Hanks, 1965; Skidmore et al., 1975; Musick e Pelletier, 1986), mas a absorção pelo vapor de água na atmosfera impede o uso destes comprimentos de onda no sensoriamento remoto (Jensen, 2000). As bandas $4(1.600-1.700 \mu \mathrm{m})$ e a banda $5(2.145-2.185 \mu \mathrm{m})$ são menos fortemente afetadas pelo vapor de água na atmosfera, mas são fortemente afetadas pela proximidade das bordas das bandas adjacentes, de absorção de água líquida (Curcio e Petty, 1951; Sim et al, 2004), sendo que a banda 5 é mais fortemente influenciada por conter o pico de absorção da hidroxila (Figura 3.6 e 3.7).

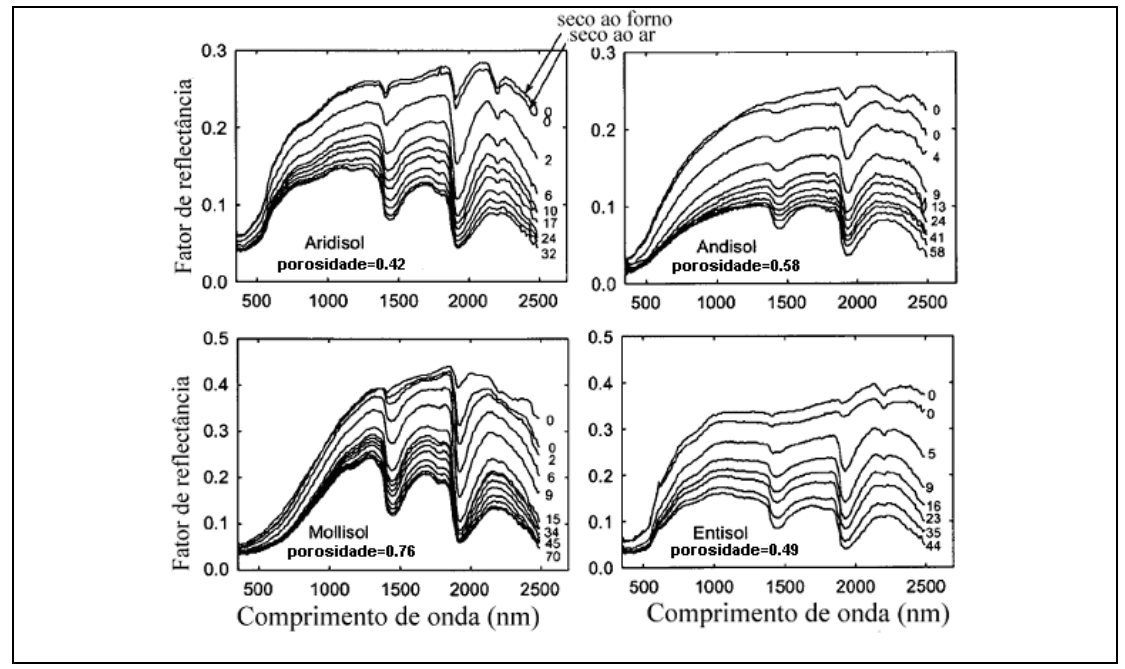

Figura 3.6 - Espectro obtido em laboratório de 4 solos com diferentes teores volumétricos de água $(\theta)$. Valores de $\theta$ em percentagem por volume são indicados junto ao respectivo espectro. (Lobel e Asner, 2002) 


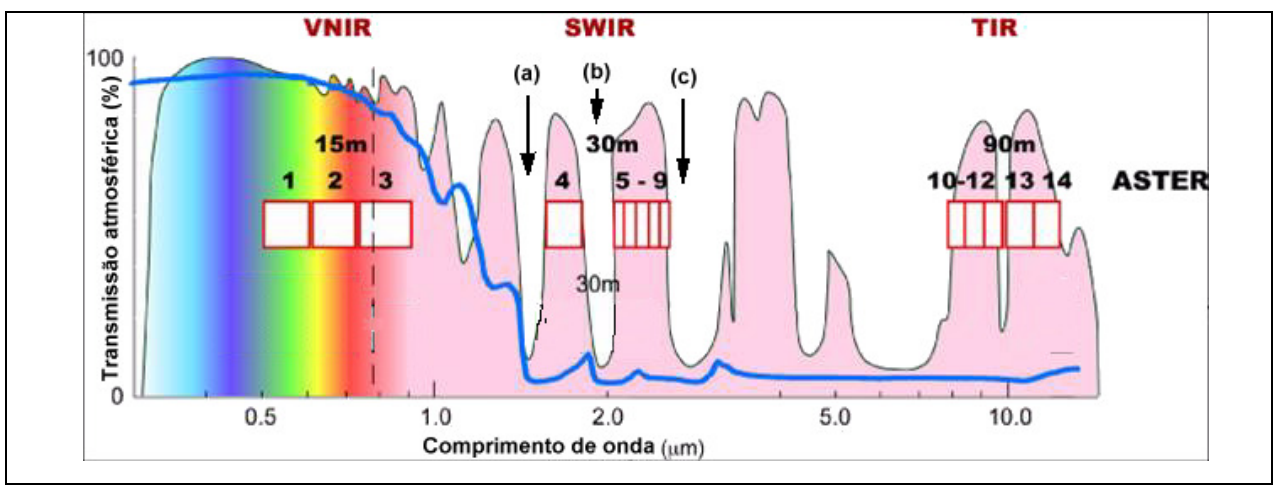

Figura 3.7 - Distribuição das bandas do sensor ASTER no espectro eletromagnético. A letras (a), (b) e (c), representam respectivamente os picos de absorção de água líquida de 1.45 $\mu \mathrm{m}, 1.95 \mu \mathrm{m}$ e 2.7 $\mu \mathrm{m}$ (Fonte: JPL/NASA, 2005. Adaptado por Santos, 2005).

As razões de bandas que envolvam o infravermelho médio (bandas de 4 a 9) e, em particular as bandas 4 e 5 e, em menor proporção a banda 9 , e as razões ente as bandas 4/5, 4/9 e 5/9 deveriam fornecer um aumento da razão numa proporção direta com o teor de água. Esta hipótese se apóia no comportamento das curvas de reflectância dos solos pela variação do teor de umidade (Bowers e Hanks, 1965) e pela comparação entre os comprimentos de onda de menor reflectância sobre a umidade (Peterson e Baumgardner, 1981).

Assim, realizou-se 21 razões de bandas entre as bandas VNIR e SWIR, segundo a Tabela a seguir:

Tabela 3.2 - Razões de bandas entre as bandas VNIR e SWIR do sensor ASTER para detecção do teor de água

\begin{tabular}{c|c}
\hline Numerador & Denominador \\
\hline 1 & 4 \\
\hline & 5 \\
\hline & 6 \\
\hline & 7 \\
\hline & 8 \\
\hline 2 & 9 \\
\hline & 4 \\
\hline & 5 \\
\hline & 6 \\
\hline & 7 \\
\hline & 8 \\
\hline 3 & 9 \\
\hline & 4 \\
\hline & 5 \\
\hline & 6 \\
\hline & 7 \\
\hline 4 & 8 \\
\hline & 9 \\
\hline 5 & 5 \\
\hline & 9 \\
\hline
\end{tabular}




\subsubsection{6 Índices espectrais}

A elaboração dos índices espectrais seguiu os princípios determinados na literatura, principalmente tomando-se como referência o sensor Landsat. Por este motivo, a maioria dos índices aqui citados tiveram que ser adaptados ao sensor ASTER.

\subsection{NDVI}

O NDVI (Normalized Difference Vegetation Index - İndice de Vegetação da Diferença Normalizada) foi realizado com as bandas 3 (NIR) e 2 (Vermelho), com as imagens com 30m de resolução, segundo a equação abaixo:

$$
N D V I=\frac{B a n d a(3)-B a n d a(2)}{B a n d a(3)+B a n d a(2)} \quad(\text { Equação 3.1) }
$$

\subsection{SAVI}

Sendo o SAVI (Soil Adjusted Vegetation Index - Índice de vegetação ajustado ao solo) similar ao NDVI, foi realizado seguindo o mesmo procedimento, sendo que o fator de ajuste do solo adotado (fator " $\boldsymbol{L}$ ") igual a 0.5 , correspondendo a uma cobertura vegetal intermediária, como já discutido no Capítulo 2 (item 2.4.1.4.1.2), a vegetação nesta área apresenta diferentes graus de cobertura, variando de muito densa $(\mathrm{L}=0.25)$, até ausente ou solo exposto $(\mathrm{L}=0)$. Assim o SAVI se apresenta, segundo a Equação 3.2, apresentada a seguir.:

$$
S A V I=\frac{\text { Banda }(3)-\operatorname{Band} a(2)}{B a n d a(3)+B a n d a(2)+0.5}(1+0.5)
$$

(Equação 3.2)

\subsection{NDMI}

O NDMI (Normalized Difference Moisture Index - Ìndice de Umidade da Diferença Normalizada) é um dos muitos índices derivados do NDVI, sendo, entretanto, uma relação entre o NIR e a primeira das bandas do infravermelho médio (SWIR). Então, para as bandas ASTER, o NDMI ficou assim estruturado:

$$
N D M I=\frac{B a n d a(3)-B a n d a(4)}{B a n d a(3)+B a n d a(4)} \quad(\text { Equação 3.3) }
$$




\subsection{Tasseled Cap}

O grande aumento de informação advinda dos sensores multi e hiperespectrais, provenientes do aumento das resoluções espaciais, espectrais e radiométricas, têm aumentado substancialmente o volume de dados e sua complexidade, ambos considerados obstáculos ou dificultadores para uma extração eficiente das informações contidas nos dados. Como resultado, numerosos métodos são empregados, sejam novos ou já comprovadamente testados há muito tempo, visando a transformação destes dados, derivando feições que são mais fáceis de serem manipuladas (menos volume) ou mais fácil de serem interpretadas (menos complexas). Destes métodos, podemos destacar a diferença e a razão entre bandas, a análise de componentes principais e o Tasseled Cap e outras tantas combinações lineares de bandas que são aplicadas sobre os dados multiespectrais, com diferentes graus de sucesso, como os citados anteriormente (NDVI, SAVI, etc).

As transformações do Tasseled Cap, também chamada de transformação KT (iniciais dos autores Kauth e Thomas, que a desenvolveram em 1976) foram utilizadas inicialmente no sensoriamento remoto, sobre imagens do Landsat Multspectral Scanner (MSS) e Thematic Mapper (TM) (Kauth e Thomas, 1976; Crist e Cicone, 1984) e representa um claro exemplo de combinações lineares de feições. Apesar de sua aceitação, seu uso é muito restrito, principalmente pela pouca compreensão do processo, mau uso da aplicação das transformações, aplicação incorreta dos seus conceitos básicos sobre os novos sensores, ou hesitação do uso destas transformações devido ao seu aparente mistério. (Crist e Kauth, 1986). Entretanto, seu conceito é bem simples: efetivamente, a Tasseled Cap é uma transformação de coordenadas pela mudança dos eixos, similar a extração das componentes principais $(\mathrm{CP})$, embora não lhe seja equivalente, posto que os coeficientes da Transformação Tasseled Cap (TTC) são obtidos de dados independentes através das ortogonalizações sucessivas dos eixos através do processo de Gram-Schimdt, gerando índices independentes de cena (Gleriani et al, 2003; Jackson, 1983).

Para a geração dos coeficientes da TTC, existe na literatura uma variedade de procedimentos. Utilizou-se o método proposto por Jackson, (1983) que partindo da forma básica e bidimensional denominada de índice de vegetação perpendicular (PVI), proposto por Richardson e Wiegand (1977), generaliza este conceito para índices no espaço n-dimensional (Figura 3.8).

Os índices espectrais em $n$-espaço, podem ser definidos como valores medidos pela projeção de dados pontuais nos eixos com direções vetoriais apropriadas (Figura 3.9). Eles 
são um tipo de transformações ortogonais, e os eixos transformados são determinados para representar padrões espectrais específicos (Jackson, 1983). Em geral, o $m_{\text {-enésimo índice }}$ espectral no $n_{\text {-espaço }}(m \leq n)$ para o $i_{\text {-enésimo }}$ pixel $\left.{ }_{m} Y_{i}\right)$ pode ser dado pela seguinte fórmula.

$$
{ }_{m} Y_{i}={ }_{m} A_{1} X_{1 i}+{ }_{m} A_{2} X_{2 i}+\ldots+{ }_{m} A_{n} X_{n i} \quad \text { (Equação 3.4) }
$$

Onde $\boldsymbol{n}$ é o número total de bandas espectrais, ${ }_{m} A_{n}$ é o coeficiente de transformação dos dados da $n$-enésima banda para o $m_{\text {-enésimo }}$ índice espectral, e $\mathrm{X}_{n i}$ é o $i_{\text {-enésima }}$ pixel de uma $n_{\text {-enésimo }}$ banda. Através do uso das 9 bandas do Áster, abrangendo a região do $0,42 \mu \mathrm{m}$ a 2,43 $\mu \mathrm{m}$ (bandas 1 a 9) determinou-se os três principais índices espectrais, como preconizado por Kauth e Thomas (1976), extrapolado para o espaço n-dimensional por Jackson (1983) e adaptado para o Landsat TM por Crist (1984):

- índice de brilho

- índice de verde

- índice de umidade

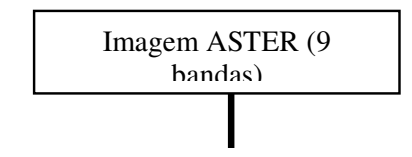
Escolha das áreas de coleta das
amostras de solo seco, solo
úmido, vegetação verde e vegetação senescente

Obtenção das amostras de reflectância de solo seco, solo úmido, vegetação verde e vegetação senescente na imagem ASTER

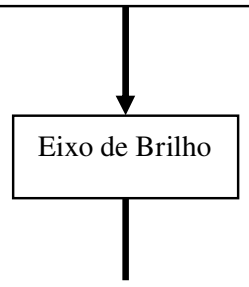

Método de ortogonalização de Gram-Schmidt

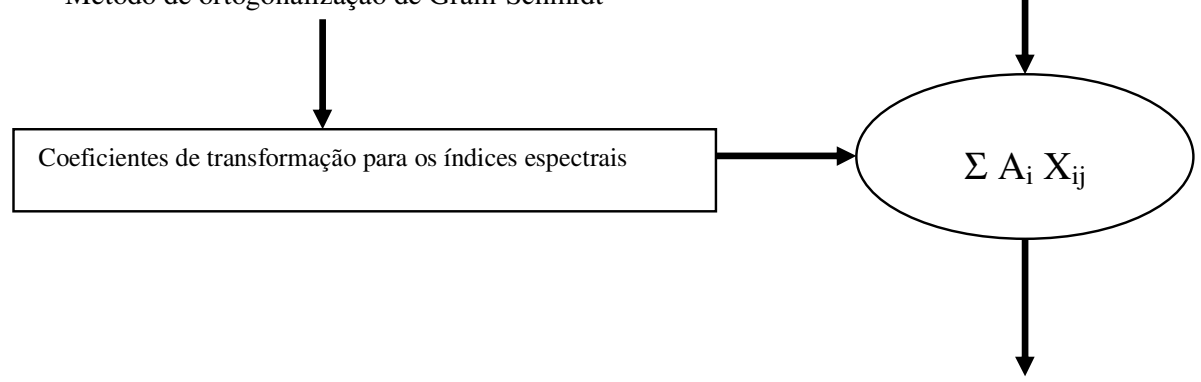

Imagem dos índices espectrais

Figura 3.8 - Diagrama metodológico de elaboração do Tasseled Cap 


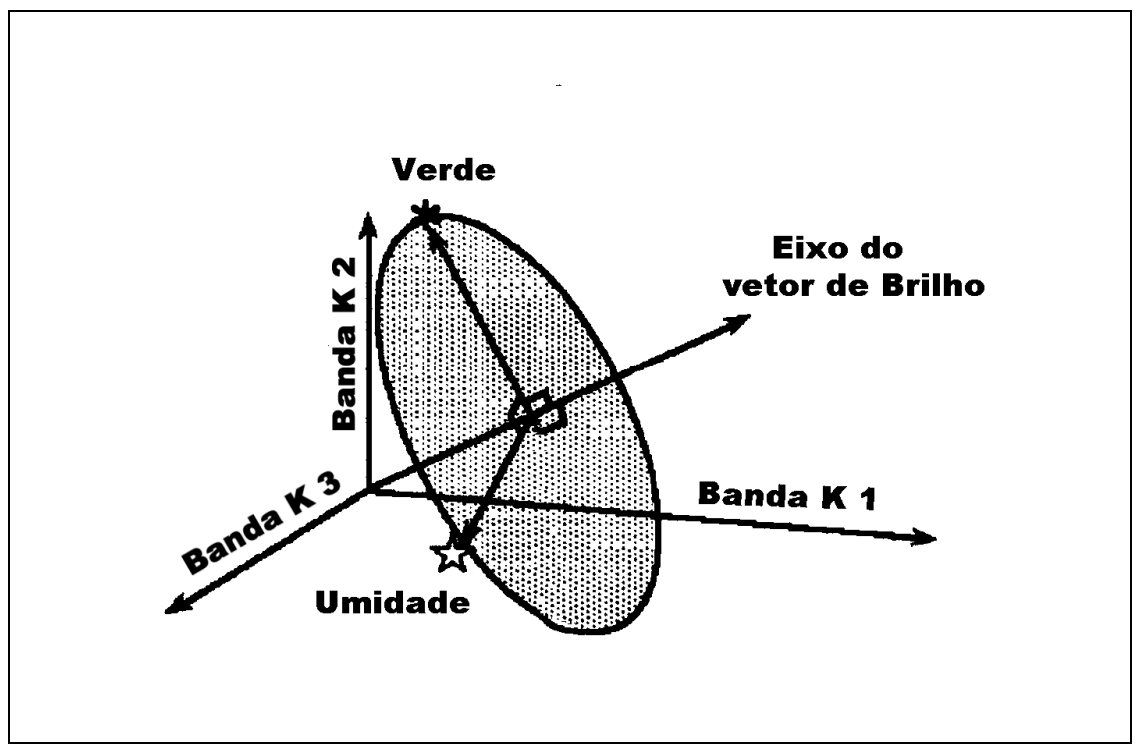

Figura 3.9 - Diagrama esquemático mostrando a relação do Brilho com os eixos do Verde e da Umidade para os índices espectrais, todos ortogonais entre si. (Adaptado de Yamaguchi e Naito, 2003)

Os índices espectrais podem ser produzidos pela simples aplicação dos coeficientes de transformação sobre dados de reflectância da superfície. Entretanto, neste método, dois pontos importantes se destacam: O primeiro é a geração dos coeficientes para os índices espectrais e o segundo é a conversão dos dados de números digitais (níveis de cinza) para reflectância.

Para este processamento, utilizou-se as imagens reamostradas para $15 \mathrm{~m}$, segundo procedimento sugerido por San et al (2003).

As imagens, por sua vez, foram analisadas em seus respectivos histogramas para se obter os valores máximos e mínimos de cada banda para realizar a conversão em reflectância relativa, segundo técnica proposta por Crane (1971), e aplicada por San et al. (2004).

As amostras necessárias para realizar a TTC foram coletadas (Figura 3.10) segundo indicado no item a seguir.

\subsection{Amostragem para a Transformação Tasseled Cap e obtenção das amostras-teste}

Foram coletadas 54 amostras, divididas em quatro grupos principais: solos úmidos (SU), solo seco (SS), vegetação verde (VV) e vegetação senescente (VS). Estas amostras foram escolhidas tendo como principal objetivo, avaliar as diferentes respostas apresentadas por elas, nas imagens resultantes de diferentes processamentos (ACP, Razão entre bandas, Índices Espectrais), assim como servir de base para realizar a Transformação Tasseled Cap (TTC) para o ASTER, segundo o método proposta por Jackson (1983). Estes mesmos pontos 
amostrais serviram de amostras-teste para correlacionar os resultados obtidos nos diferentes processamentos.

As amostras de solo (seco e úmido) foram selecionadas tomando-se por base a interpretação visual da banda $4(1.6$ a $1.7 \mu \mathrm{m})$, que melhor responde à reflectância dos solos expostos, sendo o maior valor de reflectância associado aos solos secos e os menores aos solos úmidos. As amostras de vegetação foram coletadas através da interpretação visual da composição colorida (RGB: 432), sendo a vegetação verde amostrada em áreas de floresta densa e a de vegetação senescente, correspondente à caatinga, observada na região nordeste da imagem.

Para a área efetiva total do trabalho, não se considerou o descarte das nuvens e sombras, posto que, embora os diversos tipos de processamento fossem aplicados em toda a imagem, a avaliação dos resultados seriam pontuais, em áreas de amostra-teste previamente escolhidas, baseadas na interpretação visual.

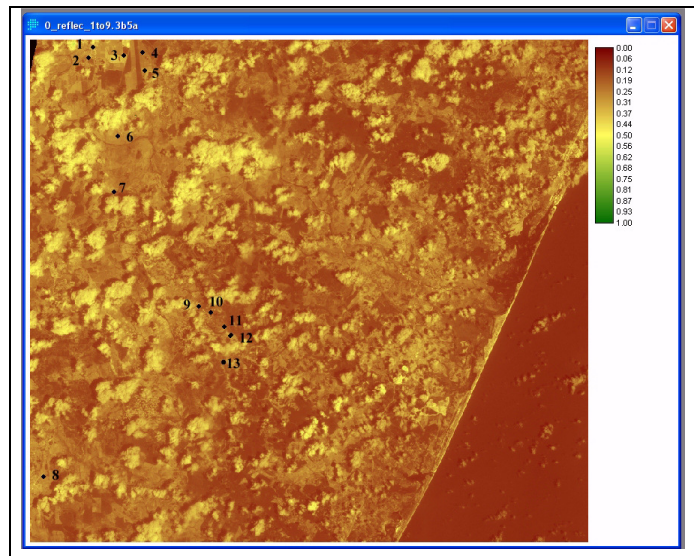

(a) Solo seco

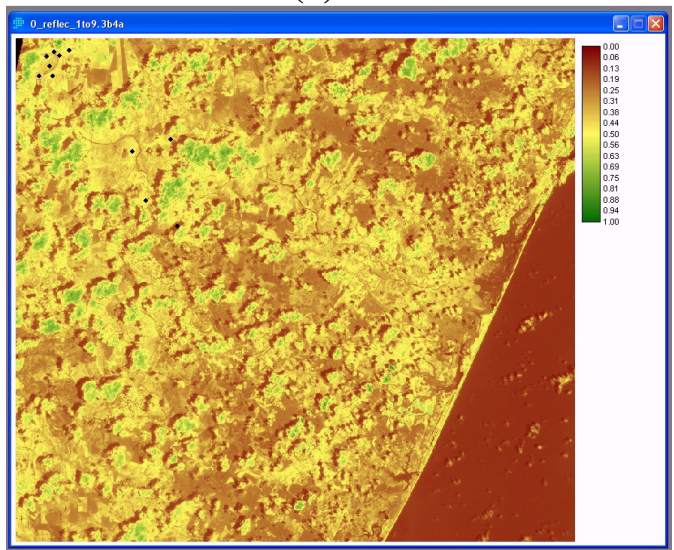

(c)Vegetação Seca

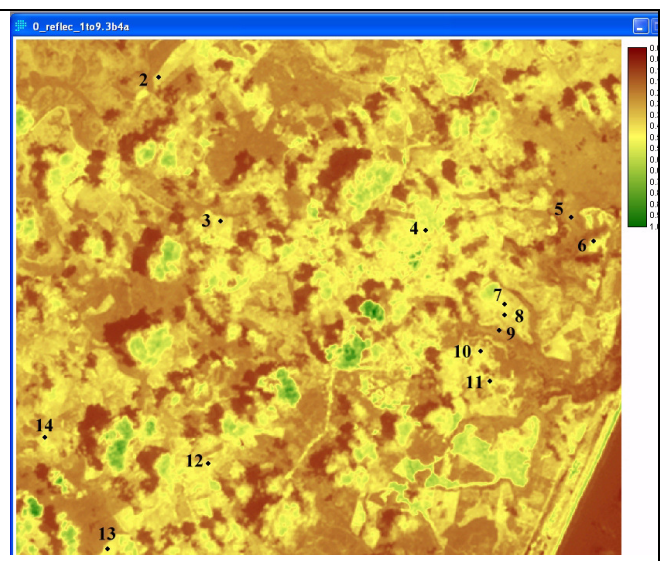

(b) Solo úmido

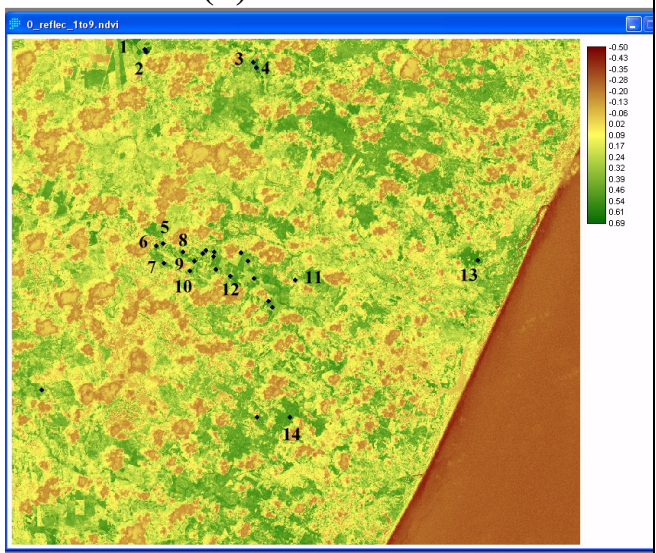

(d) Vegetação úmida 
Figura 3.10 - Amostras coletadas para elaboração da Transformação Tasseled Cap

\subsubsection{Aplicações}

Neste subítem iremos definir a técnica de classificação, o processo de amostragem da classificação e a comparação e validação dos resultados.

\subsubsection{Algoritmo de classificação}

Foi escolhido para este trabalho o classificador da máxima verossimilhança (MaxVer) por seu desempenho, por ser um classificador robusto, bastante utilizado, de experiência comprovada e extensa bibliografia.

Utilizou-se como limiar de aceitação 95\%, ou seja, que apenas 95\% de "pixels" da distribuição de probabilidade para uma dada classe que será classificada como pertencente à esta classe, sendo que 5\% serão ignorados (os de menor probabilidade), compensando a possibilidade de alguns "pixels" terem sido introduzidos no treinamento por engano, nesta classe, ou estarem no limite entre duas classes (INPE, 2003).

\subsubsection{Amostragem para a classificação}

Como a disponibilidade de informações detalhadas sobre os solos era disponível apenas para a área de referência (verdade de campo), a classificação da imagem, foi realizada apenas sobre o recorte desta área.

A área da classificação caracteriza-se por ser de relevo aplainado, com variação altimétrica entre $101 \mathrm{~m}$ a $135 \mathrm{~m}$, próxima ao litoral, com a cultura de Eucaliptus sp. A área abrange vários projetos de silvicultura da Copener Florestal (Altamira I, II e III), que serviram de delimitante da área de referência. A área tem ao todo $29 \mathrm{~km}^{2}$. Entretanto, a presença de nuvens e sombras na imagem utilizada, restringiu a área útil para $26 \mathrm{~km}^{2}$.

\subsection{As unidades de solos de referência e a definição das classes de estudo}

Inicialmente se definiu a variável a ser identificada, que seria a existência e o nível da coesão dos solos nos diferentes tipos de solo reconhecidos no mapa da verdade de campo (Figura 3.11). Segundo o mapa de solos da área de referência, na área de referência existem 12 unidades distintas de solos (Quadro 1). Estas unidades foram associadas à presença/ausência e o tipo de horizontes coesos (Quadro 2). Por fim, foram reclassificadas 
segundo estes critérios, gerando o Quadro 3, que foram utilizadas como as unidades básicas deste estudo.

Quadro 3.1 - Descrição das unidades de mapeamento de solos da área

\begin{tabular}{|c|c|c|}
\hline Sigla & Nome & Descrição \\
\hline PAd 1 & $\begin{array}{c}\text { Podzólico Amarelo } \\
\text { distrófico }\end{array}$ & $\begin{array}{c}\text { Podzólico Amarelo distrófico Tb A moderado textura } \\
\text { arenosa/média relevo plano }\end{array}$ \\
\hline PAd 4 & $\begin{array}{c}\text { Podzólico Amarelo } \\
\text { distrófico }\end{array}$ & $\begin{array}{c}\text { Podzólico Amarelo distrófico e álico Tb com fragipan A fraco } \\
\text { textura arenosa/média e arenosa/argilosa relevo plano }\end{array}$ \\
\hline PAd 7 & $\begin{array}{c}\text { Podzólico Amarelo } \\
\text { distrófico }\end{array}$ & $\begin{array}{c}\text { Podzólico Amarelo distrófico e álico Tb A moderado textura } \\
\text { média/argilosa relevo plano }\end{array}$ \\
\hline PAd 9 & $\begin{array}{c}\text { Podzólico Amarelo } \\
\text { distrófico }\end{array}$ & $\begin{array}{c}\text { 'Podzólico Amarelo distrófico e álico Tb A moderado textura } \\
\text { média/argilosa relevo suave ondulado e plano }\end{array}$ \\
\hline PAd 12 & $\begin{array}{c}\text { Podzólico Amarelo } \\
\text { distrófico }\end{array}$ & $\begin{array}{l}\text { 'Podzólico Amarelo distrófico e álico Tb com fragipan e/ou } \\
\text { "ironpan" A moderado textura média/argilosa relevo plano }\end{array}$ \\
\hline PAd 19 & $\begin{array}{l}\text { Podzólico Amarelo } \\
\text { distrófico }\end{array}$ & $\begin{array}{c}\text { Associação de Podzólico Amarelo distrófico e álico Tb com } \\
\text { fragipan e/ou "ironpan" A moderado textura média/argilosa } \\
\text { relevo plano + Podzólico Amarelo distrófico e álico Tb A } \\
\text { moderado textura argilosa relevo plano }\end{array}$ \\
\hline PAd 21 & $\begin{array}{l}\text { Podzólico Amarelo } \\
\text { distrófico }\end{array}$ & $\begin{array}{c}\text { Associação de Podzólico Amarelo distrófico e álico Tb com } \\
\text { fragipan e/ou "ironpan" A moderado textura arenosa/média } \\
\text { relevo plano suave ondulado + Podzólico Amarelo distrófico e } \\
\text { álico Tb pouco profundo A moderado textura arenosa/média } \\
\text { relevo suave ondulado }\end{array}$ \\
\hline PAd 61 & $\begin{array}{c}\text { Podzólico Amarelo } \\
\text { distrófico }\end{array}$ & $\begin{array}{l}\text { Podzólico Amarelo distrófico e álico Tb adensado com } \\
\text { mosqueado A moderado textura média/argilosa relevo plano. }\end{array}$ \\
\hline PCd 9 & $\begin{array}{c}\text { Podzólico Acinzentado } \\
\text { distrófico }\end{array}$ & $\begin{array}{l}\text { Podzólico Acinzentado distrófico e álico Tb A moderado } \\
\text { textura média/argilosa relevo plano }\end{array}$ \\
\hline PCd 16 & $\begin{array}{l}\text { Podzólico Acinzentado } \\
\text { dsitrófico }\end{array}$ & $\begin{array}{c}\text { Podzólico Acinzentado distrófico e álico Tb com fragipan e/ou } \\
\text { "ironpan" A fraco e moderado textura arenosa/média relevo } \\
\text { plano }\end{array}$ \\
\hline P 6 & Podzol & $\begin{array}{c}\text { Podzol com duripan A fraco e moderado espesso textura } \\
\text { arenosa/média relevo plano de tabuleiro }\end{array}$ \\
\hline P 7 & Podzol & $\begin{array}{c}\text { Podzol com duripan A moderado textura arenosa/média relevo } \\
\text { plano de baixada }\end{array}$ \\
\hline
\end{tabular}


Quadro 3.2- Classificação das unidades dos solos segundo presença e tipo de horizonte coeso

\begin{tabular}{|c|c|c|}
\hline Sigla & Nome & Presença e tipo de horizonte coeso \\
\hline PAd 1 & Podzólico Amarelo & Sem coesão \\
\hline PAd 4 & Podzólico Amarelo & Sem coesão \\
\hline PAd 7 & Podzólico Amarelo & Sem coesão \\
\hline PAd 9 & Podzólico Amarelo & Fragipan \\
\hline PAd 12 & Podzólico Amarelo & Fragipan \\
\hline PAd 19 & Podzólico Amarelo & Fragipan \\
\hline PAd 21 & Podzólico Amarelo & Sem coesão \\
\hline PAd 61 & Podzólico Amarelo & Sem coesão \\
\hline PCd 9 & Podzólico Acinzentado & Fragipan \\
\hline PCd 16 & Podzólico Acinzentado & Duripan \\
\hline P 6 & Podzol & Duripan \\
\hline P 7 & Podzol & \\
\hline
\end{tabular}

Quadro 3.3 - Reclassificação das unidades de solo segundo a presença e o tipo de coesão

\begin{tabular}{|c|c|}
\hline Sigla & Nome \\
\hline P & Podzol com duripan \\
\hline PA & Podzólico Amarelo sem coesão \\
\hline PAf & Podzólico Amarelo com fragipan \\
\hline PC & Podzólico Acinzentado sem coesão \\
\hline PCf & Podzólico Acinzentado com fragipan \\
\hline
\end{tabular}


Figura 3.11 - Imagem ASTER - cena completa, de 18/11/2002 (à esquerda), com destaque da área de referência (em verde), apresentada ampliada à direita. Composição colorida RGB - 321.

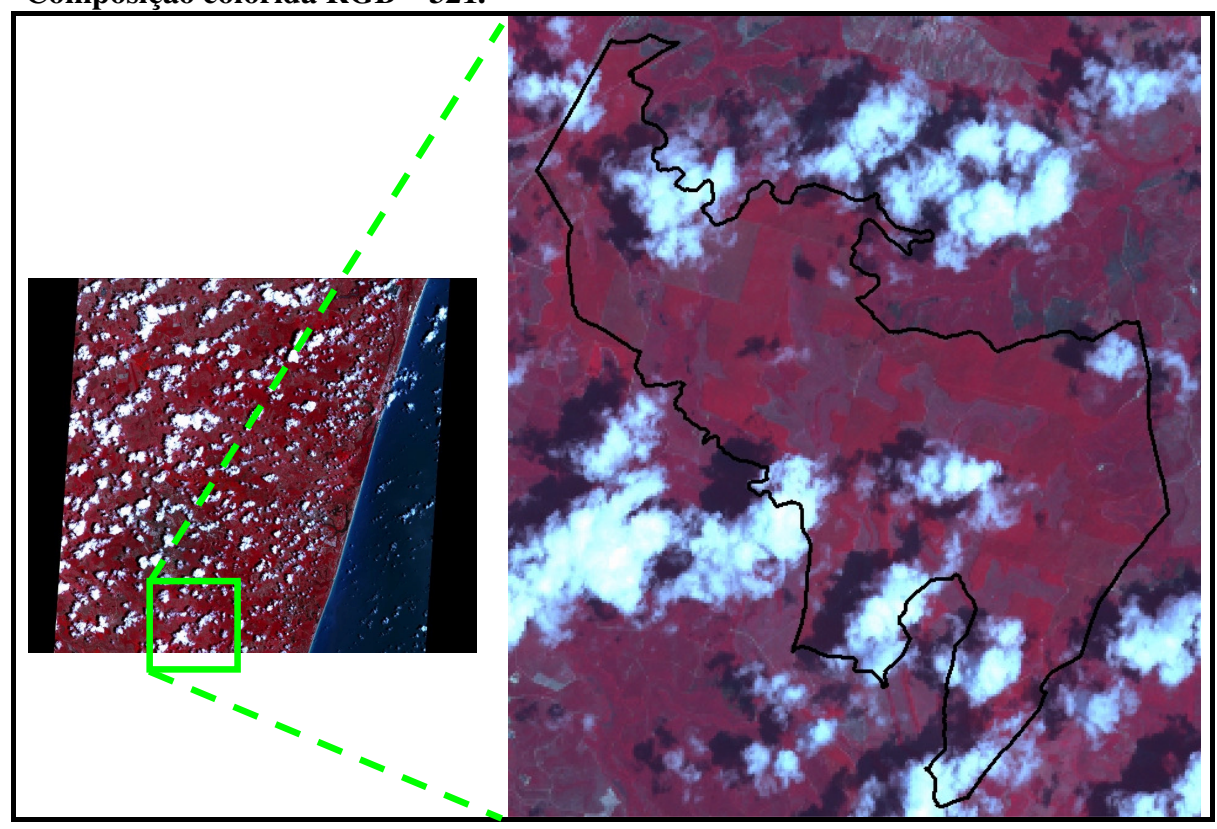

\subsection{Definição da área de estudo}

Com a definição da área para a classificação sendo restrita à área de referência (verdade e campo), a etapa seguinte foi a avaliação da imagem para a determinação da área útil de trabalho, decorrente da extensa presença de nuvens e sombras de nuvens na área e a determinação da área de amostragem e tamanho das amostras.

\subsection{Das nuvens e sombras}

O problema da cobertura de nuvens e/ou sombras na imagem escolhida pode ser observado facilmente (Figura 3.5 e 3.11). Em primeira instância, percebe-se que sua área de abrangência é inferior a $50 \%$ e superior a 20\%. Nas etapas de pré-processamento, a configuração e distribuição das nuvens não representaram problemas significativos, posto que se trabalhou com amostras pontuais, escolhidas visualmente, a partir das quais se coletou os dados e montou-se a matriz dos resultados. Entretanto, a questão da presença das nuvens e sombras se fez significativa na segunda etapa do trabalho, quando da classificação da imagem. Optou-se então, nesta etapa, por se considerar apenas a área de referência (área da imagem que corresponde ao mapa de solos 1:10.000), onde se conhecia o mapeamento dos 
solos em escala detalhada. A segunda questão foi então se iria se considerar os elementos "nuvens" e "sombras" como classes na classificação ou se seriam excluídos. Optou-se pela exclusão. A partir daí, avaliou-se qual a técnica que seria considerada. Inicialmente optou-se por um processo exclusivamente espectral: escolhendo-se uma banda onde as nuvens e sombras fossem melhor visualmente determinadas (2-VNIR), realizou-se um "saturamento" através do histograma da imagem (NC maior que 110 e NC menor que 36), zerando estes valores, permanecendo os valores compreendidos entre o intervalo de 36 a 115. Entretanto, este critério revelou-se insatisfatório, principalmente porque os valores do limite superior (NC 110), correspondente à nuvens, estavam se confundindo com outros elementos do solo como solo exposto e estrada. Então, assumiu-se um procedimento mais rigoroso, baseado exclusivamente na interpretação visual. Adotou-se como cenário a pior ocorrência possível, identificou-se as feições de nuvens e sombras (Figura 3.12 (b)) e sobre elas construíu-se uma máscara de exclusão a qual foi subtraída da imagem. Assim, chegou-se a delimitação da área final, com 19.762 pixels, correspondendo à 64\% da área de referência (Figura 3.12 (c) e (d)), ou seja, as nuvens e sombras foram eliminadas, excluídas da área de classificação. Para os demais processos, os resultados foram analisados à partir dos pontos amostrais.

\subsection{Da amostragem na área de referência (verdade de campo)}

No quadro deste estudo optou-se por recolher amostras baseadas nas unidades de solos determinadas segundo descrito no item 3.6.2.2.1 (Quadro 3.3), que foram utilizadas para treinar e validar os classificadores quanto à presença e tipo de coesão do solo.

Primeiramente tivemos que avaliar a área real de trabalho, ou seja, excluindo as nuvens e as sombras. Esta etapa foi calculada utilizando a função "Tabulação Cruzada" do software Spring. No Anexo F pode se verificar a distribuição da área das unidades de solos quanto a área com nuvens e sombras e áreas efetivas disponíveis para classificação. Observase que a classe PAd4 é a mais extensa espacialmente, com um total de 4,5 $\mathrm{km}^{2}$, dos quais $1,61 \mathrm{~km}^{2}$ estão indisponíveis pela presença de nuvens e sombras, ficando efetivamente livres para a classificação $2,89 \mathrm{~km}^{2}$, correspondendo a $10 \%$ da área total disponível para classificação. A classe de menor extensão espacial é a PAd61 que possui apenas 0,30 km2, dos quais $0,11 \mathrm{~km}^{2}$ estão recobertos, ficando disponíveis apenas $0,19 \mathrm{~km}^{2}$, respondendo por apenas $0.28 \%$ da área total disponível para classificação. 
Figura 3.12 - Determinação da área de amostragem e de classificação efetiva da imagem
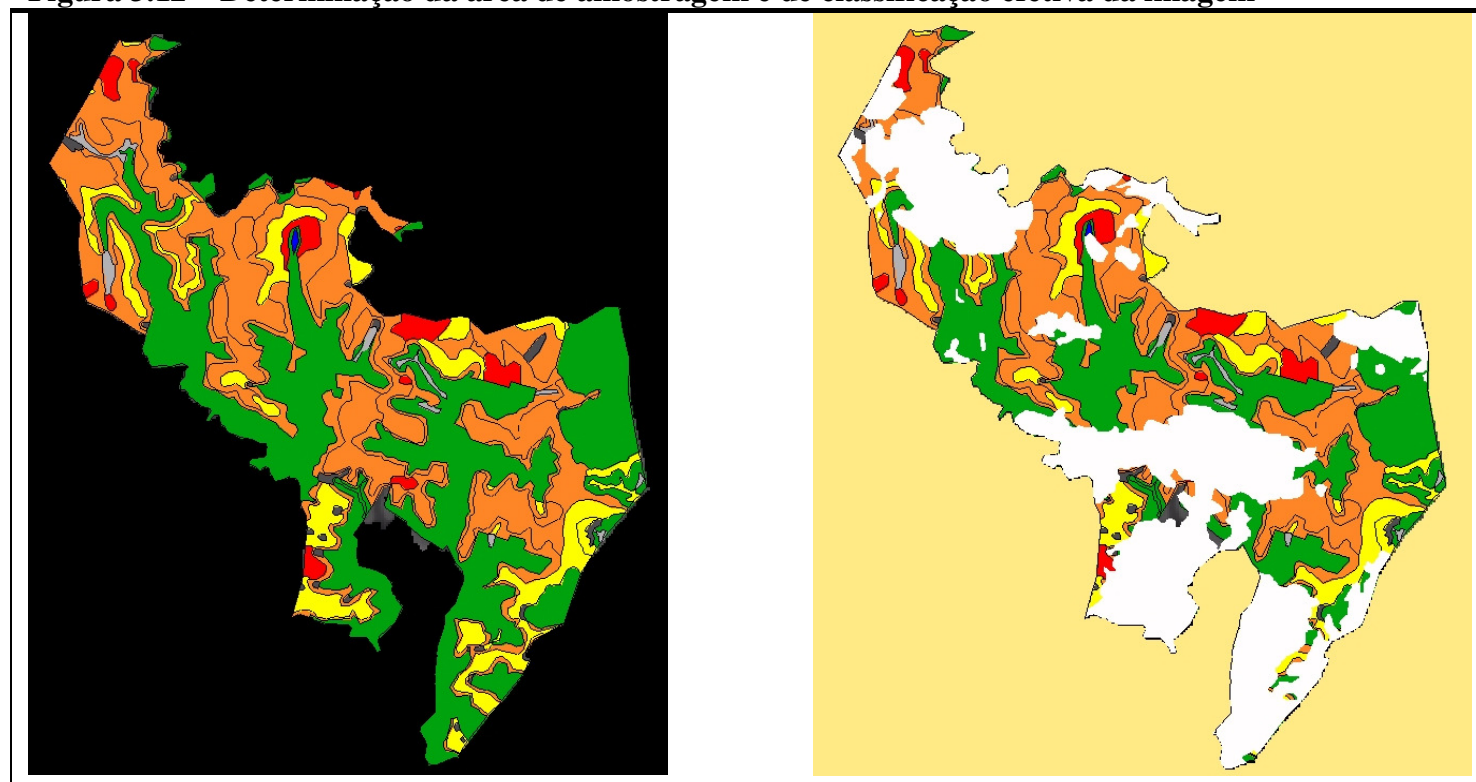

(a) Mapa das classes de solo (Escala $1: 10.000)$

(b) Em branco, áreas de cobertura de nuvens e/ou sombras, que foram excluídas da área de classificação
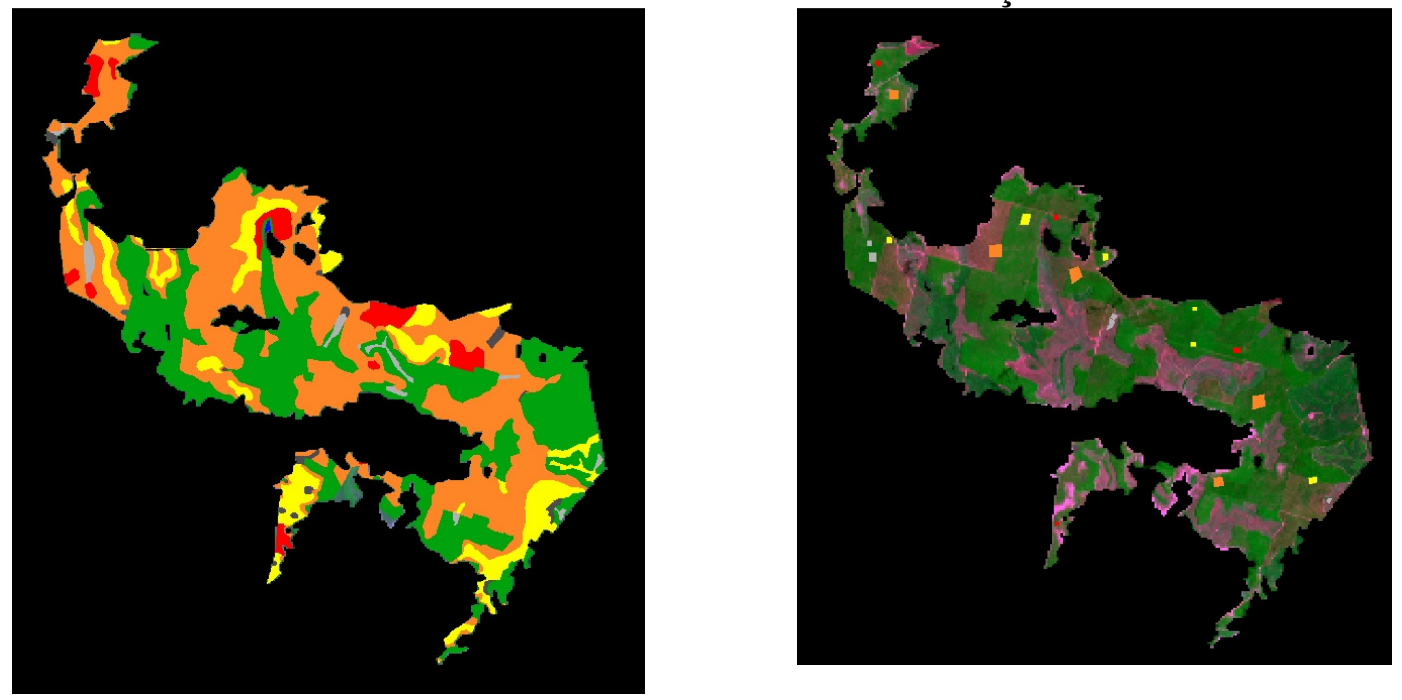

(c) Recorte do mapa de unidades de solos

(d) Recorte da imagem, com exclusão das nuvens e/ou sombras

\begin{tabular}{|c|}
\hline Podzólico Amarelo sem coesão \\
\hline Podzólico Amarelo com fragipan \\
\hline Podzólico Acinzentado sem coesão \\
\hline Podzólico Acinzentado com fragipan \\
\hline Podzol com duripan \\
\hline
\end{tabular}


A Tabela 3.3 detalha a área total, a cobertura de nuvens e a área efetiva considerando todas as 12 classes, enquanto a Tabela 3.4 expressa a área das classes de análise, utilizadas para a classificação. Assim, a classe de maior extensão espacial é o Podzólico Amarelo com fragipan (PAf), abrangendo uma área de $12,06 \mathrm{~km}^{2}$, das quais $3,96 \mathrm{~km}^{2}$ estão recobertos por sombras e/ou nuvens, restando $8,10 \mathrm{~km}^{2}$, perfazendo um total de $45.5 \%$ da área livre para classificação. A menor área corresponde ao Podzólico Acinzentado com fragipan, que apesar de possuir $0,30 \mathrm{~km}^{2}, 0,11 \mathrm{~km}^{2}$ estão recobertos por sombras e/ou nuvens, ficando livres apenas $0,19 \mathrm{~km}^{2}$, correspondentes a $1.1 \%$.

Tabela 3.3 - Área das unidades de solos: total, sob cobertura de nuvens e sombras e efetiva para classificação

\begin{tabular}{|c|c|c|c|}
\hline Unidade de solos & Área Total $\left(\mathrm{km}^{2}\right)$ & $\begin{array}{c}\text { Área sob cobertura de } \\
\text { nuvens e sombras }\left(\mathrm{km}^{2}\right)\end{array}$ & $\begin{array}{l}\text { Área efetiva para } \\
\text { Classificação }\left(\mathbf{k m}^{2}\right)\end{array}$ \\
\hline P6 & 0,55 & 0,11 & 0,44 \\
\hline P7 & 0,32 & 0,01 & 0,31 \\
\hline PAd1 & 1,02 & 0,27 & 0,75 \\
\hline PAd4 & 4,50 & 1,61 & 2,89 \\
\hline PAd7 & 0,01 & 0,00 & 0,01 \\
\hline PAd9 & 2,10 & 0,75 & 1,35 \\
\hline PAd12 & 3,85 & 1,53 & 2,32 \\
\hline PAd19 & 3,46 & 0,81 & 2,65 \\
\hline PAd21 & 0,25 & 0,01 & 0,24 \\
\hline PAd61 & 0,10 & 0,02 & 0,08 \\
\hline PCd9 & 0,32 & 0,08 & 0,24 \\
\hline PCd16 & 0,30 & 0,11 & 0,19 \\
\hline Água & 0,01 & 0,00 & 0,01 \\
\hline Área de Proteção & 11,57 & 5,26 & 6,31 \\
\hline $\begin{array}{lll}\text { Área } & \text { Total } & \text { das } \\
\text { Classes } & & \\
\end{array}$ & 28,36 & 10,57 & 17,79 \\
\hline
\end{tabular}

Tabela 3.4 - Área das Classes de Solos: total, sob cobertura de nuvens e sombras e efetiva para classificação

\begin{tabular}{l|c|c|c}
\hline Unidade de solos & Área Total $\left.\mathbf{( k m}^{\mathbf{2}}\right)$ & $\begin{array}{c}\text { Área sob cobertura de } \\
\left.\text { nuvens e sombras } \mathbf{( k m}^{\mathbf{2}}\right)\end{array}$ & $\begin{array}{c}\text { Área efetiva para } \\
\left.\text { Classificação } \mathbf{( k m}^{\mathbf{2}}\right)\end{array}$ \\
\hline PA & 3,23 & 1,04 & 2,19 \\
\hline PAf & 12,06 & 3,96 & 8,10 \\
\hline AC & 0,32 & 0,08 & 0,24 \\
\hline ACf & 0,30 & 0,11 & 0,19 \\
\hline P & 0,87 & 0,11 & 0,75 \\
\hline Água & 0,01 & 0,0 & 0,01 \\
\hline Área de Proteção & 11,57 & 5,26 & 6,31 \\
\hline $\begin{array}{c}\text { Área Total das } \\
\text { Classes }\end{array}$ & $\mathbf{2 8 , 3 6}$ & $\mathbf{1 0 , 5 7}$ & $\mathbf{1 7 , 7 9}$ \\
\hline
\end{tabular}


Assim, da área total da imagem que abrange o projeto Altamira (I, II e III), que corresponde a $28,36 \mathrm{~km}^{2}$, só foram efetivamente utilizados na classificação $17,79 \mathrm{~km}^{2}$, correspondendo a aproximadamente 63\% da área total (Anexo F).

\subsection{Número e dimensão dos polígonos amostrais na área de referência}

As amostras coletadas na área de referência foram a base principal de comparação da verdade de campo em todas as etapas do trabalho e da classificação da imagem em particular.

A pouca referência na bibliografia sobre amostragem, deve-se à inexistência de resultados teóricos suficientemente gerais sobre a questão da dimensão das amostras (McLachlan, 1992 ). Existem sobre esta questão dois pontos de vista: 1) para um dado classificador procura-se saber qual é a dimensão da amostra necessária para se garantir uma boa generalização dos resultados, ou; 2) dada uma amostra procura-se obter os melhores resultados possíveis a partir dessa mesma amostra. O segundo ponto de vista é, em muitos casos, o ponto de vista adotado na prática (ver Haykin, 1994). Respondendo a primeira questão, no caso do uso do classificador de máxima verossimilhança, o número mínimo aconselhável é de uma centena, posto ser necessário um número razoavelmente elevado de pixels para cada conjunto de treinamento, para permitir uma base segura para o tratamento estatístico (Crosta, 1993). Respondendo a segunda questão, em decorrência do tamanho das áreas e da desproporção do tamanho das classes, no caso específico desta área de estudo, se utilizará como ponto de partida a classe com menor número de pixels (ACf -212 pixels), a qual será amostrada com um mínimo de 100 pixels e, a partir daí, se buscará manter um número de pixels das amostras, proporcional ao tamanho das áreas ocupadas pelas classes.

O esquema de amostragem seguiu o critério de amostragem aleatória estratificada, desde que possuímos o conhecimento à priori da "verdade de campo" para toda a área. Berry \& Baker (1986) descrevem que a amostragem aleatória estratificada combina a vantagem da aleatoriedade e da estratificação porque evita tanto a sub-amostragem como a superamostragem dos atributos e, conseqüentemente, as possibilidades de tendência devido a presença de periodicidades espacial.

Tomou-se cuidado para que a menor classe tivesse um mínimo de 100 pixels amostrados. Para além desse aspecto note-se que para as amostras de maior dimensão e para as classes com menor número de pixels susceptíveis de serem sorteados torna-se possível que a totalidade dos pixels dessas classes sejam incluídos na amostra. Por isso será necessário um 
cuidado especial na avaliação dos resultados para as classes menores e para as amostras maiores.

Assim, partindo deste pré-requisitos, selecionou-se quatro polígonos amostrais de cada classe de solos considerada (Podzol, Podzólico Amarelo sem Coesão, Podzólico Amarelo com Fragipan, Podzólico Acinzentado sem Coesão e Podzólico Acinzentado com Fragipan).

\subsubsection{Avaliação do desempenho das diferentes técnicas de processamento}

\subsubsection{O pré-processamento e a caracterização da área}

Após o pré-processamento, os resultados foram avaliados à partir das amostras-testes, e seus diferentes resultados utilizados para caracterizar as feições de umidade de solo e da vegetação.

\subsubsection{Avaliação do desempenho da classificação}

Para avaliação do desempenho da classificação utilizou-se a matriz de erros, de onde se inferiu a exatidão global, a exatidão do produtor e a exatidão do usuário.

Utilizou-se também o coeficiente Kappa, baseando-se no critério proposto por Landis \& Koch (1977) para os valores de graus de concordância em função do índice Kappa:

Tabela 3.3 Valores do Coeficiente Kappa e seu respectivo grau de concordância entre as amostras de uma classificação

\begin{tabular}{|l|l|}
\hline kappa & Grau de concordância \\
\hline$<0$ & Sem concordância \\
\hline $0-0,2$ & Insignificante \\
\hline $0,2-0,4$ & Baixo \\
\hline $0,4-0,6$ & Moderado \\
\hline $0,6-0,8$ & Bom \\
\hline $0,8-1$ & Muito bom \\
\hline
\end{tabular}

Fonte: Landis e Koch, 1977 
A classificação da imagem foi avaliada e validada somente na área de referência (verdade de campo) devido à ausência de informações, nesta escala de detalhe, no restante da área de estudo.

\subsection{Avaliação dos resultados}

A avaliação dos resultados obtidos e a conseqüente discussão dos mesmos encontram-se no Capítulo 4. 


\section{CAPÍTULO 4 - Resultados e Discussões}

Neste capítulo buscar-se-á descrever e interpretar os resultados na área de estudo com as metodologias anteriormente descritas.

Podemos sumarizar os subitens destes capítulos baseados nas análises dos resultados dos seguintes procedimentos:

- Histograma das imagens

- Diagrama de dispersão das imagens

- Boxplot das amostras e das classes

- Análise das componentes principais

- Razão entre bandas

- Índices espectrais/Tasseled Cap

- Classificação Maxver

- Avaliação da classificação através da matriz de erro e da matriz de concordância

\subsection{As bandas do ASTER}

Antes de apresentar a análise exploratória das imagens ASTER, iremos descrever sumariamente as principais características das 9 bandas (regiões do VNIR e SWIR) das 14 bandas deste sensor e suas respectivas imagens (Figura 4.1), quanto a sua configuração e principais objetivos, as quais encontram-se sumarizadas na Tabela 4.1.

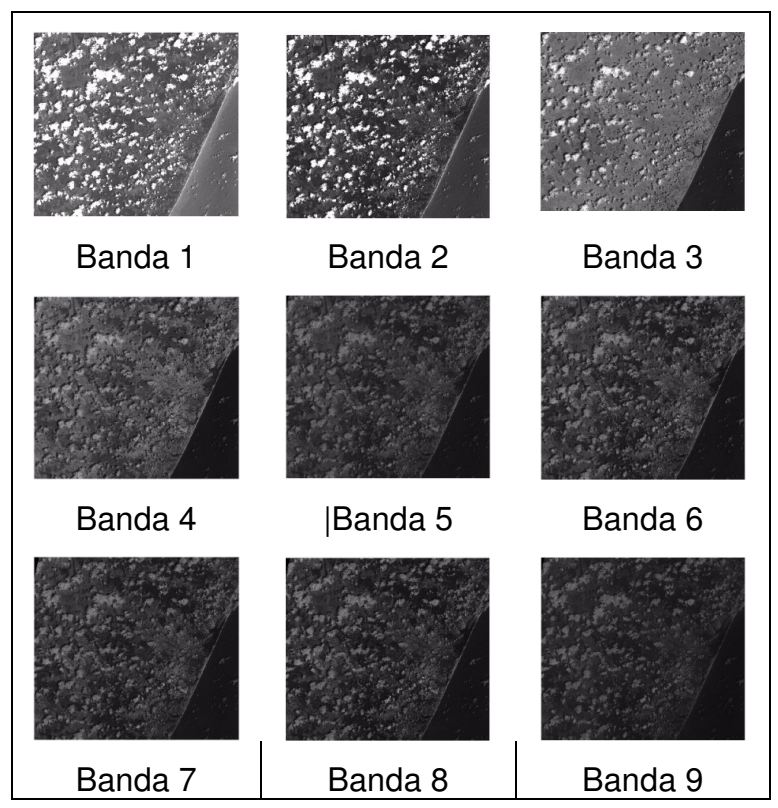

Figura 4.1 - As nove bandas ASTER utilizadas 
Tabela 4.1 - Resumo da performance do sensor ASTER

\begin{tabular}{|c|c|c|c|c|}
\hline Subsistema & $\begin{array}{c}\text { Número da } \\
\text { banda }\end{array}$ & $\begin{array}{c}\text { Intervalo } \\
\text { espectral }(\mu \mathbf{m})\end{array}$ & $\begin{array}{c}\text { Resolução } \\
\text { espacial }\end{array}$ & $\begin{array}{c}\text { Nível de } \\
\text { quantização }\end{array}$ \\
\hline \multirow{3}{*}{ VNIR } & 1 & $0.52-0.60$ & \multirow{3}{*}{$15 \mathrm{~m}$} & \multirow{3}{*}{8 bits } \\
\hline & 2 & $0.63-0.69$ & & \\
\hline & 3 & $0.78-0.86$ & & \\
\hline \multirow{6}{*}{ SWIR } & 4 & $1.600-1.700$ & \multirow{6}{*}{$30 \mathrm{~m}$} & \multirow{6}{*}{8 bits } \\
\hline & 5 & $2.145-2.185$ & & \\
\hline & 6 & $2.185-2.225$ & & \\
\hline & 7 & $2.235-2.285$ & & \\
\hline & 8 & $2.295-2.365$ & & \\
\hline & 9 & $2.360-2.430$ & & \\
\hline
\end{tabular}

\subsection{Análise exploratória}

A análise exploratória foi aqui utilizada para resumir e organizar as informações provenientes das imagens, quanto à distribuição e freqüência dos seus níveis de cinza, através de tabelas, gráficos e medidas numéricas para, a partir destes dados resumidos, procurar alguma regularidade ou padrão nas observações, visando uma interpretação objetiva da informação (Reis, 2005).

\subsubsection{A análise do histograma}

Como já citado anteriormente, o histograma de uma imagem representa a distribuição das frequiências dos seus respectivos níveis de cinza. É representado por um gráfico que dá o número de pixels na imagem para cada nível de cinza. Ele fornece informação indispensável para fazer qualquer processamento, principalmente a aplicação das técnicas de realce de imagem.

A banda com maior variância é a banda 2 (Vermelho), como pode ser comprovado por seu coeficiente de variação (0.69), embora possua apenas a terceira média mais elevada. A variância das bandas visíveis são bastante próximas, variando muito pouco, embora a Banda 1 (verde) apresente a média mais elevada (Tabela 4.2). Este fato não se reflete muito claramente no histograma, a menos que prestemos atenção ao elevado pico de 255, que corresponde à reflectância das nuvens e seu forte contrate com a água do oceano e as sombras com valores de níveis de cinza muito baixo. Podemos indicar também a influência da bruma 
atmosférica nos canais atmosféricos. Todos estes fatores, combinados, servem para explicar a elevada média nas bandas do espectro visível (Figura 4.2).

Na região do infravermelho médio, tanto a média como a variância tendem a diminuir no sentido do comprimento de onda (Tabela 4.2).

No geral, os níveis de cinza nas imagens do visível e do infravermelho próximo (VNIR - Bandas de 1 a 3) possuem suas médias relativamente distantes, enquanto as imagens do infravermelho médio (SWIR - Bandas de 4 a 9) tem suas médias muito próximas e com baixa variância, possuindo uma distribuição muito similar, principalmente as Bandas de 6 a 9 (Figura 4.3).

Tabela 4.2 - Estatística descritiva das imagens ASTER (Bandas 1-9), da subcena de 1551 x 1570 pixels - Esplanada (BA)

\begin{tabular}{|c|c|c|c|c|c|c|c|}
\hline \multicolumn{3}{|c|}{ Banda } & \multirow{2}{*}{$\begin{array}{c}\text { NC } \\
\text { Mínimo } \\
52 \\
\end{array}$} & \multirow{2}{*}{$\begin{array}{c}\text { NC } \\
\text { Máximo } \\
255\end{array}$} & \multirow{2}{*}{$\begin{array}{l}\text { Média } \\
122,23 \\
\end{array}$} & \multirow{2}{*}{$\begin{array}{c}\text { Desvio } \\
\text { Padrão } \\
60,02 \\
\end{array}$} & \multirow{2}{*}{$\begin{array}{c}\text { Coef. } \\
\begin{array}{c}\text { Variaçã } \\
\text { o }\end{array} \\
0.49\end{array}$} \\
\hline \multirow{3}{*}{ VNIR } & Verde & 1 & & & & & \\
\hline & Vermelho & 2 & 26 & 255 & 87,20 & 60,62 & 0.69 \\
\hline & $\begin{array}{c}\text { Infra-vermelho } \\
\text { próximo }\end{array}$ & 3 & 30 & 255 & 111,49 & 33,26 & 0.30 \\
\hline \multirow{6}{*}{ SWIR } & \multirow{6}{*}{$\begin{array}{c}\text { Infra-Vermelho } \\
\text { Médio }\end{array}$} & 4 & 22 & 178 & 77,77 & 25,03 & 0.32 \\
\hline & & 5 & 24 & 130 & 55,55 & 18,51 & 0.33 \\
\hline & & 6 & 18 & 154 & 58,45 & 23,51 & 0.40 \\
\hline & & 7 & 18 & 142 & 54,06 & 22,37 & 0.41 \\
\hline & & 8 & 16 & 142 & 49,96 & 23,22 & 0.46 \\
\hline & & 9 & 22 & 111 & 44,54 & 16,53 & 0.37 \\
\hline
\end{tabular}




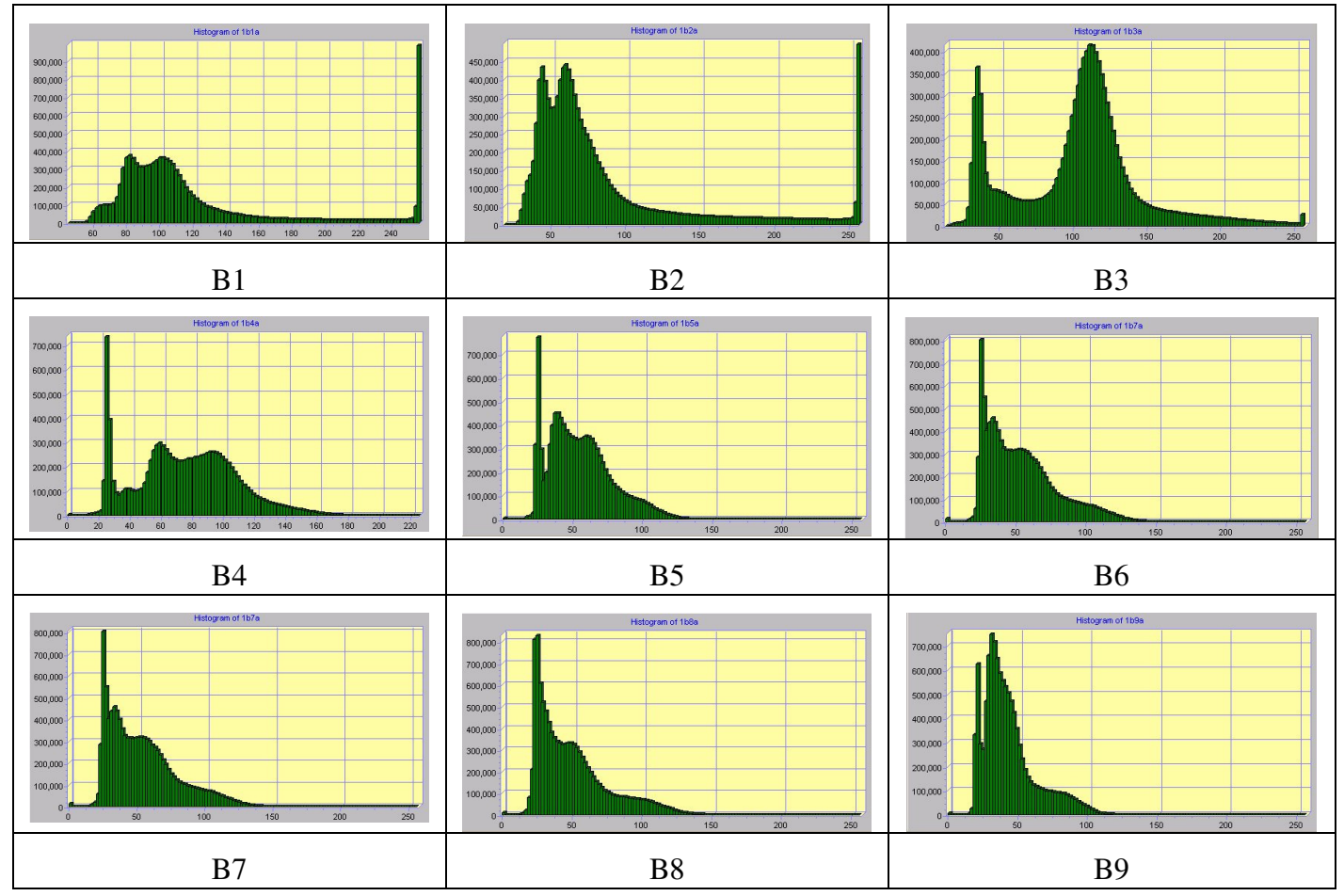

Figura 4.2 - Histograma original das imagens ASTER (Bandas 1-9)

\subsubsection{Diagramas de dispersão (scatterplot)}

Através da análise do gráfico de dispersão, podemos verificar a correlação das bandas no sentido bidirecional. Esta análise permitiu a visualização da correlação de cada par de imagens, e de seu aspecto geral, pela disposição triangular, segundo sugestão de Tukey e Tukey (1981) e Everitt (1993).

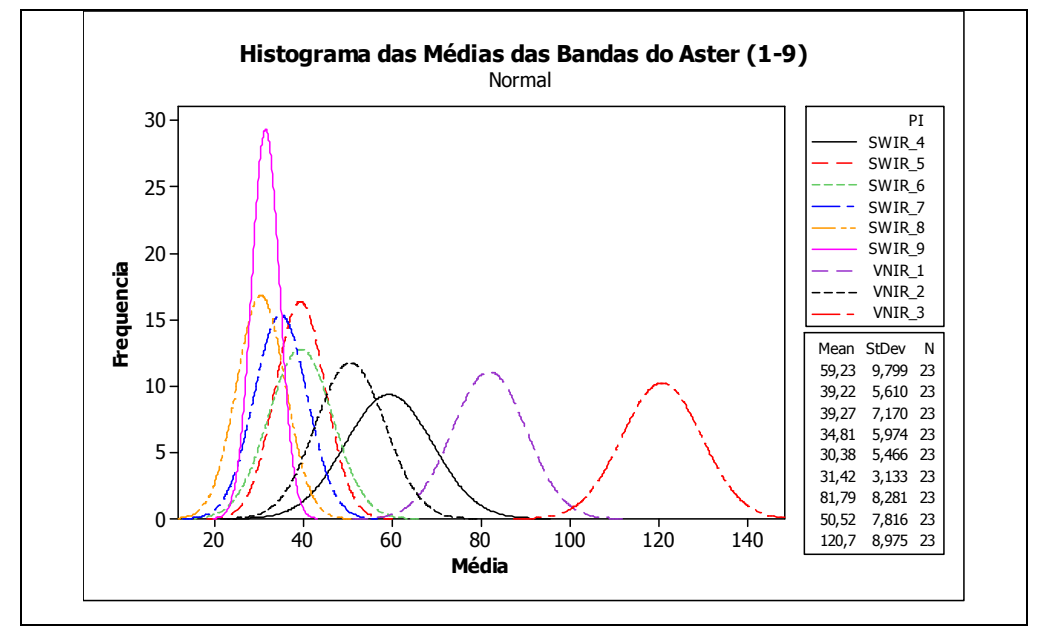

Figura 4.3 - Distribuição das médias por banda, da cena de estudo 


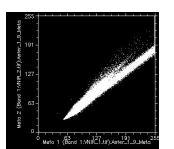

B1xB2

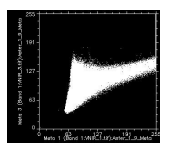

B1xB3

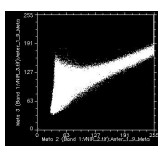

B2xB3

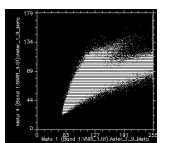

B1xB4

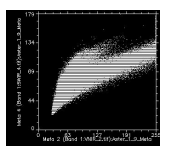

B2xB4

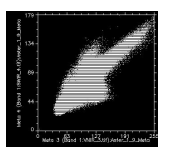

B3xB4

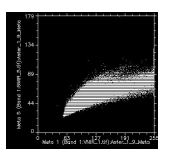

B1xB5

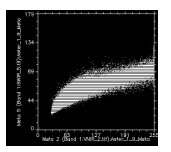

B2xB5

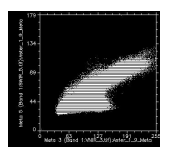

B3xB5

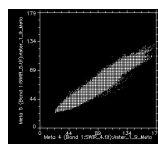

B4xB5

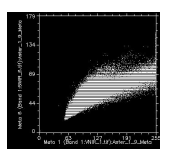

B1xB6

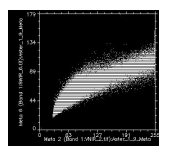

B2xB6

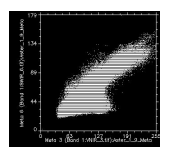

B3xB6

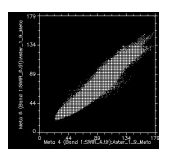

B4xB6

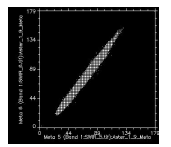

B5xB6

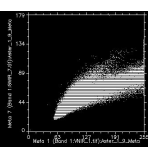

B1xB7

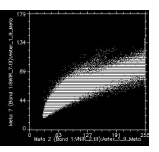

B2xB7

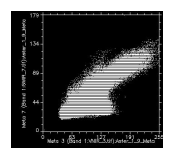

B3xB7

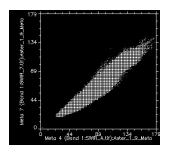

B4xB7

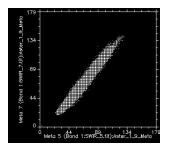

B5xB7

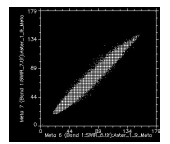

B6xB7
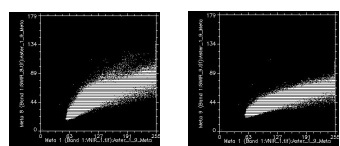

B1xB8

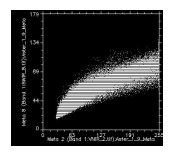

B2xB8

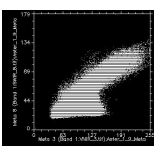

B3xB8

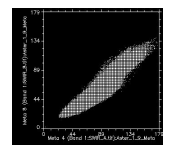

B4xB8

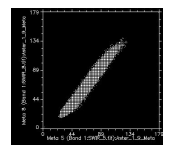

B5xB8

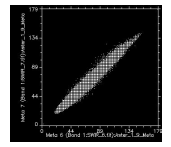

B6xB8

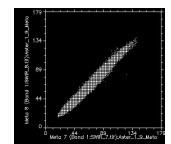

B7xB8

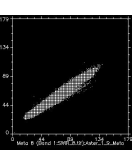

B8xB9

Figura 4.4 - Correlação entre os pares de bandas do sensor ASTER (1 a 9), para a subcena 1551x1570, correspondente ao município de Esplanada (BA)

A Figura 4.4 expressa visualmente a correlação entre as bandas, apresentada na Tabela 4.3. Em primeira aproximação, verifica-se que todas as bandas são altamente correlacionadas, seja pela proximidade do intervalo espectral (bandas SWIR), seja pela presença constante de alvos com intensa resposta na mesma região espectral (presença de nuvens e sombras, densidade de vegetação, por exemplo) 
Como sugerido pelo histograma, a Banda 3 (Infravermelho próximo - NIR) é a que possui o menor índice de correlação com as bandas das duas regiões (visível e infravermelho médio). Os canais visíveis (Bandas 1 e 2) são altamente correlacionados entre si $(0.97 \%)$, embora apresentem elevada correlação (acima de 80\%) com as bandas SWIR de 6 a 9. As menores correlações entre as diferentes regiões espectrais ocorrem entre os canais visíveis e as bandas 4 (Banda 1 e 2) e 5 (Banda 1).

Cabe destacar a elevada correlação entre as bandas da região do SWIR, em particular entre os canais de 5 a 9. Isto se justifica pelo reduzido intervalo entre eles e a contigüidade das bandas (Tabela 4.1). Cabe destacar também a elevada correlação dos canais do espectro visível com a banda 9 do SWIR (1 x 9; 2 x 9).

Tabela 4.3 - Estrutura de correlação da subcena 1551 x 1570 pixels, correspondente ao Município de Esplanada (BA) para as nove bandas do sensor ASTER

\begin{tabular}{|c|c|c|c|c|c|c|c|c|c|}
\hline & B1 & B2 & B3 & B4 & B5 & B6 & B7 & B8 & B9 \\
\hline B1 & 1.000 .000 & $\mathbf{0 . 9 7 2 4 9 5}$ & $\mathbf{0 . 6 5 3 5 1 7}$ & $\mathbf{0 . 6 7 0 2 4 4}$ & $\mathbf{0 . 7 9 0 5 7 4}$ & $\mathbf{0 . 8 1 7 3 3 3}$ & $\mathbf{0 . 8 2 9 5 4 7}$ & $\mathbf{0 . 8 6 7 6 3 5}$ & $\mathbf{0 . 8 6 3 4 0 7}$ \\
\hline B2 & $\mathbf{0 . 9 7 2 4 9 5}$ & 1.000 .000 & $\mathbf{0 . 7 1 2 3 8 1}$ & $\mathbf{0 . 7 3 1 4 5 7}$ & $\mathbf{0 . 8 3 4 7 8 0}$ & $\mathbf{0 . 8 5 9 0 3 6}$ & $\mathbf{0 . 8 6 8 4 0 9}$ & $\mathbf{0 . 8 9 9 4 4 8}$ & $\mathbf{0 . 8 9 6 3 4 1}$ \\
\hline B3 & $\mathbf{0 . 6 5 3 5 1 7}$ & $\mathbf{0 . 7 1 2 3 8 1}$ & 1.000 .000 & $\mathbf{0 . 8 5 6 7 9 3}$ & $\mathbf{0 . 8 0 8 4 4 6}$ & $\mathbf{0 . 8 0 4 7 4 5}$ & $\mathbf{0 . 7 8 7 0 5 8}$ & $\mathbf{0 . 7 7 3 1 7 0}$ & $\mathbf{0 . 7 9 9 2 4 9}$ \\
\hline B4 & $\mathbf{0 . 6 7 0 2 4 4}$ & $\mathbf{0 . 7 3 1 4 5 7}$ & $\mathbf{0 . 8 5 6 7 9 3}$ & 1.000 .000 & $\mathbf{0 . 9 6 1 7 6 9}$ & $\mathbf{0 . 9 5 4 9 7 1}$ & $\mathbf{0 . 9 3 9 2 3 7}$ & $\mathbf{0 . 9 0 9 0 7 5}$ & $\mathbf{0 . 8 9 0 6 3 8}$ \\
\hline B5 & $\mathbf{0 . 7 9 0 5 7 4}$ & $\mathbf{0 . 8 3 4 7 8 0}$ & $\mathbf{0 . 8 0 8 4 4 6}$ & $\mathbf{0 . 9 6 1 7 6 9}$ & $\mathbf{1 . 0 0 0 . 0 0 0}$ & $\mathbf{0 . 9 9 4 4 3 8}$ & $\mathbf{0 . 9 8 5 8 5 4}$ & $\mathbf{0 . 9 7 6 8 1 2}$ & $\mathbf{0 . 9 6 6 6 3 5}$ \\
\hline B6 & $\mathbf{0 . 8 1 7 3 3 3}$ & $\mathbf{0 . 8 5 9 0 3 6}$ & $\mathbf{0 . 8 0 4 7 4 5}$ & $\mathbf{0 . 9 5 4 9 7 1}$ & $\mathbf{0 . 9 9 4 4 3 8}$ & $\mathbf{1 . 0 0 0 . 0 0 0}$ & $\mathbf{0 . 9 8 9 8 9 1}$ & $\mathbf{0 . 9 8 4 7 1 6}$ & $\mathbf{0 . 9 6 8 2 8 6}$ \\
\hline B7 & $\mathbf{0 . 8 2 9 5 4 7}$ & $\mathbf{0 . 8 6 8 4 0 9}$ & $\mathbf{0 . 7 8 7 0 5 8}$ & $\mathbf{0 . 9 3 9 2 3 7}$ & $\mathbf{0 . 9 8 5 8 5 4}$ & $\mathbf{0 . 9 8 9 8 9 1}$ & $\mathbf{1 . 0 0 0 . 0 0 0}$ & $\mathbf{0 . 9 9 1 9 1 2}$ & $\mathbf{0 . 9 7 0 7 6 5}$ \\
\hline B8 & $\mathbf{0 . 8 6 7 6 3 5}$ & $\mathbf{0 . 8 9 9 4 4 8}$ & $\mathbf{0 . 7 7 3 1 7 0}$ & $\mathbf{0 . 9 0 9 0 7 5}$ & $\mathbf{0 . 9 7 6 8 1 2}$ & $\mathbf{0 . 9 8 4 7 1 6}$ & $\mathbf{0 . 9 9 1 9 1 2}$ & $\mathbf{1 . 0 0 0 . 0 0 0}$ & $\mathbf{0 . 9 8 1 5 9 8}$ \\
\hline B9 & $\mathbf{0 . 8 6 3 4 0 7}$ & $\mathbf{0 . 8 9 6 3 4 1}$ & $\mathbf{0 . 7 9 9 2 4 9}$ & $\mathbf{0 . 8 9 0 6 3 8}$ & $\mathbf{0 . 9 6 6 6 3 5}$ & $\mathbf{0 . 9 6 8 2 8 6}$ & $\mathbf{0 . 9 7 0 7 6 5}$ & $\mathbf{0 . 9 8 1 5 9 8}$ & 1.000 .000 \\
\hline
\end{tabular}

\subsubsection{Análise de bandas}

A partir do exposto, pergunta-se: afinal, qual é a melhor? Qual a melhor banda ou melhor conjunto de bandas entre todo o conjunto de bandas espectrais disponíveis, para discernir sobre um fenômeno particular? Quais bandas selecionar para analisar a umidade? Para responder esta questão muitos experimentos foram desenvolvidos para elaborar uma estratégia eficiente de seleção de bandas no conjunto de bandas disponíveis (Labovitz, 1986). Os critérios de escolha podem ser determinados de várias formas diferentes: podem ser empíricos, totalmente subjetivos, escolhidos através da tentativa-e-erro, baseados na observação da área específica ou determinado por alguma teoria em vigor (Labovitz, 1986). 
Para obtermos uma resposta, referente à presença de água nos solos, nos baseamos no comportamento espectral do solo e suas alterações devido à presença da água.

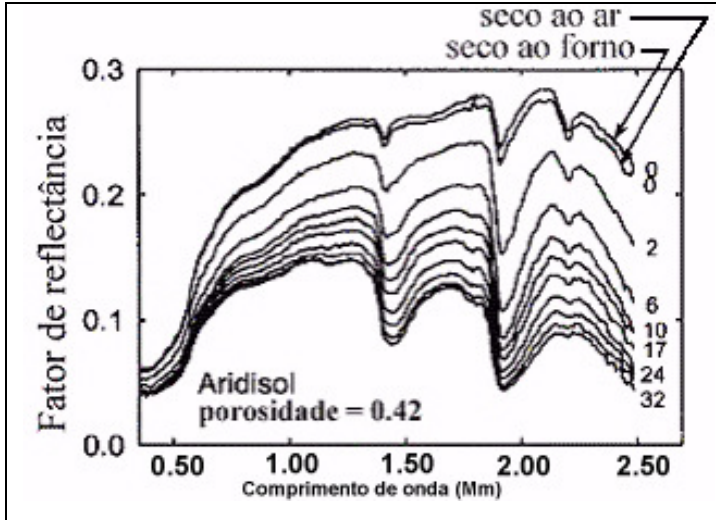

(a)

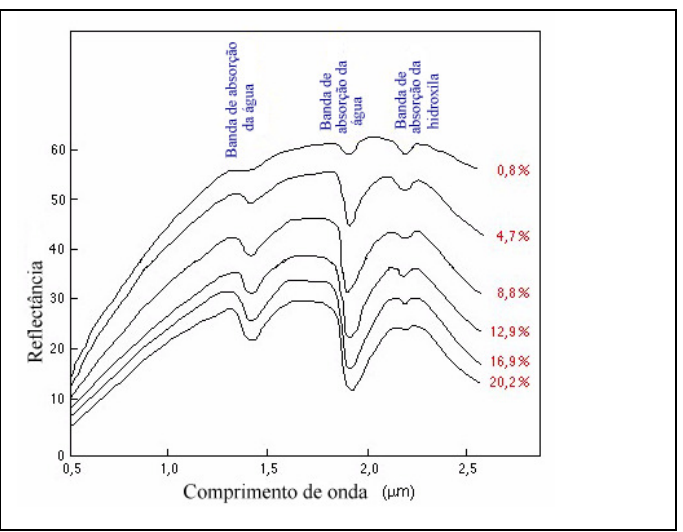

(b)

Figura 4.5 - Curvas de absorção de água, para diferentes teores de umidade.

(a) Resposta diferenciada do solo de acordo com o processo de secagem. As amostras secas ao ar apresentam um valor de reflectância menor que as amostras secas ao forno; (b) Identificação das curvas de absorção para um Aridisol ${ }^{7}$, destacando as a curva de absorção de água liquida de $1.45 \mu \mathrm{m}$ e $1.94 \mu \mathrm{m}$, apresentando no final da curva a descida acentuada para a curva de $2.72 \mu \mathrm{m}$. Em destaque também a curva de absorção da hidroxila de $2.15 \mu \mathrm{m}$ Fonte: (Bowers e Hanks, 1965)

Como já foi apresentado no Capítulo 2, o efeito da água na reflectância do solo causa a ocorrência de bandas de absorção centradas em $0.76 \mu \mathrm{m}, 0.97 \mu \mathrm{m}, 1.19 \mu \mathrm{m}, 1.45 \mu \mathrm{m}, 1.94 \mu \mathrm{m}$ e $2.72 \mu \mathrm{m}$ (Figuras 4.5 (a) e (b)) e provoca um decréscimo geral da reflectância em todos os comprimentos de onda (Curcio e Petty, 1951). A seleção de bandas então, baseou-se nas bandas que apresentam maior absorção. Segundo o comportamento espectral da água e a distribuição espectral das bandas, analisando o intervalo espectral de cada banda do sensor ASTER (Tabela 4.1) podemos então, deduzir que as melhores bandas são, em ordem crescente de importância: a banda $9(2.360-2.430 \mu \mathrm{m})$ com menor resposta, próxima ao pico de absorção de água de $2.72 \mu \mathrm{m}$; a banda $4(1.600-1.700 \mu \mathrm{m})$, próxima ao pico de absorção de água de $1.45 \mu \mathrm{m}$; e a banda $5(2.145-2.185 \mu \mathrm{m})$ que, além de estar próxima ao pico de absorção de água $1.95 \mu \mathrm{m}$, também contêm o pico de absorção de $2.15 \mu \mathrm{m}$ referentes a absorção da hidroxila (Figura 4.5).

Assim, na análise de escolha do melhor conjunto de bandas, definiu-se que a melhor composição seria das bandas 4, 5 e 9 (Figura 4.6).

${ }^{7}$ Aridisol é uma das 12 ordens de solos da U.S. Soil Taxonomy (Classificação Americana). São solos secos, de regiões quase desérticas, com baixo teor de matéria orgânica e esparsamente vegetado por plantas xerófilas ou halófitas (Encyclopedia Britannica on line). 


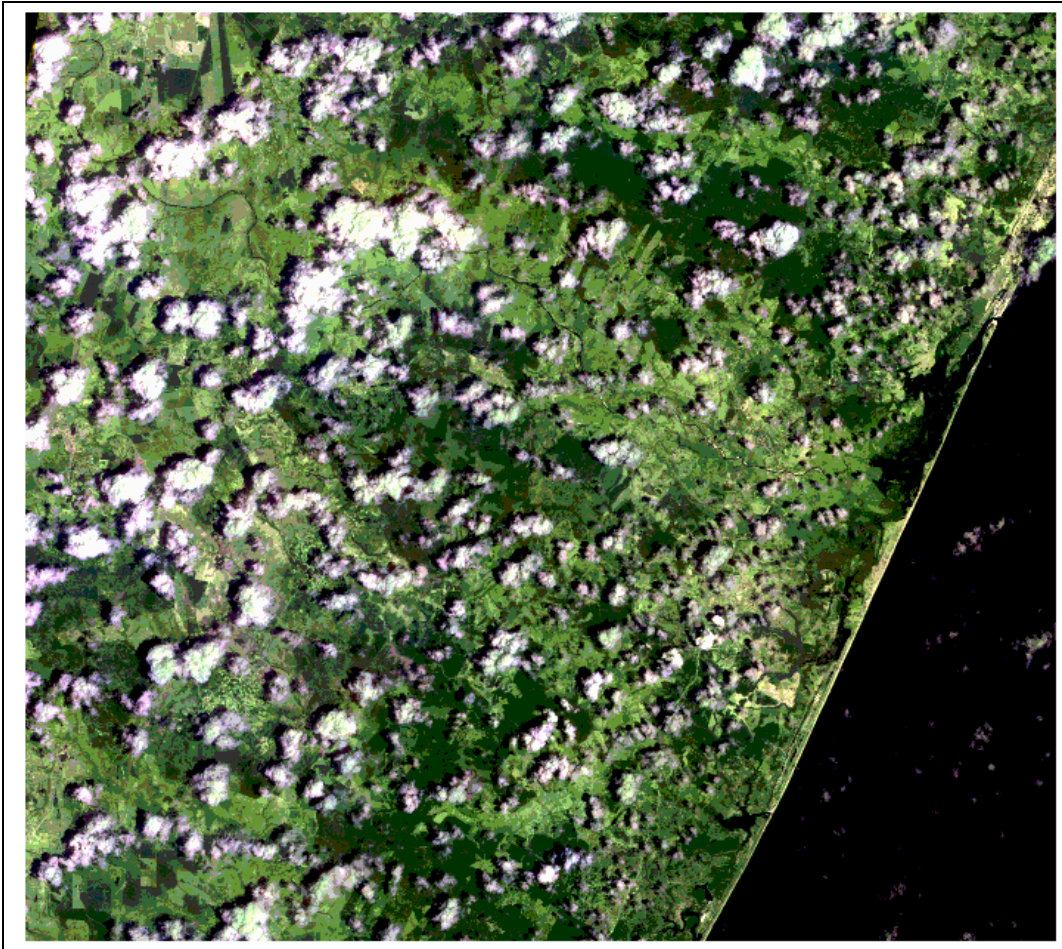

Figura 4.6 - Composição colorida RGB com as bandas de maior significância para análise de água do solo (R:5-G:4-B:9)

\subsubsection{Caracterização das amostras das classes de solos (Verdade de Campo)}

Antes de começarmos a discutir os resultados dos diferentes tipos de processamentos, vamos caracterizar sumariamente as amostras de solos coletadas através de polígonos da área de referência. Uma descrição mais detalhada e tabular sobre as amostras, tamanho dos pixels e área de localização encontra-se no Anexo F.

O método escolhido aqui foi o do boxplot, que apresenta a distribuição dos valores em torno de suas médias (média, moda e mediana) sua divisão em quartis e seus valores excepcionais. Utilizamos o boxplot para analisar 2 situações: a primeira, referente as classes de solos quanto à distribuição dos valores das classes de solo em relação às bandas espectrais, e a segunda a distribuição de cada classe entre si. 


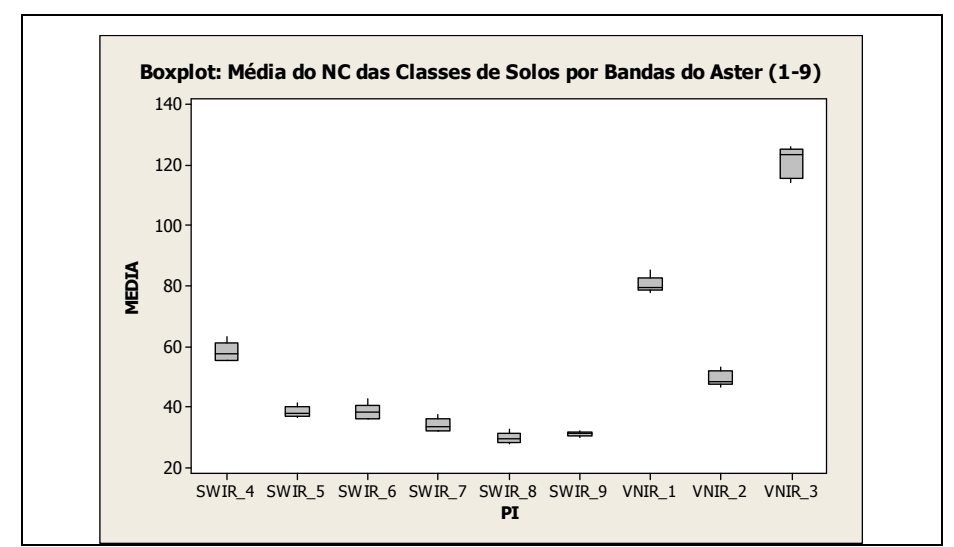

Figura 4.7- Boxplot da distribuição das médias das classes de solos por bandas

A média entre classes nos três canais da região do VNIR (Bandas 1, 2 e 3) são bastante distantes (Figura 4.7). A região dos canais SWIR, as bandas 5, 6 e 7, embora próximos, apresentam valores distintos, mas as bandas 8 e 9 estão muito próximas entre si, havendo alguma sobreposição de valores. Entretanto, o problema se agrava com a variância entre as classes, fazendo com que praticamente todas as classes se sobreponham em todas as bandas, em maior ou menor extensão, exceção apenas para a banda 9, que possui apenas um pouco de sobreposição com a banda 5. A variância dos canais visíveis 1 e 2 praticamente faz com que se sobreponham completamente, o mesmo acontecendo em menor extensão com a banda 3 (infravermelho próximo) (Figura 4.8).

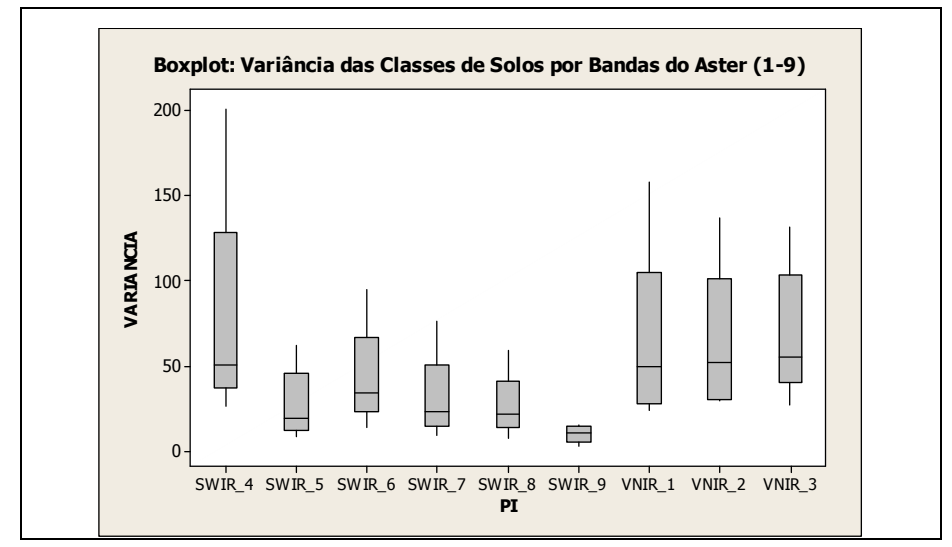

Figura 4.8 - Boxplot da variância das classes de solo por banda

Assim, no primeiro caso, verificou-se que as classes de solos encontram-se relativamente próximas umas das outras, principalmente nas bandas 5 e 9 , sendo que a banda 3 é a que possui mais separação entre valores médios das classes por banda (Figura 4.7). 
No caso da distribuição das médias e a variância de valores por classe, tem-se duas situações: verifica-se que as médias entre classes são muito similares (Figura 4.9). Isto era de se esperar, posto os solos serem da mesma família e terem um pedogênese semelhante, assim como suas características superficiais como textura, granulometria teor de matéria orgânica e cobertura, com exceção do Podzol.

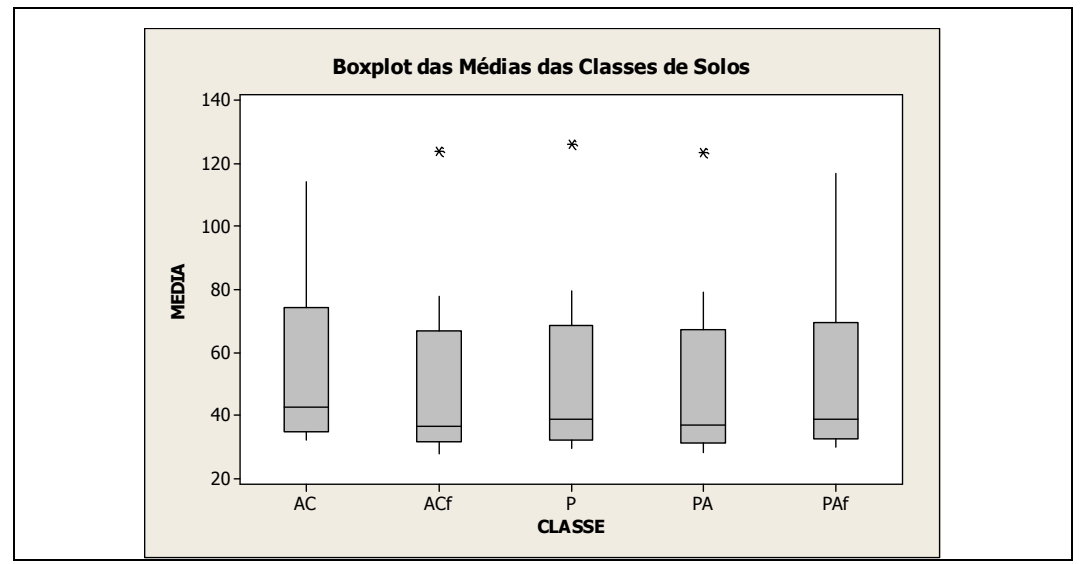

Figura 4.9 - Boxplot da média dos polígonos das classes de solos

No segundo caso, tem-se que as variâncias das classes são relativamente pequenas, exceção apenas à classe do Podzólico Acinzentado sem coesão (AC). Assim, pode se dizer que os padrões de resposta das bandas são, geralmente, muito similares entre as cinco diferentes classes (PA, PAf, P, PC, PCf). (Figura 4.9)

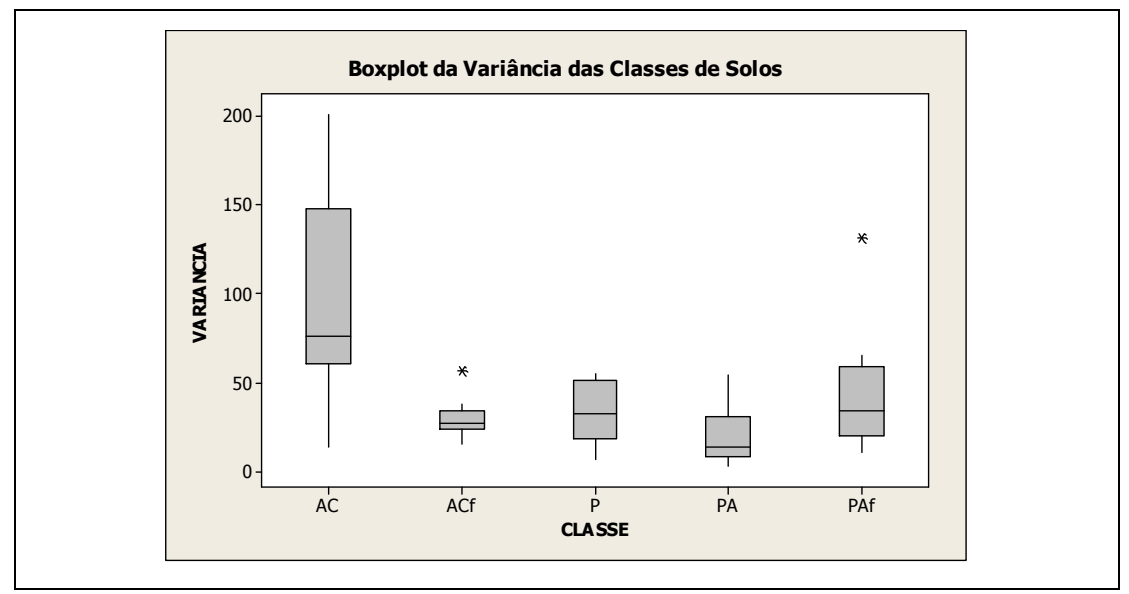

Figura 4.10 - Boxplot da variância das classes

Assim tem-se configurado um sério problema onde têm-se uma pequena variância entre classes e uma grande variância intra-classe (Figura 4.10). 
Esta descrição geral do quadro, permite compor uma certa problemática nas bandas de resposta de água, posto que a banda 5 e 9, terem médias muito próximas e uma reduzida variância. Mas a banda 4 possui não apenas uma média de classes que pode destacá-la das demais, como uma boa variância, que permite a separação no processo de classificação.

\subsection{Análise de Componentes Principais}

A componente principal é uma transformação matemática baseada apenas na matriz de covariância ou de correlação da cena, que produz novas variáveis, conhecidas como componentes ou eixos, que são combinações lineares das variáveis originais (Eastman, 2001). A matemática desta transformação pode ser buscada em várias fontes (Exemplo, Simonet e Ulaby, 1983, vol. 1).

A alta correlação entre as bandas ASTER, que são evidenciadas na matriz de correlação (Tabela 4.3) também são visíveis nas imagens ASTER individuais (Figura 4.1). A relativa baixa correlação entre as bandas NIR e as bandas SWIR é devido, principalmente ao marcante contraste entre a curva espectral da vegetação e dos componentes minerais, em particular dos solos. Isto é evidente quando se compara os resultados da curva de reflectância das amostras de solos seco (SS) e vegetação verde (VV) para as respectivas bandas do ASTER (Figura 4.1).

A Tabela 4.4 mostra a matriz de transformação (autovetores), baseados na matriz de correlação da cena e as respectivas imagens resultantes, geradas na transformação, perfazendo, ao todo, nove componentes (Figura 4.11), gerada pela matriz de autovetores. O alto grau de redundância apresentado pelas nove bandas (Figura 4.1) são apresentados na forma de contraste para as nove componentes principais (Figura 4.11) derivadas dos dados ASTER. Devido à redução da variância da cena para os componentes de ordem mais elevada, estes componentes tendem a parecer mais a ruído e menos a informação (elas contêm mais ruído do que sinal). Este atributo, inerente das componentes principais, pode levar ao descarte de componentes de ordem mais alta.

Entretanto, se nos atrelarmos apenas à uma observação inicial da tabela de autovetores, essencialmente podemos dizer que os dados são de natureza tridimensional, perfazendo um total de quase $99 \%$ da variância contida apenas nas três primeiras componentes (Tabela 4.4). Em geral, pode se ter alguma indicação de uma estrutura em quatro dimensões com a quarta componente, que contribui com apenas $0.57 \%$ da variância dos dados. Os demais componentes (5 a 9) sequer alcançam 1\% da variância total (0.63\%). 
Esta concentração da variância nos três primeiros componentes se baseia na elevada redundância das informações contidas nas bandas do sensor ASTER.

Tabela 4.4 - Componentes Principais: matriz de autovalores formado através da matriz de correlação.

\begin{tabular}{|c|c|c|c|c|c|c|c|c|c|}
\hline COMPON. & C 1 & C 2 & C 3 & C 4 & C 5 & C 6 & C 7 & C 8 & C 9 \\
\hline \% var. & 89.30 & 6.27 & 3.24 & 0.57 & 0.26 & 0.19 & 0.10 & 0.05 & 0.03 \\
\hline eigenval. & 8.04 & 0.56 & 0.29 & 0.05 & 0.02 & 0.02 & 0.01 & 0.00 & 0.00 \\
\hline
\end{tabular}

\begin{tabular}{|c|c|c|c|c|c|c|c|c|c|}
\hline eigvec.1 & 0.309332 & -0.605989 & -0.194131 & -0.213224 & -0.665928 & -0.067635 & 0.073762 & -0.020680 & 0.006130 \\
\hline eigvec.2 & 0.322254 & -0.492090 & -0.213682 & -0.219580 & 0.741412 & -0.090487 & 0.009715 & -0.040666 & -0.022286 \\
\hline eigvec.3 & 0.297550 & 0.386723 & -0.833135 & 0.153162 & -0.049239 & 0.144521 & -0.141686 & -0.029338 & 0.009515 \\
\hline eigvec.4 & 0.329057 & 0.438715 & 0.083802 & -0.552983 & -0.018861 & -0.214745 & 0.539868 & 0.178207 & -0.129426 \\
\hline eigvec.5 & 0.346068 & 0.169153 & 0.229996 & -0.000581 & -0.054835 & -0.372186 & -0.428290 & -0.585286 & -0.362222 \\
\hline eigvec.6 & 0.348242 & 0.110491 & 0.212535 & -0.115517 & -0.018686 & -0.134424 & -0.532929 & 0.466687 & 0.536446 \\
\hline eigvec.7 & 0.347837 & 0.060594 & 0.244184 & -0.006753 & 0.015869 & 0.609115 & 0.195461 & -0.475409 & 0.424470 \\
\hline eigvec.8 & 0.348653 & -0.046450 & 0.219175 & 0.182145 & 0.001364 & 0.497533 & -0.105678 & 0.413560 & -0.604424 \\
\hline eigvec.9 & 0.346505 & -0.044157 & 0.098914 & 0.728357 & 0.021401 & -0.380899 & 0.407571 & 0.088874 & 0.134691 \\
\hline
\end{tabular}

Adicionalmente, é muito instintivo o exame da imagem das componentes principais. Estas são formadas através dos autovetores de cada componente (Tabela 4.4). Alguns destes autovetores permitem uma interpretação relativamente fácil do resultado das imagens.

A primeira componente principal (CP1) contem a maioria das informações comuns a todas as imagens e, essencialmente, ela representa um somatório geral da taxa de reflectância que se relaciona, em geral, à média do albedo e da topografia. $\mathrm{O}$ autovetor da primeira componente contem aproximadamente igual peso para cada uma das nove bandas da subcena do ASTER, correspondendo a $89.3 \%$ da variância total da cena. O valor positivo de todas as cargas $^{8}$ da primeira componente pode ser interpretado como a componente de brilho na transformação dos dados (Yamaguchi e Naito, 2003), fato este que é qualitativamente comprovado pelo exame dessa componente. Num primeiro olhar mais descuidado, a primeira componente principal assemelha-se a qualquer banda do ASTER, apenas com um pouco mais de realce (Figura 4.12).

${ }^{8}$ O termo "carga" será utilizado aqui para designar a proporção de cada pixel somado das bandas do ASTER para criar o novo valor do pixel para formar a imagem da componente principal. 

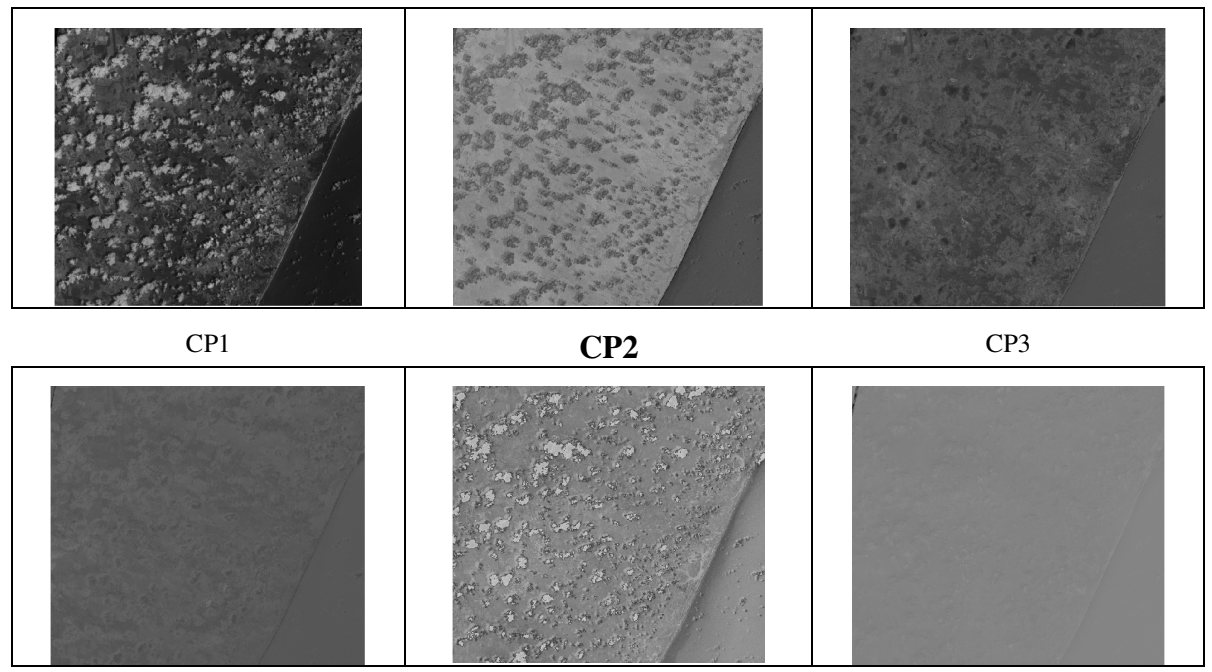

$\mathrm{CP} 4$

CP5

CP6

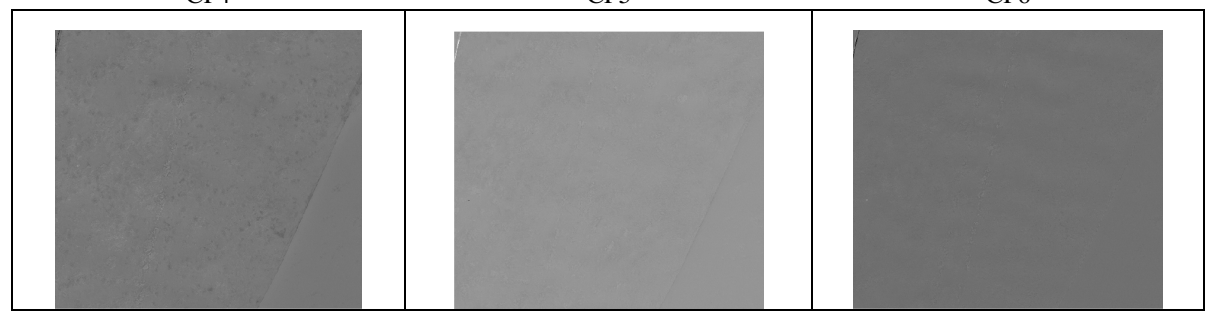

$\mathrm{CP7}$

CP8

CP9

Figure 4.11 - Principais componentes das imagens do sensor ASTER (Bandas 1 a 9), para a subcena de $1551 x 1570$ pixels, município de Esplanada (BA)

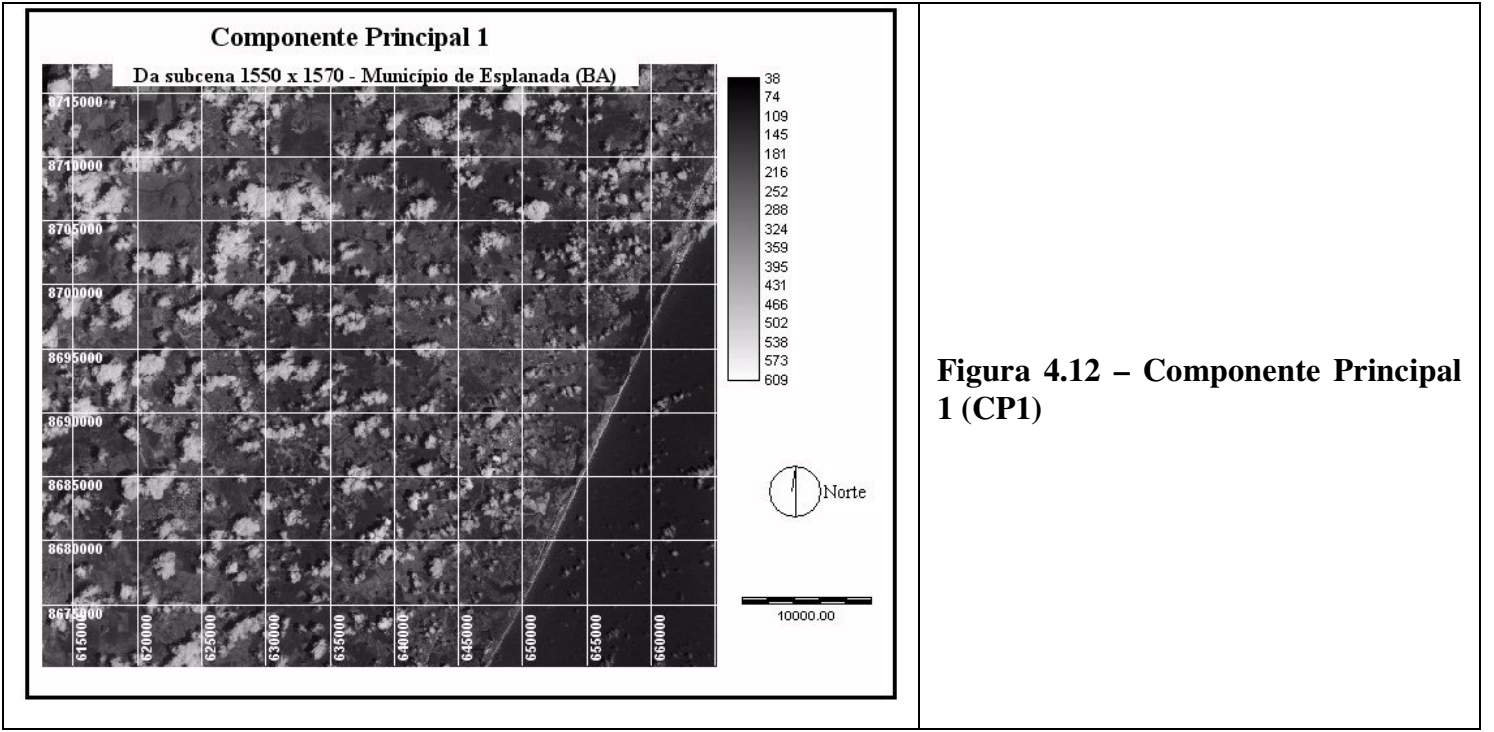

A segunda componente principal (CP2) é basicamente o contraste entre os canais Visíveis e os Infravermelhos (próximo e médio), contendo aproximadamente igual valores de 
cargas positivas (Infravermelho: 3 a 9) e negativas (Visível: bandas 1 e 2), correspondendo à $6.27 \%$ da variância da cena. As cargas das bandas 7 e 8, embora negativas, são desprezíveis. As bandas de 3 a 6 contrastam com as bandas 1 e 2, sendo que a carga dos canais visíveis é muito alta, em particular da banda 1. Este aspecto sugere que este componente mostra alvos que possuem forte contraste entre estes dois conjuntos de bandas. Ao se examinar a resposta da curva espectral da vegetação (Figura 2.9), assim como citado no referencial teórico (Capítulo 2), verifica-se que a vegetação apresenta contraste nestas duas regiões, sendo, inclusive utilizado este conhecimento para elaboração de índices espectrais de vegetação (Figura 4.13, 4.14 e 4.15).

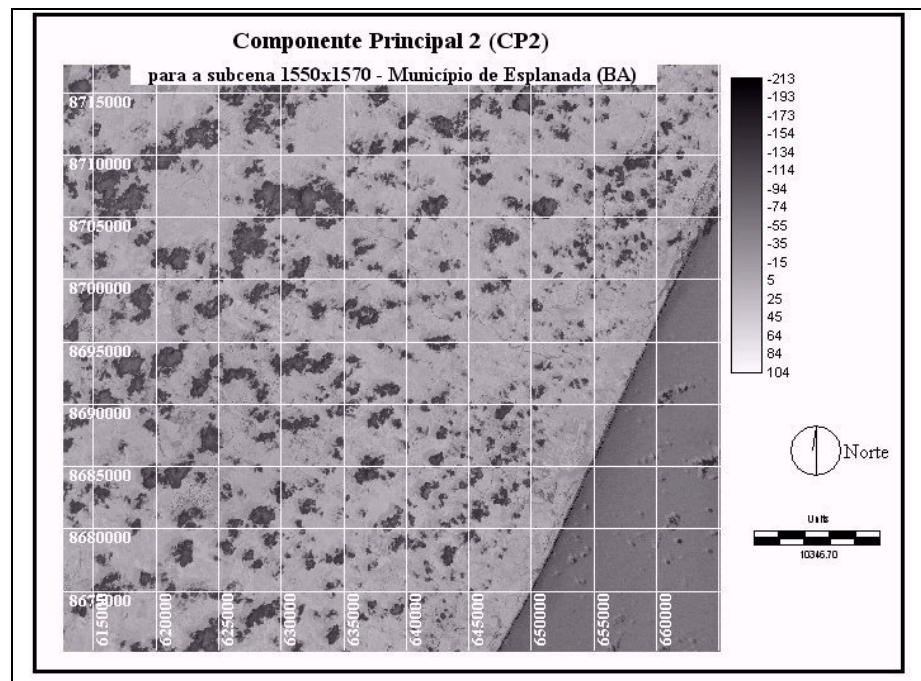

Figura 4.13 - Componente Principal 2 (CP2). A densa presença de nuvens e sombras na área torna marcante $\mathrm{o}$ contraste na imagem da segunda componente.

A terceira componente principal (CP3) possui uma grande carga positiva formada pelo somatório das bandas SWIR, em contraste com a banda 3, de carga mais elevada. Esta componente contribui com $3.24 \%$ do total da variância da cena. A contribuição das bandas 4 e 9 é insignificante. Nesta componente, as cargas igualmente distribuídas nos canais SWIR de 5 a 8 , demonstram a resposta dos elementos que se situam entre $2.145 \mu \mathrm{m}$ a $2.365 \mu \mathrm{m}$ e contrastam com a banda 3. Ao examinarmos a imagem da terceira componente estamos, verdadeiramente, verificando a forte resposta dos elementos constituintes minerais dos solos (Figuras 4.16 e 4.17). 


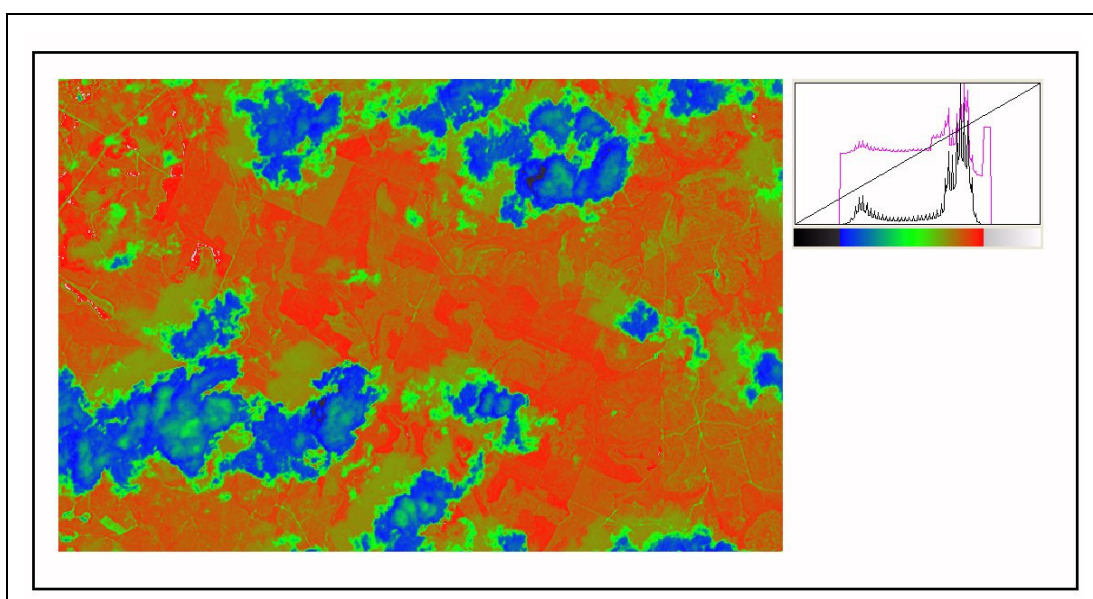

Figura 4.14 - Fatiamento "Arco íris" da segunda componente, na área de referência, onde se destacam os alvos de vegetação densa (vermelho) $\mathrm{x}$ vegetação menos densa, em verde escuro, como pico principal do histograma (ao lado). Os elementos correspondentes ao primeiro pico, de menor intensidade corresponde à densa ocorrência de nuvens e sombras na cena. ${ }^{9}$

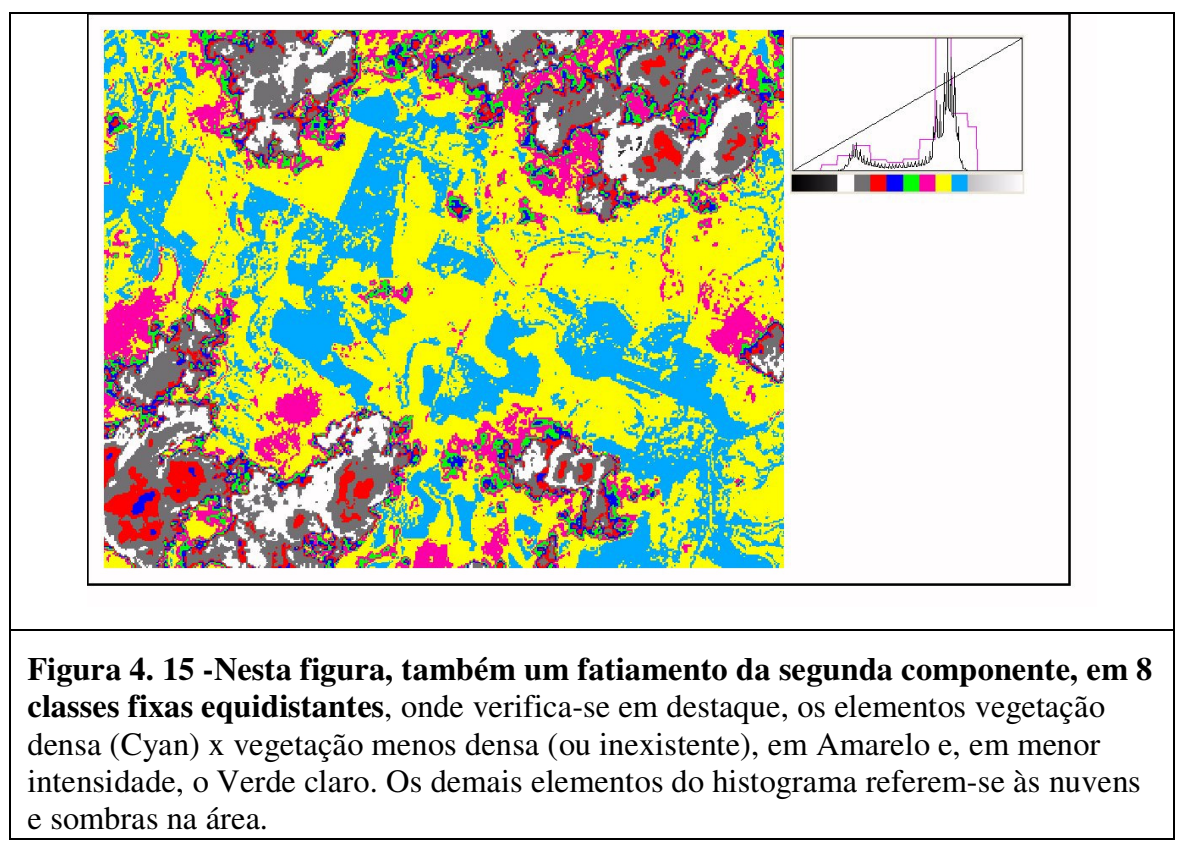

${ }^{9}$ Fatiamento é uma forma de aumento de contraste cuja operação consiste simplesmente em realçar os pixels cujas intensidades situam-se dentro de um intervalo específico (a fatia), isto é, entre um máximo e um mínimo. Consiste na divisão do intervalo total de níveis de cinza de determinadas fatias (ou classes de cores). Fatiamento normal: as fatias são definidas de modo que o intervalo entre cada faixa seja constante; Fatiamento arco-íris: é o mapeamento de um tom de cinza para uma determinada cor (INPE, 2000).. 
A quarta componente principal (CP4) contêm relativamente poucos sinais positivos e destacam-se a resposta da banda 9 e da banda 4. Poderia ser indicada como uma boa opção para analisar o teor de umidade dos solos se tivesse também uma boa reposta da banda 5, mas esta é tão baixa nesta componente que pode ser considerada inexistente, além dos valores relativamente elevados das cargas do visível, o que poderia gerar confusão no momento de diferenciar esta feição. Esta componente contribui com apenas $0.57 \%$ da variância total (Figura 4.18).

A quinta componente (CP5) contribui com apenas $0.26 \%$ da variância relaciona-se fortemente ao espectro visível (bandas 1 e 2, respectivamente o verde e o vermelho), sendo o restante das cargas desprezível. Acredita-se que esta componente ainda pode ser muito útil para estudos de vegetação.

A componente principal 6 (CP6), com apenas $0.19 \%$ é dominada pelo contraste entre as bandas SWIR, em particular as bandas 7 e $8 \mathrm{com}$ as bandas 4,5 e 9 e, assim como a componente principal 7 (CP7) com $0.1 \%$ da variância, contrastando as bandas 4, 5 e 9, a componente principal 8 (CP8), com $0.05 \%$ e a componente principal 9 (CP9), contribuindo com a restante $0.03 \%$ da variância, apresentam, todas, contrastes entre as bandas SWIR, destacando a composição mineralógica das formações superficiais, as quais não iremos entrar em detalhes aqui, posto não ser nosso objetivo. Para maiores informações, consultar Yamaguchi e Naito (2003) e San et al. (2004).

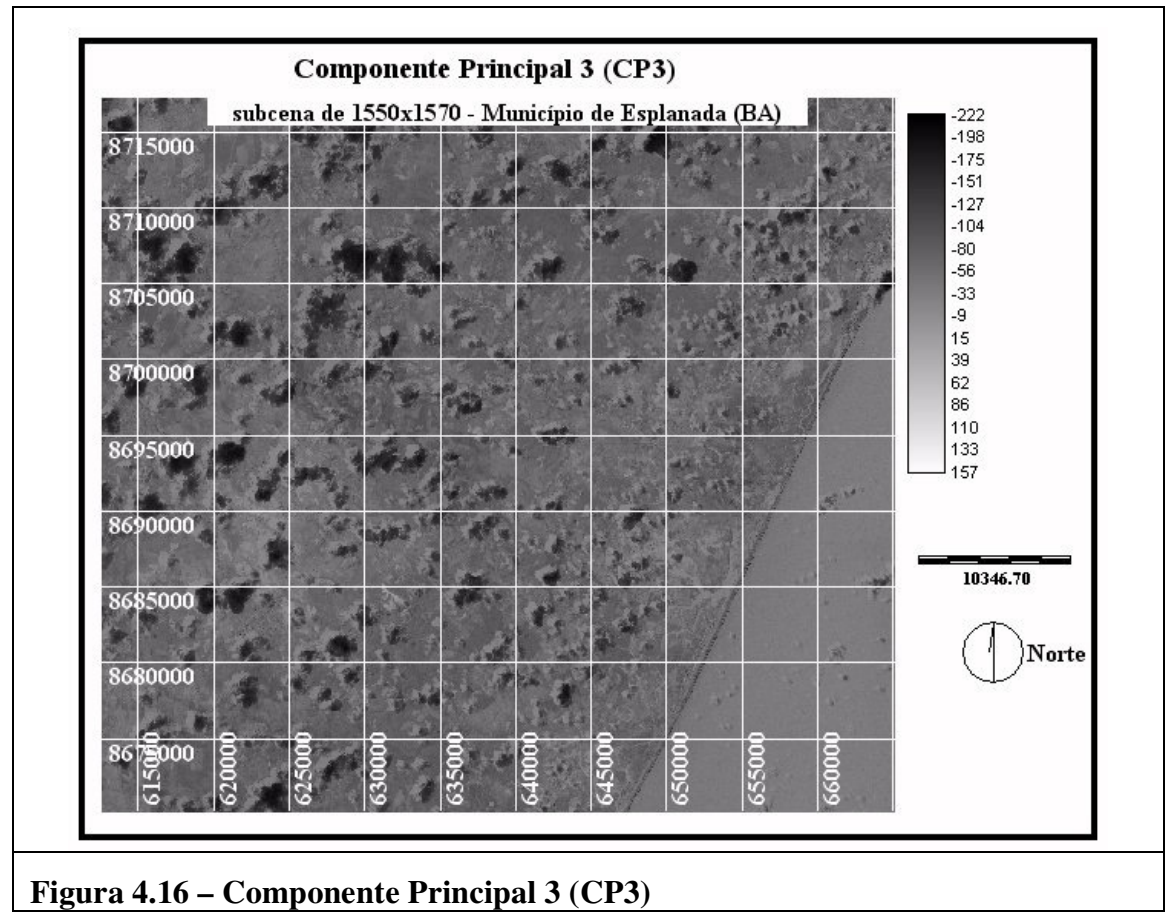


(a)

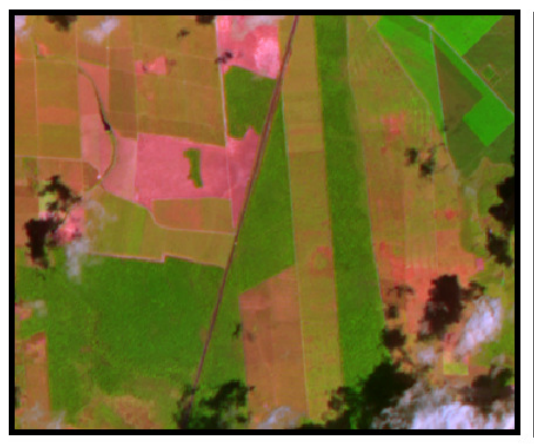

(b)

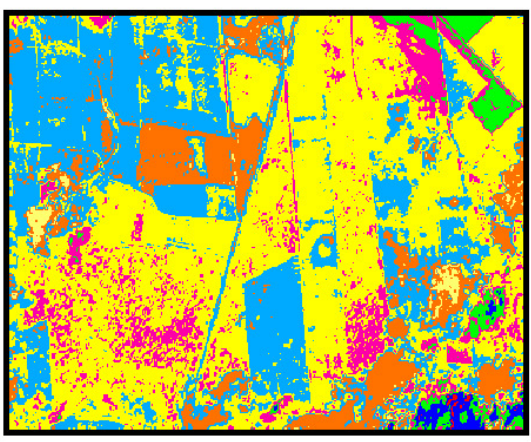

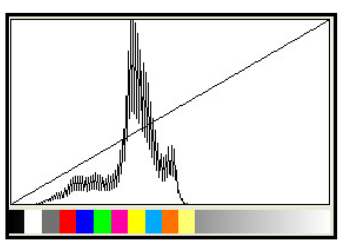

Figura 4.17 - Caracterização das feições extraídas da terceira componente principal. (a) Região noroeste da imagem, apresentando áreas com diferentes etapas de cultivo e diferentes graus de exposição dos solos (Composição colorida RGB : 4-3-2); (b) Fatiamento do histograma da terceira componente em 10 partes equiidistantes. Separação da vegetação e do solo exposto, em diferentes estágios, correspondendo a região de máxima distribuição (pico maior). A curva de freqüência à direita representa, basicamente, os componentes associados às nuvens e sombras.

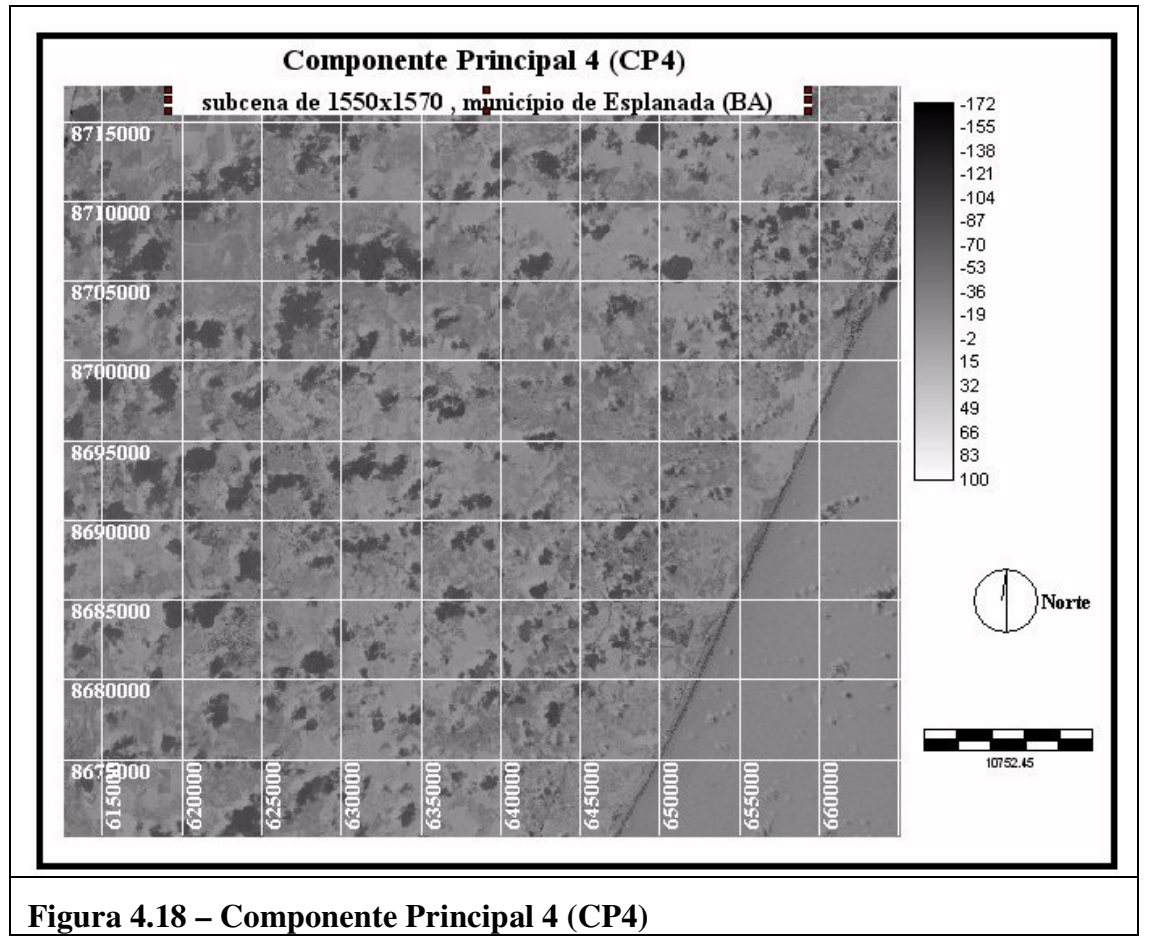




\subsubsection{A escolha da componente principal para estudos da umidade dos solos}

Como o solo é constituído por componentes minerais, sua resposta possivelmente está fortemente associada às bandas do infravermelho médio. Por outro lado, o solo é um tipo de alvo que geralmente encontra-se sob algum tipo de cobertura, existindo muito poucas áreas onde o mesmo encontra-se totalmente exposto para se poder obter uma resposta da reflectância característica e sem interferência. Entretanto, o sinal do solo é bastante forte, principalmente em áreas parcialmente cobertas por vegetação, para que seu sinal consiga chegar até o sensor, embora, na maioria das vezes, percebido apenas como "ruído de fundo"

Partindo-se da análise das bandas, sabendo que as bandas que melhor retratam a umidade dos solos são as bandas 4 e 5 e, em menor expressão, a banda 9, buscou-se nas cargas dos autovalores que compõem as imagens das componentes, em qual delas estas bandas apresentavam-se com os autovetores dominantes. Por outro lado, pelo solo se caracterizar como "ruído de fundo", somente é possível identificá-lo nas componentes de alta ordem.

A partir destas premissas foi possível selecionar a sétima componente (Figura 4.18) entre todas as demais, por atender a estas especificações (Tabela 4.4).

(a)
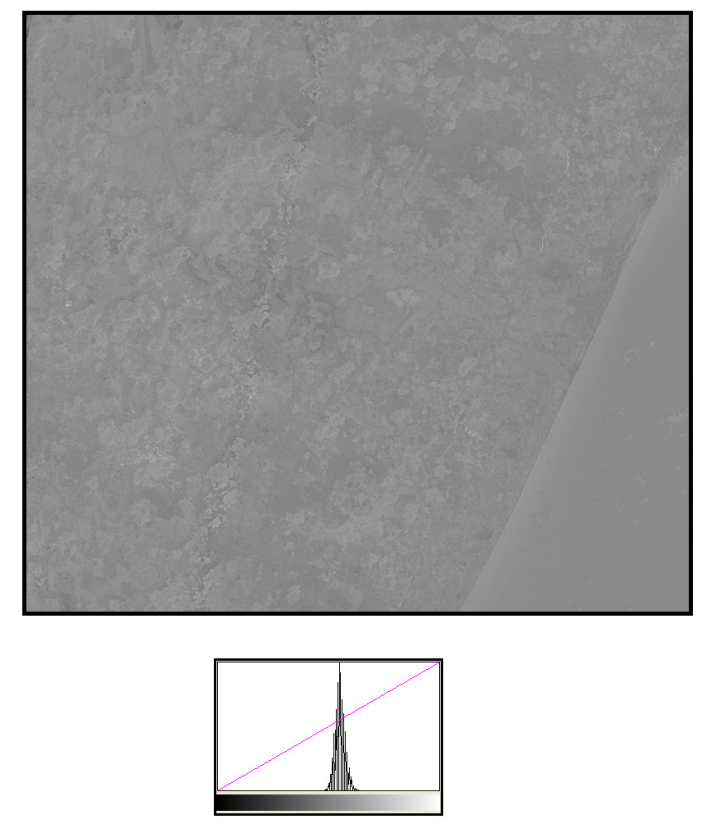

(b)
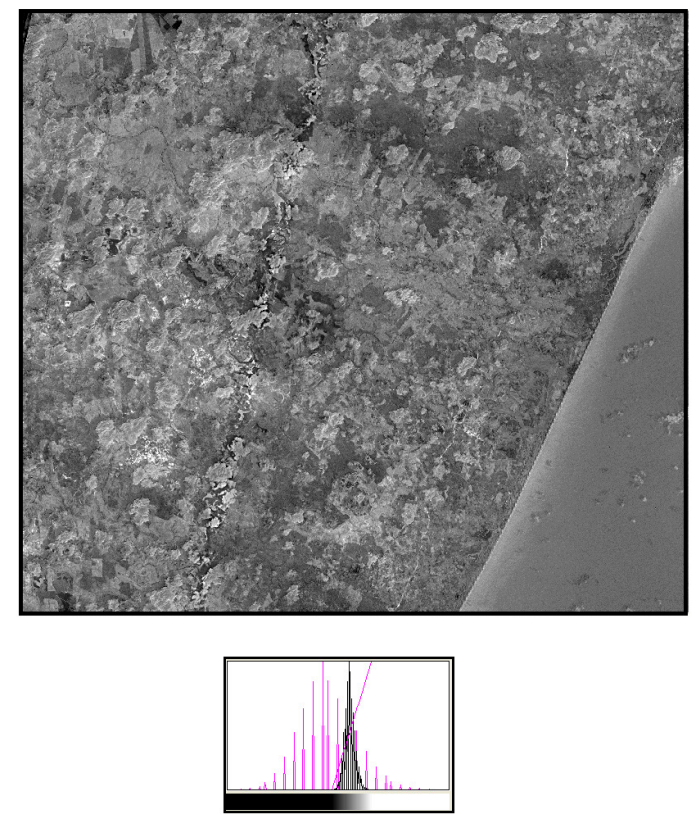

Figura 4.19 - Componente principal 7: (a) sem realce; (b) com realce linear 
Embora os resultados mais claramente visíveis concentrem-se nas três primeiras componentes, não serão nelas que encontraremos nossas respostas. Na maioria dos trabalhos sobre cobertura vegetal, principal alvo dos sensores orbitais (Richardson e Wiegang, 1977; Huete, 1988; Jackson e Huete, 1991; Qi et al., 1994; Liu e Huete, 1995; Collins e Woodcock, 1996; Yin, 1998; Jin e Sader, 2005), o solo sempre é percebido como um sinal de "background", sempre onipresente tanto quanto indesejado. Portanto, os solos somente serão captados nas ACP nos seus elementos de ordem mais elevada, quando quase toda a variância correspondente aos alvos mais superficiais e evidentes forem "retirados" da cena. Assim, baseados na abordagem de que as bandas 4, 5 e 9 são as que melhor respondem ao teor de umidade dos solos, a sétima componente se apresenta como a componente mais significativa no estudo da umidade dos solos. Portanto, não apresenta surpresa a umidade dos solos, além de estar respondendo na sétima componente, contribuir com apenas $0.1 \%$ da variância total das nove bandas. A análise da sétima componente mostra-se deveras promissora como indicadora do solo e de seu teor de umidade.

A sétima componente mostrou-se como um dos resultados mais interessantes, apesar de ser um componente de alta ordem, já muito próximo da zona de puro ruído da imagem.

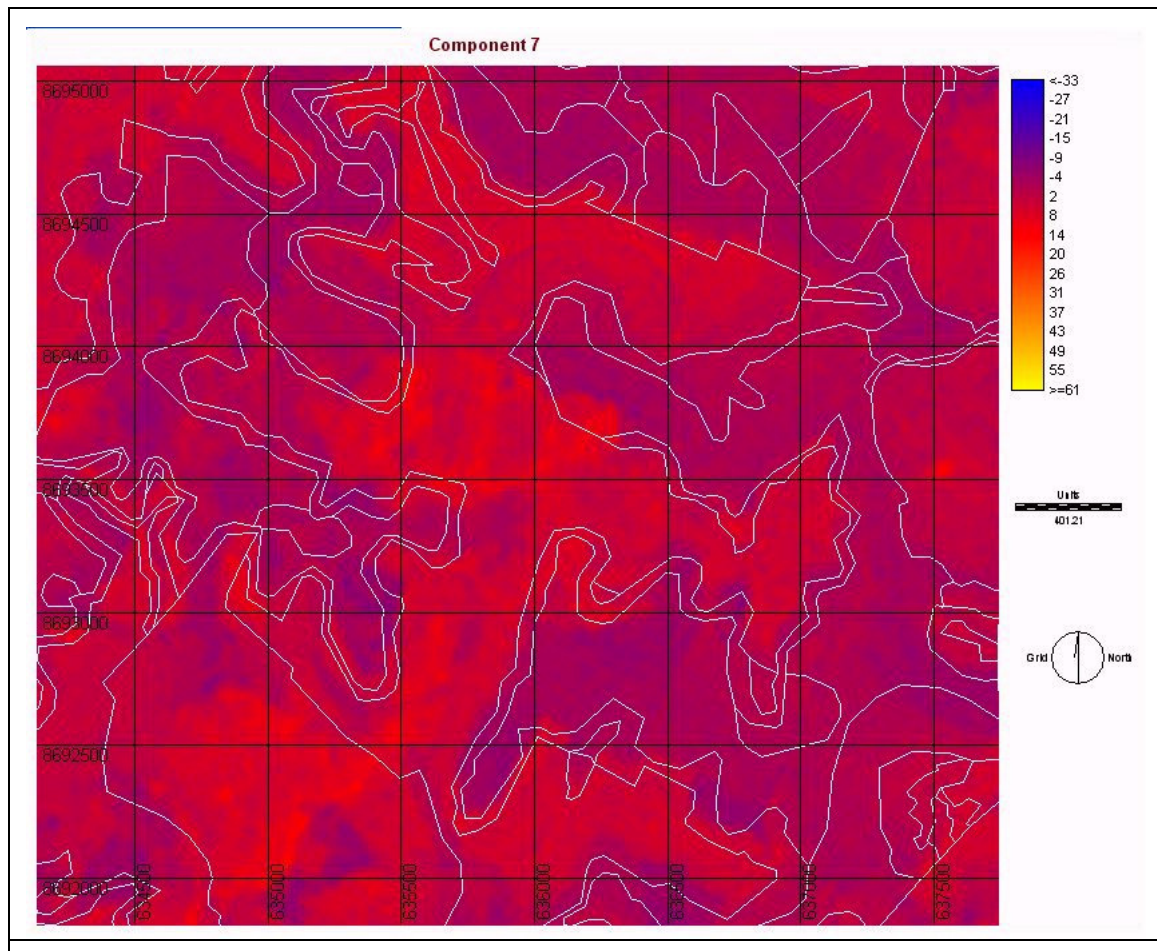

Figura 4.20 - Componente principal 7, com legenda em paleta bipolar (256 níveis). Sobreposta à sétima componente, observa-se em branco, o contorno vetorial do mapa de solos. Observa-se a variação em tons (intensidade ) de azul. Estes indicariam a concentração do teor de água. 
Foi realizada uma avaliação visual e submeteu-se à sétima componente a um tratamento de alteração de contraste (linear) e alteração de legenda, substituindo a escala de cinza por uma variação bipolar "degradée" (do azul para o amarelo) e sobre ela se sobrepôs a representação vetorial dos limites de solos da carta de referência (Figura 4.20). Verificou-se uma coincidência de padrões e intensidades de respostas que nos levaram a realizar tentativas de agrupar estes padrões de uma forma mais coerentes e com um maior controle das variáveis quantitativas. Como trata-se apenas de uma imagem, optou-se por realizar uma classificação monoespectral simples (fatiamento), baseada apenas no histograma da imagem, separando-se as freqüências em classes homogêneas de distribuição. Assim realizou-se dois tipos de fatiamento: o normal e o arco-iris, cujos resultados encontram-se nas Figuras 4.21, 4.22 e 4.23.
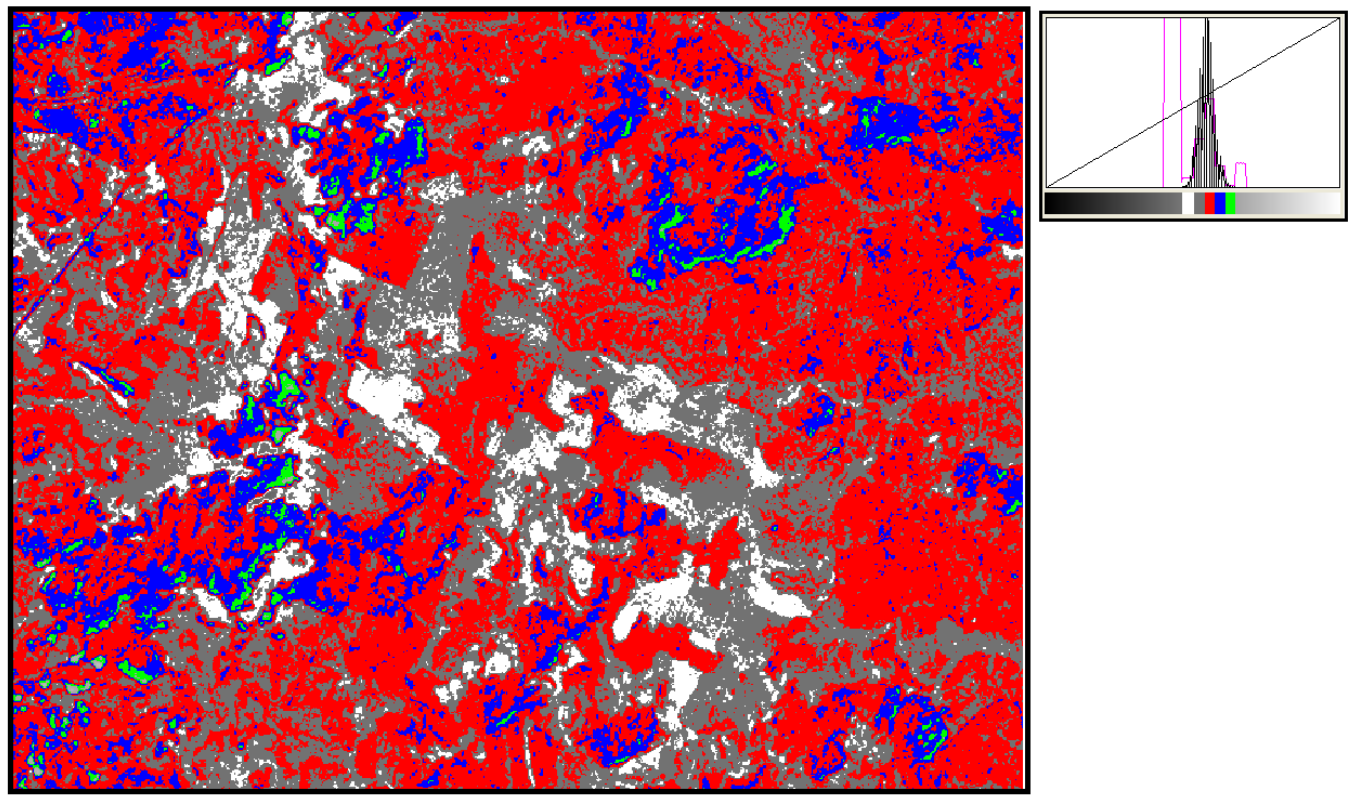

Figura 4.21 - Fatiamento normal com apenas 5 classes da sétima componente principal. Observase, mesmo neste sistema simples de classificação monoespectrasl, baseado apenas no histograma, a diferenciação das classes com diferentes teores de umidade, embora de forma grosseira. As diferenciações de umidade se apresentam principalmente nas cores branco, cinza e vermelho, correspondendo as três primeiras partições do histograma (lado esquerdo). As variações nas cores azul e verde, correspondem principalmente às nuvens e sombras. 


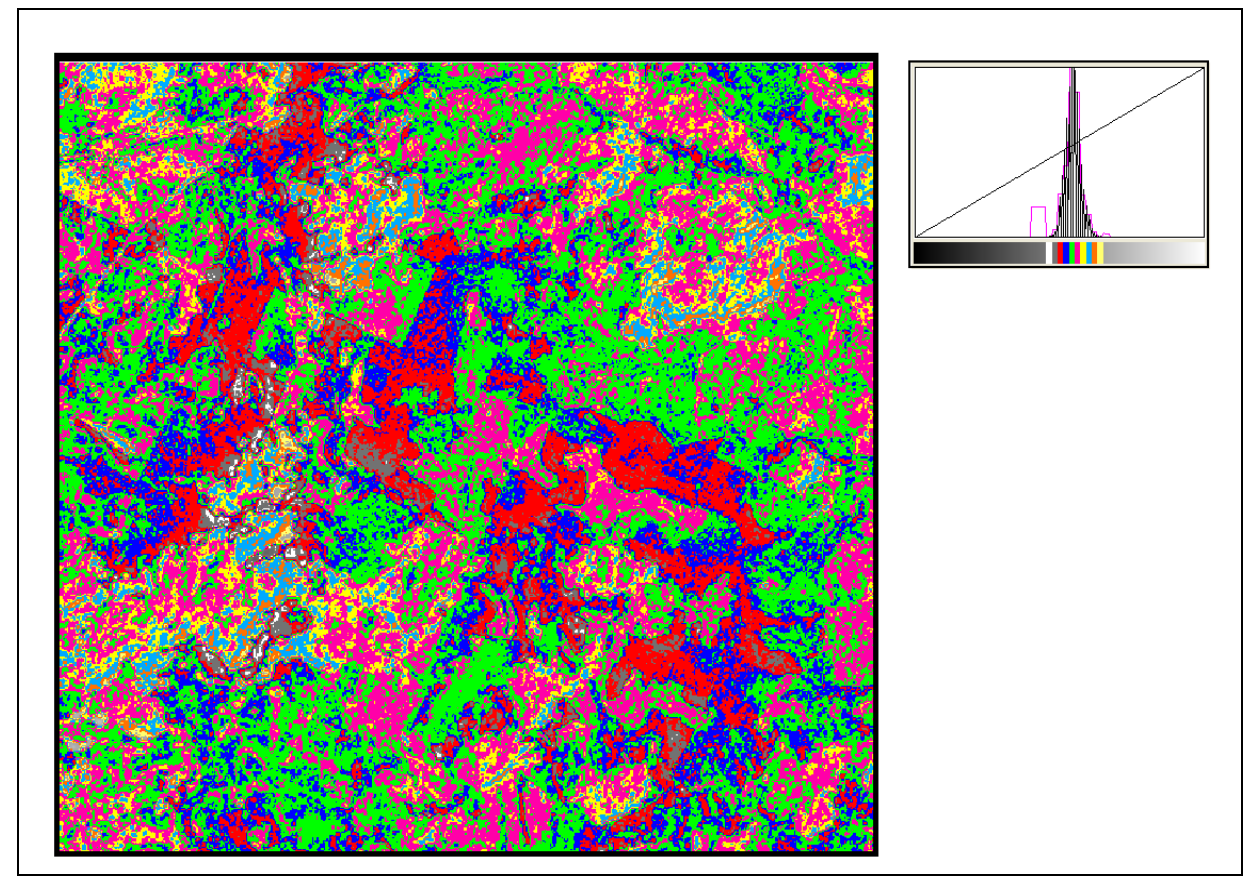

Figura 4.22 - Componente principal 7 com fatiamento normal com 10 classes. Ocorre uma maior, mas não muito significativa, aumento de diferenciação das classes de umidade do solo. A partir daí, a separabilidade das feições de umidade através desta técnica perde a significância, ou o poder de interpretação. As feições de umidade situam-se do lado esquerdo do histograma, e estão representados principalmente pelas cores do cinza, vermelho, azul, verde, rosa e amarelo. Mas para trabalhar nesta componente, recomendase utilizar máscara para as nuvens e sombras, posto estas não serem muito bem discernidas nesta componente e podem gerar confusão.

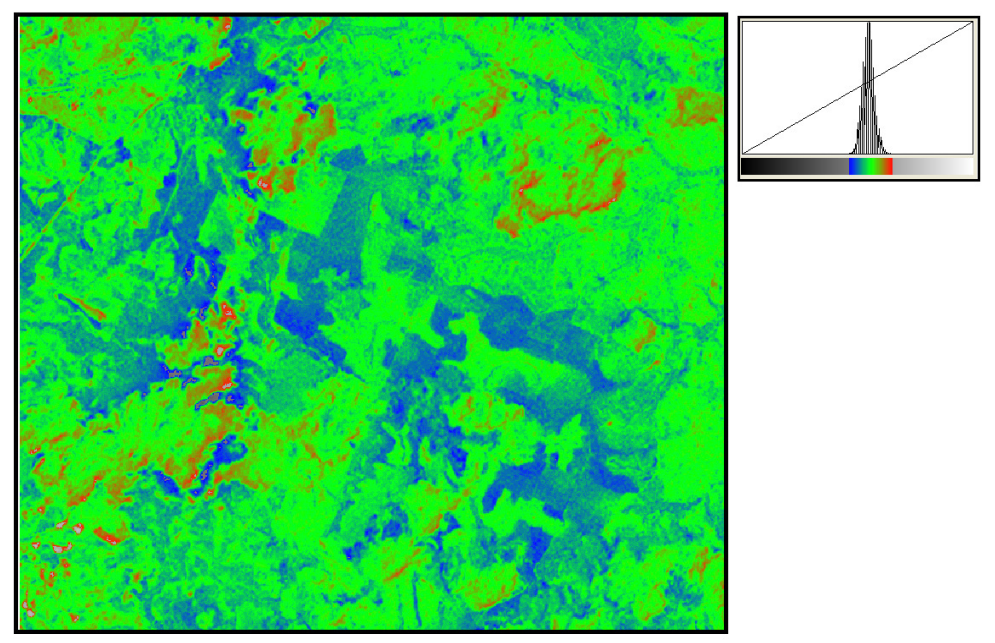

Figura 4.23- Fatiamento “Arco íris" da sétima componente, onde se observa a transição de intensidade entre as cores azul e verde, situados no lado esquerdo do histograma, correspondentes à variação de umidade do solo. 
Podemos observar também a variação da resposta nas componentes principais segundo o tipo de alvo. De acordo com as amostras em condições variáveis de umidade do solo e da vegetação (solo seco, solo úmido, vegetação senescente e vegetação verde), podemos verificar a variação das respostas nas componentes, buscando identificar a variação dos teores de umidade dos solos. Entretanto, devido a concentração da variância nas três primeiras componentes, tornou-se difícil identificar qualquer resposta nas componentes de alta ordem. Assim, excluiu-se do gráfico as três primeiras componentes (Figura 4.24).

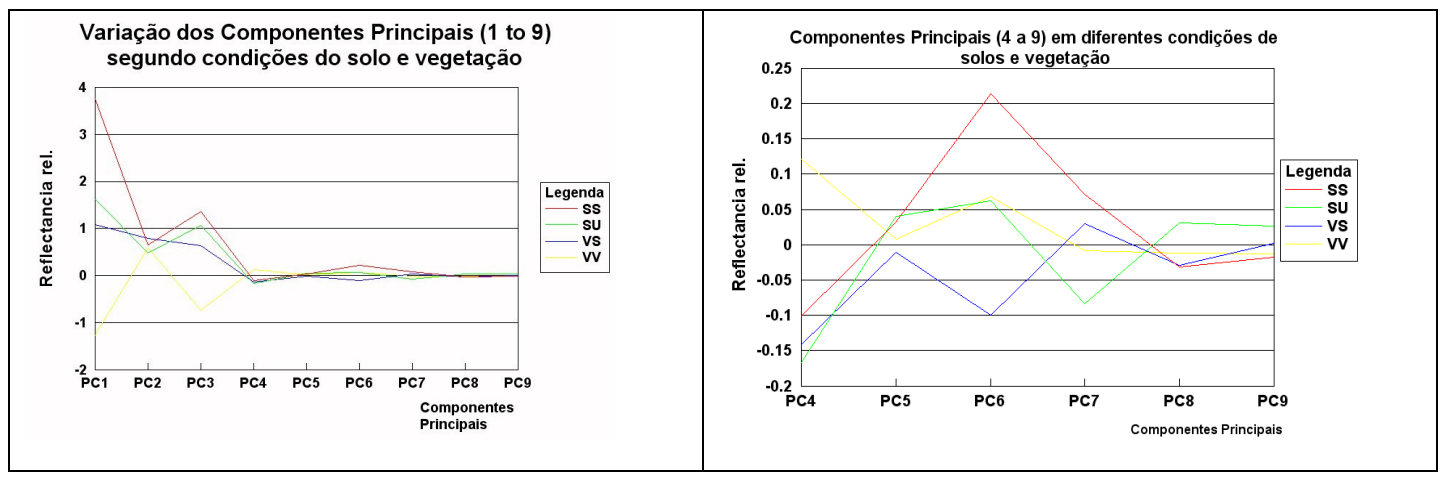

(a)

(b)

Figura 4.24 - Variação das componentes principais considerando as diferentes condições de solo e vegetação. (a) Variação com todas as nove componentes; (b) Variação considerando apenas as componentes de 4 a 9). Solo Seco (SS); Solo Úmido (SU); Vegetação Senescente (VS); Vegetação Verde (VV)

Observa-se no gráfico na Figura 4.24 (b) a clara separação do solo seco (SS - linha vermelha), do solo úmido (SU - linha verde), com respostas contrárias ao teor de umidade na sétima componente principal (CP7). A componente principal 8 (CP8), também apresenta uma distinção dos solos quanto ao teor de umidade, mas a resposta da vegetação senescente (VS linha azul) poderia mascarar os resultados.

Considerando os tipos de solo da área de referência, observa-se que o Podzólico Acinzentado sem coesão(PC - linha amarela) é a classe de solo com o menor teor de umidade, enquanto o Podzol (linha vermelha) é o que possui maior teor, o que condiz com suas características de coesão. Entretanto, o Podzólico Acinzentado com coesão (PCf - linha magenta) possui menos água que o Podzólico Amarelo sem coesão (PA - linha verde) . Isto pode ser explicado pela posição de borda de escarpa do PCf, o que, mesmo com a presença de níveis coesos, aumentariam a dinâmica hídrica pelas laterais, que é o mesmo processo que faz com que os solos PC sejam os mais dissecados, enquanto o PA é um solo típico de topo de tabuleiro, onde o escoamento hídrico, em geral, só ocorre por infiltração. O Podzólico 
Amarelo com coesão (PAf - linha azul) é apenas um pouco mais úmido que o seu correlato sem nível coeso (PA), embora se caracterize como a segunda classe de solo mais úmido (Figura 4.25).

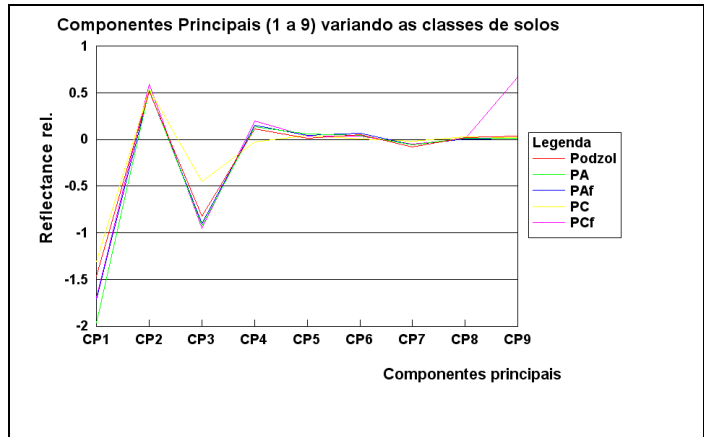

(a)

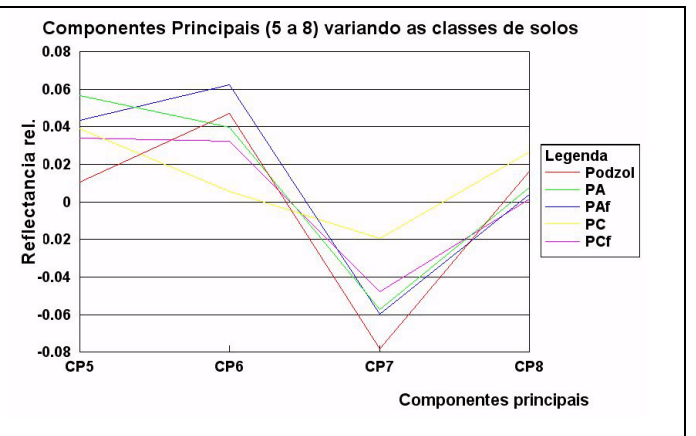

(b)

Figura 4.25 - Variação das componentes principais considerando as diferentes classes de solos da área de referência: (a) Variação com todas as nove componentes; (b) Variação considerando apenas as componentes de 5 a 9. PA= Podzólico Amarelo sem coesão; Paf = Podzólico Amarelo com coesão; PC = Podzólico Acinzentado sem coesão PCf = Podzólico Acinzentado com coesão

Assim, a análise das amostras referenda a observação visual e a classificação monoespectral realizada anteriormente.

\subsection{Razão entre bandas}

As razões entre os canais VNIR e SWIR deram resultados inesperados, contrariando parcialmente o exposto no referencial teórico.

Observando os resultados nas amostras de solo e vegetação com diferentes teores de umidade (Figura 4.26), verifica-se que os dois tipos de vegetação obtiveram respostas mais distintas que os solos, principalmente nas razões coma as bandas 1 e 3, sendo que a vegetação verde, seguida pela vegetação senescente, foram as que apresentaram as maiores respostas entre eles, o que seria o esperado, posto a vegetação responder muito forte nos canais visíveis, seja pelo próprio teor de umidade contido nas folhas, seja pela presença dos pigmentos fotossintetizantes (clorofilas e carotenóides). Entretanto, destacamos que as razões com as bandas 1 e 3, realmente demonstraram uma maior razão para os solos úmidos do que para os solos secos, indicando que estas razões serviram para identificar a umidade dos solos. Mas estas respostas não acontecem para todas as razões entre as bandas 1 e 3 com todas as SWIR: ela somente ocorre com as bandas 7, 8 e 9, sendo que as razões com a banda 3 são mais significativas que com a banda 1 , ao contrário do que se afirmou anteriormente sobre as 
bandas 4,5 e 9 . As demais razões $1 / 3,1 / 4,1 / 5,1 / 6$, assim como a 3/4, 3/5 e 3/6 apresentam resultados indistintos, onde os solos tanto seco como úmido, apresentam as mesmas respostas, o mesmo ocorrendo com as razões 4/5, 4/6, e 4/9 negando a afirmação teórica de que estas bandas (4 e 5) apresentariam o maior contraste, como pode ser observado mais detalhadamente na Figura 4.27. Nas razões com a banda 4 como numerador, todas as respostas foram indistintas quanto ao teor de umidade, inclusive a vegetação verde e a vegetação senescente reduzem suas repostas nestas razões, embora sejam ainda parcialmente distintas nas razoes $4 / 5$ e 4/6, mas completamente indistintas nas razões 4/9 e 5/9. Os valores negativos dos pixels da razão entre as bandas do infravermelho médio, em particular da razão 4/5 contraria o conceitual teórico pelo qual se espera que relação aumente com o teor de água no solo. Este fato é apoiado pela avaliação das curvas de reflectância dos solos sob diferentes teores de umidade (Figura 4.5) e pela comparação entre os comprimentos de onda que reduzem suas reflectâncias ao serem umedecidas.

As razões envolvendo a banda 2 são inconclusivas. Podem indicar a elevada reflectância dos solos expostos, em particular, sua composição mineralógica, principalmente nas razões ente as bandas mais baixas $(2 / 3,2 / 4,2 / 5,2 / 6)$ onde os solos apresentam maior reflectância que a vegetação e os solos secos mais que os solos úmidos. Na verdade, não apresentam qualquer relação com o teor de umidade.

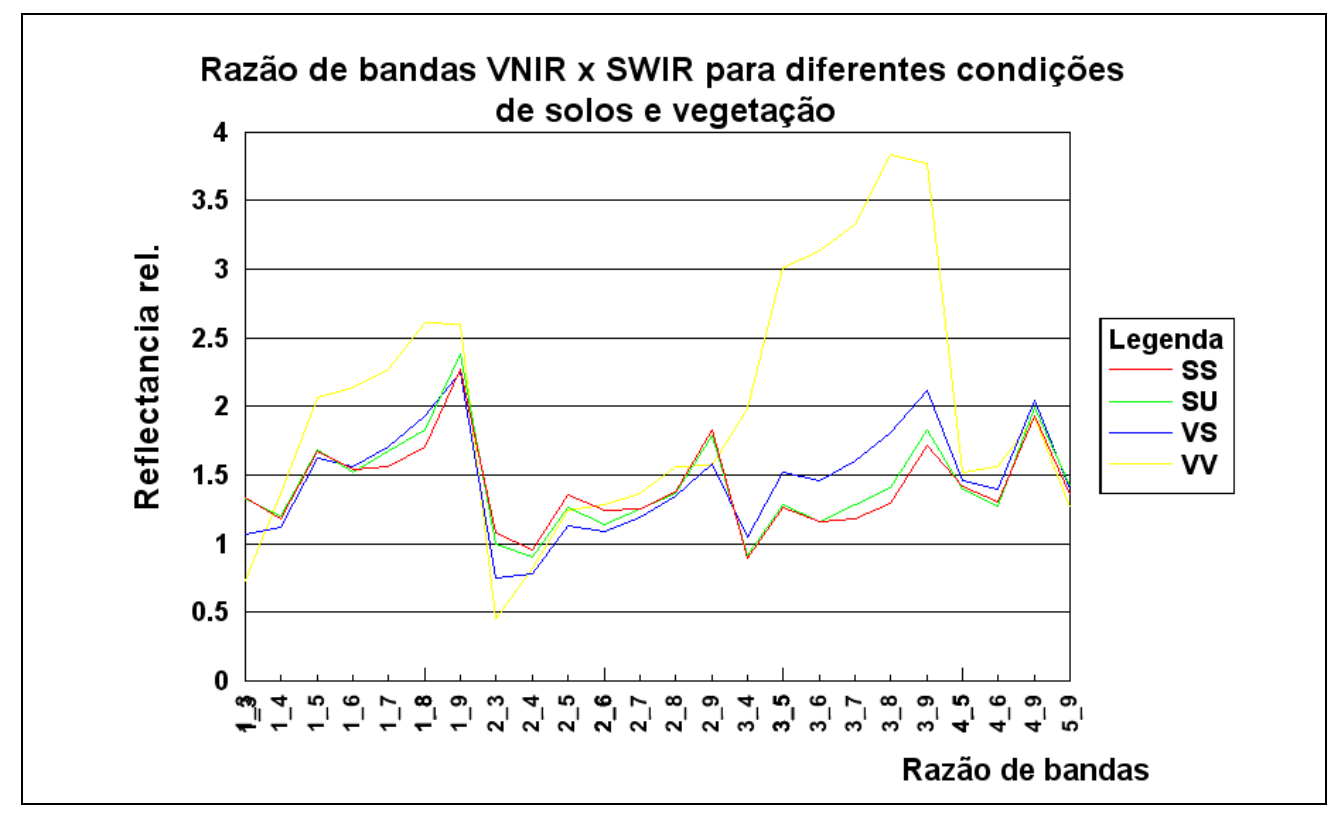

Figura 4.26 - Razão entre as bandas VNIR x SWIR para diferentes condições de umidade de solo e vegetação. Solo seco ( $\mathrm{SS}$ - Linha vermelha); Solo úmido (SU - linha verde); Vegetação senescente (VS - linha azul); Vegetação verde (VV - linha amarela) 


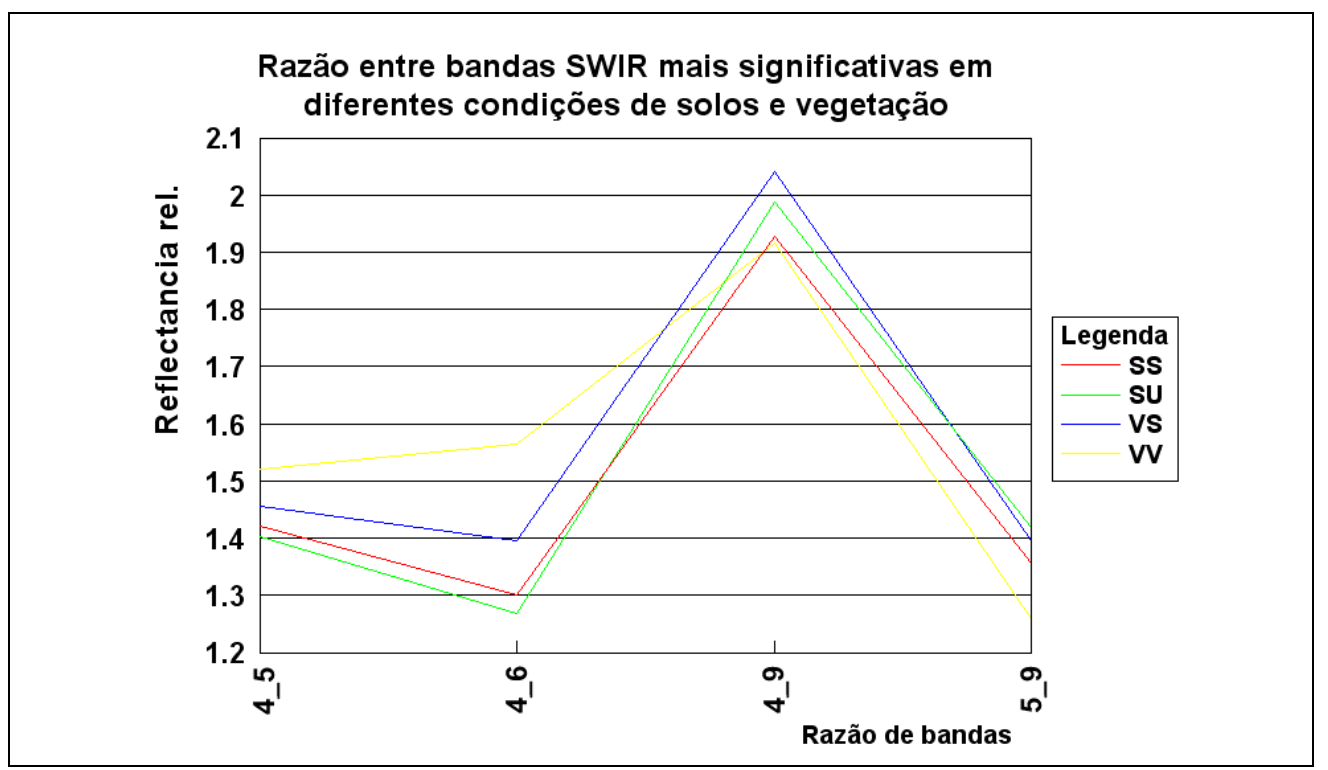

Figura 4.27 - Razão entre as bandas SWIR mais significativas para a identificação do teor de água, para diferentes condições de umidade para solos e vegetação. Solo seco (SS - Linha vermelha); Solo úmido (SU - linha verde); Vegetação senescente (VS - linha azul); Vewgetação verde (VV - linha amarela)

A Figura 4.28 ressalta a variação da resposta das amostras de solo seco e solo úmido às diferentes razões de bandas. Assim, a partir da análise das respostas apresentadas nos gráficos, podemos afirmar que as melhores razões para avaliar os diferentes teores de umidade do solo, ao menos para esta área específica, foram as razões 1/7, 1/8, 1/9, 3/7, 3/8 e $3 / 9$.

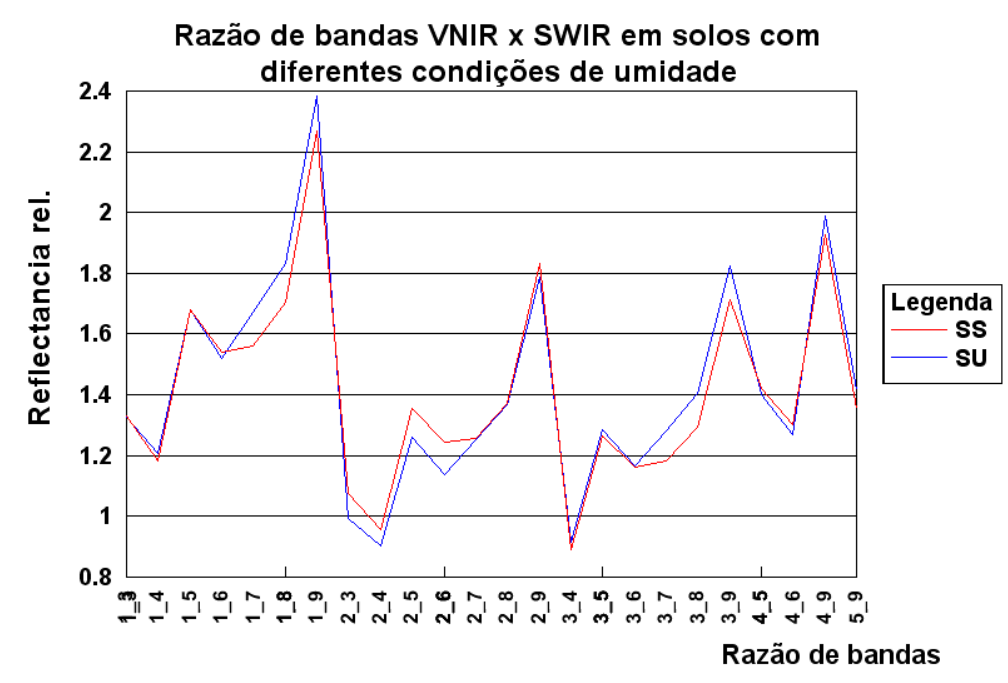

Figura 4.28 - Razão entre as bandas VNIR x SWIR para os solos em diferentes condições de umidade. Solo seco (SS - Linha vermelha); Solo úmido (SU - linha azul 
O comportamento das razões de bandas em relação às classes de solos, seguiu o mesmo padrão de resposta quanto à umidade dos solos, como pode ser observado na Figura 4.29.

O solo que apresentou as razões mais baixas foi o Podzólico Acinzentado sem coesão (PC), considerado neste trabalho como o solo mais bem drenado, principalmente devido à sua posição próxima às bordas de cabeceiras de drenagem, que aceleram o processo de escoamento da água através da sua drenagem lateral e vertical. Os solos que apresentaram maior concentração de umidade foram o Podzólico Amarelo sem coesão (PA) e o Podzólico Acinzentado com coesão (PCf). O primeiro deles (PA), embora sem coesão, situa-se em áreas aplainadas do tabuleiro, onde a drenagem por infiltração é lenta e a densa cobertura vegetal, associada a uma espessa serrapilheira por ela produzida, pode permitir a manutenção e um elevado teor de umidade superficial, formando uma camada protetora contra a dissecação. $\mathrm{O}$ Podzólico acinzentado com coesão retêm a água auxiliado pela vegetação densa e a camada de serrapilheira, o mesmo ocorrendo com o Podzólico Amarelo com coesão (PAf). Por outro lado, os Podzóis, que apresentam o mais resistente horizonte coeso, encontram-se tanto em áreas de borda de tabuleiro, onde a drenagem lateral permitiria escoamento de água, impedindo o seu acúmulo, assim como sua ocorrência se verifica em áreas onde a cobertura vegetal é mínima e o mesmo encontra-se exposto a intensa evaporação e dissecação pela radiação solar incidente.

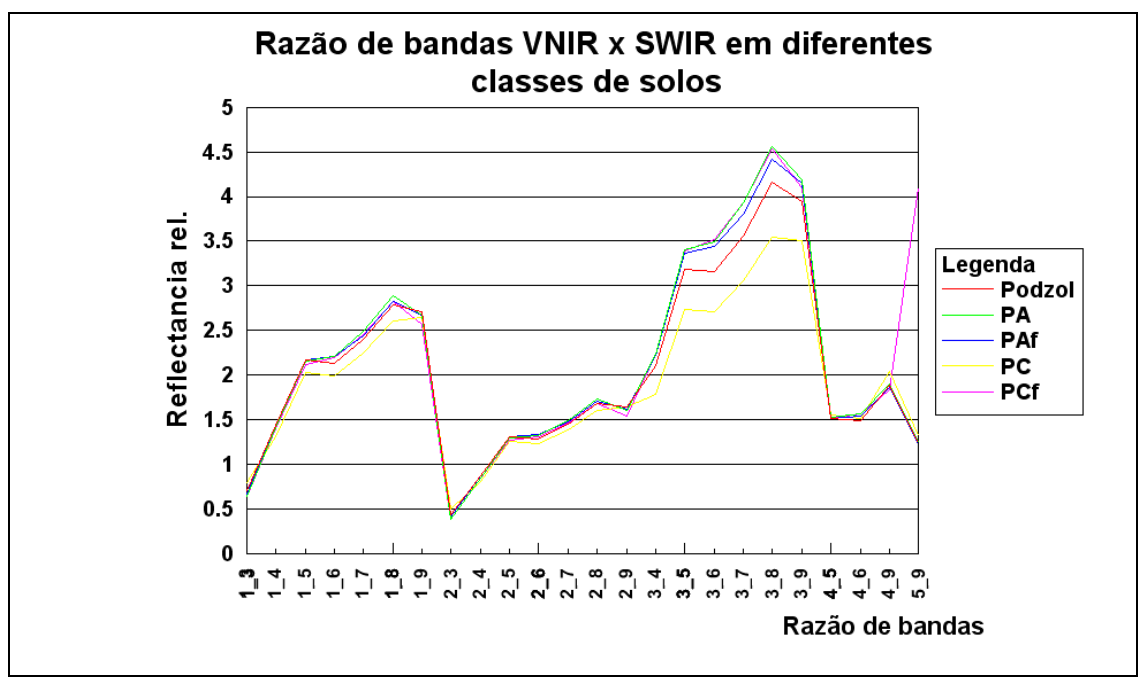

Figura 4.29 - Razão entre as bandas VNIR x SWIR para diferentes classes de solos. Podzólico Amarelo sem coesão (PA - linha verde); Podzólico Amarelo com coesão (PAf - linha azul); Podzólico acinzentado sem coesão (PC - linha amarela); Podzólico Acinzentado com coesão (PCf - linha magenta). 
Embora tenhamos tentado isolar a umidade como um fator determinante a ser identificado através da resposta da reflectância espectral, esta pode ser alterada pela presença e/ou ausência de outros fatores. O principal fator nesta área é a densa cobertura vegetal que, com sua sombras e a densa serrapilheira, pode formar uma camada protetora fazendo com que solos bem drenados mantenham elevado seu teor de umidade superficial. Por outro lado, o relevo também conta como fator predominante da dinâmica hídrica. Dificultando o escoamento, nas regiões planas e acelerando esta dinâmica em regiões de maior declividade.

Para demonstrar o potencial de separabilidade dos teores de umidade do solo, foi selecionada a razão entre as bandas 3 e 8, após comparar seus resultados com as demais razões, em particular a razão entre as bandas 1 e 8, também de grande potencial, embora com resultados ligeiramente inferiores quanto a capacidade de separar visualmente as classes de umidade. Como critério de validação, foi escolhida a área de referência, com a sobreposição da carta de solos, e verificada a concordância de resultados (Figura 4.30).

Verifica-se no conjunto das imagens retratadas na Figura 4.30, a forte tendência de identificar os diferentes teores de umidade dos solos. Na Figura (d), foi realizado um fatiamento normal com 5 classes do histograma da imagem da razão 3/8, onde os diferentes teores de umidade foram agrupados em quatro classes principais, em ordem decrescente: verde, azul, vermelho e cinza, conforme histograma. A extrema esquerda do histograma, principalmente os pixels classificados no intervalo do branco e alguns do cinza correspondem a nuvens. O resultado de outro fatiamento normal, mas com 8 classes é apresentado na Figura (e), mas esta classificação está agrupando e subdividindo elementos em classes que já não é mais possível reconhecer a associação a partir da verdade de campo disponível. Entretanto, acreditamos que este continua retratando aspectos da variação da umidade dos solos, mas que, infelizmente, falta-nos informações de campo para validar. O fatiamento em "Arco Íris" na Figura (f) apresenta-nos uma variação gradual do teor de umidade, podendo indicar de forma indireta, a direção do fluxo subsuperficial da umidade em suas áreas de diferentes concentrações, explícita neste representação pela intensidade da cor vermelha. 


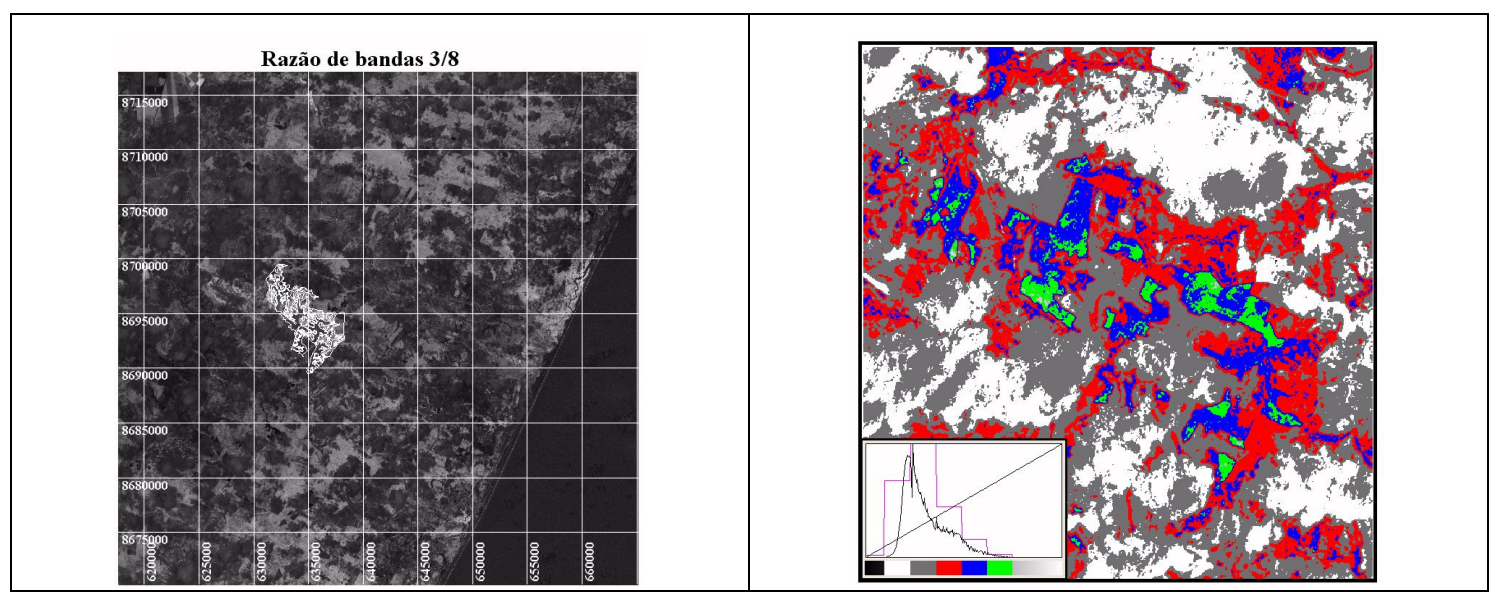

(a) Imagem obtida pelo produto da banda 3 sobre a banda 8 (Razão 3/8). Em linhas brancas, no centro da imagem, a representação vetorial da

(d) Imagem da Razão 3/8 após fatiamento normal com 5 classes carta de solos

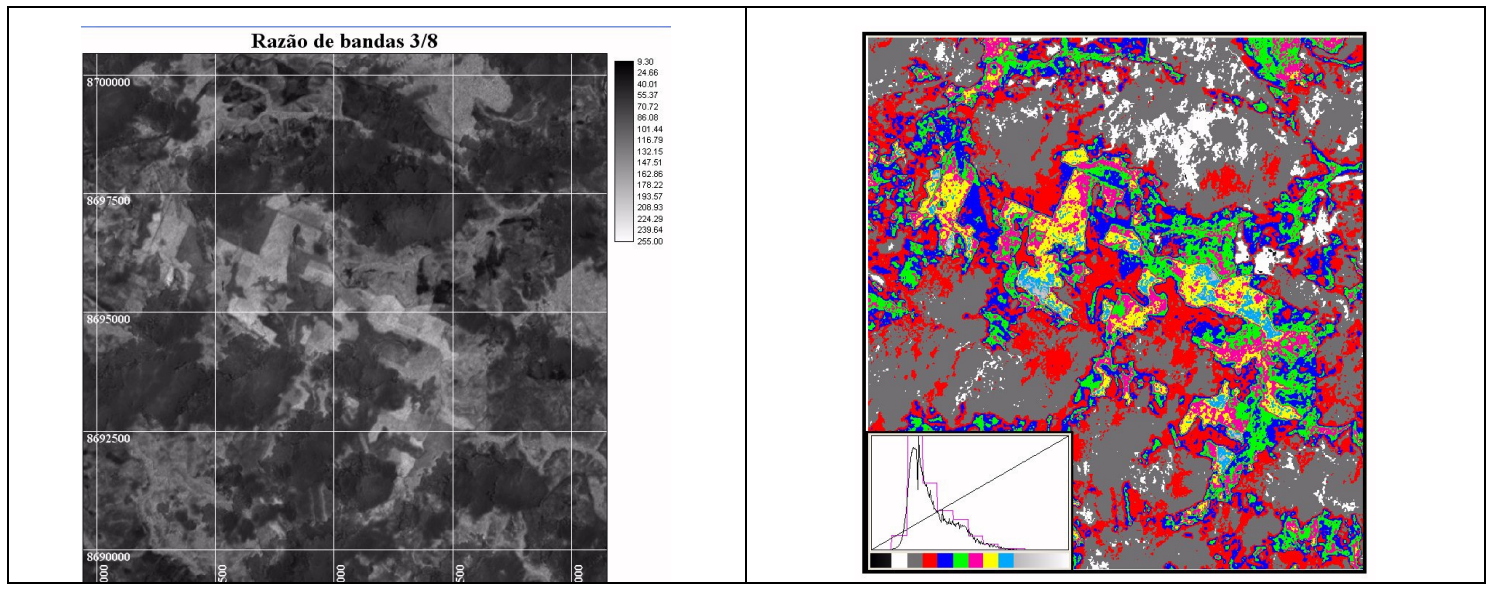

(b) Detalhe da imagem da razão entre bandas 3/8

(e) Imagem da Razão 3/8 após fatiamento normal com 8 classes

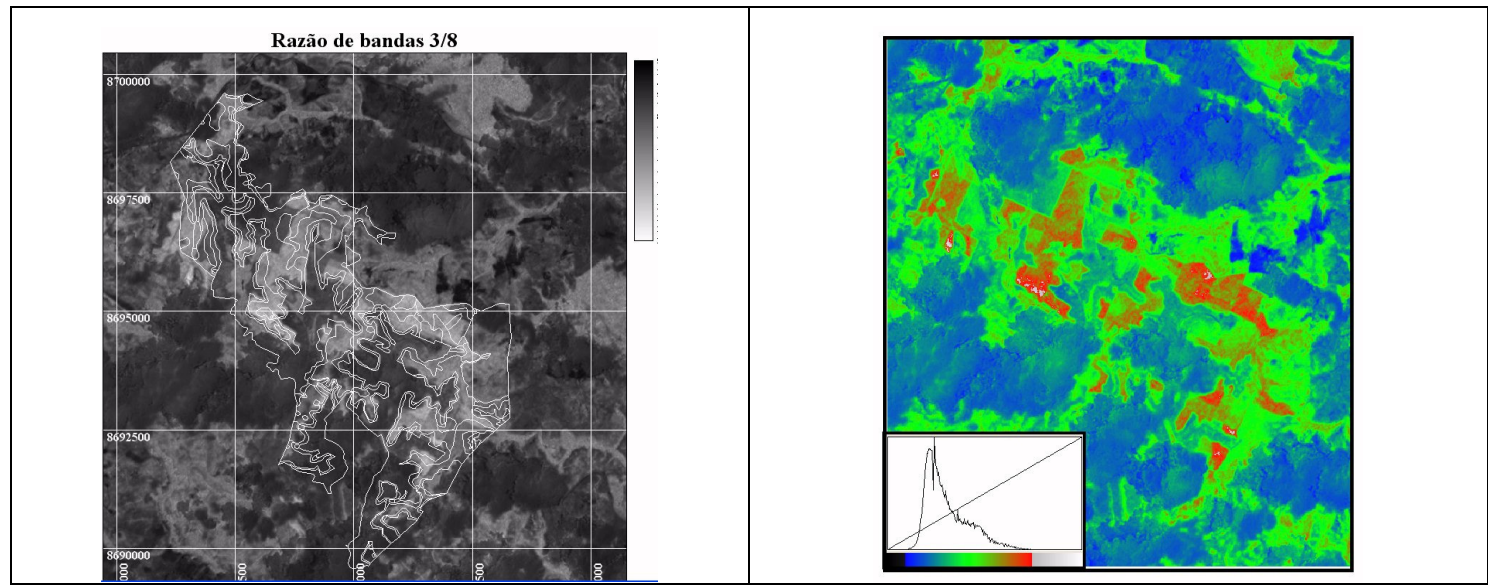

(c) Detalhe da imagem da razão de bandas 3/8, (f) Razão 3/8 fatiamento Arco Iris com destaque da sobreposição vetorial da carta de solos em linhas brancas

Figura 4.30 - Imagem da razão entre bandas 3/8, uma das mais significativas na apresentação de contraste entre os diferentes teores de umidade dos solos 


\section{5 Índices espectrais}

Nesta etapa, iremos analisar os índices espectrais em conjunto, visando avaliar comparativamente suas respectivas capacidades em diferenciar os teores de água dos solos. Na Figura 4.31 apresentamos os resultados desta comparação a partir de amostras coletadas na imagem, referentes às diferentes condições de umidade de solo e vegetação. Destaca-se neste gráfico a presença dos três primeiros produtos gerados durante a Transformação Tasseled Cap (TTC), os quais foram, neste trabalho também considerados como índices espectrais. Observa-se nesta figura a resposta elevada do índice de brilho. Esta era esperada devido ao processo de sua geração. Como o índice de Brilho ressalta o albedo da área, sendo este utilizado para gerar a "linha do solo" ${ }^{10}$, o solo seco exposto apresenta neste índice a resposta mais elevada, seguida pelos solos úmidos, vegetação senescente e por fim, a vegetação verde, que apresenta o mais baixo albedo (Figura 4.32). Interessante verificar que o solo úmido e a vegetação senescente têm uma resposta muito similar, posto que estes podem ser considerados, segundo o princípio da "linha dos solos", respectivamente como "menos solos" e "menos vegetação", ficando situados em regiões muito próximas. Assim, este índice se apresenta como um identificador viável para separar solos úmidos e secos.

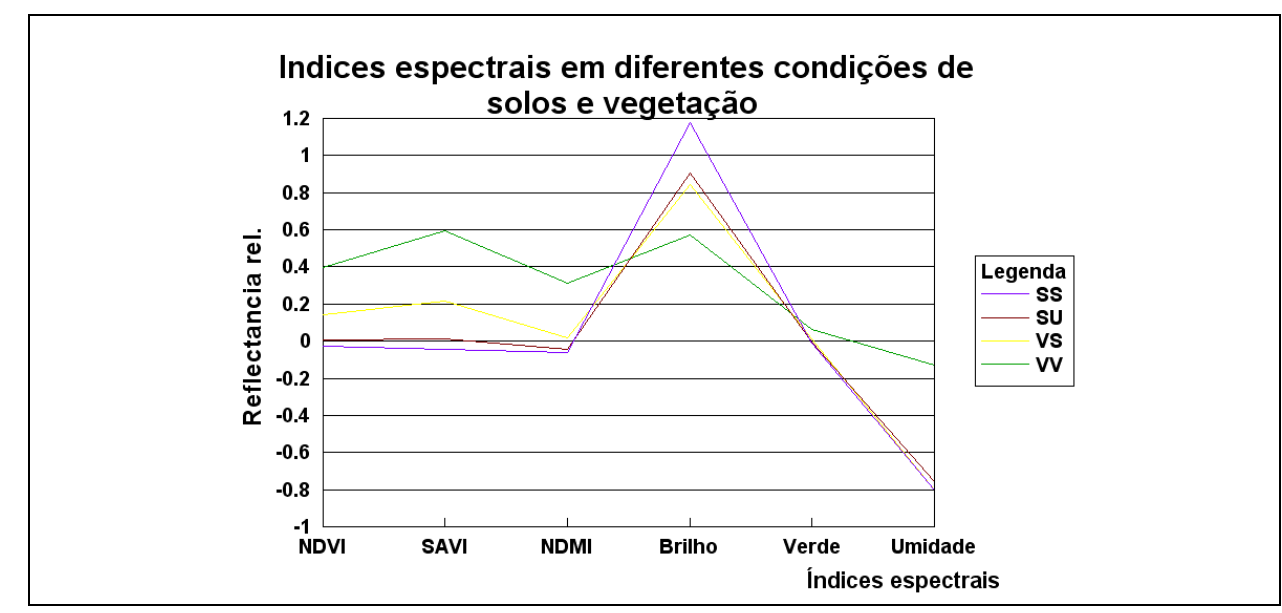

Figura 4.31 - Gráfico comparativo dos índices espectrais para as diferentes condições de umidade do solo e vegetação. Solo Seco (SS - magenta); Solo Úmido (SU - marron); Vegetação Senescente (VS - amarelo); Vegetação Verde (VV - verde)

10 A linha do solo é uma representação sintética da intensidade de reflectância de um certo conjunto de amostras de solos, tomada em duas bandas espectrais distintas, que apresentem respectivamente uma máxima reflectância e a máxima absorção (Baret et al, 1993). Trata-se de um gráfico de dispersão que, em geral, envolve as bandas do visível (vermelho) e infravermelho próximo (NIR) 


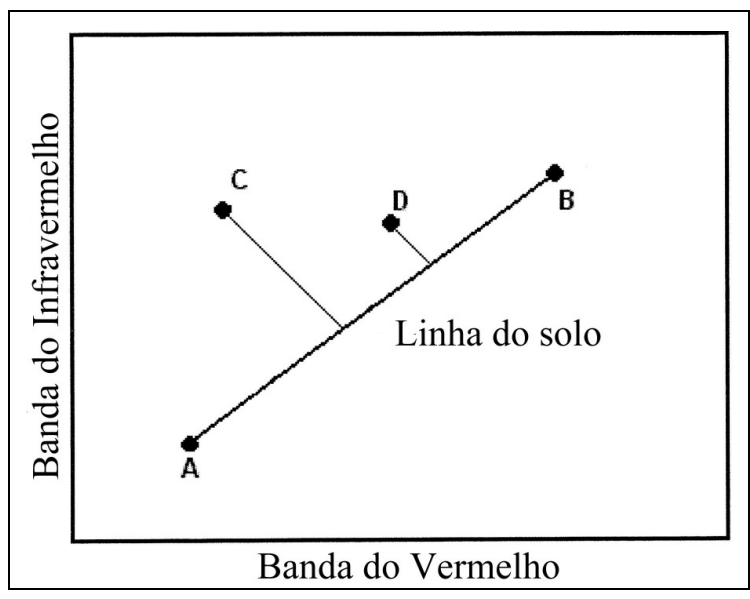

(a)

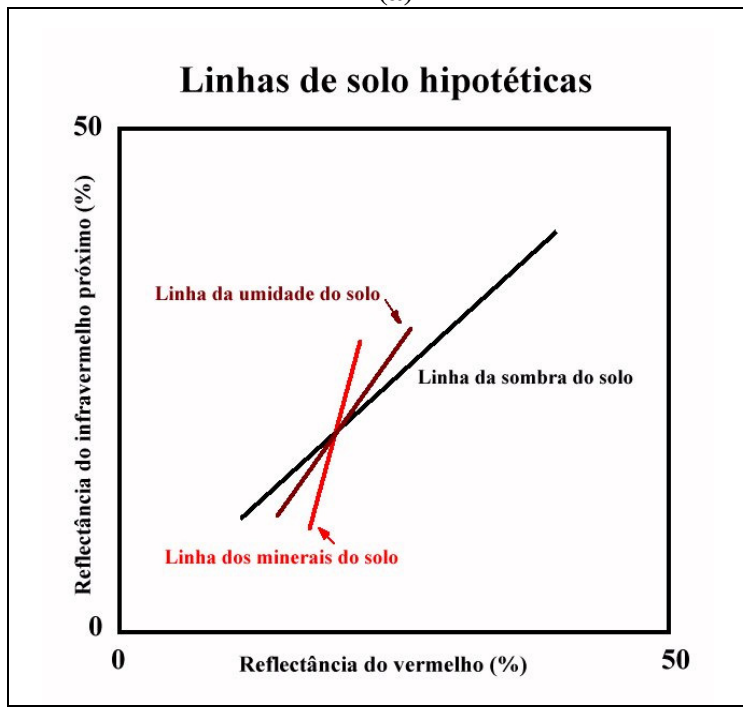

(c)

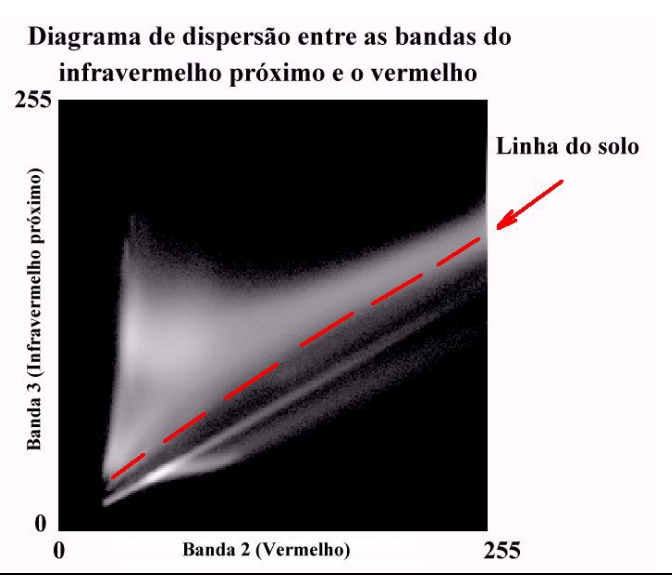

(b)

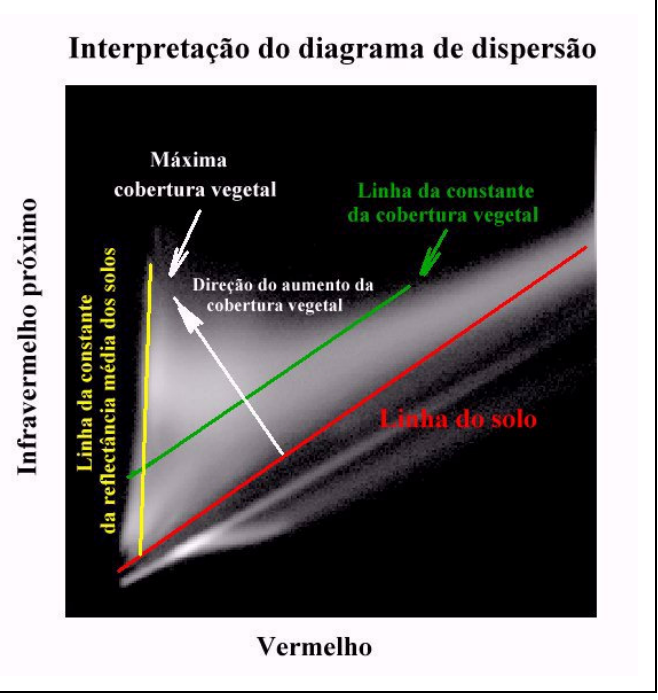

(d)

Figura 4.32 - Conceito da linha do solo demonstrando a relação linear observada entre os canais vermelho (V) e infravermelho próximo (IVP) para a reflectância do solo exposto. A linha do solo se estende dos solos escuros localizados numa região com baixo valor de reflectância do V e do IVP (Ponto A) para uma região superior com alta intensidade de brilho em V e IVP (Ponto B). O Ponto C representa o pixel puro da vegetação e o Ponto D representa o pixel de vegetação parcial (Campbell, 1996). O Ponto A equivale ao Solo Úmido (SU), o Ponto B ao Solo Seco (SS), o Ponto C à Vegetação Verde (VV) e o Ponto D à Vegetação Senescente (VS). (a) Representação esquemática da linha do solo; (b) Diagrama de dispersão das bandas 2 e3 com a definição da linha do solo; (c) Representação esquemática das diferentes linhas hipotéticas do solo: em preto, a linha do solo, em vermelho a linha dos minerais dos solos e em marrom a linha de umidade dos solos ; (d) Interpretação do diagrama de dispersão das bandas 2 e 3, com identificação da linha do solo (vermelho), da área de reflectância constante dos solos (amarelo) e direção do aumento da densidade de cobertura vegetal (branco). (Fonte: Adaptado de Jasinky e Eagleson, 1989)

Entretanto, ao se avaliar as amostras de solos secos e úmidos (Figura 4.33), embora essas estejam separados graficamente, a correlação entre as respectivas respostas é baixa (menor que 0.3), indicando que a umidade não é o fator condicionante desta separação. Como este índice identifica principalmente o solo exposto, este é muito mais influenciado pelas 
propriedades geométricas (granulometria e textura) e mineralógicas (composição) dos tipos se solos.

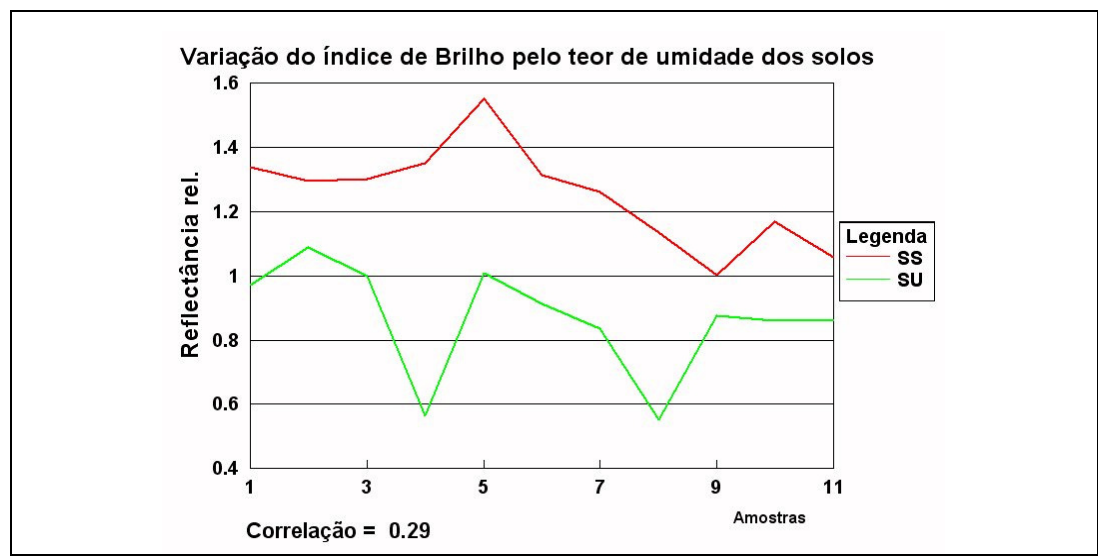

Figura 4.33 - Variação do índice de Brilho segundo condições de umidade das amostras de solo. Solo Seco (SS); Solo Úmido (SU)

Ao se avaliar o índice de Brilho segundo as classes de solos estes mostraram-se inconclusivos. Como a área de referência, onde encontram-se mapeados os solos, é densamente florestada e, conseqüentemente, de baixo albedo, os valores do índice de brilho mostraram-se muito baixos, refletindo apenas a densidade da vegetação (Figura 4.34). Isto se confirma pelos solos que possuem ocupação mais antiga com vegetação densa em avançado estágio de crescimento, apresentar mais baixo albedo (PA), enquanto os solos de borda de tabuleiro, ocupados recentemente, com vegetação nos estágios iniciais de crescimento, apresentarem as maiores resposta neste índice.

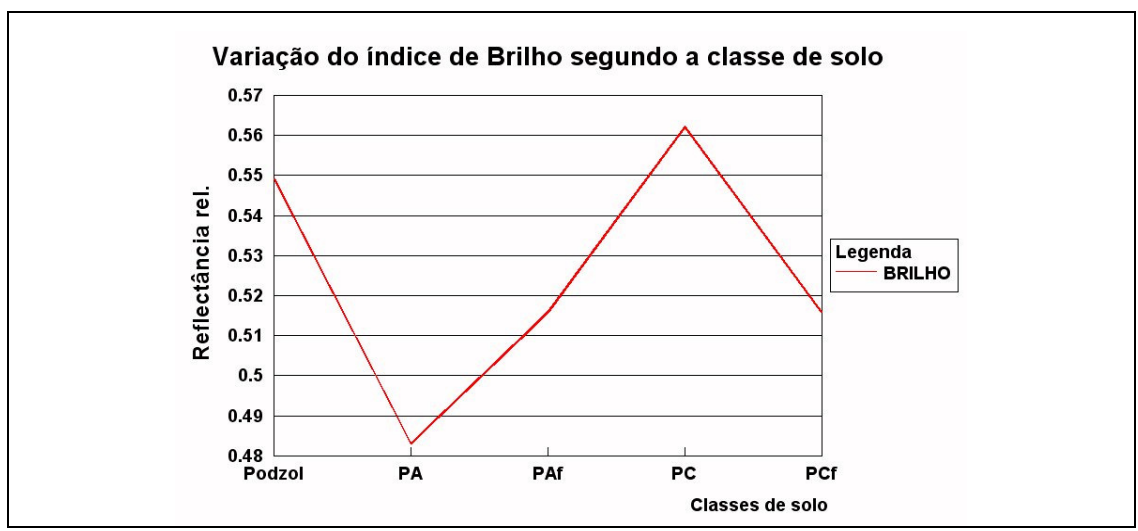

Figura 4.34 - Variação do índice de Brilho segundo classes de solos. Podzólico Amarelo sem coesão (PA); Podzólico Amarelo com coesão (PAf); Podzólico Acinzentado sem coesão (PC); Podzólico Acinzentado com coesão (PCf)

Ao se avaliar os demais índices espectrais (NDVI, SAVI e NDMI), verifica-se que estes apresentam respostas muito similares, tanto em comportamento como em intensidade. Para 
poder avaliar melhor a comparação entre os índices espectrais, foram removidos os índices de Brilho e Verde que, por concentrarem a maior parte dos dados da TTC, apresentam valores muito elevados (Figura 4.35(a)). Na Figura 4.35(b), pode se observar que os diferentes tipos de vegetação apresentam as melhores respostas, sendo que a vegetação verde (VV) apresenta uma resposta mais alta que a vegetação senescente (VS). A resposta dos solos é pouco diferenciada, embora o solo úmido apresente uma reflectância maior nos índices que o solo seco. Este fato confirma o objetivo destes índices buscam ressaltar a resposta da vegetação e minimizar os efeitos da resposta dos solos. Este fato torna-se evidente na resposta comparativa do SAVI e do NDVI, onde a vegetação no primeiro apresenta uma resposta mais alta que no segundo, embora a resposta do solo seja também mais evidente neste, apesar de pouco perceptível visualmente neste gráfico. Este fato pode ser explicado a partir de que NDVI é um dos índices espectrais mais sensíveis à presença do solo abaixo do dossel (Huete, 1985). As variações nas respostas do solo tem forte influência sobre sua resposta, o que é indesejável para quem avalia apenas o grau de cobertura vegetal, mas muito útil quando se deseja avaliar as condições do solo abaixo do dossel. O relacionamento entre as reflectâncias do infravermelho próximo (NIR) e do vermelho, para solos variando de escuros para claros, é geralmente linear, e o solo sempre cai ao longo da linha do plano cartesiano definido pelas reflectâncias das duas bandas (NIR e Vermelho), ou seja, a linha do solo. Assim, a medida que os solos são cobertos pela vegetação, a posição do pixel se afasta perpendicularmente desta linha do solo. O SAVI está entre um grupo de índices de vegetação que medem ou aproximam a distância entre o pixel e a linha do solo, retirando, assim, o efeito dos solos claros ou escuros.

O NDMI apresentou uma reposta numérica semelhante ao NDVI e ao SAVI, embora com menor intensidade. Este fato deve-se, possivelmente, ao uso da banda 4 (SWIR) para compor a diferença com o infravermelho próximo, resultando numa menor sensibilidade à clorofila das folhas.

A índice de Umidade gerado pela TTC não apresentou diferença significativa entre os alvos, exceto para a vegetação verde (VV), que, neste índice, apresentou a maior diferença em relação às demais feições. As respostas das outras variáveis, por outro lado, apresentaram-se em outra ordem, indicando as diferentes respostas de intensidade dos alvos a qual ela é sensível. O solo úmido (SU) apresentou uma resposta mais elevada que a vegetação senescente (VS) e não foi possível distingui-la do solo seco (SS). 


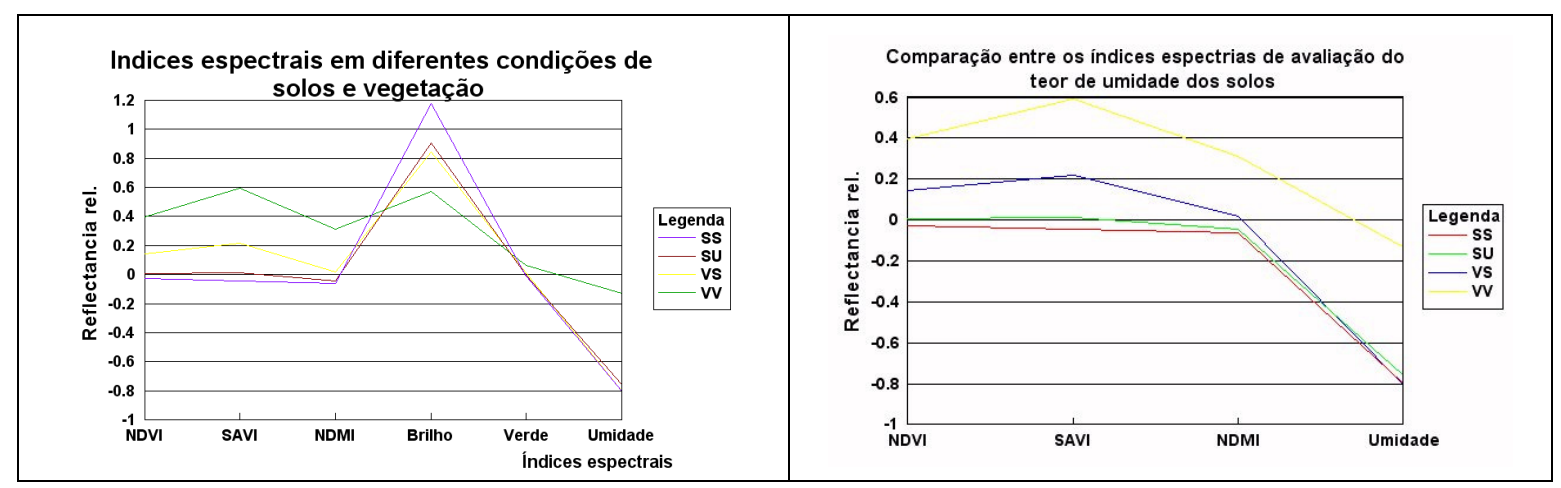

(a)

(b)

Figura 4.35 - Gráfico comparativo dos índices espectrais para as diferentes condições de umidade do solo e vegetação. Neste gráfico (a) a presença dos índices de Brilho e de Verde dificultam a comparação dos resultados. No gráfico (b) percebe-se mais claramente o comportamento dos índices espectrais, pela exclusão dos índices de Brilho e Verde. Solo Seco (SS - magenta); Solo Úmido (SU - marron); Vegetação Senescente (VS - amarelo); Vegetação Verde (VV - verde)

A resposta dos índices, segundo as diferentes classes de solos, foram igualmente semelhantes como no caso das amostras de solos e vegetação com diferentes teores de umidade, exceto para o índice de Brilho, onde os valores apresentaram respostas inversas (Figura 4.36). O Podzólico Acinzentado sem coesão (PC) por estar sem cobertura ou com vegetação rasteira, apresentou os mais baixos valores em todos os índices, exceto no Brilho, o qual foi o mais elevado, devido a resposta do albedo, enquanto que o Podzólico Amarelo sem coesão (PA), que apresentava o maior índice de reflectância para os índices de vegetação, apresentou os menores valores no índice de Brilho. É interessante verificar esta inversão de respostas ente o índice de Brilho e os demais índices, estruturados para captar a resposta da intensidade da clorofila, pois esta comparação entre eles pode ser utilizada como um indicador do estágio de desenvolvimento da cobertura vegetal. A resposta do Podzólico Acinzentado com coesão (PCf), embora bastante elevada nos índices de vegetação, não correspondeu a uma das menores respostas no índice de Brilho. Este fato deve-se a que esta área apresenta cobertura parcial mas os solos apresentam elevado teor de umidade.

O índice de umidade comporta-se de forma similar ao anterior (Figura 4.35), apresentando pouca diferenciação entre os solos, embora conserve a tendência dos demais, e tenha uma resposta inversa ao índice de Brilho. Os únicos que se apresentam como exceção são o Podzólico Amarelo com coesão (PAf) e do Podzólico Acinzentado com coesão (PCf) que, anteriormente apresentavam uma resposta intermediária e que neste índice apresentam os mais altos valores de reflectância. 


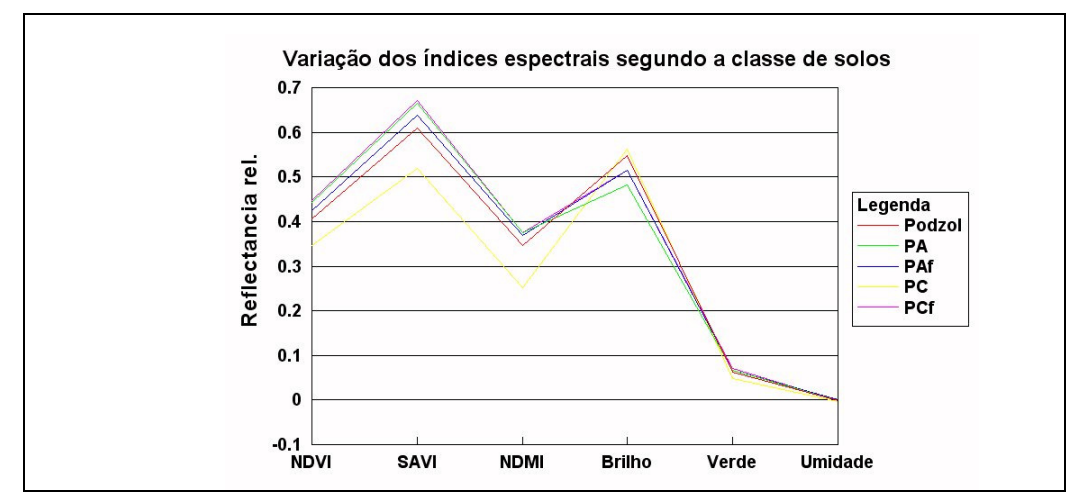

Figura 4.36 - Variação dos índices espectrais segundo a classe de solos. Podzólico Amarelo sem coesão (PA); Podzólico Amarelo com coesão (PAf); Podzólico Acinzentado sem coesão (PC); Podzólico Acinzentado com coesão (PCf)

Entretanto, demos uma maior atenção a três índices em particular, devido ao potencial teórico apresentado na bibliografia (Capítulo 2) para identificar o teor de umidade dos solos. Foram eles o NDMI, a Transformação Tasseled Cap Umidade e o NDVI. Na Figura 4.37 apresentamos a variação do índice de Umidade em condições de solo úmido e seco. A diferença entre as respostas, embora existisse, foi insignificante, apresentando-se a partir de duas casas decimais (ver escala do eixo de $\mathbf{Y}$ da Figura 4.37). Isto indica que a separabilidade, embora possível graficamente, não possui significância ou poder de representatividade em um sistema de classificação, nem seria possível de distinguir visualmente numa imagem, ficando esta restrita a poucos níveis de cinza..

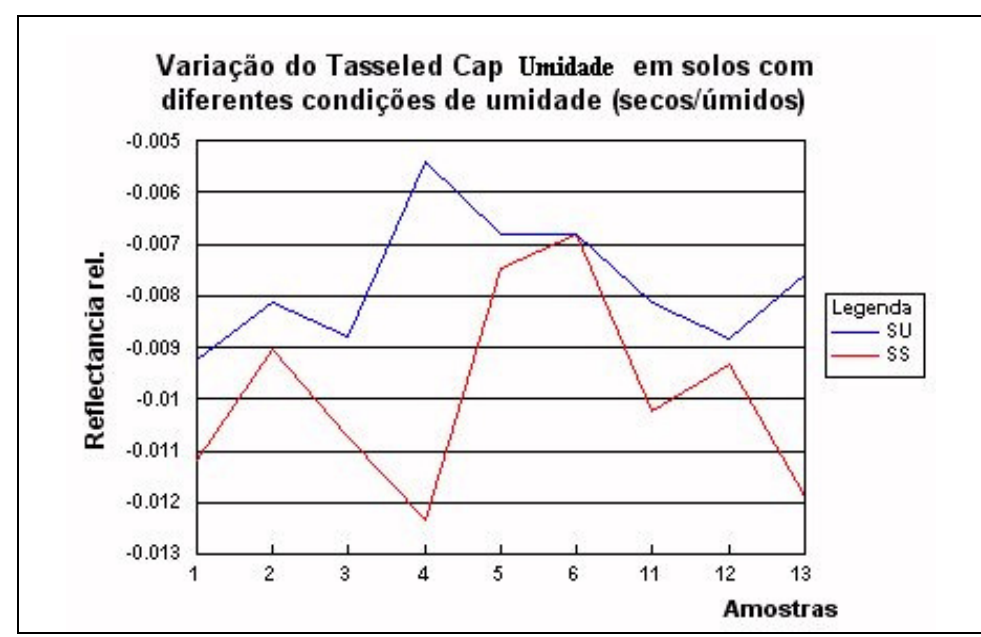

Figura 4.37 - Variação do índice de Umidade em solos com diferentes teores de umidade. Solo Úmido (SU - linha azul); Solo Seco (SS - linha vermelha)

Procedimento semelhante foi realizado comparando-se o NDMI com o índice de Umidade, para as diferentes condições de solo e vegetação (Figura 4.38). Embora as 
respostas sigam um padrão geral semelhante, estes dois índices apresentam divergências, em particular referente ao teor de umidade dos solos. Enquanto o índice de Umidade é sensível ao aumento de umidade, aumentando a reflectância, embora muito imperceptivelmente, o NDMI é completamente inerte, demonstrando não ser indicado para esta aplicação.

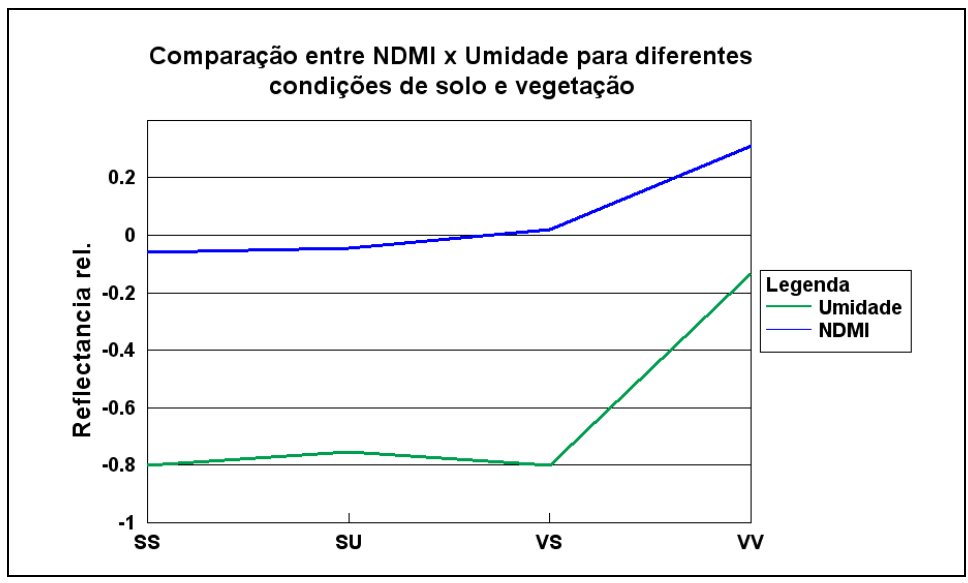

Figura 4.38 - Comparação dos resultados ente os índices NDMI e de Umidade para diferentes condições de solo e vegetação. Solo Seco (SS); Solo Úmido (SU); Vegetação Senescente (VS); Vegetação Verde (VV)

Embora teoricamente NDVI tenha maior sensibilidade ao solo sob o dossel, suas respostas quanto à variação de teor de umidade dos solos (Figura 4.39), representado pelas amostras de solo seco (SS) e solo úmido (SU) apresentaram uma baixa correlação (inferior a $0.3)$.

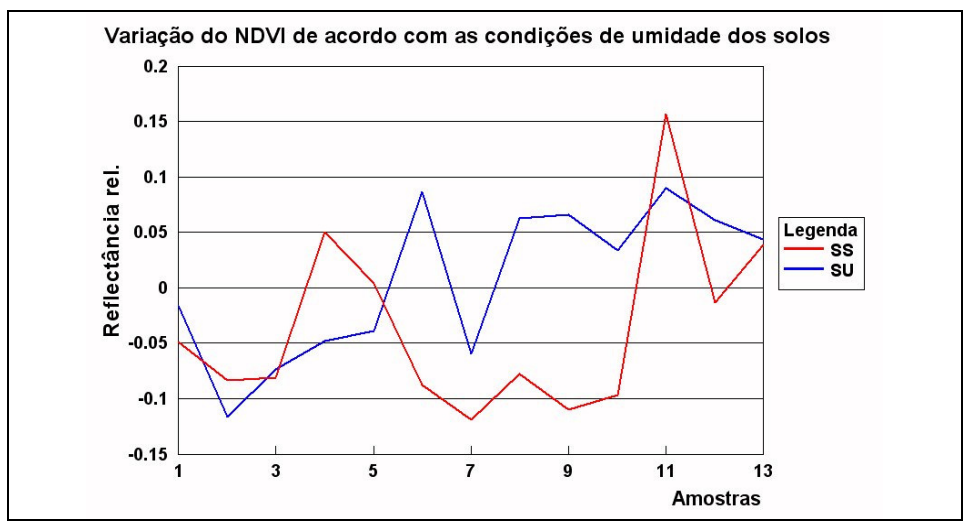

Figura 4.39 - Variação do NDVI segundo as condições de umidade dos solos. Solo Seco (SS); Solo Úmido (SU)

Em geral, podemos afirmar que todos os índices analisados possuem elevada correlação para as amostras de solo úmido, superiores a 0.95. A maior correlação observada foi entre o índice de Umidade e o NDMI (>0.98). Em seguida a do índice de Umidade com o SAVI ( > 
0.97) e terceira ente o NDMI e o NDVI (0.94). Todas estas respostas elevadas na verdade, demonstram a correlação ao teor de água das folhas e não necessariamente dos solos.

Um recorte das imagens geradas através dos índices mais significativos foram analisados e são apresentadas na Figura 4.40, ao lado de uma imagem classificada, obtida através de fatiamento normal com 10 classes. Sob estas condições, apenas o NDVI apresentou resultados mais condizentes com o mapa de referência.
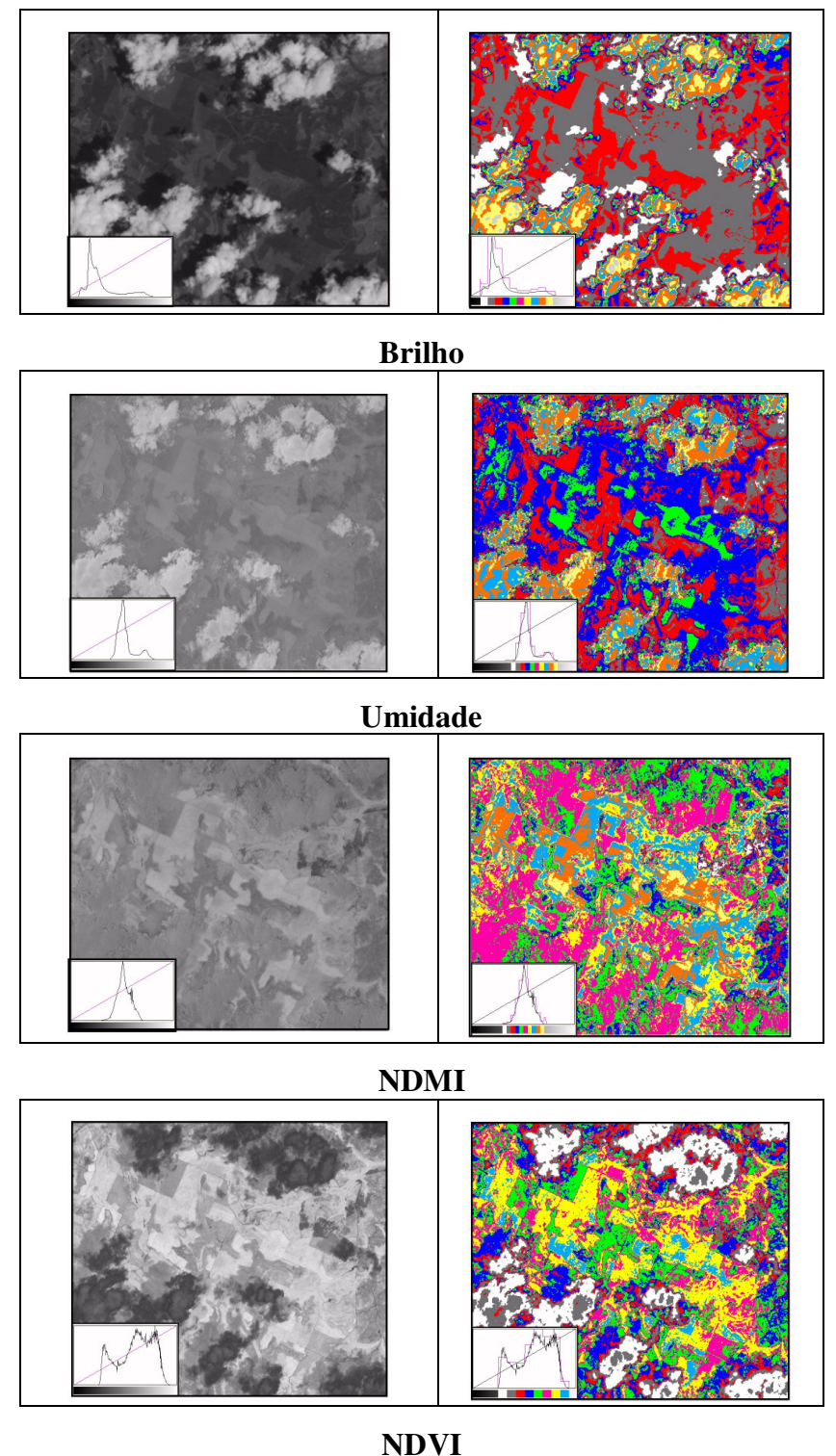

Figura 4.40 - Recorte de imagens dos índices espectrais com resultados mais significativos baseados na área de referência (à esquerda). Imagens classificadas através da técnica de fatiamento normal do histograma, em 10 classes, centradas nas áreas de maior frequiência. Observa-se, de cima para baixa, a ordem crescente de significância dos resultados 


\subsection{Classificação}

A classificação, como já discutido no Capítulo 3, foi realizada apenas sobre a área de referência, conforme exposto na metodologia. Foram utilizadas as bandas Aster de 1 a 9 . A Figura 4.41 (de (a) a (f)) retrata sumariamente o processo de identificação da área de amostra.

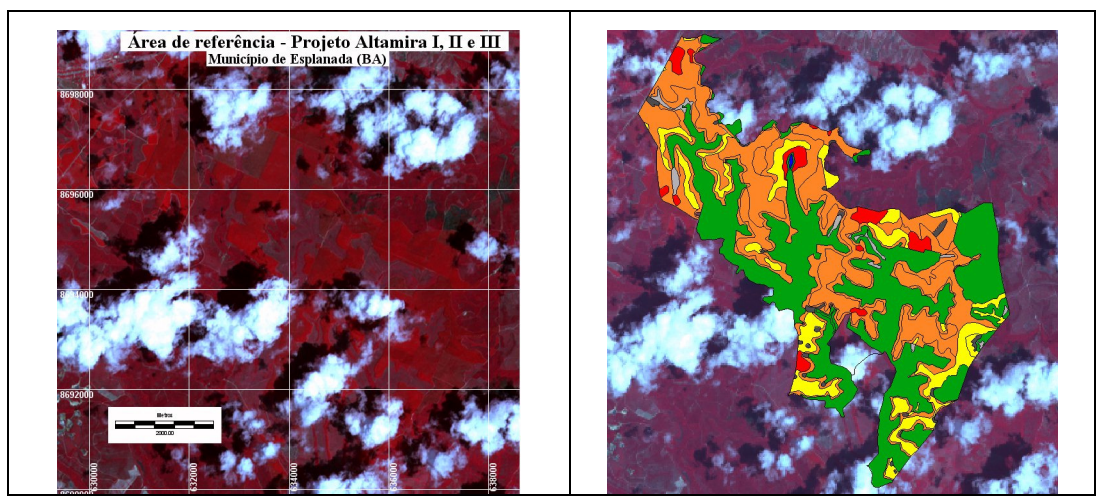

(a)

(b)

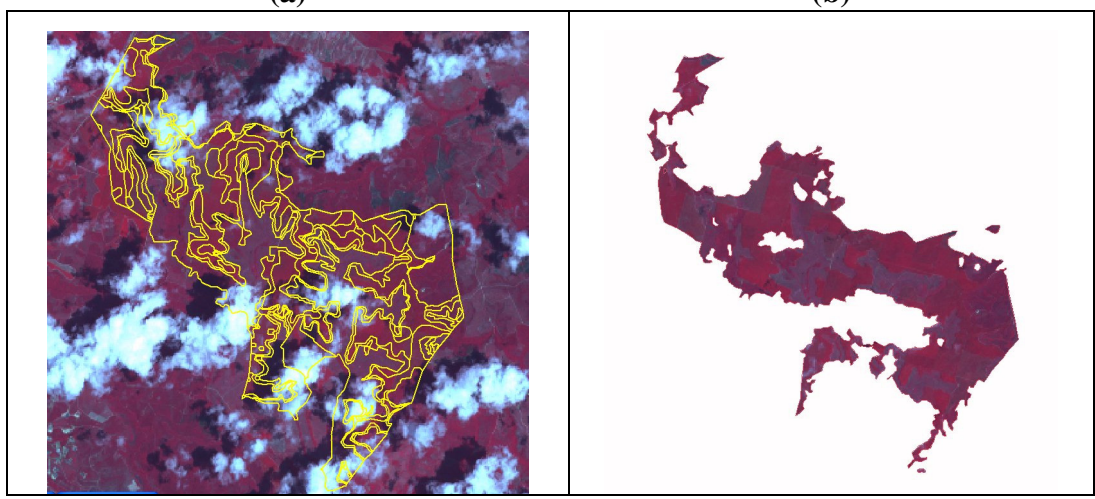

(c)

(d)

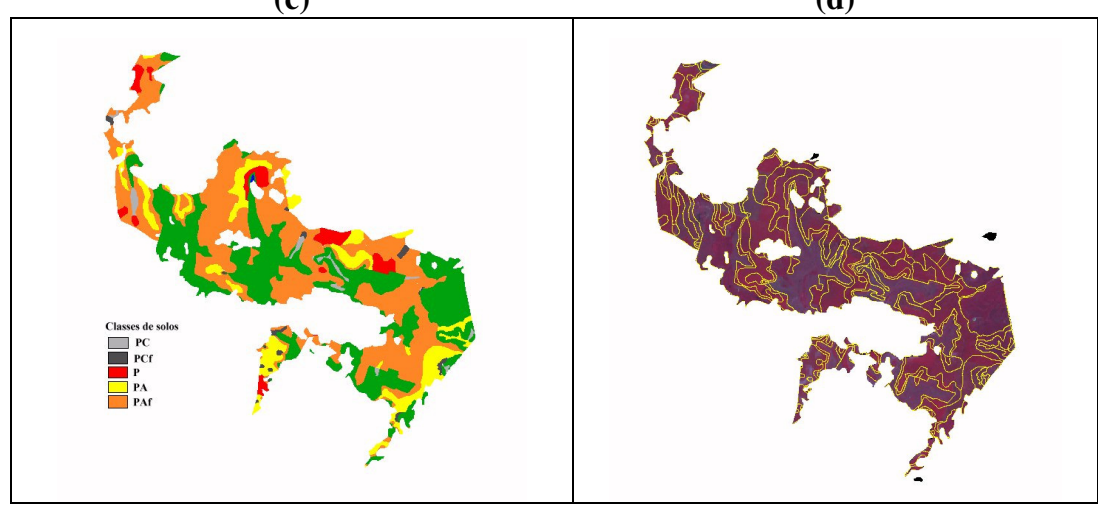

(e)

(f)

Figura 4.41 - Processo sumarizado de amostragem da área de referência. (a) Imagem recorte da área de referência; (b) Sobreposição do mapa de solos; (c) Visualização do mapa de solos sobre a imagem, com destaque para a ocorrência de nuvens e sombras recobrindo aproximadamente 30\% da área efetiva da classificação; (d) Recorte da área área a ser classificada, com exclusão das nuvens e sombras; (e) Recorte do mapa de sombras, comparando-o a área útil efetiva para classificação; (f) Imagem com os vetores das classes dos solos. 
Embora tenhamos explanado sobre as técnicas de amostragem, forma de coleta e tamanho da amostra, devido a presença das nuvens e das sombras, e ao processo de exclusão dessas duas classes, ocorreu uma redução significativa na área de referência, em torno de $35 \%$, e, conseqüentemente, também da área das classes em análise, conforme ilustrado na Figura 4.41.

A partir da área de referência, as classes de solos foram selecionadas e categorizadas em 5 classes distintas, conforme metodologia do Capítulo 3, a saber: Podzól com coesão (P); Podzólico Amarelo sem coesão (PA); Podzólico Amarelo com coesão (PAf); Podzólico Acinzentado sem coesão (PC); Podzólico Acinzentado com coesão (PCf), as quais foram amostradas, segundo critério já descrito (Figura 4.42). Para maiores detalhes sobre o tamanho da amostras (número de pixels e área correspondente), das áreas originais e do recorte das classes de exclusão, assim como estatística dos polígonos amostrais, consultar Anexo F.

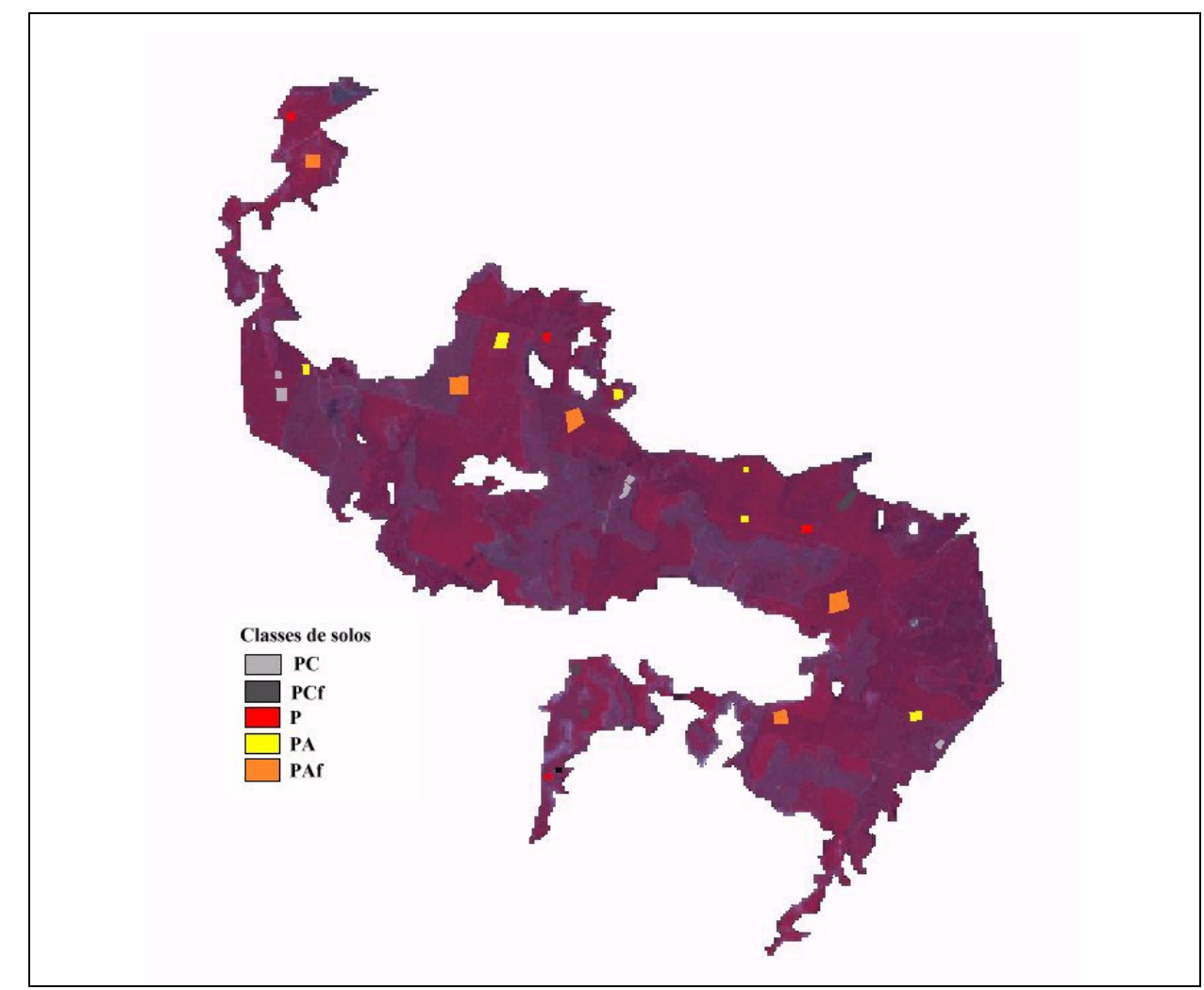

Figura 4.42 - Polígonos amostrais no recorte da área útil da imagem a ser efetivamente classificada.

Como determinado na metodologia (Capítulo 3) a classificação da Máxima Verossimilhança (MaxVer) foi realizada com um limiar de aceitação de 95\%. (Figura 4.43). 
A seguir, serão descritos os resultados obtidos a partir desta classificação aplicada sobre as imagens multiespectrais do ASTER realizadas pelo classificador de Máxima Verossimilhança (MaxVer) do Spring 4.1.1.

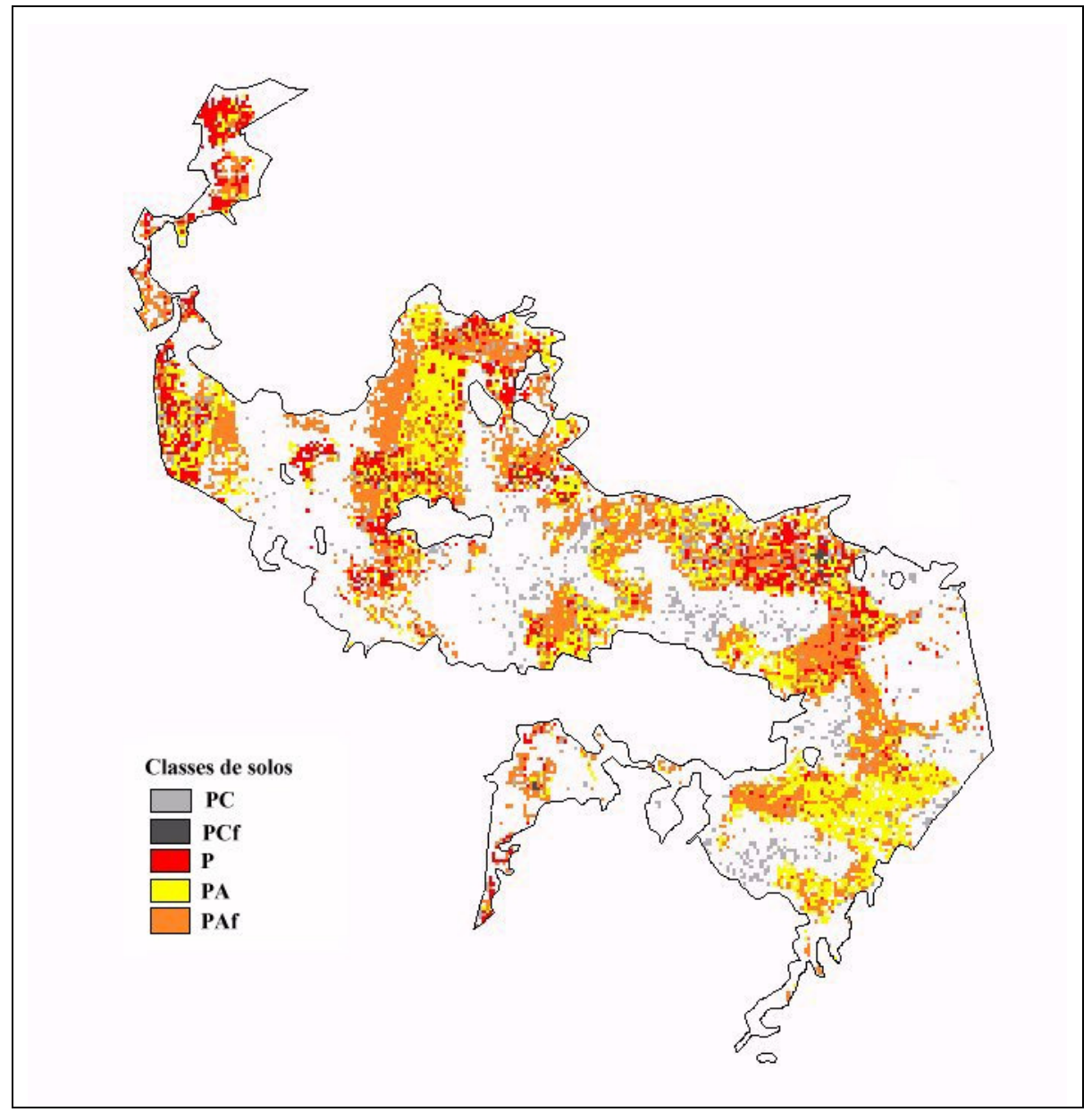

Figura 4.43 - Resultado da classificação MaxVer, com limiar de aceitação de $95 \%$

Tabela 4.5.a - Matriz de Erros da Classificação Máxima Verossimilhança com limiar de aceitação de $95 \%$ (colunas: dados de referência)

\begin{tabular}{|c|c|c|c|c|c|c|c|}
\hline & PC & PCf & P & PA & PAf & Abstencao $^{11}$ & Soma linha \\
\hline PC & 13 & 0 & 0 & 0 & 0 & 1 & 14 \\
\hline PCf & 0 & 9 & 0 & 1 & 1 & 1 & 12 \\
\hline P & 0 & 0 & 14 & 3 & 0 & 2 & 19 \\
\hline PA & 1 & 0 & 2 & 41 & 5 & 2 & 51 \\
\hline PAf & 2 & 1 & 15 & 20 & 91 & 10 & 139 \\
\hline Soma col. & 16 & 10 & 31 & 65 & 97 & 16 & 235 \\
\hline
\end{tabular}

\footnotetext{
${ }^{11}$ Pixels não classificados
} 
Tabela 4.5.b - Exatidão do Produtor $^{12}$ e Exatidão do Usuário ${ }^{13}$ para a Classificação Máxima Verossimilhança com limiar de aceitação de $95 \%$

\begin{tabular}{|c|c|c|}
\hline & Exatidão do produtor & Exatidão do usuário \\
\hline PC & $81.25 \%$ & $100.00 \%$ \\
\hline PCf & $90.00 \%$ & $81.82 \%$ \\
\hline P & $45.16 \%$ & $82.35 \%$ \\
\hline PA & $63.08 \%$ & $83.67 \%$ \\
\hline PAf & $93.81 \%$ & $70.54 \%$ \\
\hline
\end{tabular}

Desempenho geral: $\quad \mathbf{7 1 \%}$

Confusão média: $\quad 22 \%$

Abstenção média: $\quad 66.81 \%$

Kappa: $\quad 0.57$

Embora a exatidão global do mapa, representado pelo Desempenho geral para a classificação, expresso pela razão entre o total de pontos de referência e os pontos corretamente classificados, tenha sido de $71 \%$, o Kappa total para o mapa foi de apenas 0.57 , posto que este, para seu cálculo, levou em conta a matriz de erros, incluindo ai os pixels incorretamente classificados. A classificação realizada obteve um índice de concordância Bom, segundo os valores propostos por Landis e Koch (1977), (vide Tabela 3.3). Verificouse que a classe que apresentou o maior índice de confusão com as demais classes foi o PAf, assim como também apresentou o maior número de abstinências. As classes mais estáveis e com menor índice de confusão foram a PC e a PCf, enquanto que o maior índice de confusão ocorreu entre o P e o PAf. Esta dificuldade de reconhecer e diferenciar o Podzol (P) do Podzólico Amarelo com coesão (PAf) decorre que, ambos, tanto o P como o PAf, estão situados em posições topográficas similares, ambos acumulam água devido a presença dos níveis coesos e possuem cobertura vegetal similar, embora estas sejam de classes distintas.

No que se refere ao Kappa nas categorias individuais, analisamos a exatidão do usuário e do produtor, tomando por referência a classificação com limiar de aceitação de 95\%:

a) A exatidão do usuário, referente aos erros de inclusão, são relativos a todos os pontos atribuídos a uma determinada classe oriundos do erro de classificação das outras classes. Assim a exatidão do usuário indicando a probabilidade que uma categoria classificada

${ }^{12}$ Exatidão do produtor $=$ Omissão

${ }^{13}$ Exatidão do usuário = Comissão 
representasse a mesma categoria no campo foi muito boa, estando acima de $80 \%$ para todas as classes, exceto para o PAf, que ficou em torno de $70 \%$.

b) A exatidão do produtor leva em conta os erros de omissão ou exclusão, onde não são atribuídas a determinada classe os erros de classificação das outras classes. Assim, a exatidão do produtor, referiu-se a probabilidade de determinada categoria ter sido corretamente classificada de acordo com os pontos de referência. Assim, o PAf foi a classe de solo com a maior exatidão, com mais de $90 \%$, enquanto o solo menor valor foi o Podzol (P), seguido pelo Podzólico Amarelo sem coesão (PA). Interessante notar o grau de separabilidade entre as classes do Podzólico Acinzentado com coesão (PCf) e do Podzólico Acinzentado sem coesão (PC). A confusão que ocorreu nestas duas classes, distintas apenas pela presença do horizonte coeso, não ocorreu entre elas, mas com o Podzólico Amarelo com coesão (PAf). Entretanto, o mesmo não ocorreu entre o Podzólico Amarelo sem coesão (PA) e o Podzólico Amarelo com coesão (PAf), onde quase $50 \%$ dos pixels do PA foram atribuídos erroneamente à PAf.

A maior imprecisão desta classificação e a alteração dos resultados deste resultante se deve principalmente ao erro temático, o qual ocorreu de duas maneiras: primeiro, devido a categorização equivocada dos pixels à determinada classe; e a segunda pela discrepância entre as classes do objeto da imagem e seu status no terreno. No primeiro caso, isto aconteceu pela pouca variabilidade entre as classes, tanto na média como na variância entre elas. No segundo caso foi pela própria natureza do atributo, o solo com seu respectivo teor de água, o qual encontra-se em subsuperfície, e cujo sinal que chega até o sensor é enfraquecido ou distorcido pelo tipo e densidade da cobertura vegetal, além da incapacidade de se descriminar este sinal em níveis de quantização perceptíveis de serem separados. Como a quantificação deste tipo de erro está diretamente associada aos processos estatísticos que permitem determinar o grau de concordância entre as classes dos objetos e suas classes no terreno, verifica-se uma acurácia apenas mediana, se comparada a redução da área de referência e a exatidão obtida dos parâmetros através do mapa da verdade de campo. Assim, embora tivéssemos uma excelente acurácia, qualidade das informações da imagem representada e utilizássemos um classificador robusto, o resultado da classificação mostrou-se apenas satisfatório. Isto nos leva a concluir que o problema da classificação estaria não no classificador, mas no objeto a ser identificado, no caso, os tipos de solo e o seu teor de umidade. 


\section{CAPÍTULO 5 - Conclusões e Recomendações}

O principal objetivo deste trabalho foi, através de técnicas de processamento digital de imagens do espectro óptico (visível, infravermelho próximo e infravermelho médio) do sensor "Advanced Spaceborne Thermal Emission and Reflection Radiometer” (ASTER) identificar, reconhecer e caracterizar os diferentes níveis de coesão dos solos dos Tabuleiros Costeiros da Bahia. Este objetivo buscou confirmar a tese de que haveria possibilidade de descriminar os vários níveis de coesão dos horizontes subsuperficiais dos solos, através da variação do seu teor de umidade, que altera os valores da energia refletida e, conseqüentemente, dos níveis de cinza das imagens orbitais.

No final deste trabalho, pudemos confirmar que alcançamos nosso objetivo. A percepção do detalhe para estabelecer um nível qualitativo e quantitativo de maior definição, entretanto, torna-se necessário. Foi possível identificar uma diferenciação de respostas as quais foram associadas aos diferentes teores de umidade dos solos, mas faltou uma discriminação mais nítida.

Comprovamos que a metodologia escolhida e utilizada foi, através dos resultados expostos, em maior ou menor grau, eficaz para identificar a presença dos solos com horizontes coesos, através do seu teor de umidade, permitindo tanto a sua espacialização como a sua quantificação nos solos dos Tabuleiros Costeiros.

A qualidade e a configuração de suas imagens, destacando-se a resolução espectral e espacial, faz deste produto o único disponível atualmente no mercado. Entretanto, as diferentes resoluções espaciais para cada região espectral podem se apresentar como um problema a depender dos objetivos e das técnicas a serem aplicadas. No nosso caso, este foi facilmente contornado, onde, a alteração da resolução espacial dos pixels para homogeneizálos para uma única escala não se apresentou como um problema, desde que não alterou significativamente os valores de correlação espacial entre os pixels das diferentes bandas.

A razão de bandas se apresentou como uma das mais eficientes técnicas, embora de forma diferente do esperado. Somente as razões entre as bandas 1 e 3 com as bandas SWIR de mais elevado comprimento de onda, em particular com a banda 8 demonstraram bons resultados, enquanto as demais apresentaram resultados controversos ou pouco significativos. As razões que envolveram a banda 2 não demonstraram nenhum significado. As razões 1/8 e 3/8, juntamente com a sétima componente principal, apresentam-se como o melhor discriminador de teor de umidade dos solos. 
A análise de componentes principais se revelou uma excelente técnica para identificação do teor de umidade dos solos, em destaque a sétima componente (CP7), principalmente após seu tratamento, seja com alteração de legenda (alteração dos padrões de cor para os níveis de cinza), seja través do fatiamento do seu histograma. Como a sétima componente é um elemento de alta ordem, quase todos os elementos de elevada reflectância e conseqüente variância da cena já foram retirados e ela irá expressar as características dos solos expressos pelas cargas das imagens originais correspondentes às bandas 4, 5 e 9.

Os índices espectrais utilizados, apresentaram resultados diferentes, sendo alguns mais eficazes que outros. O que melhor separou os solos pelo seu teor de umidade foi o índice de Brilho da Transformação Tasseled Cap, aliás, como era de se esperar a partir da sua natureza, desde que este é gerado a partir destas informações (solo exposto seco e solo exposto úmido). Entretanto, por este mesmo motivo, este índice não apresenta o mesmo desempenho quando em áreas com vegetação, sendo eficiente somente em áreas de solos expostos. Todos os demais índices testados (NDVI, SAVI, NDMI, e o índice de Umidade gerado pelo Tasseled Cap) são, em sua essência, índices de vegetação, que buscam avaliar o teor de pigmentos fotossintetizantes presente no mesófilo das folhas (clorofila e carotenóides). Como a maioria das áreas possui vegetação, estes índices também podem ser utilizados para determinação do teor de umidade dos solos, sendo que, em última instância, o que o sensor capta, é a umidade das folhas e seu "stress" hídrico, que está diretamente associado ao teor de umidade dos solos. Destes índices, o NDVI foi o que apresentou os melhores resultados, ou seja, que apresentava valores mais distintos entre os solos úmidos e os solos secos, mesmo que estes estivessem sob cobertura vegetal, por ser mais sensível às respostas do solo subjacente e, como é um índice muito utilizado, pode ser mais facilmente interpretado. O SAVI, devido a sua própria estrutura, sendo um NDVI modificado para minimizar os efeitos dos solos sobre a resposta espectral da vegetação, apresentou resultados pouco significativos, sendo a diferença entre os valores de solo úmido e solo seco muito pequena e de difícil visualização, seja em forma gráfica, seja na própria imagem. O Tasseled Cap Umidade e o NDMI revelaram-se de pouco expressão, o que descarta em parte, seu uso para a identificação da umidade dos solos, em particular, pela dificuldade de elaboração do primeiro e da interpretação dos resultados de ambos.

A classificação multiespectral de imagens se mostrou satisfatória, segundo nosso critério, posto apresentar resultados um pouco melhores dos encontrados, em geral, na bibliografia, com um resultado Bom, segundo o índice Kappa. Os solos que apresentaram maior problema de classificação foram o Podzol (erros de omissão) e o Podzólico Amarelo 
com coesão (erros de comissão). O desempenho geral da classificação foi superior a 70\%, mesmo com um limiar de aceitação de $95 \%$. A confusão média foi de apenas $22 \%$, mesmo considerando a elevada similaridade dos solos e a homogeneidade do quadro ambiental. Cabe destacar a separabilidade entre Podzólico Acinzentado sem coesão do Podzólico Acinzentado com coesão, onde não ocorreu nenhuma confusão entre eles. Este fato pode ser explicado pelas componentes ambientais, em particular a densidade da cobertura vegetal e uso do solo diferenciado entre eles. Apesar da técnica de classificação ter demonstrado, neste caso, um resultado bastante satisfatório, a aplicação de uma classificação supervisionada ao estudo dos solos fica bastante restrita, pela necessidade da disponibilização de informações à priori, nem sempre disponíveis, relacionados à aplicação da amostragem e uma verdade de campo com informações pertinentes e em escala condizente.

Podemos então, de forma sumária afirmar que as técnicas mais simples foram as que apresentaram melhores resultados. Para a identificação de solos com horizontes coesos, através do critério de umidade, a análise de uma única banda ou de uma razão de bandas, associada às técnicas de fatiamento de histograma caracterizou-se como uma técnica simples, de fácil interpretação e com bons resultados, tanto ou melhor que outras técnicas mais elaboradas como o Tasseled Cap ou mesmo a classificação multiespectral.

Não podemos, entretanto, esquecer da natureza do objeto em estudo. Tomando como exemplo os solos da área de referência, estes apresentam, em superfície, propriedades físicas como rugosidade, estrutura e textura muito semelhantes entre si. $\mathrm{O}$ horizonte coeso cria o primeiro nível de separação, permitindo um maior acúmulo de água nas camadas superficiais, que permanecem mais ou menos constantes, a depender dos índices pluviométricos locais, gerando solos aparentemente mais úmidos para o sensor. As áreas de cultivo, ou talhões, onde se manejam plantações de eucaliptos em diferentes estágios desenvolvimento, criam o segundo nível de separação. Este pode ser associada a vários motivos: seja às diferentes idades da cultura, a espessura e constituição da serrapilheira, o teor de matéria orgânica, o grau de exposição dos solos, densidade da cobertura, sombreamento. A depender da serrapilheira, teremos uma maior ou menor camada de matéria orgânica. Onde a matéria orgânica é mais abundante, ocorre uma maior absorção e retenção de água, permitindo que os solos permaneçam úmidos por mais tempo em superfície. A densidade da cobertura reduz a exposição à dissecação e a conseqüente perda de água para a atmosfera. Já no solo exposto ou com pouca cobertura, a matéria orgânica é menor, a proteção contra a dissecação é menor, logo, a perda de água é maior e a superfície e subsuperfície ficam logo secas. Estes fatores ambientais combinados, seja o tipo de cobertura, a camada da serrapilheira, o teor de matéria 
orgânica, ou o menor ou maior nível de exposição a radiação solar direta e exposição à dissecação, servem para alterar respostas espectrais do solos específicos, servindo para descaracterizar os solos quanto ao seu teor de umidade superficial. Assim, podemos ter solos com horizontes coesos dissecados quando expostos, e solos sem horizontes coesos muito úmidos sob densa cobertura vegetal. Assim, para conhecer e explicar a resposta espectral dos solos, é necessário também conhecer as variáveis ambientais envolvidas nos diferentes processos (climáticos, pedogenéticos, geomorfológicos) e a forma como atuam e interagem no meio ambiente para se poder modelar de forma satisfatória o comportamento dos solos captados através de sensores orbitais.

Cabe aqui entretanto, tecer algumas considerações, formuladas no decorrer do processo metodológico e que se tornaram evidentes após sua conclusão. A realização deste trabalho apresentou, em sua essência dois conflitos metodológicos, devido ao nível discrepante entre eles: o primeiro, relacionado a boa qualidade da informação de referência, representada pelo mapa de solos; a segunda, é a capacidade dos dados captados pelo sensor e processados pelos diferentes métodos, perceberem e reconhecerem este nível de informação. O teor de umidade dos solos é captado de forma difusa e sutil, devido a baixa precisão do sensor para captar os sinais dos solos, gerando níveis de confusão variáveis entre as classes de solos, devido principalmente a influência da cobertura vegetal. Esta baixa precisão do sensor está associada a uma baixa resolução do mesmo. Discordando de alguns autores, acreditamos que este problema não seria resolvido com o aumento da resolução espacial nem com o da resolução espectral, mesmo que fosse possível a existência das bandas correspondentes para a resposta espectral da água, posto que a presença da água interfere em todos os comprimentos de onda, reduzindo a reflectância como um todo. Também a resposta do solo, subjacente a cobertura vegetal, tenderá a se apresentar como ruído, incorporando seu sinal nas faixas espectrais correspondentes ao estudo da vegetação. Baseados em diferentes estudos de solo, água e vegetação, realizados com diferentes sistemas sensores (monoespectrais, multiespectrais e hiperespectrais), em diferentes regiões espectrais (ópticos e microondas), acreditamos que a baixa diferenciação entre solo, água e vegetação ocorre devido a existência de uma baixa quantização, onde os 256 níveis (8 bits) não são suficientes para captar as sutis diferenças do nível de água, sequer medí-la de forma eficiente. Sugerimos a realização de trabalhos futuros, buscando avaliar as possibilidades e conseqüências de um aumento de resolução radiométrica para 11 ou 12 bits (1024 e 2048 níveis, respectivamente) para uma efetiva diferenciação entre estes três elementos ou componentes da paisagem. As imagens termais, por outro lado, se apresentariam com sendo uma solução quanto a resolução radiométrica, no caso específico do 
sensor ASTER, ou do seu comportamento termodinâmico em geral que possui uma forte associação com as caraterísticas hídricas, mas detêm o problema da baixa resolução espacial (90m).

Acreditamos que os métodos utilizados se apresentaram úteis e com resultados positivos no desenvolvimento deste trabalho, comprovando a real possibilidade de identificar, tanto o teor de umidade como reconhecer os diferentes tipos de solos através do processamento digital de imagens do sensor ASTER. Entretanto, novas pesquisas devem ser incentivadas e os métodos utilizados aprofundados, buscando uma melhor compreensão dos fatores que influenciam as diferentes respostas espectrais, além de buscar novas relações ambientais e a forma como interagem, visando desenvolver um modelo do comportamento espectral do solo mais eficiente e com usos mais amplos. 


\section{CAPÍTULO 6.0 - Referências Bibliográficas}

ABRAMS, M. The Advanced Spaceborne Thermal Emission and Radiometer (ASTER): Data products for the high spatial resolution imager Terra platform, International Journal of Remote Sensing, vol.21, 2000, pag. 847-859.

ABRAMS, M.; HOOK , S. ASTER User Handbook, Pasadena : Jet Propulsion Laboratory, 2002

ABRAMS, M; HOOK, S.; RAMACHANDRAN, B. ASTER User Handbook. $2^{\text {a }}$ Versão. Pasadena: JPL, 2002, $135 \mathrm{p}$.

ABREU, S.L.; WOHLENBERG, E.V., GONÇALVES, C. REINERT, J. Preopriedades hídricas afetadas por um sistema de manejo de um argissolo. Ilhéus: Anais da XIII Reunião Brasileira de Manejo e Conservação do Solo e da Água, $\quad$ CD-ROM, 2000, Resumo expandido no, 283. http://www.ufsm.br/ppgcs/congressos/XIIIReuniao_Brasileira_Ilheus/283.pdf

ABUELGASIM, A. A., S. GOPAL, J. R. IRONS, AND A. H. STRAHLER . Classification of ASAS multiangle and multispectral measurements using artificial neural networks. Remote Sensing of Enviroment . v. 57, 1996, 79-87.

AGBU, P.A.; FEHRENBACHER, D.; JENSEN, I.J. Soil property relationships with SPOT satellite digital data in east central Illinois. Soil Science Society od America Journal., v. 54, 1990, pag. 807-812.

AIT BELAID, M.; EDWARDS, G.; JATON, A.; THOMSON, K.P.B.; BEAULIEU, J.M. Post-segmentation classification of images containing small agricultural fields. Geocarto International, n.3, 1992, p.53-60.

AL-KHAIER, F. Soil salinity detection using satellite remote sensing. Dissertação de Mestrado. Enschede: ITC, 2003, 70 pag.

AL-KHAIER, F. Soil salinity detection using satellite remote sensing. Dissertação de Mestrado. ITC, Enschede, 2003, 70 p.

ALMEIDA, S.A.S.; SILVA, O.F.; MELLO, E.M.K.; MOREIRA, J.C.; ORTIZ, J.O.; AMARAL, S.; SOARES, J.V.; ALVES, D.S. Mapeamento de cobertura da terra utilizando técnicas de processamento de imagens na região de Ariquemes (RO-BR), com ênfase às florestas secundárias. In: SIMPÓSIO BRASILEIRO DE SENSORIAMENTO REMOTO, 8., abr. 1996, Salvador. Anais... São José dos Campos: INPE/SELPER, 1996. (CD-ROM).

ANDERBERG, M. R. . Cluster Analysis for Applications. New York, NY: Academic Press, 1973, 353 p.

ANGSTROM A. The albedo of various surfaces of ground. Geografiska Ann. V.7, 1925, pag. 323-342.

ANSELIN, L. What is special data analysis? Alternative perspectives on spatial data analysis. Technical Paper. n. 89, v. 4. National Center for Geographic Information and Analysis, Santa Barbara, 1989.

ANTOINE, P. Réflexions sur la cartografhie ZERMOS et bilan dês expériences em cours, Bulletin du B.R.G.M. , v. 2, 1977. p. 9-20.

APAN, A.; KELLY, R.; JENSEN, T.; BUTLER, D. STRONG, W. BASNET, B. Spectral discrimination and separability analysis of agricultural crops and soil attributes using ASTER imagery. 11 $^{\text {th }}$ ARSPC, Brisbane, 2002, pag, 396-411.

ARAI, K. . A supervised Thematic Mapper classification with a purification of training samples. International Journal of Remote Sensing , v. 13, n. 11, 1992, pag. 2039-2049.

ARAI, K.; THOME; K.J.; TSUCHIDA; S. ; TAKASHIMA, T.; KAWATA, Y.; MACHIDA, S.; TONOOKA, H. Field experiment in Tsukuba test site for ASTER vicarious calibration (visible to near-infrared and shortwave infrared radiometers, Journal of Remote Sensing Society of Japan, vol. 20, 2000, pag. 55-62. 
ARAUJO FILHO, J.C; CARVALHO, A.; SILVA, F.B.R. Investigações preliminares sobre a pedogênese de horizontes coesos em solos dos tabuleiros do Nordeste do Brasil. In. WORKSHOP COESÃO EM SOLOS DE TABULEIROS COSTEIROS, Aracajú, 2001. Anais. Aracajú:Embrapa Tabuleiros Costeiros, 2001, p. 123-142.

ARAÚJO, H.A. \& RODRIGUES, R.S. Regiões características do Estado da Bahia para previsão do Tempo e Clima. SEINGRA/SRH/GEREI: Salvdor, Outubro, 2000.

ARAUJO, P.H.M.; NEHME, C.C. Uso de modelos de incerteza no controle ambiental do processo erosivo na Bacia do Alto Taquari. Rio de Janeiro. Anais do III Workshop Brasileiro de Geoinformática. 2001. http://www.lbd.dcc.ufmg.br/bdbcomp/servlet/Evento?id=30

ARONOFF, S. Classification accuracy: A user approach. Photogrammetric Engineering and Remote Sensing, Maryland, v.48, n.8, p.1299-1307, Aug. 1982.

ARTHUR, S.T.; CARLSON, T.N; RIPLEY, D.A.J. Land use dynamics of Chester County, Pennsylvania, from a satellite remote sensing perspective, Geocarto International, vol. 15, 2000, pag. 25-34.

ARYA, S.P. Introduction to micrometeorology. New York: Academic Press, 1988.

ASNER, G.P. 1998. Biophysical and biochemical sources of variability in canopy reflectance. Remote Sensing. Environment, v.. 64, 1998, pag.134-153.

ASNER, G.P., AND D.B. LOBELL. 2000. A biogeophysical approach for automated SWIR unmixing of soils and vegetation. Remote Sensing. Environment. V.74, 2000, pag.:99-112.

ASNER, G.P.; LOBELL, D.B. A biogeophysical approach for automated SWIR unmixing of soils and vegetation. Remote Sens. Environ. V. 74, 2000, pag. 99-112

ASRAR G.; FUCHS, M.; KANEMASU, E.T.; HATFIELD, J.L. Estimating absorbed photosynthetic radiation and leaf area index from spectral reflectance in wheat. Agron. Journal. V. 76, 1984, pag . 300-306.

ASRAR, G.; MYNENI, R. B.; LI, Y.; KANEMASU, E. T. Measuring and modeling spectral characteristics of a tallgrass prairie, Remote Sensing of Environment, vol.27, 1989, pag. 143-155.

ATKINSON, P.M. Optimal ground-based sampling for remote-sensing investigations: estimating the regional mean. International Journal of Remote Sensing, n. 12, 1991, pag. 559-67

ATKINSON, P.M. Optimal samplig strategies for rASTER-based geographical information systems. Global Ecology and Biogeographical Letters, n. 5, 1996, pag. 271-80.

AUGUSTEIJN, M. F., L. E. CLEMENS, AND K. A. SHAW . Performance evaluation of texture measures for ground cover identification in satellite image by means of neural network classifier. IEEE Transactions on Geoscience and Remote Sensing, v.33, n. 3, 1995, pag. 616-626.

AVERY, T. E. AND G. L. BERLIN . Fundamentals of Remote Sensing and Airphoto Interpretation. 5th Ed. New York, NY: Macmillan Publishing Company, 1992, 472.

AVILA, V.E.; YOSHIBA, M.; EVANGELISTA, M.A.M.; RONDAL, J.L. A methodology for soil moisture condition detection using remotely sensed data. Asian Pacific Remote Sensing Journal , v. 7 1, 1994, pag. 109-118.

AZURRA, D.; CASTRO-GODOY, S.; KAKU, M.; KOHNO, I.; MARIN, G. Processamiento y productos ASTER el área de Sierra de Famatina, província de La Rioja, Republica Argentina. Anais. XI Simpósio Brasileiro de Sensoriamento Remoto, Belo Horizonte, 2003.

BANKO, G. A review of assessing the accuracy of classifications of remotely sensed data and methods including remote sensing data in forest inventory. Interim Report IR-98-081, Laxenburg: IIASA, November, $1998,42 \mathrm{p}$ 
BAPTISTA, G. M. M., MADEIRA NETTO, J. S., CARVAlHO JR. O. A., MARTINS, E. S., MENEZES, P. R. Mapeamento dos teores de argila de solos tropicais, por meio de dados de sensoriamento remoto hiperespectral In: Congresso Brasileiro de Ciencia do Solo, 27, 1999, Brasília.

BAPTISTA, G. M. M., MADEIRA NETTO, J. S., MENESES, P. R. Mapeamento dos teores de argila de solos tropicais por meio de dados de sensorimento remoto multiepsectral (ASTER) e hiperespectral (AVARIS). Revista Sociedade e Natureza. Uberlândia: , v.12, n.23, p.133 - 146, 2000.

BAPTISTA, G. M. M., MADEIRA NETTO, J. S., MENEZES, P. R. Determinação da relação sílica -alumina a partir de dados do sensor AVIRIS (JPL/NASA), para discretização do grau de intemperismo de solos tropicais In: IX Simpósio Brasileiro de Sensoriamento Remoto, 1998, Santos.

BAPTISTA, G.M.M; MARTINS, E.S.; MADEIRA NETTO, J.S.; CARVALHO JR., O.A.; MENESES, P.R. Use of AVIRIS Data for Mineralogical Mapping in Tropica! Soils, in the District of São João D' Aliança, Goiás. In: JPL AIRBORNE EARTH SCIENCE WORKSHOP, 7., 1998, Pasadena. Summaries. Pasadena: NASA, 1998 a. p.33-42.

BARALDI, A. e PARMIGGIANI, F. . A neural network for unsupervised categorization of multivalued input patterns: an application to satellite image clustering. IEEE Transactions on Geoscience and Remote Sensing , v. 33, n. 2, 1995, pag. 305-316.

BARRET, E.E. \& CURTIS, L.F. Introduction to environmental remote sensing. 3th ed. London: Chapman \& Hall, 1992.

BARRON, V.; MONTALEGRE, L.. Iron oxides and color of triassic sediments: application of the KubelkaMunk theory. American Journal of Science, New Haven, CT, v.286, 1986, p.792-802.

BASTOS, V.P. Técnicas de segmentação de imagens para recuperação de informações visuais. TCC Curso de Análise de Sistemas. Pelotas: UCP/EI, 2001. http://atlas.ucpel.tche.br/ vbastos/

BAUER, M.E. Spectral inputs to crop identification and condition assessment. Proceedings of the IEEE, 73, 1985, pag. 1071-1085.

BAUER, M.E.; DAUGHTRY, C.S.T.; VANDERBILT, V.C. Spectral-agronomic relationship of corn, soybean and wheat canopies. SR-P1-04187. Laboratory for Applications of Remote Sensing, Pardue University, West Lafayette. 1981, 17 pag.

BAUMGARDNER, M.F., L.F. SILVA, L.L. BIEHL AND E.R. STONER. Reflectance properties of soils. Adv. Agron.v. 38, 1985, pág. 1-44.

BAUMGARDNER, M.F.; SILVA L.F.; BIEHL L.L.; STONER E.R. Reflectance properties of soils. Adv. Agron. 1985;38:1-43.

BEDIDI, A ; CERVELLE, B. Light scattering by spherical particles with hematite- and goethite-like optical properties.Effect of water impregnation. J. Geophys. Res., v. 98, 1993, pag. 11941-11952.

BEDIDI, A ; CERVELLE, B. Moisture effects on visible spectral characteristics of lateritic soils. Soil Science, V. 153, pp.129-141, 1992.

BEDIDI, A.; CERVELlE, B.; MADEIRA NETTO, J.S.; POUGET, M. Moisture effects on visible spectral characteristics of lateritic soils. Soil Science, Baltimore, MD, v.153, n.2, p.129-141, 1992.

BEN-DOR, E.; INBAR, Y.; CHEN. Y. The reflectance spectra of organic matter in the visble near-infrared and short wave infrared region (400-2500) during a controlled decomposition process. Remote Sensing of Environment, New York, v.61, p.1-15,1997.

BEN-DOR, E.; IRONS, J.R.; EPEMA, G.F.. Soil reflectance. p. 111-188. In RENCZ, A. N. (ed.) Remote sensing for the earth sciences: Manual of remote sensing. Wiley \& Sons, New York, 1999, pag. 111-188. 
BEN-DOR, E.; IRONS, J.R.; EPEMA, J.P. Soil reflectance. In RENCZ, A.N. (ed.) Remote sensing for the earth sciences: Manual of remote sensing. New York : Wiley \& Sons, 1999, pag. 111-188.

BENEDIKTISSON, J. A. e SWAIN, P.H.. Consensus theoretic classification methods. IEEE Transactions on Systems, Man \& Cybernetics , v. 22, n. 4, 1992, pag. 688-704.

BENEDIKTISSON, J. A.; SWAIN, P.H.; ERSOY, O.K. Neural network approaches versus statistical methods in classification of multisource remote sensing data. IEEE Transactions on Geoscience and Remote Sensing, $v$. 28, n. 4, 1990, pag. 540-551.

BÉNIÉ, G.B.; THOMSON, K.P.B.; GOLDBERG, M. A comparison of four segmentation algorithms in the context of agricultural remote sensing. ISPRS Journal of Photogrammetry and Remote Sensing, Amsterdam, v.44, p.1-13, 1989.

BERGER, J. Statistical Decision Theory and Bayesian Analysis. Bew York: Springer-Verlag, 1985.

BERGER, J.O. Statistical design theory and bayesian analysis. Springer Series in Statistics. 2nd. Ed. , London: Springer, 1985.

BERKOFSKY, L. The effect of variable surface albedo on the atmospheric circulation in desert regions. J. Appl. Meteorol. , v. 15, 1976, pag. 1139-1144.

BERnARDO, J. M.; SMITH , A.F.M. Bayesian Theory. Wiley Series in Probability and Mathematical Statistics. Chichester: John Wiley and Sons, 1994.

BERNARDO, J.M. e SMITH, A.F.M. Bayesian theory. London: Wiley \& Sons, 1994

BERRY,B; BALER, A. Geographic sampling. In: MARBLE (ed) Spatial analysis - a reader in statistical geography. Englewoods Cliffs: Pretence-Hall, 1986.

BERTONI, J. \& LOMBARDI NETO, F. 1985. Conservação do Solo. Piracicaba: Livroceres.. 368 p.

BIGHAM, J.M.; GOLDEN, D.C.; BUOL S.W.; WEED, S.B.; BOWEN, L.H.. Iron oxide mineralogy of well drained Ultisols and Oxisols: II. Influence on color, surface area, and phosphate retention. Soil Sci. Soc. Am. J. , v. 42, 1978; pag. 825-830.

BISCHOF, H.; SCHNEIDER, W.; PINZ, A.J. Multispectral classification of Landsat images using neural networks. IEEE Transactions on Geoscience and Remote Sensing v. 30, n. 3, 1992, pag. 482-490.

BISHOP, M.P.; KARGEL; J.; KIEFFER, H.; MACKINNON, D.J.; RAUP, B.; SHRODER, JR, J.F. Analysis of glacier processes in high Asia, Annals of Glaciology, vol. 31, 2000, pag.: 164-170.

BITTENCOURT, G; MARENGONI, M. A customizable tool for the generation of production-based systems. In RZEVSKI, G.; PASTOR, J.; ADEY, R.A. (Ed.), Eighth International Conference on Applications of Artificial Intelligence in Engineering (AIENG'93), pag 337-352. Elsevier Applied Science, 1993.

BITTENCOUT, G. Inteligência computacional. Florianópolis: UFSC/DAS, 2001. http://www.das.ufsc.br/gia/softcomp/softcomp.html

BOLSTED, P. V. , LILLESAND, T.M. Rapid maximum likelihood classification. Photogrammetric Engineering and Remote Sensing, v. 57, n. 1, 1991, pag. 67-74.

BOLSTED, P.V. Rule-based classification models: flexible integration of satellite imagery ant thematic spatial data. Photogrammetric Engineering and Remote Sensing. n. 58, v. 7, 1992, pag. 965-71.

BORAK, J.S. \& STRAHLER, A.H. Feature selection and land cover classification of a MODIS-like data set for semi-arid environment. International Journal of Remote Sensing, n. 20, 1999. pag. 919-38. 
BOUleT, R.; CHAUVEL, A.; HUMBEL, F. X.; LUCAS, Y. Analyse structurale et pédologie I. Prise em compte de l'organization bidimensionnelle de la couverture pédológique: lês études de toposéquences et leurs principaux apports à la connaissance dês sols. Cah. ORSTOM. Ser. Pédol. Vol. XIX, N. 4, 1982. p. 309-322.

BOUlET, R.; CHAUVEL, A.; HUMBEL, F. X.; LUCAS, Y. Analyse structurale et pédologie I. Prise em compte de l'organization bidimensionnelle de la couverture pédológique: lês études de toposéquences et leurs principaux apports à la connaissance dês sols. Cah. ORSTOM. Ser. Pédol. Vol. XIX, N. 4, 1982. p. 309-322.

BOURROUGS, P.A.Soil information system. In. MAGUIRE, D.; GOODCHILD, M.; RHIND, D. Geographical information system: principles and application. New York: Weley \& Son, 1991.

BOWERS, S.A.; HANKS, R.J. Reflectance of radiant energy from soil. Journal of Soil Science, v.100, 1965, pag. 130-138.

BRADY, N.C. Natureza e propriedades dos solos. 7. ed. Rio de Janeiro: Freitas Bastos, 1989.

BRASIL. Ministério das Minas e Energia. Secretaria Geral. Folhas SD./24. Salvador. Rio de Janeiro: Projeto Radambrasil, 1983. 780p. 6 mapas policr.

BREST C.L., GOWARD S.N. Deriving surface albedo measurements from narrow band satellite data. International Journal of Remote Sensing., v. 8, 1987, pag. 351-367.

BRITES, R.S; SOARES, V.B.; RIBEIRO, C.A.A.S. Verificação da exatidão em classificação de uma imagem orbital mediante a utilização de três índices. Revista da Árvore, v.20, n. 3, p. 415-24, 1996.

BROGAARD, S.; OLAFSDOTTIR, R. Ground-truths or grounf-lies? Lund Eletronic Reports in Physical Geography, n. 1, 1997. URL:http://www.natgeo.lu.se/Publikationer/Lerpg/1/1Article.htm

BROOKS F.A. Atmospheric radiation and its reflection from the ground. J. Meteorol. 1952;9:41-52.

BRYANT, J. A fast classifier for image data. Pattern Recognition , v. 22, 1989, pag. 45-48.

BRYANT, J. On the clustering of multidimensional pictorial data. Pattern Recognition v. 11, n. 2, 1979, pag.115-125.

BUCHHEIM, M. P. AND T. M. LILLESAND . Semi-automated training field extraction and analysis for efficient digital image classification. Photogrammetric Engineering and Remote Sensing, v. 55, n. 9, 1989, pag. 1347-1355.

BUCKMAN, H.O. \& BRADY, N.C. Natureza e propriedade dos solos. 6a Ed. Rio de Janeiro: LFB, 1983.

BURNS, R. Mineralogical applications of crystal field theory. Cambridge:Cambridge University Press, 1993.

CAETANO, M.; SANTOS, T. GONÇALVES, L. Cartografia de ocupação do solo com imagens de satélite. Lisboa, Anais do ESIG, 25 a 28 de maio de 2002, pag. 526-37.

CÂMARA, G.; DAVIS, C.; MONTEIRO, A.M.; D'ALGE, J.C. Introdução à ciência da geoinformação. São José dos Campos: INPE, 2001 (2 $2^{\mathrm{a}}$ ed., revista e ampliada, disponível em www.dpi.inpe.br/gilberto/livro.

CÂMARA, G.; MONTEIRO, A.M.; FUCKS, S.D.; CARVALHO, M.S. Análise espacial e geoprocessamento. In . DRUCK, S.; CARVAlHO, M.S.; CÂMARA, G.; MONTEIRO, A.M. Análise Espacial de Dados Geográficos. São José dos Campos: INPE, 2002. ( $2^{\mathrm{a}}$ ed., revista e ampliada, disponível em http://www.dpi.inpe.br/gilberto/livro/analise/)

CÂMARA, G.; SOUZA, R.C.M. de; FREITAS, U.M.; CASANOVA, M.A. SPRING: Processamento de imagens e de dados georreferenciados. In: SIBGRAPI, 1992, Águas de Lindóia. Anais... S.1., nov. 1992. p.233242.

CAMPBEL, J.B. Introduction to remote sensing. London: Thr Guilford Press, 1987. 
CAMPBELL, J.B. Spatial correlation effects upon accuracy of supervised classification of land cover. Photogrammetric Engineering and Remote Sensing, n. 47, 1981, pag, 355-63.

CAMPOS, T. E.; FERIS, R.S. ; CESAR-JR, R. M.. Improved face non-face discrimination using fourier descriptors through feature selection. In 13th SIBGRAPI, pages 28-35. IEEE Computer Society Press. 2000

CAMPOS, T.E. Técnicas de Seleção de Atributos e de Classificação para Reconhecimento de Faces. Dissertação de Mestrado. São Paulo: IME/USP, 2003

CANNON, R. L., J. V. DAVE, J. C. BEZDEK, AND M. M. TRIVEDI . Segmentation of a Thematic Mapper image using the fuzzy c-means clustering algorithm. IEEE Transactions on Geoscience and Remote Sensing GE-24, n. 3, 1986, pag. 400-408.

CARD, D.H. Using known map category marginal frequencies to improve estimates of thematic map accuracy. Photogrammetric Engineering and Remote Sensing, Maryland, v.48, n.3, p.431-439, Mar. 1982.

CARD, D.H. Using known map category marginal frequencies to improve estimates of thematic map accuracy. Photogrammetric Engineering and Remote Sensing, Maryland, v.48, n.3, p.431-439, Mar. 1982.

CARLSON, T.N.; ARTHUR, S.T. The impact of land use - land cover changes due to urbanization on surface microclimate and hydrology: A satellite perspective, Global and Planetary Change, vol. 25, 2000, pag. : 49-65.

CARLSON, T.N.; RIPLEY, D.A.J.; SCHMUGGE, T.J. Rapid soil drying and its implications for remote sensing of soil moisture and the surface energy fluxes, Thermal Remote Sensing in Land Surface Processes, Ann Arbor Press, 2001.

CARLSON, T.N.; SANCHEZ-AZOFEIFA, A. (2000) Satellite remote sensing of land use and surface microclimate changes in San Jose, Costa Rica, Remote Sensing of Environment, vol.70, 2000, pag. 247-256.

CARPENTER, G.A.; GJAJA, M.N.; SUCHARITA, G.; WOODCOCK, C.E. A. Neural networks for remote sensing vegetation classification from Landsat-TM and terrain data. IEE Transactions on Geoscience and Remote Sensing, v.35, n.2, p.308-325, Mar. 1997.

CARVAlHo Jr, O. A.; CARVALHO, A.P.F.; MENESES, P.R.; GUIMARÃES, R.F. Análise do posicionamento da banda de absorção: novo método para tratamento de imagens hiperspectrais. Anais X SBSR. Foz do Iguaçu, 21-26 abril 2001. INPE

CEOS. Committee on Earth Observation Satellites. Coordination for the Next Decade (1995 CEOS Yearbook). European Space Agency. Smith System Engineering Ltd, UK; 1995.

CHAMBERLIN C.J., CHAMBERLIN D.G. Colour-Its measurement, computation and application. Philadelphia, PA: Heyden \& Sons, 1980.

CHAMBers, J.; CLEVElAnD, W; KLEINER, B; TUKEY, P. Graphical Methods for Data Analysis, Wadsworth, 1983.

CHAVEZ, P.S.; KWARTENG, A.Y. Extracting spectral contrast in Landsat Thematic Mapper image using selective principal component analysis. Photogrammetric Engineering and Remote Sensing. v. 55, 1989, pag. 339-348.

CHEN, K. S., Y. C. TZENG, C. F. CHEN, AND W. L. KAO . Land-cover classification of multispectral imagery using a dynamic learning neural network. Photogrammetric Engineering and Remote Sensing ., v. 61, 1995, pag. 403-408.

CHRISMAN, N.R. The error component in spatial data. In: MAGUIRE, D.J.; GOODCHILD, M.F.; RHIND, D.W. (Eds.) Geografical Information Systems: principles and aplications. London: Longman, 1991, pag. $165-74$. 
CHRISTENESEN, B T. ; SORENSEN, L H. The distribution on native and labelled carbon between soil particles size fraction isolated from long-term incubation experiment. Journal of . Soil Science.v. 36, 1985, pag. 219-229.

CHUVIECO, E.; CONGALTON, R.G. Using cluster analysis to improve the selection of training statistics in classifying remotely sensed data. Photogrammetric Engineering and Remote Sensing, Maryland, v.54, n.9, p.1275-1281, Sept. 1988.

CIERNIEWSKI J. A model for soil surface roughness influence on the spectral response of bare soils in the visible and near infrared range. Remote Sensing and Environment. , v.23, 1987, pag. 97-115

CIERNIEWSKI, J; VERBRUGGHE , M. Influence of soil surface roughness on soil bidirectional reflectance . International Journal of Remote Sensing, Vol. 18, 1997, pag. 1277 - 1288

CINTRA, F.L.D. e LIBARDI, P.L. Caracterização física de uma classe de solo do ecossistema do Tabuleiro Costeiro. Sci. Agric., 55:367-378, 1998

CIVCO, D. L. . Artificial neural networks for land-cover classification and mapping. International Journal of Geographical Information Systems . v. 7, n. 2, 1993, pag. 173-186.

CLARK, P. \& NIBLETT, T. The CN2 induction algorithm. Machine Learning, n. 3, 1989, pag. 261-84.

CLARK, R.N. Spectroscopy of rocks and minerais, and principies of spectroscopy. In: RENCZ, A.N., ed. Manual of remote sensing: remote sensing for the earth science. New York: J. Wiley 1999.

CLARK, R.N.. Spectroscopy of rocks and minerals, and principles of spectroscopy. In RENCZ, N. Remote Sensing for the Earth Sciences: Manual of Remote Sensing New York: John Wiley \& Sons, 1999, pag. 3-52..

CLARK, R.N.; SWAYZE, G.A.; GALLAGHER, A.; KING, T.V.V.; CALVIN, W.M. The U.S. Geological Survey Digital Spectral Library: Version 1 : 0.2 to 3.0 mm. U.S.G.S. Open File Report, p.93-592, 1993.

COHEN, J. A coefficient of agreement for nominal scales. Educational and Psycological Measurement, n. 20, 1960, p. 37-46.

COHEN, W. Response of vegetation indices to changes in three measures of leaf water stress. Photogrammetric Engineering and Remote Sensing. Vol. 57, 1991, pag. 195-202.

COHEN, W.B. ; SPIES, T.A.; FIORELLA, M Estimating the age and structure of forests in a multi-ownership landscape of western Oregon, U.S.A., International Journal of Remote Sensing, vol. 16 , 1995, ppg. 721-746.

COHEN, W.B.; FIORELLA, M. Comparison of methods for detecting conifer forest change with Thematic Mapper imagery In: LUNETTA, R.S. \& ELVIDGE, C.D. (Ed. ) Invited book chapter (\#6), for remote sensing change detection: Environmental monitoring methods and applications, Chelsea : Ann Arbor Press, MI, 1998.

COLEMAN, G. B. AND H. C. ANDREWS Image segmentation by clustering. Proceedings of the IEEE, $v$. 67 , n. 5, 1979, pag.773-785.

COLLINS, J.B. ; WOODCOCK, C.E. An assessment of several linear change detection techniques for mapping forest mortality using multitemporal Landsat TM data, Remote Sensing of Environment, vol. 56, 1996, pag. $66-77$.

CONDIT H.R. The spectral reflectance of American soils. Photogrammetric Engineering and Remote Sensing,., v. 36, 1970, pag 955-966

CONGALTON, R. A comparison of sampling schemes used ingenerating error matrices for assessing the accuracy of maps generated from remotely sensed data. Photogrammetric Engineering and Remote Sensing, v. 54, n. 5: 1988 , p. 593-600. 
CONGALTON, R. G. A review of assessing the accuracy of classifications of remotely sensed data. Remote Sensing of Environment. V. 37, 1991, pag. :35-46. .

CONGALTON, R.G. A compararison of sampling schemes used in generating error matrices for assessing the accuracy of maps generated from remotely sensed data. Photogrammetric Engineering and Remote Sensing, n. 54, 1988, pag. 593-600.

CONGALTON, R.G. e GREEN, K. Assessing the accuracy of remotely sensed data: princples and practices. Danvers: CRC press, 1999.

CONGALTON, R.G. Using spatial autocorrelation analysis to explore the errors in maps generated from remotely sensed data. Photogrammetric Engineering and Remote Sensing, n. 54, 1988, pag. 587-92.

COOPER, A. B.; SMITH, C. M.; SMITH, M. J. 1995: Effects of riparian set-aside on soil characteristics in an agricultural landscape: Implications for nutrient transport and retention. Agriculture, ecosystems and environment, v. 55, 1995, pag. : 61-67.

COOPER, K D; SMITH, J A . Monte Carlo reflectance model for soil surfaces with three-dimensional structure. IEEE Transactions on Geoscience and Remote Sensing. Vol. GE-23, no. 5, 1985, pag. 668-673.

COPPIN P. R.; BAUER M. E Processing of multitemporal Landsat TM imagery to optimise extraction of forest cover change features IEEE Transactions on Geoscience and Remote Sensing. Vol. 32, 1994, pag. $918-927$.

COPPIN, P. R.; BAUER, M. E. The potential contri bution of pixel-based canopy change information to standbased forest management in the northern U.S. Journal of Environmental Management, vol. 44, 1995, pag. 6982 .

COPPIN, P. R.; BAUER, M. E. Digital change detection in forest ecosystems with remote sensing imagery. Remote Sensing Environment, vol. 13, 1996, pag. 207-234.

COPPIN, P.; NACKAERTS, K.; QUEEN, L.; BREWER, K., 2001, Operational monitoring of green biomass change for forest management. Photogrammetric Engineering and Remote Sensing, vol. 67, 2001, pag. 603611.

COSTA, M.A.P. de C. Condução e retenção de água Latossolo Amarelo álico coeso do recôncavo baiano. Dissertação de Mestrado em Fitotecnia. Cruz das Almas:EA/UFBA, 1993, 125p.

CRANE, R.B. Preprocessing techniques to reduce atmospheric and sensor variability in multispectral scanner data. Proceedings of the $7^{\text {th }}$ International Symposim on Remote Sensing of Environment. Ann. Arbor, Michigan, pag. 1345, 1971.

CRESSWELL H.P., PAINTER D.J., CAMERON K.C. Tillage and water content effects on surface soil hydraulic properties and shortwave albedo. Soil Sci. Soc. Am. J., v. 57, 1993, pág. 816-824.

CRIST, E.P. ; KAUTH, R.J. The tasseled cap de-mystified, Photogrammetric Engineering and Remote Sensing, vol. 52 , 1986, pag. $81-86$

CRIST, E.P. A TM Tasseled Cap equivalent transformation for reflectance factor data. Remote Sensing of Environment, v. 17, 1985, pag. 301-306.

CRIST, E.P.; CICONE, R.C. A physically-based transformation of Thematic Mapper data: the TM Tasseled Cap. IEEE Transaction on Geoscience and Remote Sensing. v. GE-22, n. 3, a984, pag. 256-263.

CRIST, E.P.; CICONE, R.C. Applications of the Tasseled Cap concept to simulated Thematic Mapper data. Photogrammetric Engineering and Remote Sensing. v. 50, 1984, pag. 343-352.

CRIST, E.P.; LAUREN, R.; CICONE, R.C. Vegetation and soils information contained in transformed thematic mapper data, Proceedings of IGARSS' 86 symposium, 1986, pag. 1465-1470. 
CRIT, E.P.; CICONE, R.C. A physically-based transformation of Thematic Mapper data - the Tasseld Cap. IEEE Transactions on Geoscience and Remote Sensing, n. 22, pag. 256-263, 1984.

CROSTA, A.P. Processamento digital de imagens de sensoriamento remoto. Campinas: UNICAMP-Instituto de Geociências, 1992. 170p.

CROWLEY, J.K.; HOOK , S.J. Thermal Infrared Multispectral Scanner (TIMS) study of playa evaporite minerals in Death Valley, Journal of Geophysical Research, vol. 101, 1996, pag. 643-660.

CURCIO, J.A.; PETTY, C.C. The near infrared absorption spectrum of liquid water. Journal of the Optical Society of America. V. 41, 1951, pag. 302-304.

CURRAN, J.; MILTON, E.J. The relationships between the chlorophyll concentration, LAI and reflectance of a simple vegetation canopy. International Journal of Remote Sensing, v. 4, 1983, pag. 247-255.

CURRAN, P. J. ; FOODY, G.M.; KONDRATEYEV, K. YA.; KOZOGEROV, V.V.; FEDCHENKO, P.P.. Remote Sensing of Soils and Vegetation in the USSR. London: Taylor and Francis. 1990.

CURRAN, P.J.; HAY, A.M. The importance of measurement error for certain procedures in remote sensing at optical wavelengths. Photogrammetric Engineering and Remote Sensing. v. 52, 1986, pag. 229-241.

CURRAN, P.J.; WILLIAMSON, H.D. Sample size for ground and remotely sensed data. Remote Sensing of Environment, n. 20, 1986, pág. 31-41.

DALMOLIN, R.S.D.; GONÇALVES, C.N.; KLAMT, E.; DICK, D.P. Caracterização espectral de latossolos de diferentes ambientes. Resumo expandido. Anais da IV Reunião Brasileira de Ciência do Solos. Porto Alegre, 14 a 16 outubro, 2002 http://www.ufsm.br/ppgcs/

DAVIDSON, D.A. ; WATSON, A.I. Spatial variability in soil moisture as predicted from Airborne Thematic Mapper (ATM) data. Earth Surface Processes, v. 20, 1995, pag. 219-230.

DAVIS, F.W. \& SIMONETT, D.S. Gis and remote sensing. In MAGUIRE, D.J.; GOODCHILD, M.F.; RHIND, D. Geographical informations systems: principles and applications. Vol. 1, Essex, Logman Scientific and Techinical, 1991, pp.191-212.

DEMATTÊ, J. A. M.; EPIPHANIO, J. C. N.; FORMAGGIO, A. R. Influência da matéria orgânica e formas de ferro na reflectância de solos tropicais com argila de atividade baixa argila de atividade baixa. Bragantia, v.62, n.3, 2003, pág. 451-464

DEMATTÊ, J.A.M.; CAMARGO, W.P.; FIORIO, P.R.; NANNI, M. Diferentes produtos do sensoriamento remoto com o auxílio no mapeamento de solos. Anais do IX Simpósio Brasileiro de Sensoriamento Remoto SBSR , Santos - SP, 11-18 de setembro de 1998: 1381-89.

DEMATTÊ, J.A.M.; GARCIA, G.J. Alteration of soil properties through a weathering sequence as evaluated by spectral reflectance .Soil Sci Soc Am J, v. 63, 1999, pag. 327-342.

DEMATTÊ, J.A.M.; SILVA, A.L.S.; ROCHA, G.C.; CARVALHO, L.A.; FORMAGGIO, A.R.; FIRME, L.P. Variações espectrais em solos submetidos à aplicação de torta de filtro. Revista Brasileira de Ciência do Solo, V. 29, N. 3, Viçosa, Maio/Junho, 2005

DEVORE, J. L. Probability and statistics for engineering and the sciences. $5^{\text {a }}$ Ed., Pacific Grove: Duxbury, 2000 .

DIAS FLORES, C.; HOHER, C.L.; LADEIRA, M.; VICARI, R.S. Uma experiência em el uso de redes probabilísticas para el diagnóstico médico. Uma experiência brasileira. Informática médica., n. 8. art. 4. http://www.informaticamedica.org.ar/numero8/art4.htm

DICKINSON R.E., HENDERSON-SELLERS A., KENNEDY P.J. Biosphere-Atmosphere Transfer Scheme (BATS) Version 1e as Coupled to the NCAR Community Climate Model. Boulder, CO: National Center for Atmospheric Research Technical Note (NCAR TN-387+STR), 1993. 
DICKS, S. \& LO, T. Evaluation of thematic map accuracy in a land-use and land-cover mapping program. Photogrammetric Engineering and Remote Sensing, v. 56, n. 9, 1990, p. 1247-1252.

DiEUGENIO, B. On the usage of Kappa to evaluate agreement on coding tasks. http://www.cs.uic.edu/ bdieugen/PS-papers/lrec00.pdf.

DOZIER, J.; GOETZ, A.F.H. HIRIS: Eos instrument with high spectral and spatial resolution. Photogrammetria, v.43, p.167-143, 1989.

DOZIER, J.; STRAHLER, A.H. Ground investigations in support of remote sensing. In COLWELL, R.N. (Ed.) Manual of Remote Sensing. American Society of Photogrammetry. Virginia: Falls Church, 1983, pag. 959-86.

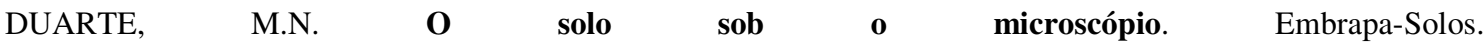
http://www.cnps.embrapa.br/search/pesqs/tema4/tema4.html (Data de publicação no site: 18/04/2000)

DUBIS, D.; PRADE, H.; YAGER, R. R. editors. Fuzzy Information Engineering. Wiley Computer Publishing, USA, 1997.

DUBOIS, D; PRADE, H Possibility Theory - An Approach to the Computerized Processing of Uncertainty. Academic Press, 1988.

DUBOIS, D; PRADE, H. A set-theoretic view of belief functions. International Journal of General Systems, v. 12, 1986, pag.193-226.

DUBOIS, D; PRADE, H. Fuzzy Sets and Systems: Theory and Applications. Academic Press, 1980.

DUBOIS, D; PRADE, H; SANDRI,S. On possibility/probability transformations. In Fuzzy Logic. Kluwer, 1993.

DUDA, R. D. e HART, P.E. . Pattern Classification and Scene Analysis. New York, NY: John Wiley \& Sons, 1973, 482 p.

DUDA, R.O.; GASCHNIG ,J.; HART, P.E. , Model design in the prospector consultant system for mineral exploration. In MICHIE, D.(Editor) Expert Systems in the Micro-eletronic Age. Edinburgh University Press, 1979.

DUKE, C., e. GUÉRIF, D.M.. Crop reflectance estimate errors from the SAIL model due to spatial and temporal variability of canopy and soil characteristics. Remote Sensing and Environment, v. 66, 1998, pag . 286-297.

DUTRA, L.V.; SOUZA, R.C.M. de; MITSUO, F.A.; MOREIRA, J.C. Análise automática de imagens multiespectrais. São José dos Campos: INPE, 1981. 40p.

DWIVED, R.S. The utility of data from various airborne sensors for soil mapping. International Journal of Remote Sensing, V.6, 1985, pag.89-100.

EASTMAN, J. R. Idrisi for Windows - version 32. Guide to GIS and image processing • Worcester: Clark Labs: Clark University, 1999. 169 p.

EASTMAN, J. R. Idrisi: exercícios tutorais. Porto Alegre: UFRGS, 1994. 109 p.

EL-SHEIK, T.S. \& WACKER, A.G. Effect of dimensionality and estimation on the performance of Gaussian classifiers. Pattern Recognition, n. 12, 1980, pag. 115-26.

ELVIDGE, C.D.; CHEN, Z. Comparison of broad-band and narrow-band red and near-infrared vegetation indices. Remote Sensing of Environment, vol. 54, 1995, pag. 38-48.

ELVIDGE, C.D.; LYON, RJ.P. Influence of rock-soil spectral variation on assessment of green biomass. Remote Sensing of Environment, v. 17, 1985, pag. 265-279. 
EMBRAPA (Empresa Brasileira de Pesquisa Agropecuária) Sistema Brasileiro de Classificação de Solos. Brasília. Centro Nacional de Pesquisa de Solos/Serviço de Produção e Informação. 1999, 412 p.

EMBRAPA. Sistema Brasileiro de Classificação de Solos. Brasília: Embrapa, 1999

EMBRAPA.. Levantamento exploratório - reconhecimento de solos da margem direita do rio São Francisco, Estado da Bahia. Recife: EMBRAPA-SNLS/SUDENE-DRN, 1977. 735 p. (EMBRAPA-SNLCS, Boletim Técnico, 52).

EMBRAPA.Vantagens da agricultura de precisão. Brasília: Embrapa, 2001< http://www.portaldoagronegocio.com.br/tecnologia/gps.asp $>$.

EPIPHANIO, J. C. N.; FORMAGGIO, A. R; SIMOES, M. DOS S. Comportamento espectral de solos de nove estados brasileiros e sistema de visualizacao de curvas espectrais. Anais do $26^{\circ}$ Congresso Brasileiro de Ciencia do Solo, Rio de Janeiro, 20-26 julho de 1997.

EPIPHANIO, J. C.N.; FORMAGGIO, A.R. Estudo de umidade do solo atraves de dados de reflectancia. Anais do $2^{\circ}$ Simposio Brasileiro de Sensoriamento Remoto, Brasília: INPE, 10-14 maio 1982

EPIPHANIO, J.C.N.; FORMAGGIO, A.R.; VALAERIANO, M.; OLIVEIRA, J.B. Comportamento espectral de solos do Estado de São Paulo. São José dos Campos: INPE, 1992, 131p.

EPIPHANIO, J.C.N.; FORMAGGIO, A.R.; VALERIANO, M.M. \& OLIVEIRA, J.B. Comportamento espectral de solos do estado de São Paulo, São José dos Campos, Instituto Nacional de Pesquisas Espaciais INPE, 1992. 131p.

ESCADAFAL R., GIRARD M.C., COURAULT D. Munsell soil color and soil reflectance in the visible spectral bands of Landsat MSS and TM data. Remote Sensing and Environment, v.27, 1989, pag. 37-46.

ESCADAFAL, R.; GIRARD, M.C.; COURAUL T , D. La couleur des sols: appréciation, mésure et realtions avec les propriétés spectrales. Agronomie, v.8, p.147-154, 1988.

ESCADAFAL, R.; GIRARD, M.C.; COURAULT, D. Munsell soil color and soil reflectance in the visible spectral bands of Landsat MSS and TM data. Remote Sensing of the Environment , v. 27, 1989, pag. 37-46.

ESPÍRITO-SANTO, F. D. B. Sensoriamento Remoto e Modelagem spacial de Dados de Inventários Florestais para a Caracterização e Mapeamento da Cobertura Vegetal na Região da Floresta Nacional do Tapajós. Dissertação de Mestrado em Sensoriamento Remoto - INPE - São José dos Campos. 2003.

ESPÍRITO-SANTO, F. D. B., SILVA, B.S.G.; SHIMABUKURO, Y.E. Detecção da dinâmica da floresta de bambu no sudeste do acre com o uso de técnicas de processamento de imagens de satélite. Anais XI SBSR, Belo Horizonte, Brasil, 05- 10 abril 2003, INPE, p. 649-656.

EVERETT, J. \& SIMONETT, D.S. Principles, concepts and philosophical problems. In: LINTZ, J.L. \& SIMONETT, D.S (Ed.) Remote Sensing of Environment. New York: Addison -Wesley, 1976, pag, 85-127.

FAO. Soil Conservation Service. Soil Taxonomic: a basic system of soil classification for making and interpreting soils surveys. New York: FAO, 1975, 256p.

FAUST, B.J.; PAVRI, J.A.; CHOVIT, B.E.; OLAH, C.J.; WILLIAMS, M.R. Imaging spectroscopy and the airborne visible/infrared imaging spectrometer (AVIRIS).Remote Sensing of Environment, New York, v. 65, 1998.

FERNANDEZ R.N., SCHULZE D.G. Calculation of soil color from reflectance spectra. Soil Sci. Soc. Am. J. , v. 51, 1987; pag.1277-1282.

FERNANDEZ R.N., SCHULZE D.G., COFFIN D.L., Van Scoyoc G.E. Color, organic matter, and pesticide adsorption relationships in a soil landscape. Soil Sci. Soc. Am. J. v.52, 1988, pag1023-1026 
FIDALGO, E.C.C. Exatidão no processo de mapeamento temático da vegetação de uma área de Mata Atlântica no Estado de São Paulo, a partir de Imagens TM-Landsat. Dissertação de Mestrado em Sensoriamento Remoto. São José dos Campos: INPE, 1995

FIORELLA, M.;RIPPLE, W.J. Analysis of conifer forest regeneration using Landsat thematic mapper data, Photogrammetric Engineering and Remote Sensing, vol. 59, 1993, pag. 1383-1388.

FIORELLA, M.;RIPPLE, W.J. Determining successional stage of temperate coniferous forests with Landsat satellite data, Photogrammetric Engineering and Remote Sensing, vol. 59,1993, pag. 239-246.

FIORIO, P. R., DEMATTE, J.A.M., FORMAGGIO, A. R. F., EPIPHANIO, J. C. N. Geoprocessamento e toposseqüências na determinação de levantamentos de solos em diferentes escalas.. Magistra. Salvador: , v.15, n.1, p.001 - 010, 2003.

FIORIO, P.R. Dados radiométricos obtidos nos níveis terrestres e orbital na avaliação dos solos. Tese de Doutorado em Agronomia. Escola Superior de Agricultura "Luiz de Queiroz. Piracicaba, 2002, 198p.

FIORIO, P.R.; DEMATTÊ, J.A.M.; NANNI, M.R. \& GENÚ, A.M. Regressões lineares múltiplas utilizando-se dados espectrais obtidos por sensores em laboratório e orbital, na estimativa de atributos do solo. In: SIMPÓSIO BRASILEIRO DE SENSORIAMENTO, 11., Belo Horizonte, 2003. Anais. Belo Horizonte, INPE, 2003. p.8592.

FITZGERALD, R.W.; LEES, B.G. Assessing the classification accuracy of multisource remote sensing data. Remote Sensing of Environment, New York, v.47, p.362-368, 1994.

FITZPATRICK-LINS, K.. Comparison of sampling procedures and data analysis for a land-use and land-cover map. Photogrammetric Engineering and Remote Sensing. v. 47, pag.343-351. 1981.

FLAIG, W.; BEUTELSPACHER, H.; RIETZ, E. Chemical composition and physical properties of humic substances. In: GIESEKING, J.E., ed. Soil components: organic components. New York: Springer-Verlag, 1975.

FLEISS, J.L. Statistical methods for rates and proportions. New York: Wiley and Sons, 1981.

FOODY, G. M. Using prior knowledge in artificial neural network classification with a minimal training set. International Journal of Remote Sensing , v. 16, n. 2, pag.: 301-312, 1995.

FOODY, G. M. On the compensation for chance agreement in image classification accuracy assessment. Photogrametric Engineering and Remote Sensing, v. 58, n. 10, p. 1459-1460, 1992.

FOODY, G. M., M. B. MCCULLOCH, AND W. B. YATES Classification of remotely sensed data by an artificial neural network: issues related to training data characteristics." Photogrammetric Engineering and Remote Sensing v. 61, n. 4, pag. 391-401, 1995.

FOODY, G.M. On the compensation for change agreement in image classification from remotely-sensed data. Photogrammetric Engineering and Remote Sensing, n. 58, pag. 1459-60, 1992

FOODY, G.M.. Soil moisture content ground data for remote sensing investigations of agricultural regions. International Journal of Remote Sensing, v. 12, 1995, pag. 1461-1469.

FORMAGgiO, A. R. ; EPIPHANIO, J. C. N. . Características Multiespectrais de Alguns Solos Tropicais do Estado de São Paulo. In: XXV CONGRESSO BRASILEIRO DE CIENCIA DO SOLO, 1995. Anais. VICOSA, MG. p. 1517-1519.

FORMAGGIO, A. R.; EPIPHANIO, J. C. N. Estudos radiometricos das culturas de trigo e de feijao em tres tipos de latossolos. Anais do $5^{\circ}$ Simposio Brasileiro de Sensoriamento Remoto, Natal: INPE/SElPER, de 11-15 outubro 1988, pág 393-399. 
FORMAGGIO, A. R.; EPIPHANIO, J. C. N. Feições espectrais e parâmetros analíticos de solos tropicais brasileiros.Anais do $\mathbf{1 0}^{\circ}$ Simpósio Brasileiro de Sensoriamento Remoto, Foz do Iguaçu:INPE, 21-26 abril 2001, pág 1399-1401.

FORMAGGIO, A. R.; EPIPHANIO, J. C. N.; VALERIANO, M. M. Comportamento espectral (450-2500 nm)e mineralogia de argila de alguns solos tropicais brasileiros. Anais do $7^{\circ}$ Simposio Latinoamericano de Percepcion Remota, Puerto Vallarta: SELPER, 8 novembro 1995, pág. 843-852

FORMAGGIO, A. R.; EPIPHANIO, J. C. N.; VALERIANO, M. M.. Relacoes entre reflectancia espectral na faixa de 0,4 a 2,5 um e caracteristicas fisico-quimicas de solos tropicais brasileiros. Anais do $6^{\circ}$ Simposio Latinoamericano de Percepcion Remota, Cartagena: SELPER, 03-08 outubro de 1993, pág. 53.

FORMAGGIO, A. R.; EPIPHANIO, J. C. N.; VALERIANO, M. M.; OLIVEIRA, J.B. Caracteristicas multispectrais de alguns solos tropicais do estado de São Paulo, Anais do $\mathbf{2 5}^{\circ}$ Congresso Brasileiro de Ciencia do Solo, Resumo Expandido, Viçosa, 23-29 julho 1995, pág. 1517-1519.

FORMAGGIO, A.R.; EPIPHANIO, J.C.; VALERIANO, M.M.;OLIVEIRA, J.B. Comportamento espectral (450-2450 nm) de solos tropicais de São Paulo. Revista Brasileira de Ciência do Solo, 20:467-474, 1996.

FORMAGGIO, A.R.; EPIPHANIO, J.C.N.; VALERIANO, M.M.; OLIVEIRA, J.B. Comportamento espectral 9450-2.450nm) de solos tropicais de São Paulo. Revista Brasileira de Ciência do Solo, v. 20, 1996, pág. 467474.

FORMAN, R.T.T.; GODRON, M. Landscape ecology. New York: John Wiley \& Sons, 1986. 620p.

FRANCELINO, M.R.; FERNADES F .; SCHIMITH, R.S.; VIEIRA, E.M. Utilização de imagem ASTER na determição de classes de uso do solo no Município de Viçosa, MG. Anais XI SBSR, Belo Horizonte, 5 - 10 abril 2003, INPE, p 1297-1301.

FRASIER, G. W.; HART, R.H.; SCHUMAN, G.E. . Rainfall simulation to evaluate infiltration/runoff characteristics of a shortgrass prairie. Journal of Soil and Water Conservation. V. 50, 1995, pág. :460-463.

FRED. A. Reconhecimento estatístrico de padrões. Notas de aula. Publicado em 1999. ltodi.est.ips.pt/jascenso/padroes/ teoricas/Aula\%203\%20-\%20Teoria\%20de\%20Decisão.pdf

FRITSCH, E.; MORIN, G.; BEDIDI, A. Transformation of haematite and Al-poor goethite to Al-rich goethite and associated yellowing in a ferralitic clay soil profile of the middle Amazon Basin (Manaus, Brazil). European Journal of Soil Science, v. 56, n.5, 2005, pag. 575-588.

FUJISADA, H. ASTER Level-1 data processing algorithm (Advanced Spaceborne Thermal Emission and Reflection Radiometer, IEEE Transactions on Geoscience and Remote Sensing, vol. 36, 1998, pag.11011112.

FUJISADA, H.; SAKUMA, F.; ONO, A.; KUDOH, M Design and preflight performance of ASTER instrument protoflight model, IEEE Transactions on Geoscience and Remote Sensing, vol. 36, 1998, pag. 1152-1160.

GALVÃO, L.S.; PIZZARO, M.A.; EPIPHANIO, J.C.N. Variations in reflectance of tropical soils: spectralchemical composition relationships from AVIRIS data. Remote Sensing of Environment, v. 75, 2001, pag. $245-255$

GALVÃO, L.S.; VITORELLO, I. Role of organic matter in obliterating the effects of iron on color and on spectral reflectance of Brazilian tropical soils. International Journal of Remote Sensing, London, v.191, p.969-1979, 1998.

GALVÃO, L.S.; VITORELLO, I.; FORMAGGIO, A.R. Realtionships of spectral reflectance and color among surface horizons of tropical soil profiles. Remote Sensing of Environment., v. 61, 1997, pag. 24-33.

GALVÃO,L.S.; VITORELLO, I. Role of organic matter in obliterating the effects of iron on spectral reflectance and color of Brazilian tropical soils. International Journal of Remote Sensing, London, v.19, 1998, p.19691979. 
GALVÃO,L.S.; VITORELLO, I.; ALMEIDA FILHO, R. Effects of band positioning and bandwidth on NDVI measurements of tropical savannas. Remote Sensing of Environment, New York, v.67, 1999, p.181-193.

GALVÃO,L.S.; VITORELLO, I.; FORMAGGIO, A.R. Relationships of spectral reflectance and color among nearand sub-surface horizons of tropical soil profiles. Remote Sensing of Environment, v. 61, p. 24-33, 1997.

GAO, X.; HUETE, A.R.; NI, W.; MIURA, T. Optical-biophysical relationships of vegetation spectra without background contamination. Remote Sensing of Environment, no. 74, 2000, p. 609-620.

GARDNER, B.R.; BLAD, B.L.; THOMPSON, D.R.; HENDERSON, K.E. Evaliation and interpretation of Thematic Mapper rations in equations for estimating corn growth parameters. Remote Sensing of Environment, v. 18,1985 , pag. $225-234$.

GATES, D.M.; KEEGAN, H.J.; SCHLETER, J.C.; WEIDNER, V.R. Spectral properties of plants. Applied Optics. Vol. 4, 1965, pag. 11-20.

GAUSMAN, H. W.. Reflectance of leaf components. Remote Sensing of Environment, v. 6, 1977, pag. 1-9.

GAUSMAN, H. W.; EVE, J.H.; GERBERMANN, A.H.; ESCOBAR, D.E. Leaf spectral characteristics of nine woody plant species from Texas rangelands.. 1975, pag. 5333-349.

GAUSMAN, H. W.; HEALD, JR., C.M.; ESCOBAR, D.E.. Effect of Rotyfenchulus reniformis on reflectance of cotton plant leaves. Journal. of Nematology , v. 7, 1975, pag.368-374.

GAUSMAN, H.W.; RODRIGUEZ, R.P.; ESCOBAR, D.E.. Ultraviolet radiation reflectance, transmittance, and absorptance by plant leaf epidermises. Agronomic Journal. Vol. 67, 1975, pag. 720-724.

GELMAN, A. Bayesian Data Analysis. London: Chapman and Hall, 1995.

GIACINTO, G.; ROLI, F. Dynamic Classifier selection based on multiple classifier behaviour, Pattern Recognition, vol. 34, 2001, pag. 179-181.

GIACINTO, G.; ROLI, F.; BRUZZONE, L. Combination of Neural and Statistical Algorithms for Supervised Classification of Remote-Sensing Images, Pattern Recognition Letters, vol. 21, 2000, pag. 385- 397

GIACINTO, G.; ROLI, F.; BRUZZONE, L.Combination of neural and statistical algorithms for supervised classification of remote-sensing images. Pattern Recognition Letters, n. 2, 2000, pag. 385-97.

GIACINTO, G.; ROLI, F.; FUMERA, G. Selection of image classifiers. Electronics Letters , vol. 36, 2000, pag. $420-422$.

GIAROLA, N.F.B.; SILVA, A. P. Conceitos sobre solos coesos e Hardsetting. Scientia Agrícola, v. 59, n. 3, p. 613-620, jul./set. 2002

GIAROLA, N.F.B.; SILVA, A.P.; IMHOFF, S. \& DEXTER, A.R. Contribution of natural soil compaction on hardsetting behavior. Geoderma, v.113, pág. 95-108, 2003.

GIAROLA, N.F.B; SILVA, A. P., TORMENA, C.; SOUZA, L.S; RIBEIRO, L.P. Similaridades entre o caráter coeso dos solos e o comportamento hardsetting: estudo de caso. Revista Brasileira de Ciência do Solo, v. 25, 2001, pág. 239-247.

GILLESPIE, A.G.; KAHLE, A.B.; WALKER, R.E. Color enhancement of highly correlated image. I Decorrelation and HIS contrast stretches. Remote Sensing of Environment, v. 20, 1986, p. 209-235.

GILLIES, R.R.; CUI; J.; CARLSON, T.N.; KUSTAS, W.P.; HUMES, K.S. Verification of the "triangle" method for obtaining surface soil water content and energy fluxes from remote measurements of NDVI and surface radiant temperature, International Journal of Remote Sensing, vol. 18, 1997, pag. 3145-3166. 
GLERIANI, J. M.; FORMAGGIO, A. R.; EPIPHANIO, J. C. N. Influencia dos solos no sensoriamento remoto da cultura do feijão. Anais do $\mathbf{2 5}^{\circ}$ Congresso Brasileiro de Ciencia do Solo, Resumo Expandido, Viçosa, 23-29 julho 1995, pág. 2369-2371.

GLERIANI, J. M.; FORMAGGIO, A. R.; EPIPHANIO, J. C. N; RUDORFF, B. F. T. Influencia do solo de fundo e da geometria de iluminacao e observacao em indices de vegetação. Anais do $7^{\circ}$ Simposio Latinoamericano de Percepcion Remota, Puerto Vallarta: SELPER, 8 novembro 1995, pág. 813-819

GLERIANI, J.M.; ANTUNES, M.A.H.; EPIPHANIO, J.C.N. Coeficientes da transformação espectral Tasseled Cap para Uma cena com predomínio de Latossolo Roxo. Anais XI SBSR, Belo Horizonte, Brasil, 05-10 abril 2003, INPE, p. 101-107.

GONG, P.; HOWARTH, P. J. An assessment of some factors influencing multiespectral land-cover classification. Photogrametric Engineering and Remote Sensing. v. 56, n. 5, p. 597-603, 1990.

GONG, P.; HOWARTH, P.J. Na assessment of some factors influencing multispectral land-cover classification. Photogrametric Engeneering and Remote Sensing. V. 56, n. 5, p. 597-603, 1990

GONZALES, R.C.; WOODS, R.E. Digital image processing. Massachusetts. Addison-Wesley, 1993.

GOWARD, S.N.; MASEK, J.G.; WILLIAMS, D.L.; IRONS, J.R.; THOMPSON, R.J. The Landsat 7 mission Terrestrial research and applications for for the 21 st century. Remote Sensing of Environment, n. 78, 2001, pag. 3-12.

GRANT, L., 1987. Diffuse and specular characteristics of leaf reflectance. Remote Sensing of Environonment. v. 22, 1987, pag. 309-322.

GRANT, R.H. The partitioning of biologically active radiation in plant canopies. International Journal of. Biometeorology. Vol. 40, 1997, pag. 26-40.

GRANT, R.H.; JENKS, M.; PETERS, P.; ASHWORTH, E., 1995. Scattering of ultraviolet and photosynthetically active radiation by Sorghum bicolor: influence of epicuticular wax. Agric. Forest Meteorol. Vol. 75, 1995, pag. 263-281.

GRASER E.A., VAN BAVEL C.H.M. The effect of soil moisture upon soil albedo. Agric. Meteorol. , v. 27, 1982. pag. 17-26.

GYER, M. S. (1992). Adjuncts and alternatives to neural networks for supervised classification. IEEE Transactions on Geoscience and Remote Sensing v. 22, n. 1, 1992, pag. 35-46.

HALL, F. G.; KNAPP, D.E.; HUEMMRICH, F., Physically based classification and satellite mapping of biophysical characteristics in the southern boreal forest, Journal of Geophysical Resarch, vol. 102, 1997, pag. 29569-29580.

HALL, F. G.; STREBEL, D. F.; NICKESON, J. E.; GOETZ, S. J., Radiometrie rectification: toward a common radiometric response among multidate, multisensor images. Remote Sensing of Environment, vol. 35, 1992, pag. 11-27.

HALL, F.G. \& BADHWAR, G.D. Signature-extendable technology: global space-based crop recognition. IEEE Trasactions on Geoscience and Remote Science. GE: 25, 1987, pag. 93-103.

HALL, F.G.; STRBEL, D.E.; NICKSON, J.E.; GOER, S.J. Radiometrics rectification: toward a common radiometric response among multidate, multisensor images. Remote Sensing of Environment, v. 17, 1985, pag. 265-279.

HALPERN, J.Y.; MOSES, Y.O. A guide to the modal logics of knowledge and belief. In Proceedings of IJCAI 9,, 1985, pag. 480-490.

HARALICK, R. M. AND I. H. DINSTEIN (1975). A spatial clustering procedure for multi-image data. IEEE Transactions on Circuits and Systems ,CAS-22, v.5, 1975, pag. 440-450. 
HARALICK, R.M. \& FU, K. Patterns regonition and classification. In: COLWELL, R.N. (Ed.) Manual of Remote Sensing. 2nd ed. American Society of Photogrammetry. Virginia: Falls Church, 1983, pag. 793-805..

HARALICK, R.M. Edge and region analisys for digital image data. Computer Graphics and Image Processing, n. 12, 1980, pag. 60-73.

HARDIN, P. J. (1994). Parametric and nearest-neighbor methods for hybrid classification: a comparison of pixel assignment accuracy. Photogrammetric Engineering and Remote Sensing v. 60, n. 12, 1994, pag. 1439-1448.

HARDIN, P. J. AND C. N. THOMSON . Fast nearest neighbor classification methods for multispectral imagery. The Professional Geographer, v. 44, n. 2, 1992, pag. 191-201.

HARDISKY, M.A.; KLEMAS, V.; SMART, R.M. The influence of soil salinity, growth form, and leaf moisture on the spectral radiance of Spartina alterniflora canopies, Photogrammetric Engineering and Remote Sensing , vol. 49, 1983, pag. 77-83.

HARTIGAN, J. A. Clustering Algorithms. New York, NY: John Wiley \& Sons, 1975, 351 p.

HARTLEY, H.O.; RAO, J.N.K. Maximum-likelihood estimation for the mixed analysis of vaiance model. Bometrika. v. 54, p. 93-108, 1967.

HAYKIN, S. Neural Networks: A comprehensive Foundation. New York: Macmillan College Publishing Company, Inc, 1994.

HEERMANN, P. D. AND N. KHAZENIE (1992). Classification of multispectral remote sensing data using a back-propagation neural network. IEEE Transactions on Geoscience and Remote Sensing , v. 30, n. 1, 1992, pag. : 81-88.

HEILMAN, J.L.; BOYD, W.E. Soil background effects in the spectral response of a three-components rangelands scene. Remote Sensing of Environment, v. 19, 1986, pag. 127-137.

HELLMAN, M.J.; RAMSEY , M.S. (2001) Analysis of hot springs in Yellowstone National Park using ASTER and AVIRIS remote sensing, EOS, Transactions of American Geophysical Union, vol. 82, 2001, F1360.

HENDERSON, T.L.; BAUMGARDNER, M.F. \& FRANZMEIER, D. High dimensional reflectance analysis of soil organic matter. Soil Science Society of America Journal., vol. 56, 1992, pag. 865-872.

HENDERSON, T.L.; BAUMGARDNER, M.F.; FRANSMEIER, D. High dimensional reflectance analysis of soil organic matter. Soil Science Society of America Journal, Madison, v.56, 1992 , pag. 865-72.

HILLEL, D. . Environmental soil physics. San Diego: Academic Press, 1998.

HLAVAY, H.; JONAS, K.; ELEK, S.; INCZEDY, J. Characterization of the particle size and christallinity of certain minerais by infrared spectrophotometry and other instrumental methods -I. Investigations on clay minerais. Clays and Clay Minerais, Boulder, CO, v .25, p.451-456, 1977.

HOFFER, R.M. Biological and physical considerations in applying computer-aided analysis techniques to remote-sensor data. In: SWAIN, P.H. \& DAVIS, S.M. (Eds.) Remote Sensing: the quantitative approach. New York: MacGraw-Hill, 1978, pag. 227-87.

HOLMES, M.G.; KEILLER, D.R. Effects of pubescence and waxes on the reflectance of leaves in the ultraviolet and photosynthetic wavebands: a comparison of a range of species. Plant Cell Environment. vol. 25, 2002, pag. 85-93.

HOLMGREN G.G.C. A rapid citrate-dithionite extractable iron. Soil Sci. Soc. Am. Proc.;v. 31, 1967, pag. 210211.

HOOK, S.J.; DMOCHOWSKI, J.E; HOWARD, K.A; ROWAN, L.C.; KARLSTROM , K.E. Mapping weight percent silica variation from remotely acquired multispectral thermal infrared data with examples from the Hiller 
Mountains, Nevada, USA and Tres Virgenes-La Reforma, Baja California Sur, Mexico, Journal of Geophysical Research, 2003

HOOK, S.J.; MYERS, J.J; THOME, K.J.; FITZGERALD, M.; KAHLE , A.B. The MODIS/ASTER airborne simulator (MASTER) - A new instrument for Earth science studies, Remote Sensing of Environment, vol. 76, 2001, pag 93-102.

HORLER, D.N.H; AHERN, F.J. Forestry information content of thematic mapper data, International Journal of Remote Sensing, vol. 7, 1, 1986, pag. 405-428.

HSEIH, P.-F. \& LANDGREBE, D. Classification of high dimensional data. Report TR-ECE 98-4, School of Electrical and Computer Engineering, Pardue University, W. Lafayette, 1998.

HUANG, C.; WYliE, B. ; YANG, L.; HOMER, C.; ZYLSTRA, G. Derivation of a Tasseled Cap Transformation based on Landsat 7 at-satellite reflectance. Sioux Fallas, USGS Eros Data Center, 2001

HUANG, H; WYLIE, C.; HOMER, L.: YANG , L; ZYLSTRA, G. A tasseled cap transformation for Landsat 7 ETM+at-satellite reflectance, International Journal of Remote Sensing, vol. 23, 2002, pag. . 1741-1748.

HUEMMRICH, K.F.; BLACK, T.A.; JARVIS, P.G.; McGAUGHEY, J.H.; HALL, F.G. High temporal resolution NDVI phenology from micrometeorological radiation sensors. Journal of Geophysical Research, Vol. 104, 1999, pag. 27935-27944

HUETE, A. R. A soil-adjusted vegetation index (SAVI). Remote Sensing of the Environment. V. 25, 1988, p. 295-309.

HUETE, A. R. Separation of Soil-plant Spectral Mixtures by Factor Analysis. Remote Sensing of the Environment. V. 19, 1986. p.237-251.

HUETE, A. R. Spectral response of a plant canopy with different soil backgrounds. Remote Sensing of the Environment. v.7, 1985, p. 37-53.

HUETE, A.R. \& WARRICK, A.W. Assement of vegetation and soil water regimes in partial canopies with optical remotely sensed data. Remote Sensing of Environment, v. 32, 1990, p. 155-167.

HUETE, A.R. A soil-adjusted vegetation index (SAVI). Remote Sensing of Environment, v. 25, 1988, pag. 295-309.

HUETE, A.R. Soil and sunangle interactions on partial canopy spectra. . International Journal of Remote Sensing, v.8, n.2, 1987, pag. 1307-1317.

HUETE, A.R.; JACKSON, R.D. Soil atmosphere influences on the spectra of partial canopies. Remote Sensing of Environment, v. 25, 1988, pag. 89-105

HUETE, A.R.; JACKSON, R.D. The suitability of spectral indices for evaluation vegetation characteristics on arid rangeland. Remote Sensing of Environment, v. 23, 1987, pag. 213-232.

HUETE, A.R.; JACKSON, R.D.; POST, D.F. Soil-dependent spectral response in a developing plant canopy. Remote Sensing of Environment, v. 17, 1985, pag. 37-53.

HUETE, A.R.; LIU, H.Q.; BATCHILY, K.; VAN LEEUWEN, W.J.D. 1997. A Comparison of Vegetation Indices over a Global Set of TM Images. Remote sensing of environment, vol. 59, 1997, pag. 440-451

HUMMEL, J.R.; RECK R.A. A global surface albedo model. J. Appl. Meteorol. v18, n. 3, 1979, pag.:239-253.

HUNT JR; A.M.. ROCK, B.N.Detection of changes in leaf water content using near- and middle-infrared reflectance, Remote Sensing of Environment. vol. 30, 1989, pag. 43-54.

HUNT, G.R. Eletromagnetic radiation: the communication link in remote sensing. In: SIEGEL, B.S.; GILLESPIE, .A.R., ed. Remote sensing in geology. New York: .J. Wiley, 1980. 
HUNT, G.R.; SALISBURY, J. W .Visible and near infrared spectra of minerals and rocks. I. Silicate minerais. Modern Geology, Amsterdam, v.1, p.283-300, 1970.

HUNT, G.R.; SALISBURY, J.W. ;LEMHOFF, C.J. Visible and near-infrared spectra of minerals and rocks: III. Oxides and hydroxides . Mod. Geol., vol. 2, 1971, pag 195-205

HUNT, G.R.; SALISBURY, J.W.; LENHOFF, C.J. Visible and Near-Infrared Spectra of Minerais and Rocks: III. Oxides and hydroxides. Modern Geology, Amsterdam, v.2, p.195-205, 1971.

HUNT, G.R.; SALISBURY, J.W.; LENHOFF, C.J. Visible and near-infrared spectra of minerais and rocks: VI. Additional silicates. Modern Geology, Amsterdam, v.4:p.85-106, 1973.

IBGE. Folha SC-24-Z-C-VI, Carta topográfica, Esplanada. Rio de Janeiro, 1988. Esc. 1:100.000.

IDSO, S.B.; JACKSON, R.D.; REGINATO, R.J.; KIMBALL, B.A.; NAKAYAMA, F.S. The depence of bare soil albedo on soil water content. Journal of the Applied Meteorology, v. 14, 1975, pag. 109-113.

IDSO, S.B.; REGINATO, R.J.; JACKSON, R.D.; KIMBALI, B.A.; NAKAYAMA, F.S. The three stages of drying of field soil. . Soil Science of Society of American Proceedings, v. 38, 1974, pag. 831-837.

INPE. Departamento de Processamento de Imagens. Manual de operação do SPRING: versão.3.6. São Jose dos Campos, SP. URL:file:/home/spring/help, outubro de 2003.

IRONS, J. R., B. L. MARKHAM, R. F. NELSON, D. L. TOLL, D. L. WILLIAMS, R. S. LATTY, AND M. L. STAUFFER The effects of spatial resolution on the classification of Thematic Mapper data. International Journal of Remote Sensing v. 6, n. 8, 1985, pag.1385-1403.

IRONS, J.R.; RANSON, K.L. Estimating big bluestem albedo from directional reflectance measurements. Remote Sensing of Environonment. v. 25, 1988, pag. 185-199.

IRONS, J.R.; WEISMILLER, R.A.; PETERSEN, G.W. Soil reflectance. pag. 66-106. In ASRAR, G. (Ed.) Theory and applications of optical remote sensing. New York: John Wiley \& Sons, 1989.

ISHIDA, T. ; ANDO, H. Use of disjunctive cokriging to estimate soil organic matter from Landsat thematic image. International journal of Remote Sensing, vol. 20, 1999, pag. 1549-1565.

ISHIDA, T., H. ANDO, AND M. FUKUHARA. Estimation of complex refractive index of soil particles and its dependence on soil chemical properties. Remote Sensing of Environment., v. 38, 1991, pag. 173-182.

IWAI, O. K.; QUINTANILHA, J. A. utilização de imagens de satélite como ferramenta de auxílio ao planejamento urbano. S. Paulo, No prelo, 2005

JACKSON, R.D. Spectral indices in n-space. Remote Sensing of Environment, v. 20, 1983, p. 209-235.

JACKSON, R.D.; EZRA, C.E. Spectral response of cotton to suddenly induced water stress. International Journal of Remote Sensing, v.6, n.1, 1985, pag. 177-185.

JACKSON, R.D.; HUETE, A.R. Interpreting vegetative indices. Preventative Veterinary Medicine, V.11, 1991, pag. 185-200.

JACKSON, R.D.; KIMBALL, B.A.; REGINATO, R.J.; NAKAYAMA, F.S. Diurnal soil water evaporation time-depth-flux patterns. Soil Science of Society of American Proceedings, v. 37, 1973, pag. 505-509.

JACKSON, R.D.; SLATER, P.N.; PINTER, P.J. Discrimination of growth and water stress in wheat by various vegetation indices through clear and turbid atmospheres. Remote Sensing of the Environment, vol. 15, 1983, pag. 187-208.

JACKSON, R.D.; SLATER, P.N.; PINTER, P.J. Discrimination of growth and water stress in wheat by various vegetation indices through clear and turbid atmospheres. Remote Sensing of Environment, v. 13, 1983, pag. 187-208. 
JACKSON, R.D.; SLATER, P.N.; PINTER, P.O. Discrimination of growth and water stress in wheat by various indices through clear and turbid atmospheres. Remote Sensing of Environment., v. 13, 1983, pag. 187-208.

JACOB, F.; PETITCOLIN,F; SCHMUGGE, T.J.; VERMOTE, E.; FRENCH, A.N.; OGAWA, K. Comparison of land surface emissivity and radiometric temperature derived from MODIS and ASTER sensors, Remote Sensing of Environment. 2002.

JACOMINE, P.K.T. Distribuição geográfica, características e classificação dos olos coesos dos Tabuleiros Costeiros. In: REUNIÃO TÉCNICA SOBRE SOLOS COESOS DOS TABULEIROS, Cruz das Almas, 1996. Pesquisa e desenvolvimento para os Tabuleiros Costeiros; Anais. Aracajú: EMBRAPA, CPATC; EMBRAPA, CNPMF; EAUFBA, IGUFBA, 1996. P. 13-24.

JACOMINE, P.K.T. Evolução do conhecimento sobre solos coesos no Brasil. In. WORKSHOP COESÃO EM SOLOS DE TABULEIROS COSTEIROS, Aracajú, 2001. Anais. Aracajú:Embrapa Tabuleiros Costeiros, 2001, p. 19-46.

JAIN, A. K. ; R. C. DUBES Algorithms for Clustering Data. Englewood Cliffs, NJ: Prentice Hall, 1988, 320 p.

JAIN, A. K.; DUIN, R. P. W.; MAO, J. Statistical pattern recognition: A review. IEEE Transactions on Pattern Analysis and Machine Intelligence, v. 22, n. 1, 2000, p. 4-37.

JAIN, A. K.; MURTY, M. N.; FLYNN, P.J. Data clustering: a review. ACM Computing Surveys, v. 31, n. 3, 1999, pag. 264-323.

JAMES, M.. Classification Algorithms. London: Collins, 1985, 209 p.

JARDIM-LIMA, D. ; NELSON, B.W. Uso de índices de vegetação no monitoramento da cobertura verde no perímetro urbano da cidade de Manaus. Anais XI SBSR, Belo Horizonte, Brasil, 05 - 10 abril 2003, INPE, p. $1827-1833$.

JASINSKI, M.F.; EAGLESON, P.S. The structure of red-infrared scattergrams of semivegetated landscapes. IEEE Transactions on Geoscience and Remote Sensing, v. 27, n.4, 1989, pag. 441-451.

JEER, S. Land-Based Classification Standards. Online, http://www.planning.org/LBCS. American Planning Association: Chicago, Illinois, 2001.

JENSEN FINN V.; OLSEN, KRISTIAN G.; ANDERSEN, STIG K. An Algebra of Bayesian Belief Universes for Knowledge-Based Systems. Networks. New York: John Wiley \& Sons, Inc., v.20, p.637-659, 1990.

JENSEN, J. R. Introductory Digital Image Processing - A Remote Sensing Perspective. 2a. Ed, Upper Saddle River: Prentice Hall, 1996, 316 p.

JENSEN, J.R. Introductory Digital Image Processing: A Remote Sensing Perspective. New York: PrenticeHall, 1986

JENSEN, J.R. Remote sensing of the environment : an earth resource perspective . Upper Saddle River: Prentice Hall, 2000.

JENSEN, J.R. Introductory digital image processing: A remote sensing perspective. New Jersey: Prentice Hall , 1986.

JENSEN, J.R. Introductory digital image processing: A remote sensing perspective. Upper Saddle River : Prentice-Hall, 1995. 316p

JIA, X. ; RICHARDS, J.A.. Efficient maximum likelihood classification for imaging spectrometer data sets. IEEE Transactions on Geoscience and Remote Sensing v. 32, 1994, pag. 274-281.

JIM, S. SADER, S.A. Comparison of time series tasseled cap wetness and the normalized difference moisture index in detecting forest disturbances. Remote Sensing of Environment, Vol. 94, 2005, pag. 364-372 
JOLY, F. A cartografia. Campinas: Papirus, 1990. 136p.

JUPP, D.L.B.; STRAHLER, A.H.; WOODCOCK, C.E. Autocorrelation and regularization in digital images: II Simple image models. IEEE Trasactions on Geoscience and Remote Science. n. 27, 1989, pag. 247-56.

JUPP, D.L.B.; WALKER, J.; PENRIDGE, L.K. Interpretation of vegetation structure in Landsat MSS iamgery: a case study in disturbed semi-arid Eucalyot woodlands. Part 2. Model-based analysis. Journal of Environmental Management. n. 23, 1986, pag. 35-57.

JUPP, D.L.B; STRAHLER, A.H.; WOODCOOK, C.E. Autocorrelation and regularization in digital images: II. Simple image models. IEEE Transactions on Geoscience and Remote Sensing, n. 27, 1989, pag. 247-56.

JUSTICE, C.; HALl, D.; SAlOMONSON, V.; PRIVETTE, J.;RIGGS, G.; STRAHLER, A.; LUCHT, W.; MYNENI, R., KNJAZIHHIN, Y.; RUNNING, S.; NEMANI, R.; VERMOTE, E.; TOWNSHEND, J.; DEFRIES, R.; ROY, D.; WAN, Z.; HUETE, A.;VAN LEEUWEN, W.J.D.; WOLFE, R.; GIGLIO, L.; MULLER, J-P.; LEWIS, P.; BARNSLEY, M, The Moderate Resolution Imaging Spectroradiometer (MODIS): Land remote sensing for global change research. IEEE Transactions on Geoscience and Remote Sensing. Vol. 36, 1998, pag. 1228-1249.

JUSTICE, C.; VERMOTE, E.; TOWNSHEND, J. R. G.; DEFRIES, R.; ROY, D. P.; HALL, D. K.; SALOMONSON, V. V.; PRIVETTE, J.;RIGGS, G.; STRAHLER, A.; LUCHT, W.; MYNENI, R.; KNJAZIHHIN, Y.; RUNNING, S.; NEMANI, R.;WAN, Z.; HUETE, A.; VAN LEEUWEN, W.; WOLFE, R. The Moderate Resolution Imaging Spectroradiometer (MODIS): Land remote sensing for global change research. IEEE Transactions on Geoscience and Remote Sensing, vol. 36, 1998, pag. 1228-1249

JUSTICE, C.O.; TOWNSHEND, J.R.G.; HOLBEN, B.N.; TUCKER, C.J. Analysis of the phenology of global vegetation using meteorological satelltte data, International Journal of Remote Sensing, vol.6, 1985, pag. 1271-1318.

JUSTICE. C.O.;STARR, D. ; WICKLAND, D.; PRIVETTE, J.; SUTTLES, T. EOS Land validation coordination: An update. The Earth Observer, vol. 10, 1998, pag. 55-60.

KAMPF, N.; SCHWERTMANN, U. Quantitative determination of goethite and hematite in kaolinitic soils by X-ray diffraction. Clay Minerals. v. 17, 1982, pag. 359-363

KAMPF, N.; SCHWERTMANN, U., Goethite and hematite in a climosequence in southern Brazil and their application in classification of Kaolinitic soils. Geoderma, v. 29, 1983, pag. 27- 39.

KAMPF, N.; SCHWERTMANN, U., Relações entre óxidos de ferro e a cor dos solos cauliniticos do Rio Grande do Sul. Revista Brasileira de Ciência do Solo, v. 7, 1983, pág. 23- 31.

KANELLOPOULOS, I.; VARFIS, A.; WILKINSON, G.G; MEGIER, J. . Land cover discrimination in SPOT imagery by artificial neural network-a twenty class experiment. International Journal of Remote Sensing $v$. 13, n. 5, 1992, pag. 917-924.

KARAVANOVA, E.I Spectral reflectance as a tools to study soils in semi-arid regions. 10 $^{\text {th }}$ International Soil Conservation Organization Meeting. Pardue University/USDA, 2001. <http://topsoil.nserl.purdue.edu/nserlweb/isco99/pdf/ISCOdisc/SustainingTheGlobalFarm/P185-Karanova.pdf> Acessado em 12/11/2004

KARAVANOVA, E.I ; SOROKINA, N.P.; KUDELINA, E.A. Spectral reflectivity as a diagnostic criteria of the degree of erosion of the gray forest soils. $\mathbf{1 0}^{\text {th }}$ International Soil Conservation Organization Meeting. Pardue University/USDA,

2001.

<http://topsoil.nserl.purdue.edu/nserlweb/isco99/pdf/ISCOdisc/SustainingTheGlobalFarm/P185-Karanova.pdf>

Acessado em 12/11/2004

KARAVANOVA, E.I.; . SHRESTHA, D. P.; ORLOV, D.S. Application of remote sensing techniques for the study of soil salinity in semi-arid <http://www.itc.nl/personal/shrestha/RS_for_salinity.pdf>Acessado em 12/11/2004 
KARGEL, J.S.; KIEFFER , H.H. Opportunity for nearly comprehensive global glacier monitoring with ASTER, EOS, Transactions of American Geophysical Union, vol. 76, 1995, 91.

KARMANOV, 1.1. Genesis and geography of soils: application of spectrophotometric coefficients to the study of soil-forming processes. Soviet Soil Science, Washington, DC, v.2, p.152-165, 1968.

KAUTH, R. J.; LAMBECK, P.F.; RICHARDSON, W.; THOMAS, G.S; PENTLAND, A.P. Feature Extraction Applied to Agricultural Crops as Seen by Landsat; Proceedings, of the Technical Session, LACIE Symposium. Houston: National Aeronautics and Space Adminiatration, 1979, PAG. 705-721.

KAUTH, R.J. \& THOMAS, G. The tasselled cap - a graphic description of the spectral-temporal development of agricultural crops as seen by Landsat. Proceedings of the Symposium on Machine Processing of RemotelySensed Data 1976, PArdue University, West Lafayette, IN, pp. 4B-41-4 B-51.

KAUTH. R.J. \& THOMAS, G.S. The tasseled cap - a graphic description of the spectral-temporal development of agricultural crops as seen by Landsat. Preceedings of the Symposium on Machine Processing of Remote Sensed Data, Purdue University, West Lafayette, Indiana, 1976, 41-51.

KAUTH. R.J. \& THOMAS, G.S. The tasseled cap - a graphic description of the spectral-temporal development of agricultural crops as seen by Landsat. Preceedings of the Symposium on Machine Processing of Remote Sensed Data, Purdue University, West Lafayette, Indiana, 1976, 41-51.

KETTIG, R. L. ;D. A. LANDGREBE Classification of multispectral image data by extraction and classification of homogeneous objects. IEEE Transactions on Geoscience and Remote Sensing GE-v. 4, n. 1, 1976, pag. 1926.

KHODJA, A.; HOTYAT, M.; CHATELAIN, A.; GILG, J.P. Partition d'une image satellitaire et caractérisation de son contenu par une méthode de segmentation d'images: Application à la forêt de Bouconne (France) et à la ville d'Oran (Algérie). Photo-Interpretation, Paris, n.1995/1, p.25-30. 1995.

KHODJA, A.; MENGUE, A. Amélioration de l'aport thématique d'une image SPOT XS par les processus spatiaux et une méthode de segmentation: application à la région de Lagdo (Nord-Cameroun). International Journal of Remote Sensing, London, v.17, n.5, p.879-886, 1996.

KIEHL, E.J. Manual de edafologia - Relações Solo-Planta. S. Paulo: Editora Ceres, 1979.

KLIR, G.J. A principle of uncertainty and information invariance. International Journal of General Systems, v. 17, 1990, pag .249-275.

KOHN, A.F. Reconhecimento de padrões, uma abordagem estatística. Apostila, EEP - Universidade de São Paulo. 1998.

KORNBLAU, M.L. ; CIPRA, I.E. Investigation of digital Landsat data for mapping soil under range vegetation. Remote Sensing of Environment, v. 13, 1983, p. 103-112.

KOSKO, B. Neural Networks and Fuzzy Systems. Prentice-Hall, 1992.

KRIEGLER, F.; MALILA, W.; NALEPKA, R. ;RICHARDSON, W. . Preprocessing transformations and their effects on multispectral recognition.. In: Proceedings of the Eighth International Symposium on Remote Sensing of Environment., 1969, pag. 97-131.

KRISTOF, S.J.; ZACHARY, A;L. Mapping soil features from Multiespectral Scanner data. $7^{\text {th }}$ Symposium on Remote Sensing of Environment, Annual Arbor, MI, v.3, 1974, pag 2095-2105.

KUMITA, K.; UNO,S; HAYASHI, I.; SAITO, G. Quantification of soil content in vegetated areas by remote sensing, presented at International Geoscience and Remote Sensing Symposium (IGARSS) '93, held in Tokyo, Japan, 1993. 
LABOVITZ, M.L. Issues arising from sampling designs and band selection in discriminating ground reference attributes using remotely sensed data. Photogrammetric Engieering and Remote Sensing, v. 52, n.2, p. 201$211,1986$.

LADEIRA, M. Representação de Conhecimento Incerto. Porto Alegre: II/CPGCC da UFRGS, 1996. 57p. (Trabalho Individual n. 558).Ladeira Marcelo; VICCARI, Rosa. M. Representação de Conhecimento Incerto. Recife: DI/ UFPE, 1996. 51p. (Desenvolvido para apresentação na XV Jornada de Atualização em Informática, evento do XVI Congresso da Sociedade Brasileira de Computação).

LADEIRA, M.; VICCARI, R. M.; COELHO, H. Redes Bayesianas Multi-agentes. In: CONGRESSO DA SOCIEDADE BRASILEIRA DE COMPUTAÇÃO, XIX, 1999, Rio de Janeiro. Anais do II Encontro Nacional de Inteligência Artificial. Rio de Janeiro, 1999. (Texto de suporte ao tutorial de mesmo nome apresentado no II ENIA). 38p.

LAMPINEM, J. ; VEHTARI, A. Bayesian approach for neural networks - review and case studies. Neural Networks, n. 14, 2001, pag. 257-74.

LANDGREBE, D. A. The development of a spectral-spatial classifier for the earth observational data. Pattern Recognition $v$. 12, 1980, pag. 165-175.

LANDIS, J.R.; KOCH, G.G. The measurement of observer agreement for categorical data, Biometrics, v. 33, 1977, p. 159-174.

LEE, C. ; D. A. LANGREBE . Fast likelihood classification. IEEE Transactions on Geoscience and Remote Sensing $v .29$, n. 4, 1991, pag. 509-517.

LEE, K-S.; LEE, G.; TYLER, E.J. Thematic mapping and digital elevation modeling of soils characteristics in hilly terrain. Soil Science Society American Journal, n.52, 1988, p. 1104-1107.

LEVINE, J. S. (ED) Global Biomass Burning: atmospheric, climatic, and biospheric implications Massachusetts: MIT Press, 1991.

LEWIS, D.T.; SEEVERS, P.M.; DREW, J.V. Use of satellite imagery to delineate soil association in the Sand Hills region of Nebraska. Soil Science Society American Journal, n.39, 1975, p. 330-335.

LIANG, S. An optimization algorithm for separating land surface temperature and emissivity from multispectral thermal infrared imagery, IEEE Transactions on Geoscience and Remote Sensing, vol. 39, 2001, pag. 264274.

LILLESAND, T.M.; KIEFER, R.W. Remote sensing and image interpretation. New York: John Wiley \& Sons, 1994. 750p.

LIMA, A. A. C.; OLIVEIRA, F.N.S.; AQUINO, A. R.L. Limitações do uso dos solos do Estado do Ceará por susceptibilidade à erosão. Fortaleza: Embrapa, Documento 54, Maio 2002. http://www.cnpat.embrapa.br/publica/pub/SerDoc/doc_54.pdf

LIMA, H.V.; SILVA, A.P.; ROMERO, R.E.; JACOMINE, P.K.T. Comportamento físico de um argissolo acinzentado coeso no estado do Ceará. Revista Brasileira de Ciências do Solo. vol.29, no.1, Viçosa. Jan./Feb. 2005

LIN, D.S.; WOOD, E.F.; BEVEN, K. ; SAATCHI, S. Soil moisture estimation over grass-covered areas using AIRSAR. International Journal of Remote Sensing , v. 15, 1994, pag. 2323-2343.

LINDSEY, S.D.; GUNDERSON, R.W. ; RILEY, J.P. Spatial distribution of point soil moisture estimates using Landsat TM data and fuzzy-c classification. Water Resources Bulletin, v. 28, n. 5, 1992, pag. 865-875.

LIU, H.Q. ; HUETE, A. A feedback based modification of the NDVI to minimize Canopy background ant atmosferric noise. IEEE Transaction on Geoscience and Remote Sensing, v. 33, n. 2, 1995, pag. 457-465. 
LIU, Z. K. ; XIAO, J,Y. Classification of Remotely-Sensed Image Data Using Artificial Neural Networks. International Journal of Remote Sensing , v. 12, n. 11, 1991, pag. 2433-2438.

LOBELL, D.B.; ASNER, G.P. Moisture effects on soil reflectance. Soil Science Society American Journal. V.66, p. 722-727, 2002

LOVEJOY, S. \& SCHERTZER, D. Generalised sclae invariance in the atmosphere and fractal models of rain. Water Resources Research, n. 21, 1985, pag. 1233-50.

MA, Z.; REDMOND, R. L. Tau coefficient for accuracy assessment of classification of remote sensing data. Photogrammetric Engineering and Remote Sensing, v. 61, n. 4, p. 435-439, 1995.

MADEIRA NETTO, J. ; BEDIDI, A. ; POUGET, M. Spectral (mir) determination of kaolinite and gibbsite contents in lateritic soils. Comptes Rendus de L' Academie des Sciences Serie II Fascicule A-Sciences de la Terre et dDes Planetes, v. 321, n. 2, 1995, pág. 119-127.

MADEIRA NETTO, J. S Etude quantitative des relations constituants min ralogiques reflectance diffuse des latosols brésiliens. Application àl'utilisation pédologique des données satellitaires TM (region de Brasília). Tese de Doutorado em Pedologia. Universite de Paris VI (Pierre et Marie Curie), U.P. VI, Paris, França, 1991.

MADEIRA NETTO, J. S. Spectral reflectance properties of soils. Photo Interprétation. França: , v.2, n.34, p.59 - 76, 1996.

MADEIRA NETTO, J. S., BEDIDI, A., CERVELLE, B., POUGET, M. Spectrometric indices (visible) of hematite and goethite contents in lateritic soils. Application to a TM image for soil mapping around Brasilia. International Journal of Remote Sensing. Estados Unidos: , v.18, n.13, p.2835 2852, 1997.

MADEIRA NETTO, J. S., POUGET, M., BEDIDI, A., $\quad$ CERVELLE, B. Informações quantitativas sobre a mineralogia dos latossolos a partir da reflectância espectral no visível e infravermelho próximo e médio In: Simpósio Brasileiro de Sensoriamento Remoto 7, 1993, Curitiba.

MADEIRA NETTO, J. S., POUGET, M., HUMBEL, F. X. Du labour au satéllite un apport a la cartographie des sols au Brésil. Science Du Sol. França: , v.27, n.1, p.61 - 64, 1989.

MADEIRA NETTO, J. S.; BÉDIDI, A.; CERVELLE, B.; FLA Y , N. Spectral (MIR) Determination of Kaolinite and Gibbsite Contents in Lateritic Soils. Comptes Rendus de I' Academie des Sciences, serie lia, t.321 , p.119128,1995 .

MADEIRA NETTO, J.S. Étude quantitative des relations constituants mineralogiques -réflectance diffuse des latosols brésiliens: application à I'utilisation pédologique des données satellitaires TM (région de Brasi-lia). Collection Etudes et Theses Paris: Éd. I'ORSTOM, 1993.236p.

MADEIRA NETTO, J.S. Spectral reflectance properties of soils. Photo Interprétation, Paris, v.2, p.59-76, 1996.

MADEIRA NETTO, J.S.; BEDIDI, A.; CERVELLE, B.; POUGET, M.; FLAY, N. Visible spectrometric indices of hematite $(\mathrm{Hm})$ and goethite $(\mathrm{Gt})$ content in lateritic soils: the application of a Thematic Mapper (TM) image for soil-mapping in Brasília, Brazil. International Journal of Remote Sensing, London, v.18, p.2835-2852, 1997.

MADEIRA, J..; BEDIDI, A.; CERVELLE, B.; POUGET , M.; FLAY , N. Visible spectrometric indices of hematite (Hm) and goethite (Gt) content in lateritic soils: the application of a Thematic Mapper (TM) image for soil-mapping in Brasilia, Brazil. International Journal of Remote Sensing. V. 18, 1997, pag. 2835 - 2852

MADEIRA, J.; BEDIDI, A.; CERVELLE, B.Visible spectrometric indices of hematite (Hm) and goethite (Gt) content in lateritic soils: the application of a Thematic Mapper (TM) image for soil-mapping in Brasilia, Brazil. International Journal of Remote Sensing, v. 18, n. 13, 1997, pag. 2835-2852. 
MAH, A. Mapping surface cover types using ASTER data. Gis Development: the Geospatial Resource Portal. 2003. <www. Gisdevelopment.net/technology/rs/techrs0023pf.htm> Acessado em 24/05/2004.

MALENGREAU, N; BEDIDI, A.; MULLER, J-P. Spectroscopic control of iron oxide dissolution in two ferralitic soils. European Journal of Soil Science, v. 47, n.1, 1996, pag. 13-20.

MANABE, S., Carbon dioxide and climate change. Advances in Geophysics, vol. 25, 1983, pag. 39-82.

MARBLE, D.F.; PEUQUET, D.J.; BOYLE, A.R.; BRYANT, N.; CALKINS, H.W; JOHNSON, T. Geographic information systems and remote sensing. In: In COLWELL, R.N. (Ed.) Manual of Remote Sensing. American Society of Photogrammetry. Virginia: Falls Church, 1983, pag. 923-57.

MARDIA, K.V. ; MARSHALL, R.J. Maximum likelihoos models for residual covariance in spatial regression. Biometrika. v. 17, n. 1, p. 135-46, 1984.

MATA, F.; CAVACO, G.; CAETANO, M. Validação de cartografia temática produzida pro classifcação de imagens obtidas pro deteç̧ão remota: estado da arte. Anais do ESIG. Lisboa. 13-16 de julho de 2004. pag. 569582.

MATHER, P.M. Land cover classification revisited. In ATKINSON, P.M. \& TATE, N.J. Advances in Remote Sensing and GIS Analysis. Chichester: John Wiley, 1999, pag. 7-16.

MATTHIAS A.D.; POST D.F.; ACCIOLY, L.; FIMBRES, A.; SANO, E.; BATCHILY A.K. Measurement of albedos for small areas of soil. Soil Sci. , v. 164, 1999, pag. 293-301.

MATTHIAS, A.D.; FIMBRES, A.; SANO, E.E.; POST, D.F.; ACCIOLY, L.; BATCHILY, A.K.; FERREIRA, L.G. Surface Roughness Effects on Soil Albedo Soil Sci. Soc. Am. J., v. 64, n. 3, 2000; pag. 1035 - 1041.

MAXIMO, O. A. Utilizacao de dados do SAR JERS-1 em modelos preditivos de umidade do solo e coeficiente de retroespalhamento. Tese de Doutorado em Sensoriamento Remoto. São Jose dos Campos: INPE, 1997.

MAXWELL, E. L. (1976). "Multivariate systems analysis of multispectral imagery." Photogrammetric Engineering and Remote Sensing, v. 42, n. 9, 1976, pag. 1173-1186.

MAYERS, V.I. Crops and soils. In. AMERICAN SOCIETY OF PHOTOGRAMMETRY. Manual of remote sensing. Fall Church, 1975. Cap. 22, pag. 1715-1807.

MAYERS, V.I. Remote sensing applications in agriculture. In. AMERICAN SOCIETY OF PHOTOGRAMMETRY. Manual of remote sensing. $2^{\mathrm{a}}$ Ed. Fall Church, 1983. Cap. 33, pag. 2119-2136.

McDERMOTT, J. R1 : A rule-based configurer of computer systems. Artificial Intelligence, v. 19, n. 1, 1982, pag. 39-88..

MCLACHLAN, G. Discriminant Analysis and Statistical Pattern Recognition, Londres: John Wiley \& Sons, 1992.

MEDEIRA NETTO, J.S..A.; BAPTISTA, G.M.M. Reflectância espectral de solos. Brasília: Embrapa Cerrados, 2000,55 pag.

MEHLDAU, G. AND R. A. SCHOWENGERDT (1990). A C-extension for rule-based image classification systems. Photogrammetric Engineering and Remote Sensing, v. 56, n. 6, 1990, pag. 887-892.

MENESES, P. R., NOVO, E. M. L. M., FERREIRA, L. G., M NETTO, J. S., PONZONI, J., GALVÃO, L. S. Sensoriamento remoto: reflectâncias dos alvos naturais. Brasilia : Editora Universidade de Brasilia, 2002, v.1. p.250.

MENESES, P.R.; FERREIRA JR., L.G. Comportamento espectral de alvos naturais como base para a interpretação de imagens multiespectrais. Coleção Textos Universitários Brasília: UnB, 1995. 76p.. 
MEREMBECK, B.F.; TURNER, B.J. Directed canonical analysis and the performance of classifiers under its associated linear transformation. IEEE Trans. Geoscience Remote Sensing. GE-18, 1980, p. 190-196.

MINSKY, M. A framework to represent knowledge. In The Psychology of Computer Vision, pages 211-277. McGraw-Hill, 1975.

MINSKY, M.L ; PAPERT, S.A. Perceptrons: An Introduction to Computational Geometry. M.I.T. Press, 1969.

MIURA,T.; HUETE,A.R.; VAN LEEUWEN,W.J.D.; DIDAN, K. . Vegetation detection through smoke-filled AVIRIS images: An assessment using MODIS bandpasses. Journal of Geophysical Research, Vol. 103 , 1998, pag. 32

MOIK, J.G. Digital processing of remotely sensed images. NASA SP-431.Scientific ant Technical Information Branch National Aeronautics and Space Administration. Washington DC, 1980

MONIZ, A.C. Elementos de Pedologia. Rio de Janeiro. Livros Técnicos e Científicos, 1975. 460 p.

MONTGOMERY, D.C. ; RUNGER, G.C. Estatística aplicada e probabilidade para engenheiros. $2^{\mathrm{a}}$ Ed., Rio de Janeiro: LTC Editora, 2003.

MORAN, M. S.; HYMER, D. C.; QI, J.; SANO, E. (2000). Soil moisture evaluation using multi-temporal synthetic aperture radar (SAR) in semiarid rangeland. Agricultural and Forest Meteorology, v.105, 2000, pag. 69- 80 .

MORAN, M. S.; HYMER, D.C; QI, J.; MARSETT, R.C.; HELFERT, M.K.; SANO, E.E. soil moisture evaluation using radar and optical remote sensing in semiarid rangeland. American Meteorological Society, Special Symposium on Hydrology, Phoenix, Arizona, 11-16 Jan 1998, CD-ROM

MORAN, M. S.; VIDAL, A.; TROUfLEAU, D.; QI, J.; ClARKE, T. R.; PINTER JR., P. J.; MITCHELL, T. A.; INOUE, Y.; NEALE, C. M. U. . Combining multifrequency microwave and optical data for crop management. Remote Sensing of Environment, v. 61, 1997, pag. 96- 109.

MORAN, M.S.; CLARKE, T.R; INOUE, Y.; VIDAL, A. Estimating crop water deficit using the relation between surface-air temperature and spectral vegetation index. Remote Sensing of Environment , V. 46, 1994, pag. 246-263.

MORAN, M.S.; INOUE, Y. \& BARNES, E.M. Opportunities and limitations for image based remote sensing in precision crop management. Remote Sensing of Environment, vol. 61, 1997, pag. 319-346.

MORAN, M.S.; IONOUE, Y.; BARNES, E.M. Opportunities and limitations for image-based remote sensing in precision crop management. Remote sensing of Environment., v. 61, 1997, pag. 319-346.

MORAN, M.S.; PINTER, P.J. ; CLOTHIER, B.E.; ALLEN, S.G. Effect of water stress on the canopy architecture and spectral indices of irrigated alfalfa. Remote sensing of environment, vol. 29, 1989, pag. 251261.

MOREIRA, M.A.Fundamentos do sensoriamento remoto e metodologias de aplicação. São José dos Campos: INPE, 2001, 250p.

MORRIS, R.V.; LAUER, H.V.; LAWSON, C.A.; GIBSON JR., E.K.; NACE, G.A.; STEWART, C. Spectral and other physiochemical properties of submicron powders of hematite (a-Fe2O3)' maghemite (g-Fe2O3)' maghnetite ( $\mathrm{Fe} 3 \mathrm{O} 4)^{\prime}$ goethite (a-FeOOH), and lepidochrosite (g-FeOOH). Journal of Geophysical Research, Washington, DC, v.90, p.3126-3144, 1985.

MULLER, E.; DUCHAMPS, H. Modeling soil moisture-reflectance. Remote Sensing of Environment, v. 76, n. 2, 2001, pag. 173-180.

MULLINS, C.E.; YOUNG, I.M.; BENGHOUGH, A.G. \& LEY, G.J. Hard-setting soils. Soil Use Manag, v. 3, 1987, pag. 79-83. 
$\begin{array}{rrr}\text { MURRAY-DARLING BASIN MINISTERIAL COUNCIL. The salinity audit of the Murray- } \\ \text { Darling } & \text { Camberra, } & 1999 .\end{array}$ http://www.mdbc.gov.au/naturalresources/pdf/Final Salt Audit.pdf

MUSICK, H.B.; PELLETIER, R.E. Response of some Thematic Mapper band ratio to variation in soil water content. Photogrammetric Engineering and Remote Sensing. v. 52, 1986, pag. 1661-1668.

MUSICK, H.B.; PELLETIER,R.E. Response to soil moisture of spectral indexes derived from bi-directional reflectance in Thematic Mapper wavebandas. Remote Sensing of Environment, v. 25, 19858, pag. 167-184.

MYNENI, R.B.;. ASRART, G. Atmospheric Effects and Spectral Vegetation Indices. Remote Sensing of Environment, vol.47, 1994, pag. 390-402.

NACIF, P.G.S. Efeito da subsolagem em propriedades físico-hídricas de um Latossolo Amarelo álico coeso, representativo do Recôncavo Baiano. Dissertação de Mestrado em Agronomia. Viçosa: UFV, 1994, 75P.

NANNI, M.R. Delimitação de unidades fisiográficas para estudo dos solos utilizando análise multivariada e técnicas de sensoriamento remoto. Dissertação de Mestrado. Universidade Federal do Paraná: Curitiba, 1995, $196 \mathrm{p}$.

NANNI, M.R.; ROCHA, H. O. Integration of GIS technology, remote sensing and multivariate analysis in the delimitation of physiographic units for pedological mapping. Boletim IG - Universidade de São Paulo - Série Científica, v. 28, 1997, pág. 129-143.

NASA. Landsat 7 Project.< http://landsat.gsfc.nasa.gov> Acessado em 15/04/2002

NASSAU, K. The origins of color in minerais. American Mineralogist, Washington, DC, v.63, p.219-229, 1978.

NEMANI, R.; PIERCE, L.; RUNNING, S. Developing satellite-derived estimates of surface moisture status, Journal of Applied Meteorology, vol. 32, 1993, pag. : 548-557.

NEMANI, R.; PIERCE, L.; RUNNING, S.; BAND, L. (1993) Forest ecosystem processes at the watershed scale: Sensitivity to remotely-sensed leaf area index estimates, International Journal of Remote Sensing, vol. 14, 1993, pag. 2519-2534.

NEMANI, R.R..; PIERCE, L; RUNNING, S.; BAND, L. Forest ecosystem processes at the watershed scale: Sensitivity to remotely-sensed leaf area index estimates, International Journal of Remote Sensing, vol. 14 , 1993, , pag. 2519-2534.

NEMANI, R.R.;PIERCE, L; BAND, L.E.; RUNNING, S.W.. Forest ecosystem processes at the watershed scale: sensitivity to remotely sensed leaf area index observations. International Journal of Remote Sensing , vol. 14, 1993, pag. 2519-2534.

NEMANI, R.R.;PIERCE, L; RUNNING, S.W.. Developing satellite-derived estimates of surface moisture status. Journal of Applied Meteorology . vol. 32, 1993, pag. 548-557.

NIMOMIYA, Y. Mapping quartz carbonate minerals and mafia-ultramafic rocks using remotely sensed multispectral termal infrared ASTER data. Proceedings of SPIE, 4710, 2002, p. 191-202.

NJOKU, E.G.; ENTEKHABI, D. Passive microwave remote sensing of soil moisture. Journal of Hydrology. V. 184, 1996, pág. 101-129.

NÓBREGA, M. T.; GASPARETTO, N. V. L.; NAKASHIMA, P. Metodologia para cartografia geotécnica de Umuarama-PR, Maringá, Boletim de Geografia. Ano 10. N. 1, p. 05-10, 1992.

NOGIT, A.; WEIDONG, S.; TAKAGIT, M. An alternative correction of atmospheric effects for NDVI estimation. IEEE Transaction on Geoscience and Remote Sensing, vol. 54, 1993, pag. 1137-1339.

NOVO, E. M. L. Sensoriamento remoto, princípios e aplicações. São Paulo: Blucher, 1992. 308 p. 
OGAWA, K.; ROKUGAWA, S.; MATSUNAGA, T. ; NINOMIYA, Y. Evaluation of thickness of desert varnish coatings on rock using thermal infrared remote sensing, Remote Sensing Society of Japan, vol.19, 1999, pag. 45-58.

OLIVEIRA, J. B., JACOMINE, P. L. T. \& CAMARGO, M. N. Classes gerais de solos do Brasil: Guia auxiliar para o conhecimento. 2.ed. Jaboticabal. FUNEA, 1992. 201p.

OLIVEIRA, M. C. N. Métodos de estimação de parâmetros em modelos geoestatísticos com diferentes estruturas de covariâncias: uma aplicação ao teor de cálcio no solo.Tese de Doutorado em Estatística e Experimentação Agronômica. Escola Superior de Agronomia Luiz de Queiroz/USP. Piraçicaba, 2003, 153 pag.

OPPENHEIMER, C. Crater lake heat losses estimated by remote sensing, Geophysical Research Letters, vol. 23, 1996, pag. 1793-1796.

ORLOV, D.S. Quantitative patterns of light reflection by soils. I. Influence of particles (aggregate) size on reflectivity. Science Papers of High School Biology, v.4, p.206-210, 1966.

ORTIZ, M.J.; FORMAGGIO, A.R.; EPIPHANIO, J.C.N. Classification of croplands through integration of remote sensing, GIS, and historical database. International Journal of Remote Sensing, London, v.18, n.1, p.95-105, 1997.

OTTERMAN, J.; FRASER, R.S. Earth-atmosphere system and surface reflectivities in arid regions from Landsat MSS data. Remote Sensing of Environment, v. 5, 1976, pag. 247-266.

PALACIOS-ORUET A; USTIN, S.L. Remote sensing of soil properties in the Santa Monica Mountains I. Spectral Analysis. Remote Sensing of Environment, New York, v.65, 1998, pag. 170-183.

PEARL, J. Evidential Reasoning using in Intelligent Systems. Journal of Intelligent Information Systems, v.9 n.2, , 1997, p.157-180

PEARL, J. Probabilistic Reasoning in Intelligent Systems: Networks of Plausible Inference. Palo Alto: Morgan Kaufmann Publishers, 1988

PEASE R.W.; NICHOLS D.A. Energy balance maps from remotely sensed imagery. Photogramm. Eng. Remote Sens., v. 42, 1976, pag. 1367-1373.

PERRY, C. R.,; LAUTENSCHLAGER, L. F. Functional equivalence of spectral vegetation indices, Remote Sensing of Environonment. v. 14, 1984, pag. 169-182.

PERRY, C.C.; LAUTENSCHLAGER, A. Functional equivalence of spectral vegetation indices. Remote Sensing of Environment, v. 14, 1984, pag. 169-182.

PETERSON, D.L. \& RUNNING, S.W. Applications in forest science and management. In. ASRAR, G. (Ed.) Theory and applications of optical remote sensing. Weley: New York, 1989, pag. 429-73.

PIERI, D.C.; CRISP, J.; KAHLE, A.B. Observing volcanism and other transient phenomena with ASTER, Journal of the Remote Sensing Society of Japan, vol. 15, 1995, pag. 56-61.

PINTY, B., M.M. VERSTRAETE, AND N. GOBRON. The effect of soil anisotropy on the radiance field emerging from vegetation canopies. Geophys. Res. Lett. , v. 25, 1998, pag. :797-800.

PIZARRO, M. A.; GALVÃO, L. S.; EPIPHANIO, J.C.N. Caracterização espectral de solos tropicais através de componentes principais e da correlação entre reflectância e análises químicas. Anais do $10^{\circ}$ Simpósio Brasileiro de Sensoriamento Remoto, Foz do Iguaçu. 21-26 abril 2001, pág 1451-1460.

PIZARRO, M.A.; FERNANDES, D. Aplicação da medida de divergência na determinação de membros de referência em imagens hiperespectrais. Anais XI SBSR, Belo Horizonte, Brasil, 05-10 abril 2003, INPE, p. 1083-1090. 
PIZARRO, M.A.; FERNANDES, D. Avaliação de métodos de estimativa de coerência Espectral para seleção de membros de referência em Imagens hiperespectrais. Revista Brasileira de Cartografia, v. 57, 2005

PLANET, W.G. Some comments in reflectance measurements of wet soils. Remote Sensing of Environment, v. 1, 1970, pag. 89-105.

PORTELA, J.C.; LIBARDI, P.L.; LIER, Q.J. Retenção da água em solos sob diferentes usos no ecossistema tabuleiros costeiros. Revista Brasileira de Engenharia Agrícola e Ambiental, Campina Grande, v. 5, n. 1, p. 49-54, 2001.

POST D.F.; BRYANT, R.B.; BATCHILY, A.K.; HUETE, A.R.; LEVINE, S.J.; MAYS, M.D.; ESCADAFAL, R. Correlations between field and laboratory measurements of soil color. In: BIGHAM J.M., CIOLKOSZ E.J. (Eds.). Soil color. SSSA Spec. Publ. 31. Madison, WI: SSSA, 1993:35-49.

POST, D. F. ; MARTIN, E. S. ; SIMANTON, J. R. ; SANO, E. E. . Use of hand-held radiometers to evaluate the cover and hydrologic characteristics of semiarid rangelands. Arid Soil Research and Rehabilitation, v. 13, 1999, pag. 201-217.

POST, D.F.; HORVATH, E.H.; LUCAS, W.M.; WHITE, S.A.; EHASZ, M.J.; BATCHILY, A.K. Relations between soil color and Landsat reflectance on semiarid rangelands. Soil Sci. Soc. Am. J. , v. 58, 1994, pag. $1809-1816$.

POST, D.F; FIMBRES, A.; MATHIAS, A.D.; SANO, E.E.; ACCIOLY, L.; BATCHILY, A.K.; FERREIRA, L.G. Predicting Soil Albedo from Soil Color and Spectral Reflectance Data. Soil Science Society of America Journal. V. 64, 2000, pag. 1027-1034

POTTER, K.N.; HORTON, R.; CRUSE, R.M. Soil surface roughness effects on radiation reflectance and soil heat flux. Soil Sci. Soc. Am. J. , v. 51, 1987, pag. 855-860.

POUJADE, V.; LAURORE, L. Méthode de segmentation thématique par coopération spectrale-texturale sur des images de SPOT. Photo-Interpretation, Paris, v.1990, n. 3-4, 1990, pag 41-46.

PRADO, P. I.; LEWINSOHN, T. M.; CARMO, R. L.; HOGAN, D. J. Ordenação Multivariada na Ecologia e seu Uso em Ciências Ambientais. Ambiente e Sociedade, Campinas, SP: v.10, 2002, p. 69-83.

PRATT, W.K. Digital image processing. California: John Whiley \& Sons, 1991

PRICE, J. C. (1993), Estimating leaf area index from satellite data, IEEE Transaction on Geoscience and Remote Sensing, vol. 31, 1993, pag. 727-734.

PRICE, J. C. An approach for analysis of reflectance spectra. Remote Sensing of Environment, vol. 64, 1998, pag. 316-330.

PRICE, J. C. Calibration of satellite radiometers and the comparison of vegetation indices, Remote Sensing of Environonment. v. 21, 1987, pag. 15-27.

PRICE, J. C. Estimating vegetation amount from visible and near infrared reflectance measurements, Remote Sensing of Environonment. v. 41, 1992, pag. 29-34.

PRICE, J. C. On the information content of soil reflectance data, Remote Sensing of Environonment. v. 33 1990, pag. 113-121.

PRICE, J.C. Estimating Leaf Area Index from satellite data. IEEE Transaction on Geoscience and Remote Sensing, vol. 31, 1993, pag.727-734.,

PRICE, J.C. How unique are spectral signatures?. Remote Sensing of Environonment. v. 49, 1994, pag. 181186.

PRICE, J.C; BAUSCH, W.C. Leaf area index estimation from visible and near-infrared reflectance data Remote Sensing of Environonment. v. 52, 1995, pag. 55-65. 
PRICE, K.P.; GUO, X.; STILES, J.N. Optimal Landsat TM band combinations and vegetation indices for discrimination of six grassland types in eASTERn Kansas. International Journal of remote Sensing. V. 16, 2002, pag 1-12.

PRICE, K.P.; GUO. X.; STILES, J.M. Optimal Landsat TM band combinations and vegetation indices for discrimination of six grassland types in eASTERn Kansas. International Journal of Remote Sensing, v. 23, 2000, pag. 5031-5042.

PRICE, K.P.; VARNER, V.C./ MARTINKO, E.A.; RUNDQUIST, D.C. Analysis of multitemporal narrow-band spectroradiometer measurements from six prairie treatments in Kansas. Proceedings of the '92 ASPRS/ACSM Annual Convention and Exposition, Albuquerque, 1992, pag. 372-385.

PRINCE, S. D. A quantitative description of some mopane woodlands in the Luangwa Valley, Zambia Government Document, National Parks and Wildlife Service, Chilanga, Zambia, 1971

PRINCE, S.D. ; GOWARD, S.T.. 1995. Global primary production: a remote sensing approach. Biogeography, v. 22, 1995, pag. $815-835$.

PRINCE, S.D. A model of regional primary production for use with coarse resolution satellite data. International Journal of Remote Sensing, v. 12, 1991, pag. 1313-1330.

PRISLEY, S.P.; SMITH, J.L. Using classification error matrices to improve the accuracy of weighted land-cover models. Photogrammetric Engineering and Remote Sensing, v.53, n.9, 1987, pag. .1259-1263

PROJETO RADAMBRASIL. Levantamento de recursos naturais. Folha SD. 24. Salvador. Rio de Janeiro: 1983. 780p. 6 mapas policr.

QI, J.; CABOT, F.; MORAN, M.S.; DEDIEU, G. Biophysical parameter estimations using multidirectional spectral measurements. Remote Sensing of Environment, 54, 1995, p. 71-83.

QI, J.; CHEHBOUNI, A. ; HUETE, A.R.; KERR, Y.H. Modified Soil Adjusted Vegetation Index (MSAVI). Remote Sensing of Environment, 48, 1994, p.119-126.

RAMSEY, M.S.; DEHN, J. Spaceborne observations of the 2000 eruption of Bezymianny Volcano, Kamchatka: A comparison of new results from ASTER to realtime monitoring using AVHRR, Journal of Volcanology and Geothermal Research, 2002,

RAMSEY, M.S.; DEHN, J. The first year of volcanic data from ASTER: Case studies of Bezymianny and Sheveluch Volcanoes, Kamchatka, EOS, Transactions of American Geophysical Union, vol. 82, 2001, F1354.

RAMSEY, M.S.; FINK, J. H. Estimating lava vesicularity: A new technique using thermal infrared remote sensing data, EOS, Transactions of American Geophysical Union, vol. 77, 1996, F803.

RAMSEY, M.S.;. HARRIS, A.J.L; DEHN, J.; PIRIE, D. Thermal anomaly monitoring of the ongoing eruptions at Soufriere Hills Volcano, Montserrat and Bezymianny Volcano, Kamchatka: First results from the new ASTER instrument, EOS, Transactions of American Geophysical Union, vol. 81, 2001,

RAUDYS, S.; PIKELIS, V. On dimensionality , sample, size, classification error and complexity of classification algorithms in pattern recognition. IEEE Transactions on Pattern Analysis and Machine Intelligence, n.2, 1980, pag. 242-52.

REED, B.C.; BROWN, J.F.; VANDERZEE, D.; LOVELAND, T.R.; MERCHANT, J.W.; OHLEN, D.O. 1994. Measuring phenological variability from satellite imagery. Vegetation Science, v.5, 1994, pag. 703-714.

REGINATO, R.J.; VEDDER, F.J.F.; IDSO, F.S.B.; JACKSON, F.R.D.; BLANCHARD, F.M.B.; GOETTELMAN, F.R. An evaluation of total solar reflectance and spectral band ratioing techniques for estimating soil water content. Journal of Geophysical Research, Volume 82, 1977, p. 2101-2104

REIFSNYDER, W.E. Radiation geometry in the measurement and interpretation of radiation balance. Agric. Meteorol., v. 4, 1967, pag. 225-265. 
REIS, M. M. Análise estatística. UFSC, 2005. http://www.inf.ufsc.br/ marcelo/CPGA.html

REITER, R. A logic for default reasoning. Artificial Intelligence, v.13, n. 1-2, 1980, pag. 81-132.

RESENDE, M.; CURI, M.; RESENDE, S. B. de; CORRÊA, G. F. Pedologia: Base para distinção de ambientes. Viçosa. NEPUT, 1995. 304p

REZENDE, J. de O. Solos coesos dos tabuleiros costeiros: limitações agrícolas e manejo. (SEAGRI-SPA. Estudos Agrícolas, 1). Salvador: SEAGRI-SPA, 2000, 117p.

REZENDE, J. de O.; MAGALHÃES, A. F. de J.; SHIBATA, R. T.; ROCHA, E. S.; FERNANDES, J. C.; BRANDÃO, F. J. C.; REZENDE, V. J. R. P. Citricultura nos solos coesos dos tabuleiros costeiros: análise e sugestões. (SEAGRI-SPA. Estudos Agrícolas, 3). Salvador: SEAGRI-SPA, 2002. 11p. .

REZENDE, J. O. Os solos coesos dos Tabuleiros Costeiros: limitrações agrícolas e manejo. (Série Estudos Agrícolas, 1). Salvador: SEAGRI, SPA, 2000, 117 paginas,

RIBEIRO, L. P. Evolução da cobertura pedológica dos tabuleiros costeiros e a gênese dos horizontes coesos. In. WORKSHOP COESÃO EM SOLOS DE TABULEIROS COSTEIROS, Aracajú, 2001. Anais. Aracajú:Embrapa Tabuleiros Costeiros, 2001, p. 161-168.

RIBEIRO, L. P. Os latossolos amarelos do Recôncavo Baianao: gênese, evolução e degradação. Salvador:Seplantec, CADCT, 1998, 99p.

RIBEIRO, L. P. Premiers resultats sur la gênese dês sols a horizons indures dans la region du Cruz das Almas, BA, Brésil. In Table Ronde sur l' Órganization et Dinamique Interne de la Couverture Pedologique. Caen, 1991. Anais. Caen: CNRS, 1991, 1v.

RIBEIRO, L. P. Premiers resultats sur la gênese dês sols a horizons indures dans la region du Cruz das Almas, BA, Brésil. In Table Ronde sur l' Órganization et Dinamique Interne de la Couverture Pedologique. Caen, 1991. Anais. Caen: CNRS, 1991, 1v.

RIBEIRO, L.P. Sílica em horizontes coesos de solos da Bahia. Salvador: Universitas, 38:59-80, 1986.

RIBEIRO, L.P. Sílica em horizontes coesos de solos da Bahia. Universitas, 38:59-80, 1986.

RICH, E. Artificial Intelligence. McGraw-Hill Book Company, 1983.

RICHARDS, J. A. Remote Sensing Digital Image Analysis. Berlin: Springer-Verlag, 1986.

RICHARDS, J.A. Classifier performance and map accuracy. Remote Sensing of Environment, New York, v.57, p.161-166, 1996

RICHARDS, J.A. Classifier performance and map accuracy. Remote Sensing of Environment, New York, v.57, p.161-166, 1996.

RICHARDS, J.A. Remote Sensing Digital image Analysis: an introduction. New York: Spring-Verlag, 1986, $281 \mathrm{p}$.

RICHARDSON, A. J.; AND WIEGAND, C. L. Distinguishing vegetation from soil background information, Photogrammetric Engineering and Remote Sensing, vol. 43, 1977, pag. 1541-1552

RICHARDSON, A.J. \& WIEGANG, C.L. Distinguishing vegetation from soil background information. Photogrammetric Engineering and Remote Sensing, n. 43, 1989, p. 1541-1552.

RICHARDSON, A.J.; WIEGAND, C.L. Distinguishing vegetation from soil background information. Photogrametric Engineering and Remote Sensing, n. 43, 1977, pag. 1541-1552.

RIPLEY, B.D. Pattern recognitiom and neural networks. Cambridge: Cmaprodge University press, 2000. 
RIPPLE, W.J.; SCHRUMPF, B.J.; ISAACSON, D.L. The influence of observational interdependence on spectral reflectance relationships with plant and soil variables. International Journal of Remote Sensing, v.7, n.2, 1986, pag. 291-294.

ROBERTS, D. A.; GARDNER, M.; CHURCH, R.; USTIN, S. ; SCHEER, G; GREEN, R.O. Mapping chaparral in the Santa Monica Mountains using multiple endmember spectral mixture models, Remote Sensing of Environment. v. 65, 1998, pag. 267-279.

ROBINOVE, C.J. The logical of multispectral classification and mapping of land. Remote Sensing of Environment, v. 11, 1981, pag. 231-44

ROBINOVE, C.J.; CHAVEZ, P.S.; GEHRING, D.; HOLMGREN, R. Arid land monitoring using landsat albedo differences images. Remote Sensing and Environment, v. 11, 1981, pag. 133-156.

ROCHA, O. H. Integração de dados através de análise de agrupamentos e interpretação de imagens orbitais para levantamento de solos. Tese para Professor Titular. Universidade Federal do Paraná. Curitiba, 1993, 106p.

ROLI, F.; GIACINTO, G. An approach to the automatic design of multiple classifier systems , Pattern Recognition Letters, vol. 22, 2001, pag. 25-33.

ROLI, F.; GIACINTO, G.; VERNAZZA, G. Comparison and combination of statistical and neural network algorithms for remote-sensing image classification. Int. Journal of EARSel Advances in Remote Sensing,Vol. 64, n. 31., 1997, pag. 22-31.

ROUJEAN, J.L.; BRÉON, M.B. Estimating PAR absorbed by vegetation from bidirectional reflectance Measurements . Remote Sensing of Environment, vol. 51, 1995, pag. 375-384.

ROUSE, J. W.; HAAS, R. S.; SCHELL, J. A.; DEERING, D. W. Monitoring vegetation systems in the Great Plains with ERTS. Proceedings, 3rd ERT S Symposium, vol. 1, 1973, pag. 48-62.

ROUSE, J. W.; HAAS, R., H.; DEERING, D. W.; SCHELL, J. A.; HARLAN, J. C. Monitoring the vernal advancement and retrogradation (green wave effect) of natural vegetation; NASA/GSFC Type III Final Report, Greenbelt, MD., 1974. p. 371.

ROWAN, L. ; MARS, J. Lithological mapping in the Montain Pass, California area using ASTER data. Remote Sensing of Environment, v. 84, 2002, p. 350-366.

RUIMY, A.; DEDIEU, G.; SAUGIER, B. Methodology for the estimation of terrestrial net primary production from remotely sensed data . Journal of Geophysical Research, vol. 99, D3, 1994, pag. 5263-5283.

RUNNING, S. W., 1990, Estimating terrestrial primary productivity by combining remote sensing and ecosystem simulation. In. HOOBS, R.J. \& MOONEY, H.A. Remote Sensing of Biosphere Functioning. New York: Springer-Verlag, 1989, pag. 65-86.

RUNNING, S.W.; JUSTICE, C.O.; SALOMONSON, V.; HALL, D.; BARKER, J.; KAUFMAN, Y.J.; STRAHLER, A.H.; HUETE, A.R.; MULLER, J.P.; VANDERBILT, V.; WAN, Z.M.; TEILLET, P.; CARNEGGIE, D. Terrestrial remote sensing science and algorithms planned for EOS/MODIS, International Journal of Remote Sensing, vol. 15, 1994, pag. 3587-3620.

RYHERD, S.; WOODCOCK, C. Combining spectral and texture data in segmentation of remotely sensed images. Photogrammetric Engineering and Remote Sensing, v.62, n.2, 1996, pag.181-194.

SAITO, G.; ISHITSUKA, N.; MATANO, Y; KATO, M. Aplication of Terra/ASTER on agriculture land mapping. Anais da 22n. Asina Conference on Remote Sensing, 5-9 novembro 2001, Singapura. http://www.crisp.nus.edu.sg/ acrs2001/pdf/106SAITO.pdf.

SAN, B.T.; SUMER, E.O.; GURCAY, B. Comparison of band ratioing and spectral indices methods for detecting alunita and kaolinite minerals using ASTER data in Biga Region, Turkey. International Society of Photogrammetry and Remote Sensing. $\mathbf{X X}^{\text {th }}$ Congress Anais, Istambul, July 2004, Comission 7. <www.isprs.org/istanbul2004/comm7/comm7.html> (Acessado em Janeiro de 2005) 
SANDVIG, R. Vegetation cover monitoring. Earth and Environmental Science. New Mexico Tech., 2003

SANO, E. E. ; HUETE, A. R. ; TROUfLEAU, D. ; MORAN, M. S. ; VIDAL, A. . Relation between ERS-1 synthetic aperture radar data and measurements of surface roughness and moisture content of rocky soils in a semiarid rangeland. Water Resources Research, v. 34, n. 6, p. 1491-1498, 1998.

SANO, E. E. ; MORAN, M. S. ; HUETE, A. R. ; MIURA, T. . C- and multiangle Ku-band synthetic aperture radar data for bare soil moisture estimation in agricultural areas. Remote Sensing of Environment, v. 64, p. 7790, 1998.

SANO, E. E. ; MORAN, M. S. ; HUETE, A. R. ; MIURA, T. . Ku-Band SAR data for bare soil moisture retrieval over agricultural fields. In: IGARSS'97, 1997. Proceedings of the IGARSS'97. Singapore : Geoscience and Remote Sensing Society, 1997. v. 1. p. 98-100.

SANTOS, R.L Evolução das vertentes e as relações morfogênese/pedogênese nos bordos dos tabuleiros de Cruz das Almas (BA). Dissertação de Mestrado em Geoquímica e Meio Ambiente, Salvador: IGEO/UFBA, 2003.

SANTOS, T.A.G. Actualização de cartografia temática com imagens de satélite. Dissertação de Mestrado em Sistemas de Informações Geográficas. Lisboa: Universidade Técnica de Lisboa, 2003.

SCHOWENGERDT, R. A. . Remote Sensing, Models and Methods for Image Processing, 2nd Ed., San Diego: Academic Press, 1997.

SCHOWENGERDT, R.A. Techniques for image processing and classification in remote sensing. Florida: Academic Press, 1983. 249p.

SCHULZE D.G., NAGEL J.L., VAN SCOYOC G.E., HENDERSON T.L., BAUMGARDNER M.F. Significance of organic matter in determining soil colors. In: BIGHAM J.M., CIOLKOSZ E.J., (Eds.). Soil color. Madison: SSSA Spec. Publ. 31. SSSA, 1993, pag. 71-90.

SCHWERTMANN U. Relations between iron oxides, soil color, and soil formation. In: BIGHAM J.M., CIOLKOSZ E.J., (Eds.). Soil color. Madison: SSSA Spec. Publ. 31. SSSA, 1993, pag. 51-69.

SERPICO, S.B. \& ROLI, F. Classification of multi-sensor remote- sensing images by structured neural networks. IEEE Transactions on Geoscience \& Remote Sensing, n. 36, v. 12, 2001, pag. 311-26.

SERPICO, S.B.; BRUZZONE, L. ROLI, F. An experimental comparison of neural and statistical nonparametric algorithms for supervised classification of remote-sensing images. Pattern Recognition Letters, $\mathrm{n}$. 17, 1996, pag. 1331-41.

SHAFER, G.A Mathematical Theory of Evidence. Princeton: Princeton University Press, 1976.

SHERMAN, D.M.; WAITE, T .D. Electronic spectra of Fe3+ oxides and oxide hydroxides in the near IR to near UV. American Mineralogist, Washington, DC, v.70, p.1262-1269, 1985.

SIEGEL R.; HOWELL J.R. Thermal radiation heat transfer. New York: McGraw-Hill, 1972.

SILVA, E.M.; SILVA, E.M.; SILVA, E.M.; GONÇALVES V.; MUROLO, A.C. A pesquisa operacional: programação linear, simulação. $3^{\mathrm{a}}$ ed. São Paulo: Atlas, 1998, 184 p.

SIMMONS, E.L.. Relation of the diffuse reflectance remission function to the fundamental optical parameters. Optica Acta, v.19, p.845-851, 1972.

SIMONETT, D.S.; REEVES, R.G.; ESTES, J.E.; BERTKE, S.E.; SAILER, C.T. The development and principles of remote sensing. In: COLWELL, R.N. (Ed.) Manual of Remote Sensing. Falls Church : American Society of Photogrammetry., 1983, pag. 1-32.

SINGH, A. Some clarifications about the pairwise divergence measure in remote sensing. International Journal of remote Sensing, n. 5, 1984, p. 623-627. 
SINGH, A.N.; DWIVED, R.S. The utility of Landsat imagery as an integral part of the data base for small scale soil mapping. International Journal of Remote Sensing, V.7, 1986, pag.1099-1108.

SKIDMORE, E.L., J.D. DICKERSON, AND H. SHIMMELPFENNIG. 1975. Evaluating surface-soil water content by measuring reflectance. Soil Sci. Soc. Am. Proc. 39:238-242.

SKIDMORE, E.L.; DICKERSON, J.D.; SHIMMELPFENNIG, H. Evaluating surface-soil water content by measuring reflectance. Soil Science Society of America Proceedings, v.39, 1975, pag. 138-242.

SLATER, P.N.; JACKSON, R.D. Atmospheric effect on radiation reflected from soil and vegetation as measured by orbiting sensors using various searnning directions. Journal of Applied Optics, v. 21, 1982, pag. 3912-3931.

SOARES-FILHO, B.S. Modelagem da dinâmica de paisagem de uma região de fronteira de colonização amazônica. Tese de Doutorado em Engenharia de Transportes. São Paulo: USP, 1998.

SOUZA, L. da S.; PAIVA, A.Q. de. Variação do potencial total da água em uma topossequência de solos de tabuleiros, durante dois anos. Pesquisa Agropecuária Brasileira, Brasília, v.36, n.2, p.349-355, 2001.

SOUZA, L. E. Estimativa de incertezas e sua aplicação na classificação de recursos minerais. Dissertação de Mestrado em Engenharia. Porto Alegre: UFRGS/PPGEM, 2002

SOUZA, L.D.; SOBRINHO, A. P.C.; SOUZA, L.S.; LEDO, C.S.; RIBEIRO, L.S. Avaliação de Plantas Cítricas, em Diferentes Profundidades de Plantio, em Latossolo Amarelo do Recôncavo Baiano: II. Produção de Frutos. Anais do XVII Congresso Brasileiro de Fruticultura, Belém , 18 a 22 de novembro de 2002. nº 673.

SOUZA, L.S., SOUZA, L.D., CALDAS,R.C. Identificação da coesão com base em atributos físicos convencionais em solos dos tabuleiros costeiros. In: WORKSHOP COESÃO EM SOLOS DOS TABULEIROS COSTEIROS, 2001, Aracaju. Anais... Aracaju: Embrapa Tabuleiros Costeiros, 2001. p.169-190.

STAR, J. ESTES, J.E. Geographic Information Systems: an introduction. Prentice Hall, Englewood Cliffs , New Jersey, 1990.

StatSci.S-PLUS: Statistical Analysis in S-PLUS. Statistical Sciences, Inc. Seattle, Washington, 1993

STEELE Jr. , G.L. Common LISP, the Language. Burlington : Digital Press, 1984.

STEFANOV, W.L. Remote sensing of urban ecology at the Central Arizona- Phoenix Long Term Ecological Research site, Arid Lands Newsletter, vol. 51, 2003 (http://ag.arizona.edu/OALS/ALN/aln51/stefanov.html).

STEFANOV, W.L.; CHRISTENSEN; P.R.; RAMSEY, M.S. Monitoring urban land cover change - An expert system approach to land cover classification of semiarid to arid urban centers, Remote Sensing of Environment, vol. 77, 2001, pag. 173-185.

STEFANOV, W.L.; CHRISTENSEN; P.R.; RAMSEY, M.S. Remote sensing of urban ecology at regional and global scales: Results from the Central Arizona-Phoenix LTER site and ASTER urban environmental monitoring program, In JÜRGENS, C. (Editor), Remote Sensing of Urban Areas, Regensburger Geographische Schriften, 2001, pag. 313-321.

STEHMAN, S.V. Comporison of systematic and random sampling for estimating the accuracy of maps generated from remotely sensed data. Photogrammetric Engineering and Remote Sensing, n. 58, 1992, pag. $1343-50$.

STONER, C.R.; BAUMGARDNER, M.F. Characteristic variations in reflectance of surface soils. Soil Science of Society of American Journal, v. 45, 1981, pag. 1161-1165.

STONER, E.R. \& BAUMGARDNER, M.F. Characteristics variations in reflectance of surface Soils. Science of Society of America Journal, vol. 45, 1980, pag. 1161-1165. 
STORY, M.; CONGALTON, R. G. Accuracy assessment: a user's perspective. Photogrametric Engineering and Remote Sensing, v. 52, n. 3, 1986, pag. 399, 1986.

STRAHLER, A.H.; WOODCOOK, C.E.; SMITH, J.A.. On the nature of models in remote sensing. Remote Sensing of Environment, n. 20, 1986, pag. 121-39

STRENS, R.G.J.; WOOD, B.J. Diffuse reflectance and optical properties of some iron and titanium oxides and oxihydroxides. Mineralogical Magazine, London, v.43,1979, pag.347-354.

SU, H.; RANSOM, M.D.; KANEMASU, E.T. Delecting soil information on a native praire using Landsat TM and Spot satellite data. Soil Science Society American Journal, n.53, 1989, p. 1479-1483.

SUDENE - Dados Climáticos do Estado da Bahia - Série Pluviometria 5, Recife, 1978.

SUDENE - Dados Climáticos do Estado da Bahia - Temperatura 5, Recife, 1979.

SUDENE. Banco de Dados Hidroclimatológicos do Nordeste. http://www.sudene.gov.br/ Acessado em $13 / 04 / 2000$

SWAIN, P.H. \& DAVIS, S.M. Remote sensing: the quantitative approach. New York: MacGrow Hill, 1978.

SWAYZE, G.A.; CLARK, R.N.; GOETZ, A.F.H.; GORELICK, N.S.; CHRIEN, T.G. Spectral identification of surface materiais using imaging spectrometer data: evaluating the effects of detector sampling, bandpass, and signal to noise ratio using the U.S.G.S. Tricorder Aigorithm. 1997.

THEODORIDIS, S. \& KOUTROUMBAS, K. Pattern Recognition. Academic Press, USA, 1st edition. 1999.

THOMPSON, , D.R.; HAAS, R.H.; MILFORD, M.H.Evaluation of Landsat Multispectral Scanner data for mapping vegetated soil Landscape. Soil Sceince Society American Journal, vol. 45, 1981, pag. 91-95

THOMPSON, D. R.; WEHMANEN, A Using Landsat Digital Data to Detect Moisture Stress in Corn-Soybean Growing Regions, Photogrammetric Engineering and Remote Sensing, vol. 46, 1980, pag. 1082-1089.

THOMPSON, D.R. \& HENDERSON, K.E. Detecting soils under cultural vegetation using digital Landsat Thematic Mapper data. Soil Science Society American Journal, n.48, 1984, p. 1316-1319.

THOMPSON, D.R. \& HENDERSON, K.E. Evaluation of Thematic Mapper for detecting soil properters under grassland vegetation. IEEE Trans. Geoscience Remote Sensing. GE-22, 1987, p. 319-322.

THOMPSON, D.R.; HENDERSON, K.E.; HOUSTON, A.; GLEN, J.; PITTS, D.E. Variation in alluvial derived soils as measured by Landsat Thematic Mapper. Soil Science Society American Journal, n.48, 1984, p. 137142.

TONOOKA, H. An atmospheric correction algorithm for thermal infrared multispectral data over land - A watervapor scaling method, IEEE Transactions on Geoscience and Remote Sensing, vol. 39, 2001, pag. 682-692.

TORRENT J., SCHWERTMANN U. Influence of hematite on the color of red beds. J. Sediment. Petrol. , v. 57, 1987, pag. 682-686.

TORRENT J., SCHWERTMANN U., FECHTER H., ALFEREZ F. Quantitative relationships between soil color and hematite content. Soil Sci. , v. 136, 1983, pag. 354-358.

TORRENT J., SCHWERTMANN U., SCHULZE D.G. Iron oxide mineralogy of some soils of two river terrace sequences in Spain. Geoderma , v. 23, 1980, pág. 191-208.

TOUTIN, T. Three-dimensional topographic mapping with ASTER stereo data in rugged topography, IEEE Transactions on Geoscience and Remote Sensing, vol. 40. 2002, pag. 2241-2247. 
TOVINKERE, V.R.; PENALOZA, M. ; LOGAR, A. ; LEE, J.; WEGER, R.C.; BERENDES, T.A.; WELCH, R.M. An intercomparison of artificial intelligence approaches for polar scene identification, Journal of Geophysical Research, vol. 98, 1993, pag. 5001-5016.

TREITZ, P.M.; HOWARTH P.J.; GONG, P. Application of satellite and GIS technologies for land-cover and land-use mapping at the rural-urban rringe: A case study. Photogrammetric Engineering and Remote Sensing, v.58, n.4,1992, p.439-448.

TSO, B. ; MATHER, P.M. Classificatiom methods for remotely sensed data. London: Taylor \& Francis, 2001

TUCKER, C. J.; HOLBEN, B. N.; ELGIN, J.H, JR.; MCMURTREY, J. E. Relationship of spectral data to grain yield variation. Photogrammetric Engineering and Remote Sensing, vol. 45, 1980, pag. 657-666.

TUCKER, C. J.Remote sensing of leaf water content in the near infrared, Remote Sensing of Environonment. v. 10, 1980, pag. 23-32.

TUCKER, C. T. Red and photographic infrared linear combinations for monitoring vegetation. Remote Sensing of Environment, v. 8, 1979, pag. 127-150.

TUCKER, C.J. ; HOLBEN, B.; ELGIN, J.H.; McMURTREY, J.M. Relationship of spectral data to grain yield variation. Photogrammetric Engineering and Remote Sensing, vol. 46, 1980, pag. 657-666.

TUCKER, C.J. A comparison of satellite sensor bands for vegetation monitoring. Photogrammetric Engineering and Remote Sensing, vol. 44, 1978, pag.. 1369-1380.

TUCKER, C.J. Red and photographic infrared linear combinations for monitoring vegetation. Remote Sensing of Environonment. v. 8, 1979, pag. 127-150.

TUCKER, C.J. Remote sensing of leaf water content in the near infrared. Remote Sensing of Environonment. v. 10,1980 , pag. $10-23$

TUCKER, C.J.; ELGIN, J.H.; McMURTREY, J.M. Relationship of red and photographic infra-red spectral data to alfalfa agronomic values. International Journal of Remote Sensing, v. 1, 1980, pag. 69-75.

TUCKER, C.J.; GARRAT, M.W. Leaf optical system modeled as a stochastic process. Applied Optics, v. 16, 1976, pag. 635-642.

TUCKER, C.P.; TOWNSHEND, J.R.G; GOFF, T.E. African Land-Cover Classification Using Satellite Data. Science, Vol. 227, 1985, pag. 369-375

TUKEY, J.W. Data-based graphics: visual display in the decades to come. Statistical Science, n.5, v. 3, 1990, p. 327-339.

TUKEY, J.W. Exploratory data analysis. Reading:Addison Wesley, 1977.

TWOMEY, S.A.; BOHREN, C.F.; MERGENTHALER, J.L. Reflectances and albedo differences between wet and dry surfaces. Appl. Optics, v. 25, 1986, pag. :431-437.

ULABY, F.T., P.C. DUBOIS, AND J.V. ZYL. Radar mapping of surface soil moisture. Journal of Hydrology., v. 184, 1996, pag. 57-84.

Urban Renewal Administration, Housing and Home Finance Agency, and Bureau of Public Roads, Department of Commerce. 1965. Standard Land Use Coding Manual: A Standard System for Identifying and Coding Land Use Activities. (SLUCM). Washington, D.C.: Government Printing Office.

USGS. Landsat Project.< http://landsat.usgs.gov/ > Acessado em 15/04/2002

VALERIANO, M.M.; EPIPHANIO, J.C.N.; FORMAGGIO, A.R.; OLIVEIRA, J.B. Bi-directional reflectance factor of 14 soils classes from Brazil. International Journal of remote Sensing. V. 16, 1995, pag. 113-128. 
VALERIO FILHO, M.; EPIPHANIO, J. C. N.; FORMAGGIO, A. R. Metodologia de interpretacao de dados de sensoriamento remoto e aplicação em pedologia. São Jose dos Campos: INPE, 1981.

VALERIO FILHO, M.; EPIPHANIO, J.C. N. Processamento digital de dados TM/Landsat aplicados na cartografia de solo. Anais do $\mathbf{4}^{\mathbf{0}}$ Simposio Latinoamericano de Sensoriamento Remoto. Gramado: Selper, 1015 agosto 1986, pág. 118.

VAN LEEUWEN ,W.J.D.; HUETE, A.R. Effects of Standing Litter on the Biophysical Interpretation of Plant Canopies with Spectral Indices. Remote Sensing of Environment, Vol. 55,1996, pag. 123-138 .

VANI, K.; SANJEEVI, S. Fusion of ASTER image data for enhanced mapping of landcover features.< http://www.gisdevelopment.net/application/environment/pp/envp0005.htm> Acessado em 21/08/2004

VEHTARI, A. \& LAMPINEN. Bayesian MLP neural networks for image analysis. Pattern Recognition Letters, n. 21, 2000, par. 1183-91.

VELCEK, J. ; KING, D. Detection of subsurface soil moisture by thermal sensing: results of laboratory, closerange and aerial studies. Photogrammetric Engineering and Remote Sensing , v. 49, n. 11, 1983, pag. 15931597.

VERBESSELT, J, EKLUNDH, L.; JÖNSSON, P. Biophysical drought metrics extraction by time series analysis of SPOT Vegetation data. IEEE Geoscience and Remote Sensing, v.874, 2004, pag. 2062-2065

VERBESSELT, J, FLECK, S.; COPPIN, P. Estimation of fuel moisture content towards Fire Risk Assessment: A review. In VIEGAS, P. (Ed) Forest Fire Research \& Wildland Fire Safety. Rotterdam : Millpress,. 2002 , pag.1-11.

VETTORAZZI, C.A.; COUTO, H.T.Z. Análise de exatidão de classificação em mapas obtidos através da interpretação de imagens orbitais em duas escalas. In. VI SBSR. Anais. São José dos Campos: INPE, 1990, p. 769-775.

VIEIRA, L. S.; DOS SANTOS, P. C. T. ; VIEIRA, M. N. I. 1988. Solos - propriedades, classificacão e manejo. ABEAS/MEC. (BS)

VIEIRA, L.S Manual de ciência do solo. $2^{\text {a }}$ Ed. S. Paulo: Editora Ceres, 1988.

VITORELLO, I. \& GALVÃO, L.S. Spectral proprierts of geologic materials in the 400 to 2500 nm range: review for applications to mineral exploration and lithologic mapping. Photo Interpretation, vol. 34, 1996, pag. 77-99.

WALCH, S.J. LIGHTFOOT, D.R. BUTLER, D.R. Recognition and assessment of error ingeographic information systems. Photogrammetric Engineering and Remote Sensing, n. 53, 1987, pag. 1423-30.

WALLACE, J.F.; CAMPBEL, N. Analysis of remotely sebsed data. In. HOOBS, R.J. \& MOONEY, H.A. Remote Sensing of Biosphere Functioning. New York: Springer-Verlag, 1989, pag. 291-304.

WEISMILLER, R.A; PERSINGER, I.D.; MONTGOMERY, O.L. Soil inventory from digital analysis of satellite scanner and topographic data. Soil Science Society American Journal, n.41, 1977, p. 1166-1170.

WELCH, R.; LANG, H.R.; KAHLE, H.B.; TSU , H. The Advanced Spaceborne Thermal Emission and Reflectance Radiometer (ASTER) stereo subsystem: A source of digital elevation models (DEMS) for Earth science research, EOS, Transactions of American Geophysical Union, vol. 74(16 supplement), 1993, pag. 194

WESSELS, R.L.; KARGEL; J.S.; KIEFFER , H.H. ASTER measurement of supraglacial lakes in the Mount Everest region of the Himalaya, Annals of Glaciology, vol. 34, 2002, pag. 399-408.

WESTIN, F.C ; FRAZEE, C.J. Landsat data - its use in a soil survey program. Soil Science Society American Journal, n.41, 1976, p. 1166-1170. 
WESTIN, F.C. ; LEMME, G.D. Landsat spectral signature: studies with soil association and vegetation. Photogrammetric Engineering and Remote Sensing, n. 44, 1978, p. 315-325.

WIEGANG, C.L.; GAUSMAN, H.W.; ALLEN, W.A. Physiological factors and optical parameters as a basis of vegetation discrimination and stress analysis. Operational Remote Sensing. American Society of Photogrammetry, Falls Church, 1972, pah. 88-102.

WIGNERON, J.-P., T. SCHMUGGE, A. CHANZY, J.-C. CALVET, AND Y. KERR.. Use of passive microwave remote sensing to monitor soil moisture. Agronomie , v.18, 1998, pág. 27-43.

WOODCOCK, C.; HARWARD, V.J. Nested-hierarchical scene models and image segmentation. International Journal of Remote Sensing, v.13, n.16, 1992, , p.3167-3187.

WOODCOCK, C.E; STRAHLER, A.H. The fator of scale in remote sensing. Remote Sensing of Environment, n. 21, 1987, pág. 311-32.

WOODCOCK, C.E; STRAHLER, A.H.; JUPP, D.L.B. The use of variograms in remote sensing: Scene models and simulated images. Remote Sensing of Environment, n. 25, 1988, pág. 323-48.

WOODCOCK, C.E; STRAHLER, A.H.; JUPP, D.L.B. Autocorrelation and regularization in digital images: II. Simple image models, IEEE Trasactions on Geoscience and Remote Science. n. 27, 1989, pag. 247-56

WOOLEY, J.T. . Reflectance and transmittance of light by leaves. Plant Physiology, vol. 47, 1971, pag. 656662.

WRIGHT, G.G.; BIRNIE, R.V. Detection of surface soil variation using high-resolution satellite data: results from the U.K. Spot-simulation investigation. International Journal of Remote Sensing, v. 7, 1986, p. 757766.

WYSZECKI G.; STILES W.S. Color science: Concepts and methods, quantitative data and formulae, 2nd ed New York: John Wiley and Sons, 1982.

YAMAGUCHI, Y. Possible techiniques for lithologic discrimination using shortwavelength-infrared bands of the Japanese ERS-1. Remote Sensing of Environonment. v. 23, 1987, pag. 117-129.

YAMAGUCHI, Y. Possible techniques for lithologic discrimination using the short wavelength bands of the Japonese ERS-1. Remote Sensing of Environment, v. 23, 1987, p. 117-129.

YAMAGUCHI, Y.; FUJISADA, H.; TSU, H.; SATO, I. ; WATANABE, H.; KATO, M.; KUDOH, M.; KAHLE, B.; PNIEL, M. ASTER early image evaluation, Advances in Space Research, vol. 28, 2001, pag. 6976.

YAMAGUCHI, Y.; KAHLE, A.B.; TSU, H.; KAWAKAMI, T.; PINEL, M. Overview of Advanced Spaceborne Thermal Emission and Reflection Radiometer (ASTER). IEEE Transaction on Geoscience and Remote Sensing, vol. 36, 1998, pag. 1062-1071.

YAMAGUCHI, Y.; KAHLE, A.B.; TSU, H.; KAWAKAMI, T.; PNIEL, M. Overview of Advanced Spaceborne Thermal Emission and Reflection Radiometer (ASTER). IEEE Transactions on Geoscience and Remote Sensing, n. 36, pag. 1062-1071, 1998.

YAMAGUCHI, Y.; NAITO, C. Spectral indices for lithologic discrimination and mapping by using the ASTER SWIR bands. International Journal of Remote Sensing. N. 24, v. 22, pag. 4311-4323, 2003.

YIN, X. The albedo of vegetated land surfaces: systems analyses and mathematical modeling. Teor. Appl. Climatol., v. 60, 1998, pag, 121-140.

ZADEH, L.A . Fuzzy sets as a basis for a theory of possibility. Fuzzy Sets and Systems, v. 1, 1978, pag. :3-28.

ZADEH, L.A. Fuzzy sets. Information and Control, v. 8, 1965, pag. 338-353. 
ZHU, G.; BLUMBERG , D.G. Classification using ASTER data and SVM algorithms - The case study of Beer Sheva, Israel. Remote Sensing of Environment, vol. 80, 2002, pag. 233-240. 
ANEXOS 


\section{ANEXOA}

\section{Dados climáticos do Município de Esplanada/Bahia}

Pluviosidade e Temperaturas médias do

Pluvosidade diária dos meses com imagens ASTER com menor cobertura de nuvens

Dados Climáticos Gerais

Balanço Hídrico

Pluviosidade e Temperaturas médias do Município de Esplanada (BA)

Local: Esplanada

Lat: $11^{\circ} 47^{\prime} \mathrm{S}$;

Long: $37^{\circ}-57^{\prime \prime} \mathrm{W}$

Alt: $181 \mathrm{~m}$

Período: 1913-

1987

\begin{tabular}{|c|c|c|}
\hline S & $\begin{array}{r}P \\
(\mathrm{~mm})\end{array}$ & $\stackrel{\circ}{ } \mathbf{C}$ \\
\hline JAN & 51.2 & 5.3 \\
\hline FEV & 66.6 & 5.5 \\
\hline MA & $\begin{array}{r}102 . \\
4\end{array}$ & 5.4 \\
\hline$A B$ & $\begin{array}{r}129 . \\
4\end{array}$ & 4.6 \\
\hline MAI & $\begin{array}{r}170 . \\
9\end{array}$ & 3.5 \\
\hline JUN & $\begin{array}{r}145 . \\
8\end{array}$ & 2.4 \\
\hline JUL & $\begin{array}{r}143 . \\
6\end{array}$ & 1.5 \\
\hline $\mathbf{A G}$ & 90.2 & 1.3 \\
\hline
\end{tabular}




\begin{tabular}{|rr|r|r|} 
& SET & 61.8 & 2.3 \\
\hline & OUT & 56.8 & 3.5 \\
\hline & NO & & \\
V & & 73.1 & 4.5 \\
\hline & & & \\
& DEZ & 67.7 & 4.8 \\
\hline & AN & 117 & 2 \\
UAL & & 6.2 & 3.7 \\
\hline
\end{tabular}

Fonte

(SUDENE)

Pluviosidade diária dos meses que apresentaram as melhores imagens do ASTER

\begin{tabular}{|c|c|c|c|c|c|}
\hline \multirow{2}{*}{$\begin{array}{c}\text { Ano } \\
\text { Dia/Mês }\end{array}$} & \multirow{2}{*}{\multicolumn{2}{|c|}{$\begin{array}{c}1999 \\
\text { novembro|dezembro }\end{array}$}} & \multicolumn{3}{|c|}{2002} \\
\hline & & & outubro & novembro & dezembro \\
\hline 1 & 0 & 0 & 0 & 0 & 0 \\
\hline 2 & $\mathbf{0}$ & $\mathbf{0}$ & 0 & 0 & 0 \\
\hline 3 & 0 & 0 & 0 & 0 & 0 \\
\hline 4 & 0 & 5.8 & 0 & 0 & 0 \\
\hline 5 & $\mathbf{0}$ & 4.5 & 0 & $\mathbf{0}$ & 0 \\
\hline 6 & 0 & 0 & 0 & 0 & 0 \\
\hline 7 & 0 & 0 & 0 & 7 & 0 \\
\hline 8 & $\mathbf{0}$ & 12.4 & 0 & 10 & 5.2 \\
\hline 9 & 0 & 0 & 0 & 8 & 0 \\
\hline 10 & 0 & 0 & 0 & 6 & 0 \\
\hline 11 & 0 & 0 & 2 & 0 & $\mathbf{0}$ \\
\hline 12 & $\mathbf{0}$ & 0 & 4.5 & 0 & $\mathbf{0}$ \\
\hline 13 & 0 & 0 & 2 & 0 & 0 \\
\hline 14 & 0 & 0 & 0 & 0 & 0 \\
\hline 15 & 0 & 0 & 0 & $\mathbf{0}$ & $\mathbf{0}$ \\
\hline 16 & 0 & 13.8 & 0 & 0 & 0 \\
\hline 17 & 0 & 0 & 0 & $\mathbf{0}$ & 0 \\
\hline 18 & 0 & 34 & 0 & 0 & 0 \\
\hline 19 & 0 & 34 & 0 & 3.2 & 0 \\
\hline 20 & 0 & 0 & 0 & 2 & 0 \\
\hline
\end{tabular}




\begin{tabular}{|c|c|c|c|c|c|}
\hline 21 & $\mathbf{0}$ & $\mathbf{1 1 . 3}$ & $\mathbf{0}$ & $\mathbf{0}$ & $\mathbf{0}$ \\
\hline 22 & $\mathbf{0}$ & $\mathbf{0}$ & $\mathbf{0}$ & $\mathbf{1 0}$ & $\mathbf{0}$ \\
\hline 23 & $\mathbf{0}$ & $\mathbf{0}$ & $\mathbf{0}$ & $\mathbf{4}$ & $\mathbf{0}$ \\
\hline 24 & $\mathbf{0}$ & $\mathbf{0}$ & $\mathbf{0}$ & $\mathbf{0}$ & $\mathbf{0}$ \\
\hline 25 & $\mathbf{0}$ & $\mathbf{0}$ & $\mathbf{0}$ & $\mathbf{3 . 3}$ & $\mathbf{0}$ \\
\hline 26 & $\mathbf{0}$ & $\mathbf{0}$ & $\mathbf{0}$ & $\mathbf{0}$ & $\mathbf{0}$ \\
\hline 27 & $\mathbf{0}$ & $\mathbf{0}$ & $\mathbf{3}$ & $\mathbf{0}$ & $\mathbf{0}$ \\
\hline 28 & $\mathbf{0}$ & $\mathbf{0}$ & $\mathbf{2 . 5}$ & $\mathbf{0}$ & $\mathbf{0}$ \\
\hline 29 & $\mathbf{0}$ & $\mathbf{0}$ & $\mathbf{0}$ & $\mathbf{0}$ & $\mathbf{0}$ \\
\hline 30 & $\mathbf{0}$ & $\mathbf{0}$ & $\mathbf{0}$ & $\mathbf{0}$ & $\mathbf{0}$ \\
\hline 31 & & $\mathbf{0}$ & $\mathbf{0}$ & & $\mathbf{0}$ \\
\hline Total & $\mathbf{0}$ & $\mathbf{1 1 5 . 8}$ & $\mathbf{1 4}$ & $\mathbf{5 3 . 5}$ & $\mathbf{5 . 2}$ \\
\hline
\end{tabular}

Fonte: SRH/BA 
n

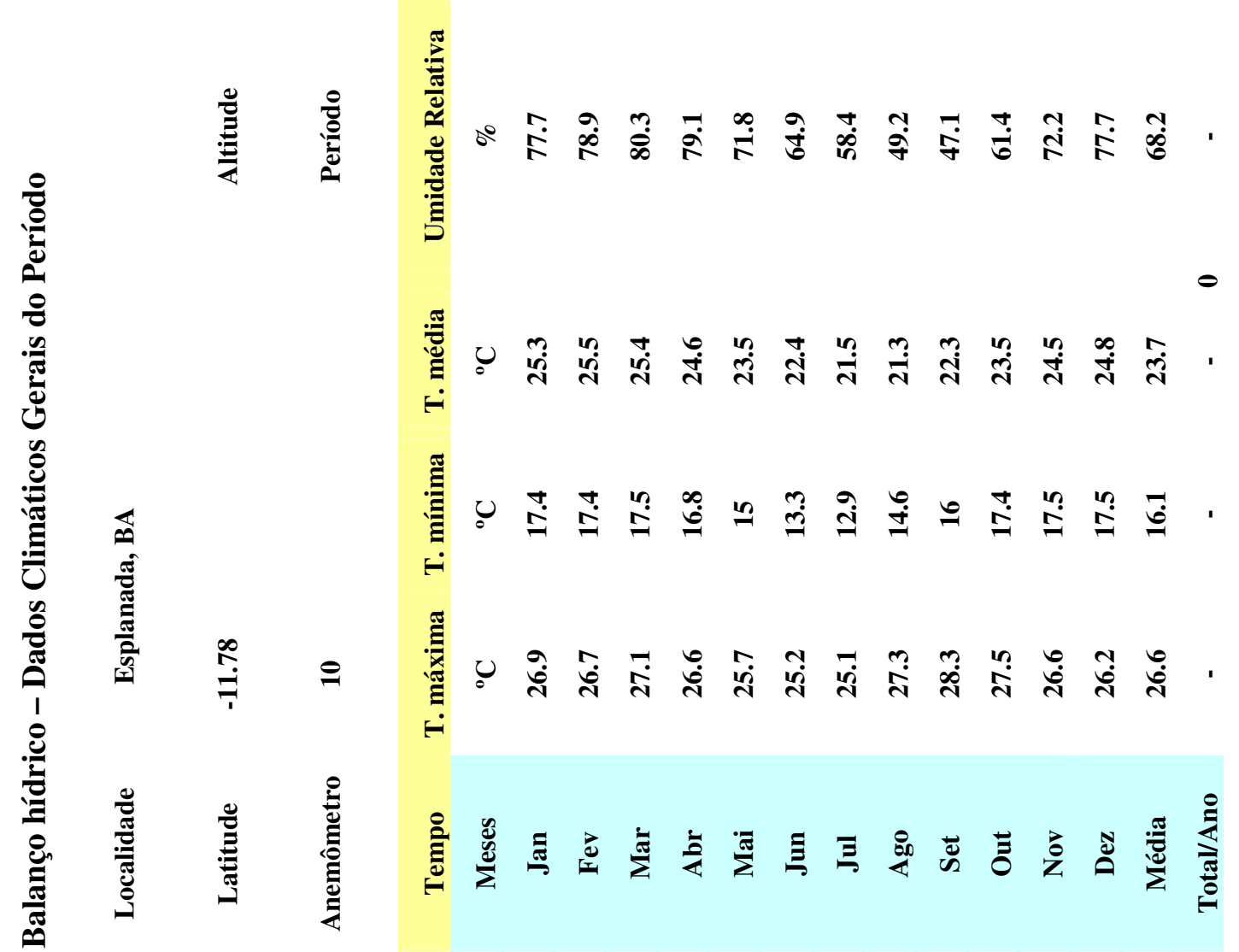

季

I

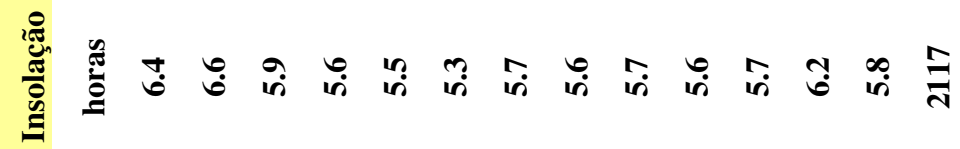

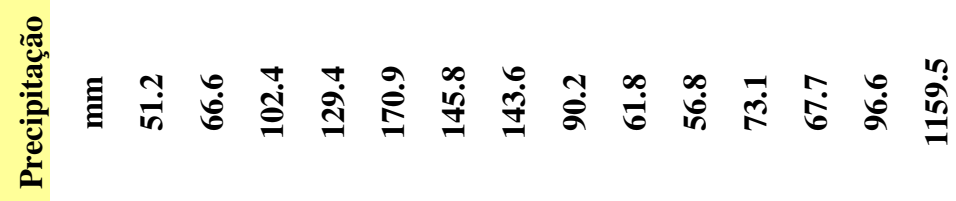

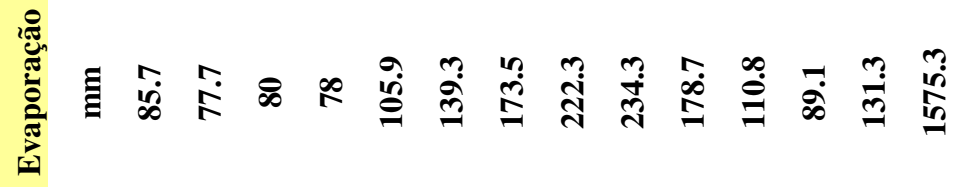




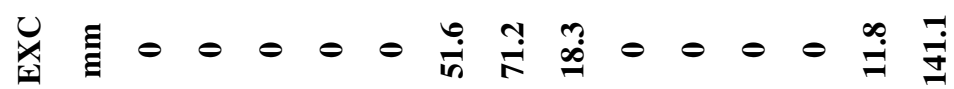

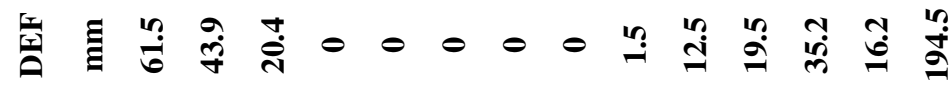

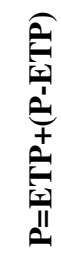

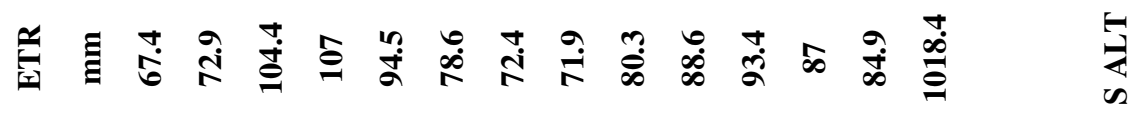

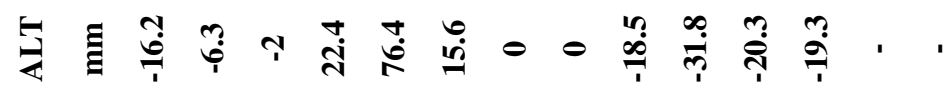

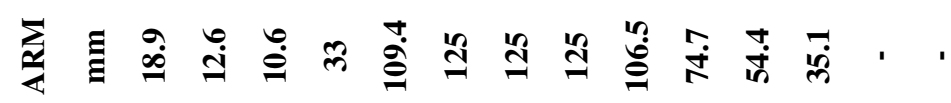

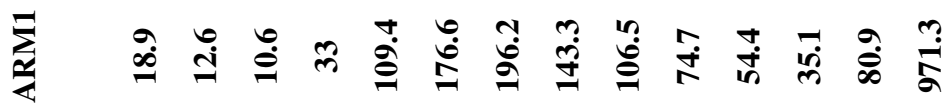

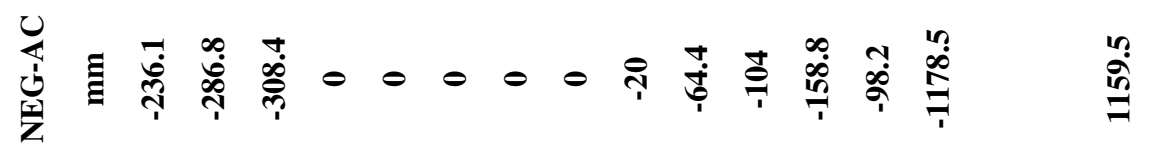

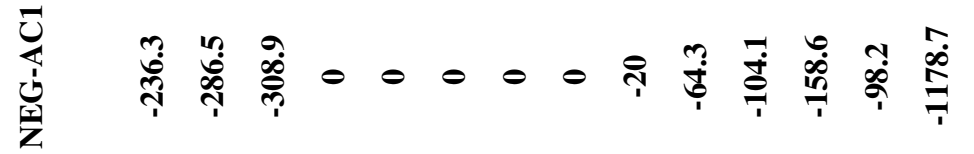

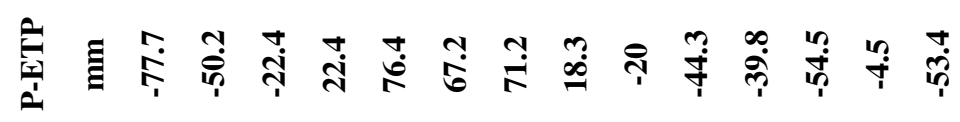

产 豆 


\section{ANEXO B}

\section{Descrição do sensor ASTER}

O Advanced Spaceborne Thermal Emission and Reflection Radiometer (ASTER) é uma avançado imageador multiespectral que foi lançado a bordo da plataforma Terra (NASA), em dezembro de 1999. O ASTER cobre uma larga região do espectrocom 14 bandas ao todo, que vão desde o espectro visível ao infravermelho termal com elevada resolução espacial, espectral e radiométrica. Uma visada posterior adicional na banda infra-vermelho próximo fornece uma cobertura para formar um estereopar. A resolução espacial varia com o comprimento de onda: $15 \mathrm{~m}$ no visível e no infravermelho próximo (VNIR), 30m nas ondas curtas infra-vermelho (SWIR), e 90m no termal infra-vermelho (TIR). Cada cena do ASTER recobre uma área de $60 \mathrm{~km}$ x $60 \mathrm{~km}$.

\section{O SISTEMA ASTER}

O ASTER tem uma cobertura global completa, devidp a sua óbita cíclica de $8 \%$. Durante sua translação ele adquire 650 cenas por dia, que são processadas para o nível 1-A; destas cerca de 150 são processadas para o nível 1B. Todas as cenas 1A e 1B são transferidas para o arquivo EOSDIS no EROS Data Center (EDC) e o Land Processes Distributed Active Archive Center (LP-DAAC), apra armazenamento, distribuição e processamento de dados em produtos de alto nível. Todos os produtos de dados do ASTER são armazenados com uma implementação específica da Hierarchical Data Format chamado HDF-EOS.

O ASTER consiste em três diferentes subsistemas: visível e infra-vermelho próximo (Visible and Near-infrared - VNIR) que possui três bandas com resolução espacial de 15m, e uma visada adicional posterior para formação do estereopar; Ondas curtas infravermelho (ou Infravermelho médio), (Shortwave Infrared - SWIR)com 6 bandas, com resolução espacial de 30m; e o infravermelho termal (Thermal Infrared - TIR) com 5 bandas com resolução espacial de $90 \mathrm{~m}$. Cada subsistema opera em diferentes regiões espectrais, com seus próprios telescópios, que foi construído por uma companhia japonesa. As bandas espectrais são apresentadas na tabela 1, e sua comparação com as bandas espectrais do Landsat Thematic Mapper na figura 1. A visada para tras, que permite formar a capacidade estereoscópica, é utilizada na banda espectral infra-vermelho próximo (banda 3B) 


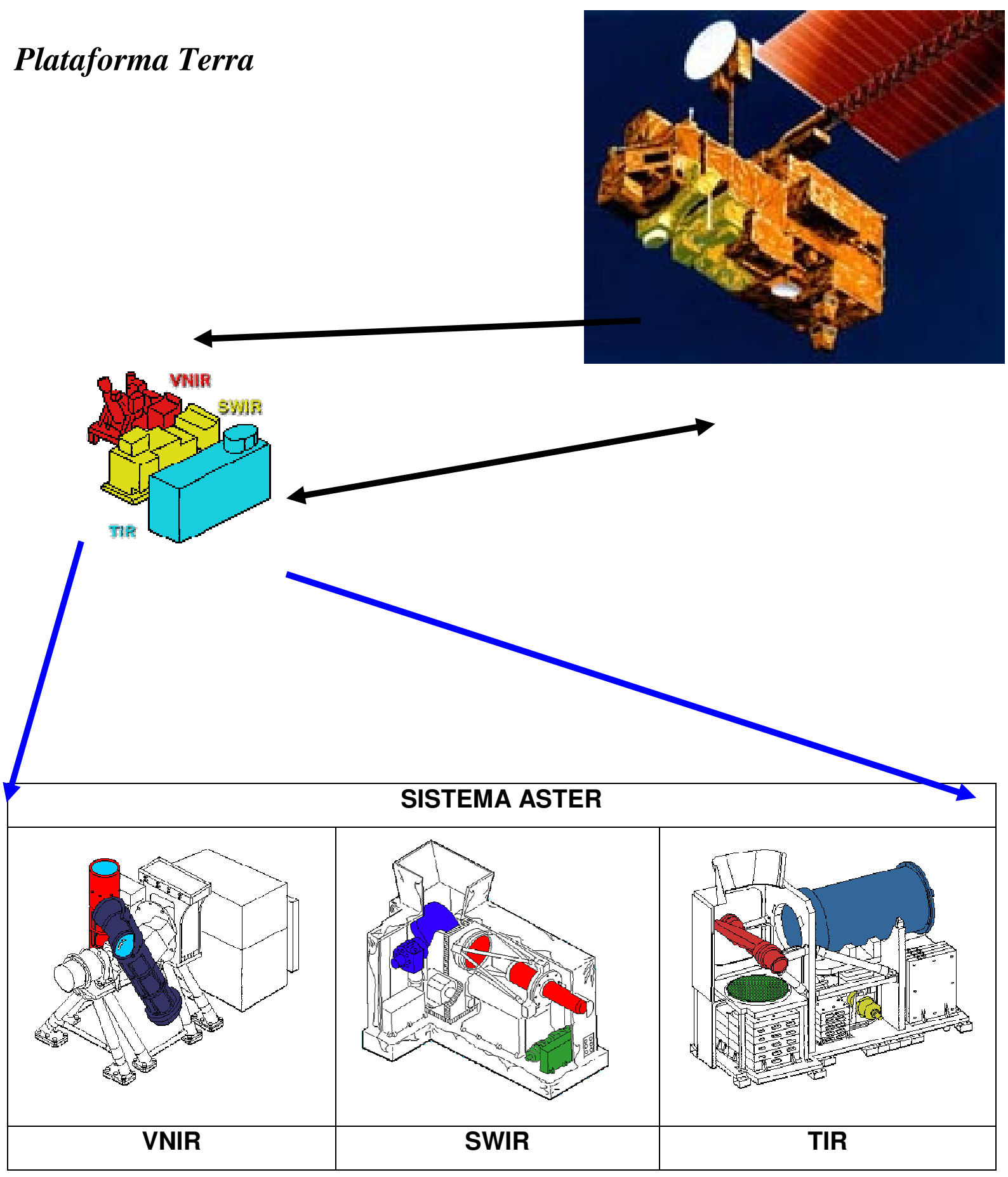

Características dos 3 sistemas sensores do ASTER 


\begin{tabular}{|c|c|c|c|c|}
\hline Subsistema & Banda & Intervalo Espectral $(\mu \mathrm{m})$ & $\begin{array}{c}\text { Resolução Espacial } \\
(\mathrm{m})\end{array}$ & $\begin{array}{c}\text { Níveis de } \\
\text { Quantificação }\end{array}$ \\
\hline \multirow{4}{*}{ VNIR } & 1 & $0.52-0.60$ & \multirow{4}{*}{15} & \multirow{4}{*}{8 bits } \\
\hline & 2 & $0.63-0.69$ & & \\
\hline & $3 \mathbf{N}$ & $0.78-0.86$ & & \\
\hline & 3B & $0.78-0.86$ & & \\
\hline \multirow{6}{*}{ SWIR } & 4 & $1.60-1.70$ & \multirow{6}{*}{30} & \multirow{6}{*}{8 bits } \\
\hline & 5 & 2.145-2.185 & & \\
\hline & 6 & 2.185-2.225 & & \\
\hline & 7 & 2.235-2.285 & & \\
\hline & 8 & $2.295-2.365$ & & \\
\hline & 9 & $2.360-2.430$ & & \\
\hline \multirow{5}{*}{ TIR } & 10 & $8.125-8.475$ & \multirow{5}{*}{90} & \multirow{5}{*}{12 bits } \\
\hline & 11 & $8.475-8.825$ & & \\
\hline & 12 & $8.925-9.275$ & & \\
\hline & 13 & $10.25-10.95$ & & \\
\hline & 14 & $10.95-11.65$ & & \\
\hline
\end{tabular}

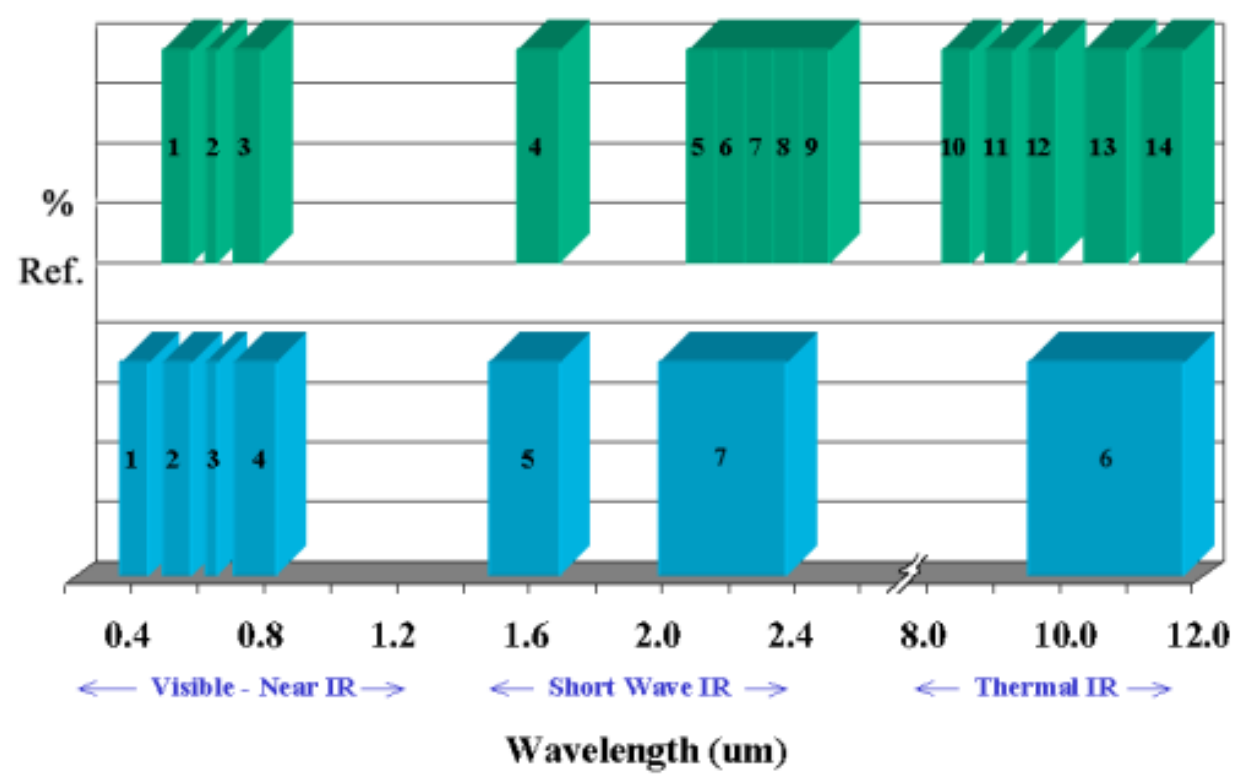

ASTER

Landsat 7

Figura 1: Comparação das bandas espectrais entre o ASTER e o Landsat-7 Thematic Mapper.

(Nota: \% Ref é o percentual da reflectância). 


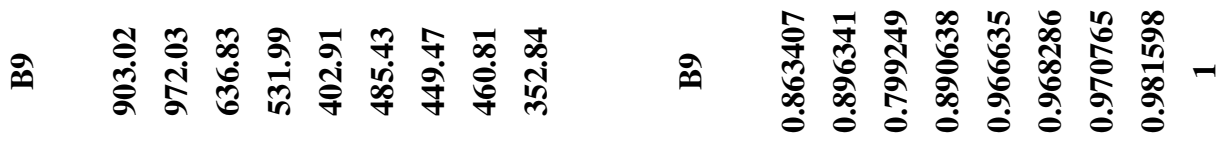

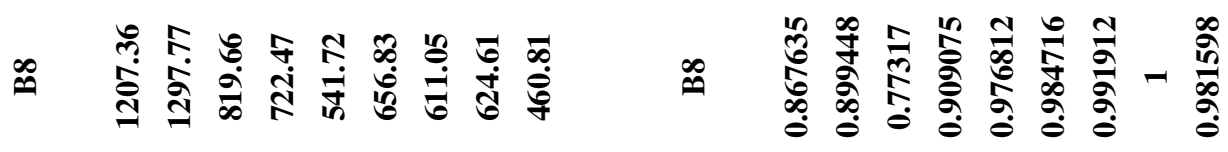

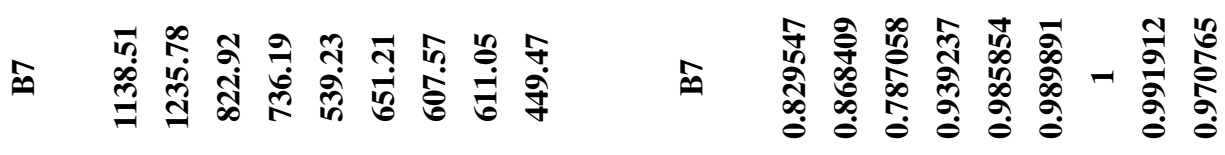

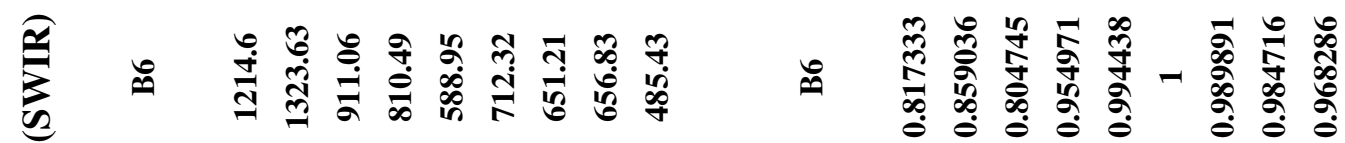

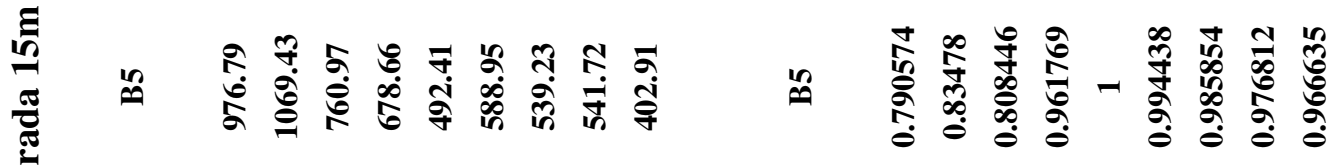

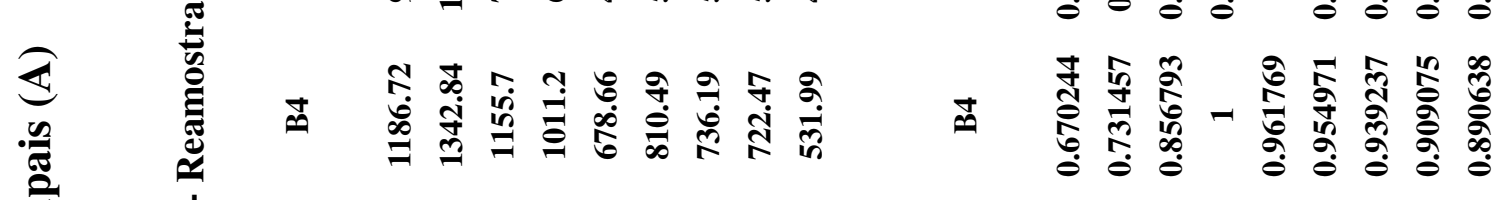

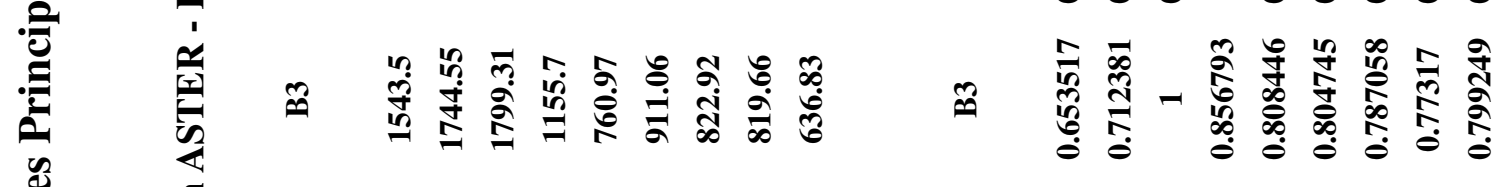

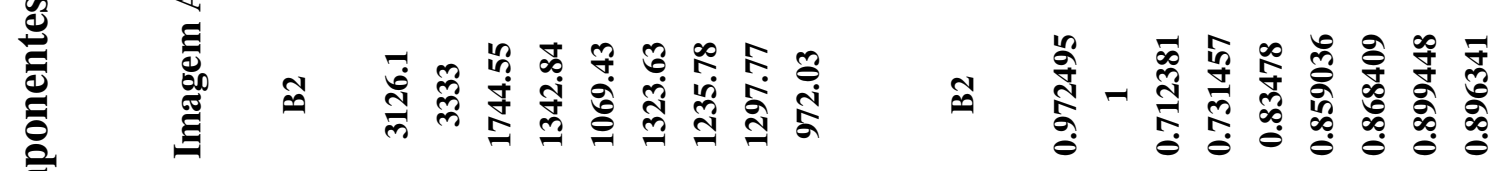

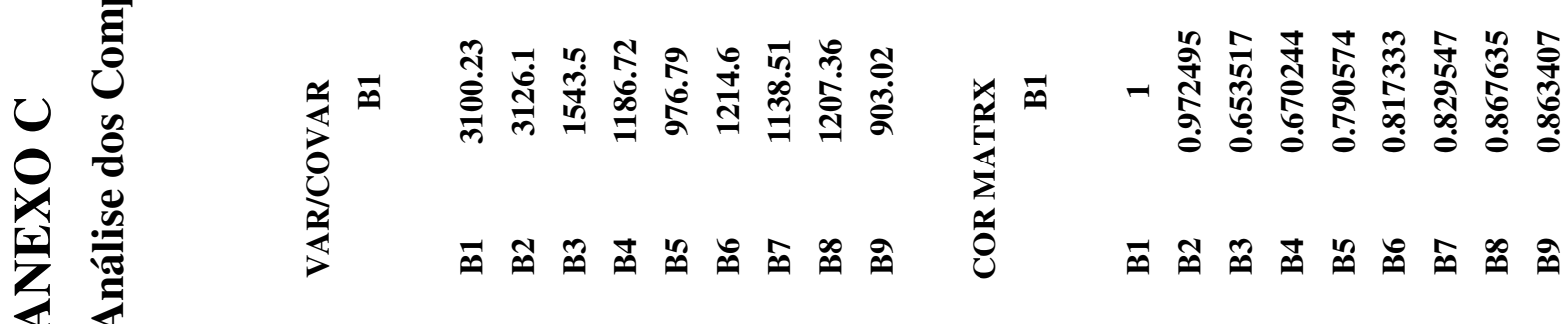




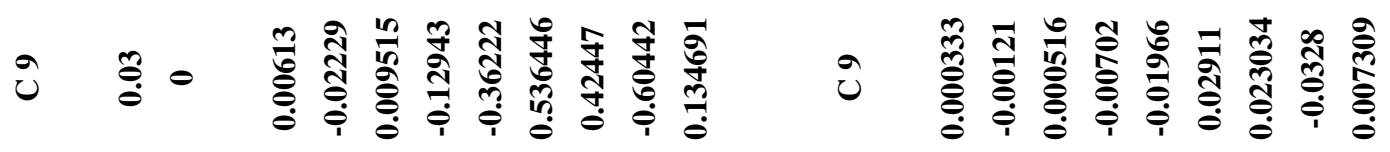

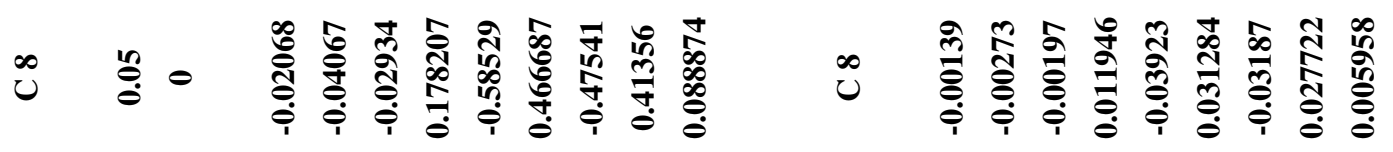

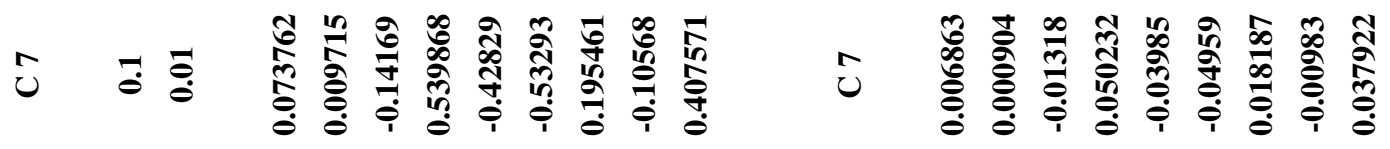

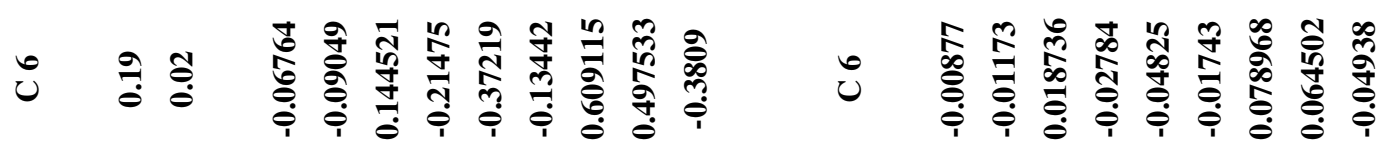

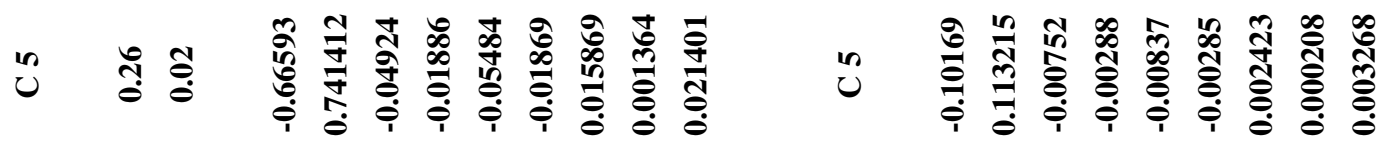

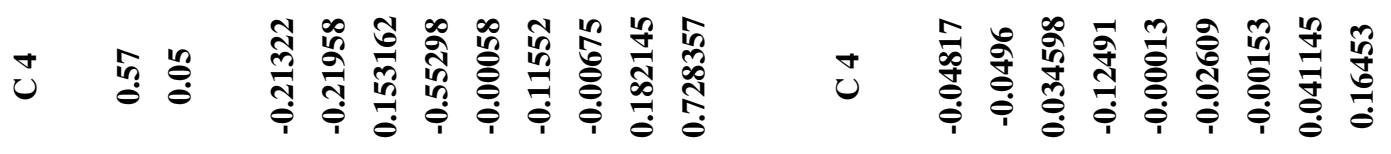

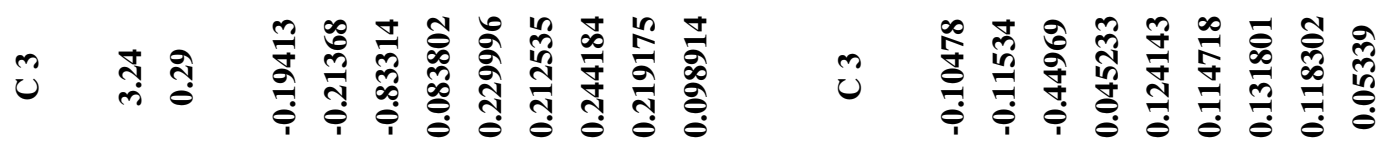

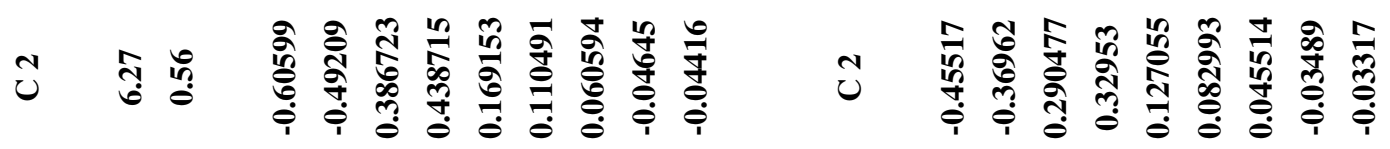

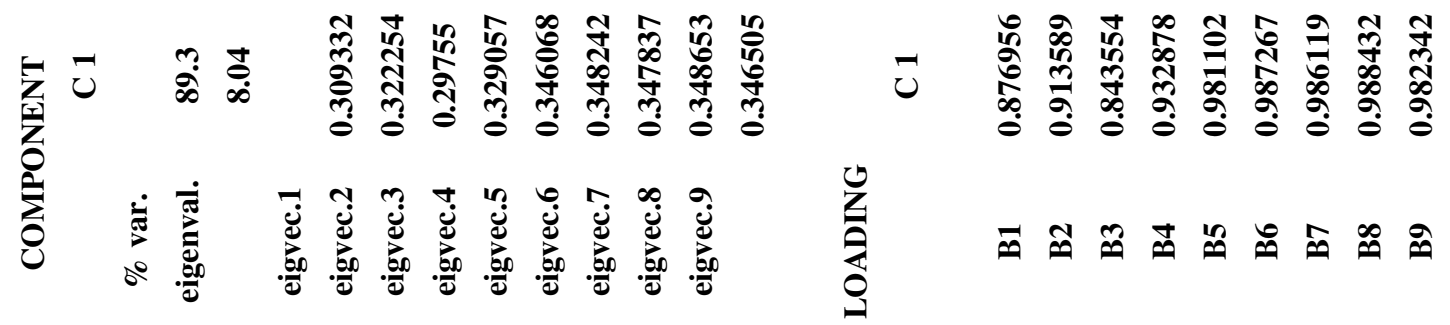




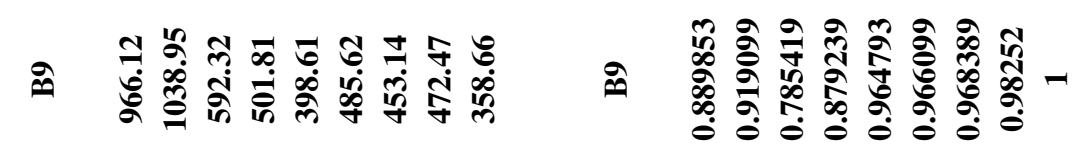

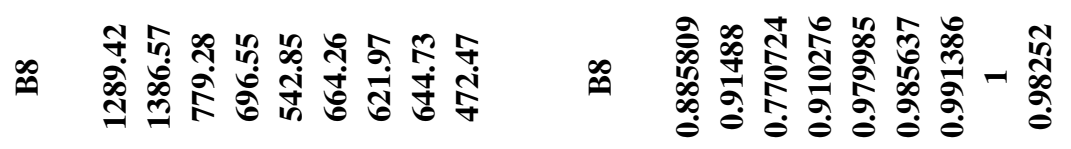

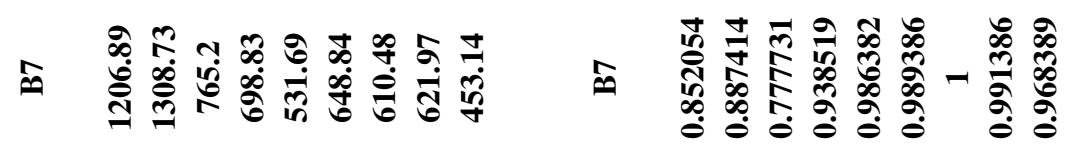

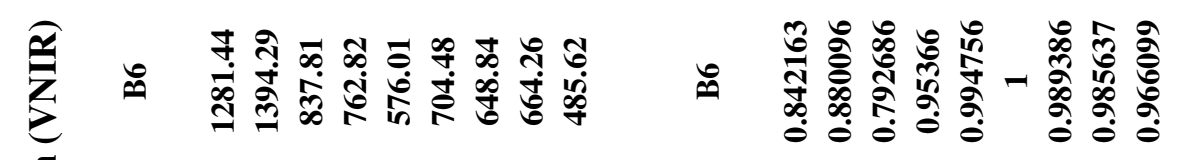

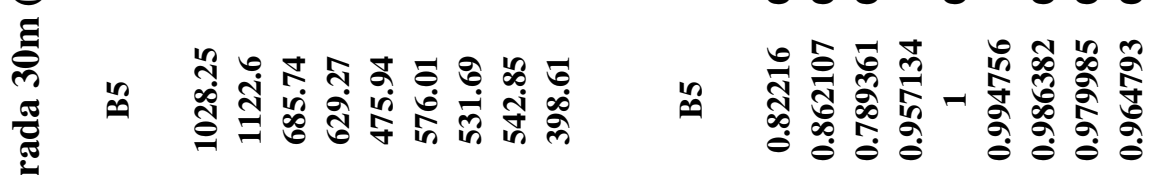

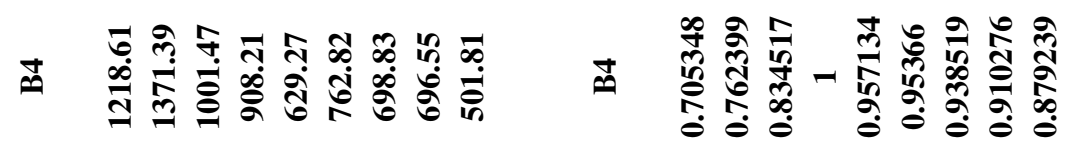

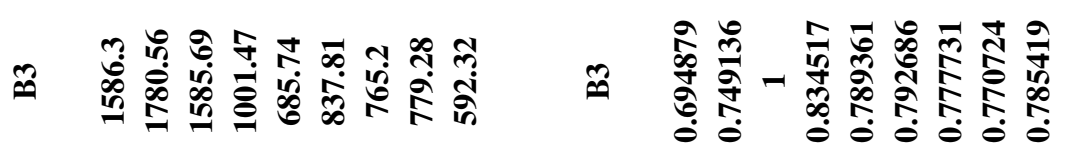

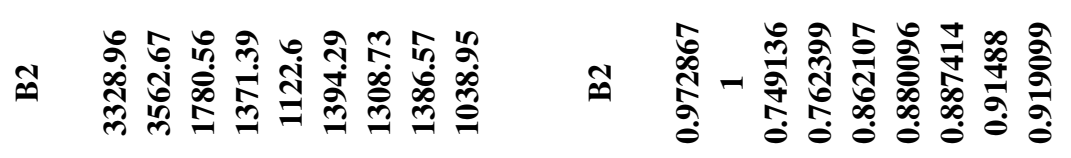

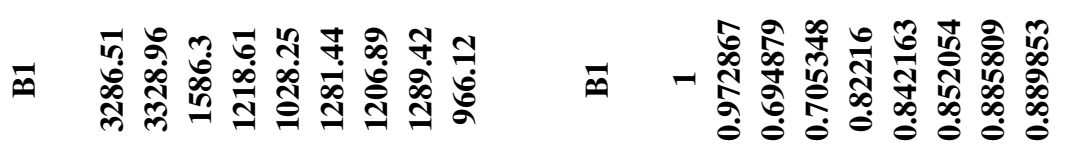

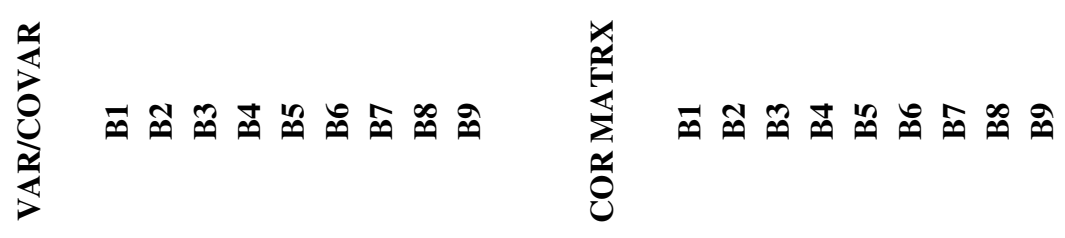




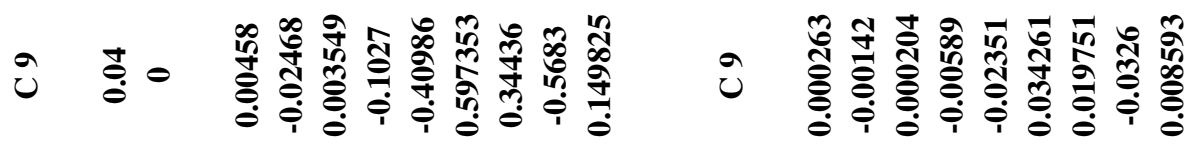

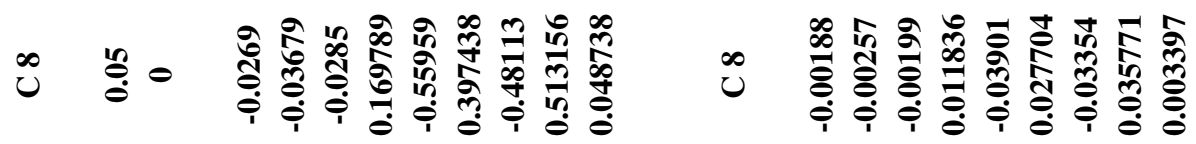

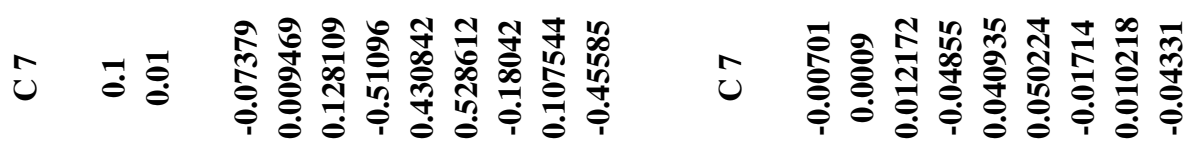

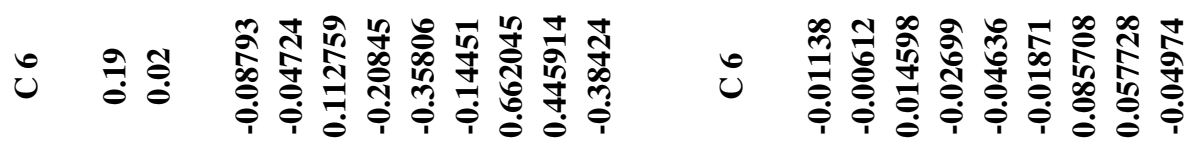

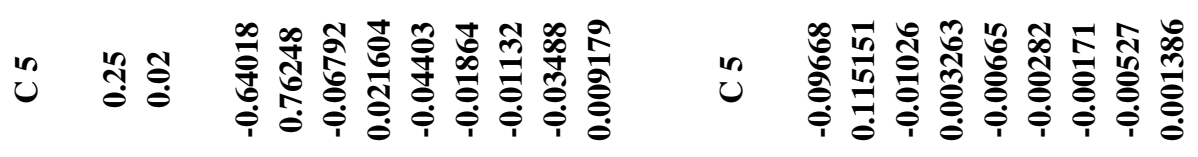

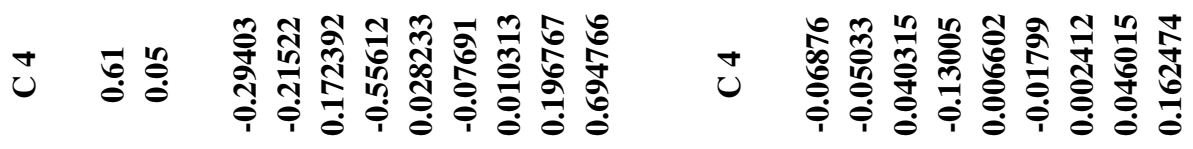

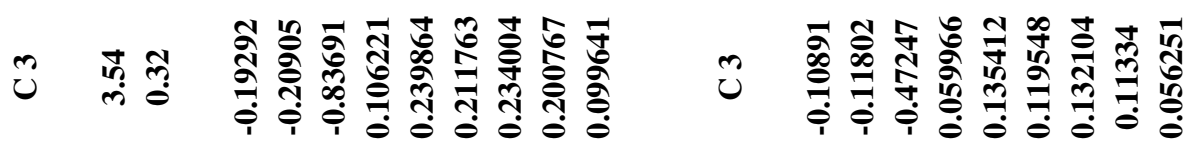

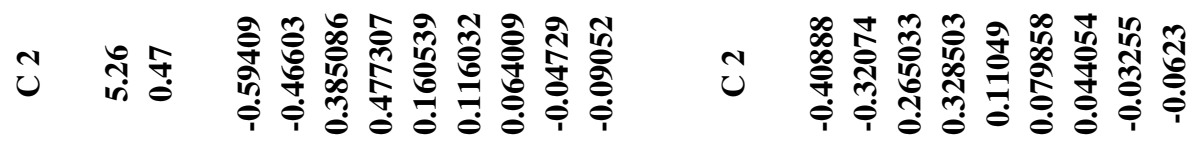

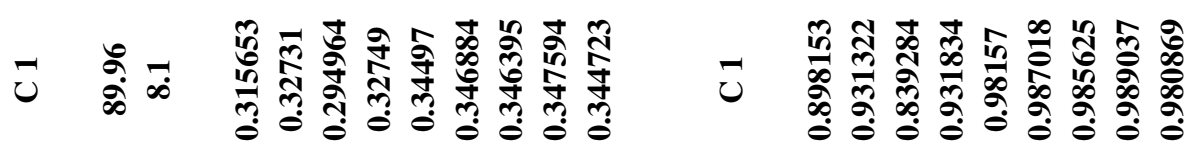

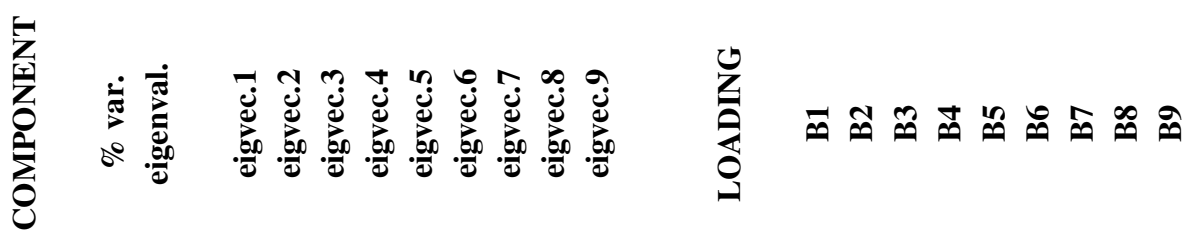




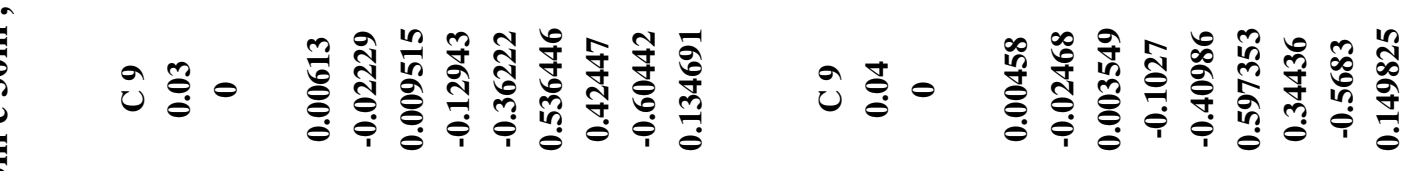

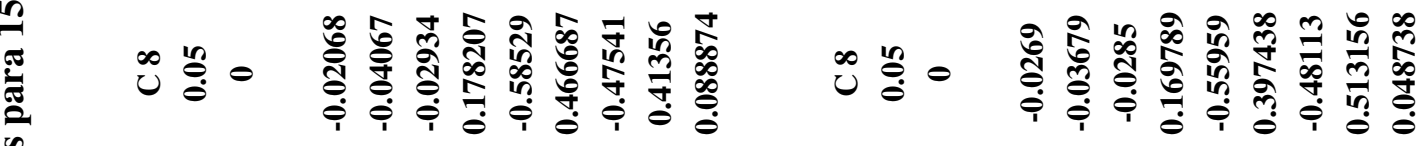

(2)

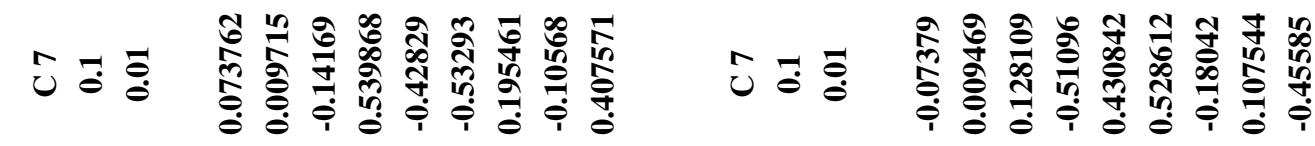

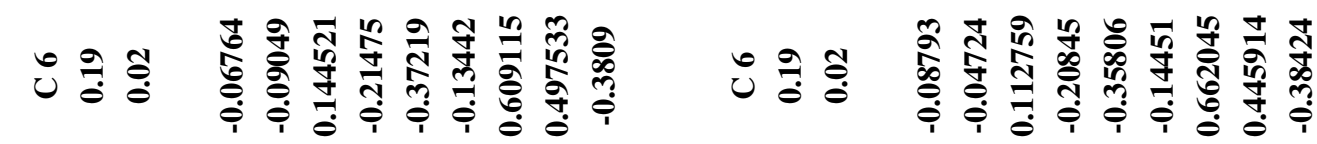

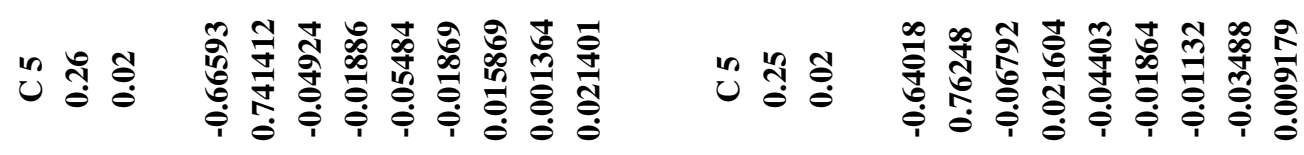

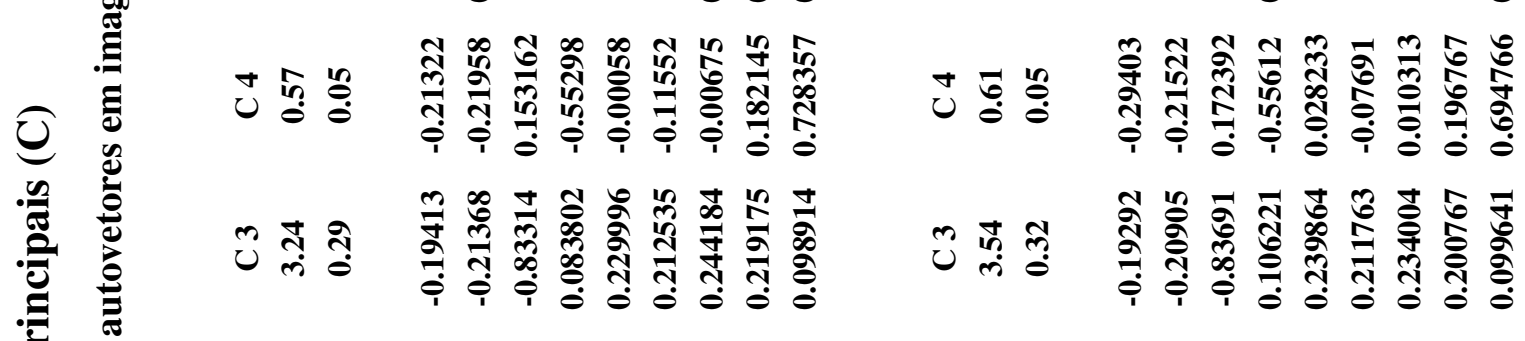

थ

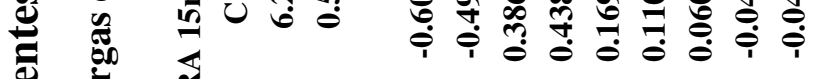

ฮั:

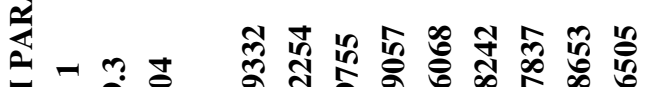

î

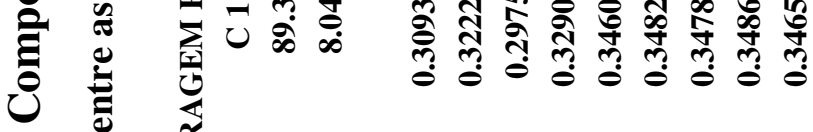

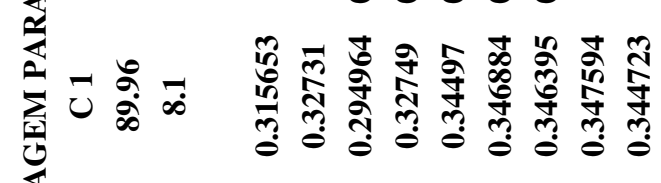

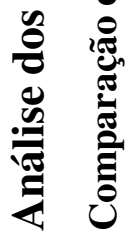

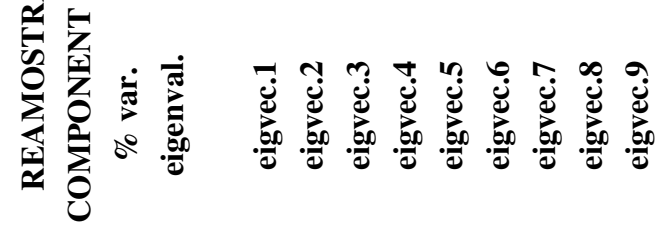


$\vec{x}$

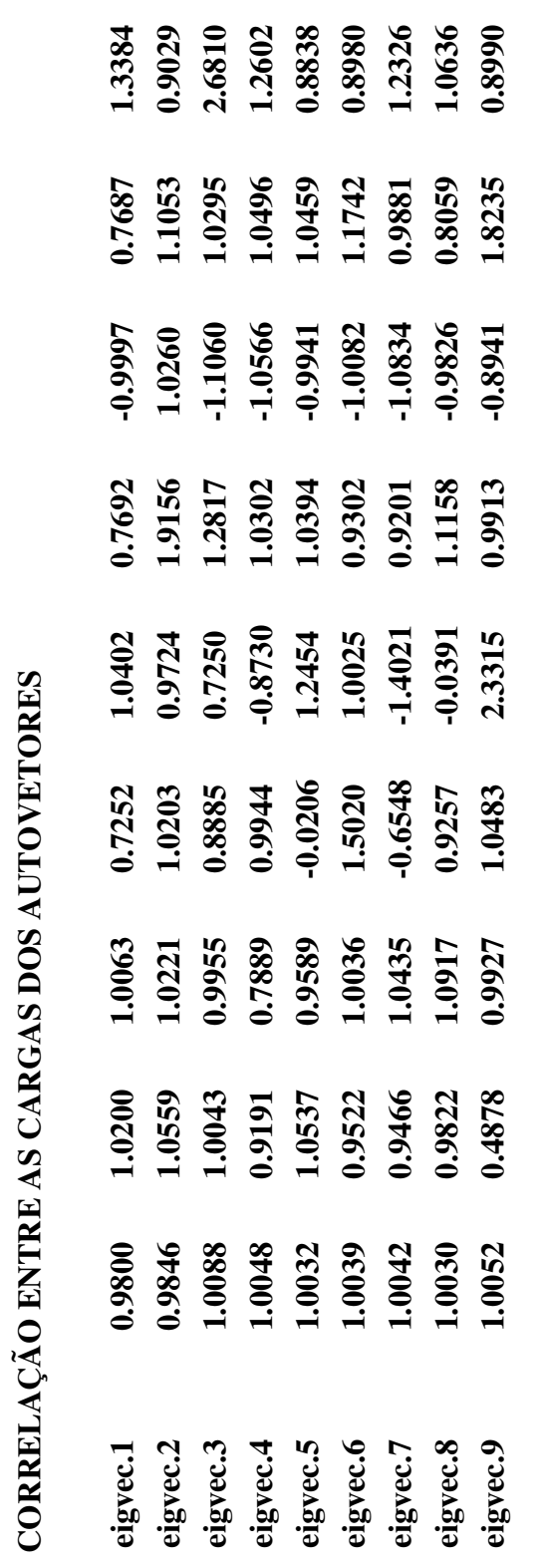





\section{ANEXO D}

Tabela de Cálculo do Tasseled Cap para o ASTER, segundo metodologia proposta por Jackson, 1983.

(a) Amostras

TASSELED CAP - AMOSTRAS

\begin{tabular}{|c|c|c|c|c|}
\hline \multirow{15}{*}{$\begin{array}{l}\text { SOLO } \\
\text { SECO }\end{array}$} & & BRILHO & VERDE & AMARELO \\
\hline & AM1 & 1.184594 & -0.02010053 & -0.009319776 \\
\hline & AM2 & 1.369864 & -0.02689093 & -0.01135667 \\
\hline & AM3 & 1.371621 & -0.02915491 & -0.009188958 \\
\hline & AM4 & $\mathbf{1 . 0 3 8 3 3 7}$ & $\mathbf{0 . 0 0 3 3 0 2 7 0 1}$ & -0.008288772 \\
\hline & AM5 & 1.05701 & -0.00467895 & -0.01155167 \\
\hline & AM6 & 1.023975 & -0.004147622 & -0.01211737 \\
\hline & AM7 & 1.164547 & -0.009652017 & -0.00927974 \\
\hline & AM8 & & & \\
\hline & AM9 & 1.114075 & -0.0037321 & -0.00360503 \\
\hline & AM10 & 1.014324 & 0.0137497 & -0.003264631 \\
\hline & AM11 & 1.230749 & 0.004218267 & -0.003203502 \\
\hline & AM12 & 1.215731 & -0.004190877 & -0.004146956 \\
\hline & AM13 & 1.56648 & -0.01248126 & -0.002443188 \\
\hline & AM14 & & & \\
\hline
\end{tabular}

\begin{tabular}{|c|c|c|c|c|}
\hline & & BRILHO & VERDE & AMARELO \\
\hline \multirow{14}{*}{$\begin{array}{c}\text { SOLO } \\
\text { ÚMIDO }\end{array}$} & AM1 & 0.5850363 & -0.003064765 & -0.00631057 \\
\hline & AM2 & $\mathbf{0 . 7 8 9 2 2 5 2}$ & 0.01228509 & -0.007913901 \\
\hline & AM3 & 0.832482 & 0.01635058 & -0.005886947 \\
\hline & AM4 & 1.200783 & -0.02157351 & -0.005504676 \\
\hline & AM5 & 0.5681385 & $\mathbf{0 . 0 0 3 6 5 6 5 3 7}$ & -0.00698538 \\
\hline & AM6 & 1.021809 & 0.00806178 & -0.004718331 \\
\hline & AM7 & 0.988369 & -0.02071504 & -0.007009235 \\
\hline & AM8 & 0.9965458 & -0.02228912 & -0.007936215 \\
\hline & AM9 & 0.5252415 & -0.006945817 & -0.006312846 \\
\hline & AM10 & 0.9000254 & -0.006414614 & -0.008875187 \\
\hline & AM11 & 0.8583783 & $-\mathbf{0 . 0 0 7 4 1 3 3 5 7}$ & -0.005879886 \\
\hline & AM12 & 0.8178734 & 0.006839852 & $\mathbf{- 0 . 0 0 8 8 3 6 9 7 7}$ \\
\hline & AM13 & 0.8927374 & 0.01600373 & -0.006227458 \\
\hline & AM14 & 0.8224216 & -0.002965604 & -0.009680996 \\
\hline
\end{tabular}




\begin{tabular}{|c|c|c|c|c|}
\cline { 2 - 5 } \multicolumn{1}{c|}{} & & BRILHO & VERDE & AMARELO \\
\hline \multirow{5}{*}{ VEG. } & AM1 & $\mathbf{0 . 5 3 1 9 7 1 5}$ & $\mathbf{0 . 1 0 6 6 0 0 4}$ & $\mathbf{0 . 0 0 1 3 7 9 4 5}$ \\
\cline { 2 - 5 } VERDE & AM2 & $\mathbf{0 . 5 0 8 2 8 0 3}$ & $\mathbf{0 . 1 1 4 6 6 2 5}$ & $\mathbf{0 . 0 0 2 5 3 5 7 1 1}$ \\
\cline { 2 - 5 } & AM3 & $\mathbf{0 . 4 8 0 3 7 5 5}$ & $\mathbf{0 . 1 1 1 1 5 1}$ & $\mathbf{0 . 0 0 2 6 2 7 7 0 5}$ \\
\cline { 2 - 5 } & AM4 & $\mathbf{0 . 5 5 8 1 9 8 9}$ & $\mathbf{0 . 0 9 7 6 9 6 3 2}$ & $\mathbf{0 . 0 0 1 0 0 8 6 6 2}$ \\
\cline { 2 - 5 } & AM5 & $\mathbf{0 . 4 6 3 9 3 7 6}$ & $\mathbf{0 . 0 8 1 9 3 2 2 7}$ & $\mathbf{0 . 0 0 0 6 0 2 0 3 2}$ \\
\cline { 2 - 5 } & AM6 & $\mathbf{0 . 5 2 0 3 8 2 8}$ & $\mathbf{0 . 0 8 7 8 7 3 9 6}$ & $\mathbf{0 . 0 0 0 1 3 4 4 6 7}$ \\
\cline { 2 - 5 } & AM7 & $\mathbf{0 . 5 6 3 6 9 8 6}$ & $\mathbf{0 . 0 8 6 7 8 6 9 9}$ & $\mathbf{- 0 . 0 0 0 2 7 0 1 6 5}$ \\
\cline { 2 - 5 } & AM8 & $\mathbf{0 . 5 3 1 4 2 8 3}$ & $\mathbf{0 . 1 1 6 1 4 0 6}$ & $\mathbf{0 . 0 0 1 7 9 2 9 3 9}$ \\
\cline { 2 - 5 } & AM9 & $\mathbf{0 . 4 9 7 0 7 3 4}$ & $\mathbf{0 . 0 8 3 4 2 1 6 5}$ & $\mathbf{- 0 . 0 0 0 1 9 9 1 7 9}$ \\
\cline { 2 - 5 } & AM10 & $\mathbf{0 . 4 6 3 0 0 7 7}$ & $\mathbf{0 . 0 9 0 7 7 2 6 7}$ & $\mathbf{0 . 0 0 1 6 3 6 1 3 4}$ \\
\cline { 2 - 5 } & AM11 & $\mathbf{0 . 4 9 7 7 4 2 1}$ & $\mathbf{0 . 0 7 5 2 6 8 1}$ & $\mathbf{- 0 . 0 0 0 2 8 3 9 2}$ \\
\cline { 2 - 5 } & AM12 & $\mathbf{0 . 4 8 2 6 1 1 8}$ & $\mathbf{0 . 0 8 6 8 0 3 3 6}$ & $\mathbf{0 . 0 0 0 4 9 8 0 6 1}$ \\
\cline { 2 - 5 } & AM13 & $\mathbf{0 . 6 1 1 7 1 9 5}$ & $\mathbf{0 . 1 2 4 8 0 8 3}$ & $\mathbf{0 . 0 0 1 3 4 4 0 5 6}$ \\
\cline { 2 - 5 } & AM14 & $\mathbf{0 . 4 9 8 4 7 4 5}$ & $\mathbf{0 . 8 5 0 0 9 1 6}$ & $\mathbf{0 . 0 0 0 3 4 2 5 5 4}$ \\
\hline
\end{tabular}

\begin{tabular}{|c|c|c|c|c|}
\cline { 2 - 5 } \multicolumn{1}{c|}{} & & BRILHO & VERDE & AMARELO \\
\hline \multirow{5}{*}{ VEG. } & AM1 & $\mathbf{0 . 8 2 7 1 1 5 8}$ & $\mathbf{0 . 0 1 0 3 0 9 7 1}$ & $\mathbf{- 0 . 0 0 9 8 2 4 7 2 9}$ \\
\cline { 2 - 5 } SENESC. & AM2 & $\mathbf{0 . 8 6 2 4 9 9 7}$ & $\mathbf{0 . 0 1 6 7 1 0 2 7}$ & $-\mathbf{0 . 0 0 9 0 6 1 3 2 5}$ \\
\cline { 2 - 5 } & AM3 & $\mathbf{0 . 8 1 5 9 2 0 8}$ & $\mathbf{0 . 0 1 9 0 8 2 5 1}$ & $\mathbf{- 0 . 0 0 6 9 1 7 8 7 7}$ \\
\cline { 2 - 5 } & AM4 & $\mathbf{0 . 9 7 6 0 3 8 6}$ & $\mathbf{0 . 0 0 5 8 6 4 6 7 2}$ & $\mathbf{- 0 . 0 1 0 1 9 7 0 1}$ \\
\cline { 2 - 5 } & AM5 & $\mathbf{0 . 7 3 7 5 0 9 7}$ & $\mathbf{0 . 0 1 8 2 2 4 2}$ & $\mathbf{- 0 . 0 0 6 9 4 3 2 5 9}$ \\
\cline { 2 - 5 } & AM6 & $\mathbf{1 . 0 0 1 2 1 2}$ & $\mathbf{0 . 0 2 3 1 8 4 5 7}$ & $\mathbf{- 0 . 0 0 9 2 9 5 4 8}$ \\
\cline { 2 - 5 } & AM7 & $\mathbf{0 . 9 4 0 2 9 4 2}$ & $\mathbf{0 . 0 0 6 2 8 0 7 6 5}$ & $\mathbf{- 0 . 0 0 9 8 7 5 9 3 7}$ \\
\cline { 2 - 5 } & AM8 & $\mathbf{0 . 8 1 6 1 9 5 6}$ & $\mathbf{0 . 0 1 9 0 1 8 7 3}$ & $\mathbf{- 0 . 0 0 8 0 0 1 0 7 1}$ \\
\cline { 2 - 5 } & AM9 & $\mathbf{0 . 9 8 6 2 3 2 5}$ & $\mathbf{0 . 0 0 4 8}$ & $\mathbf{- 0 . 0 0 8 6 7 4 8 5 2}$ \\
\cline { 2 - 5 } & AM10 & $\mathbf{0 . 8 2 0 4 5 6 1}$ & $\mathbf{0 . 0 1 3 3 2 2 4 2}$ & $\mathbf{- 0 . 0 1 0 3 0 1 1 8}$ \\
\cline { 2 - 5 } & AM11 & $\mathbf{0 . 8 5 0 8 4 3 2}$ & $\mathbf{- 0 . 0 0 6 7 1 4 4 9 7}$ & $\mathbf{- 0 . 0 1 1 2 9 8 9 8}$ \\
\cline { 2 - 5 } & AM12 & $\mathbf{0 . 8 3 7 5 0 2 9}$ & $\mathbf{0 . 0 2 5 0 2 1 5 8}$ & $\mathbf{- 0 . 0 7 7 6 9 7 5 3}$ \\
\cline { 2 - 5 } & AM13 & $\mathbf{0 . 8 4 7 8 1 1 2}$ & $\mathbf{0 . 0 0 8 9 1 6 2 1 8}$ & $\mathbf{- 0 . 0 0 9 6 9 6 6 9 7}$ \\
\cline { 2 - 5 } & AM14 & $\mathbf{0 . 9 1 2 6 1 9 9}$ & $\mathbf{0 . 0 2 2 7 7 3 8 2}$ & $\mathbf{- 0 . 0 0 7 4 6 8 3 5 6}$ \\
\hline
\end{tabular}




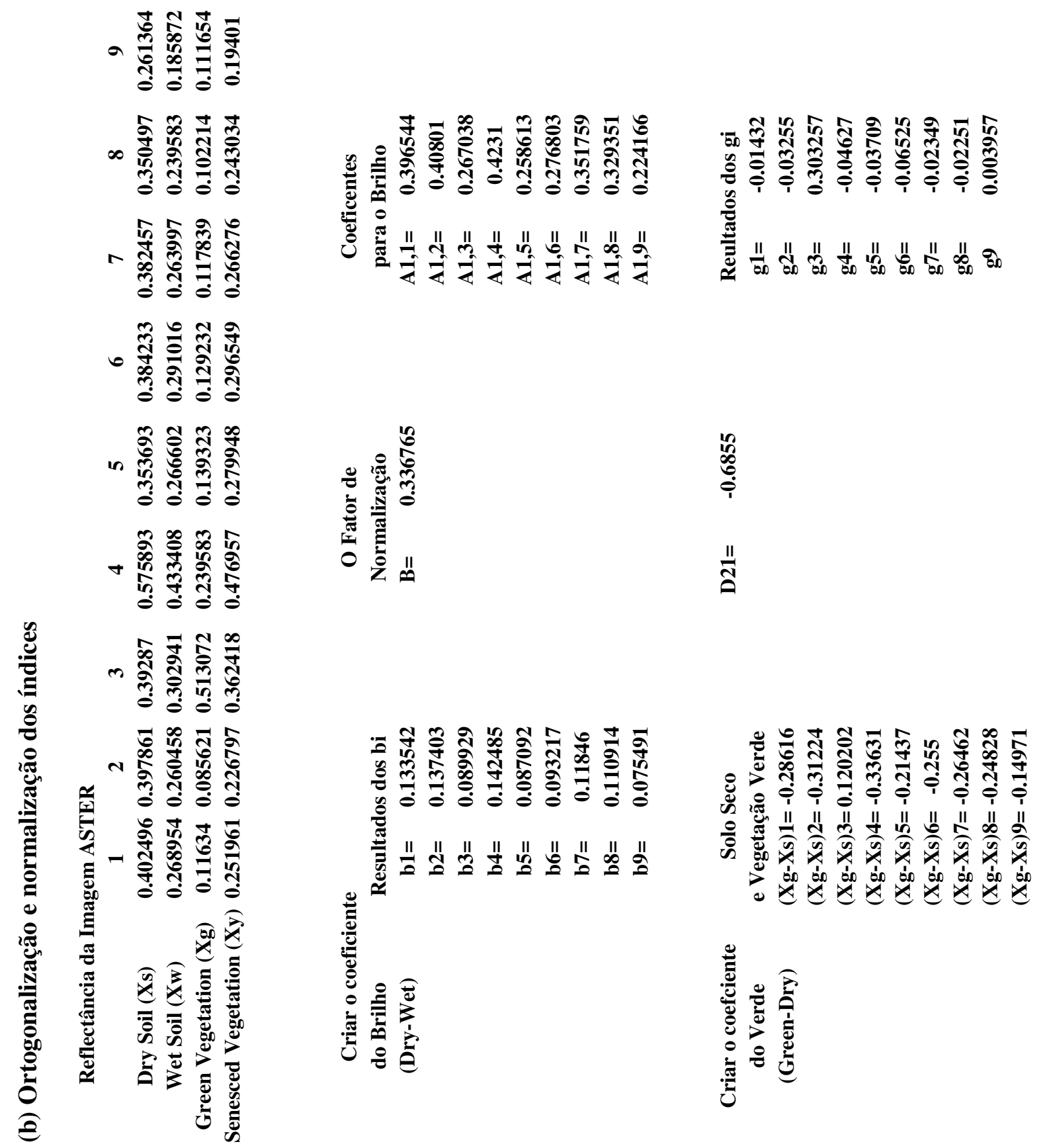



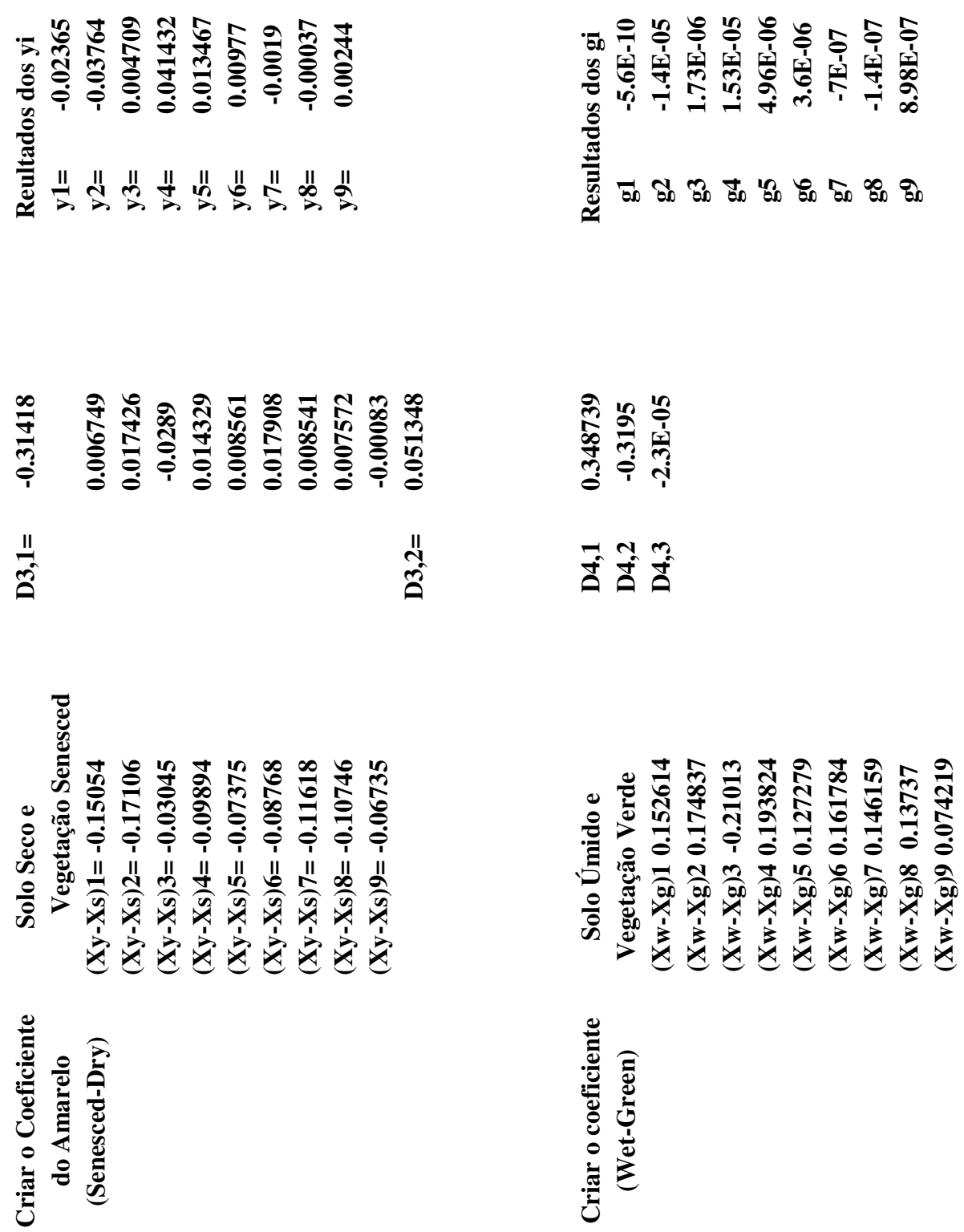


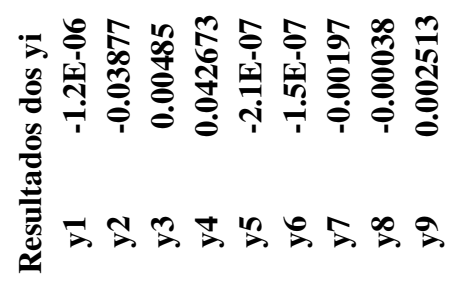

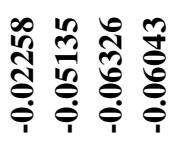

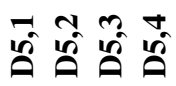
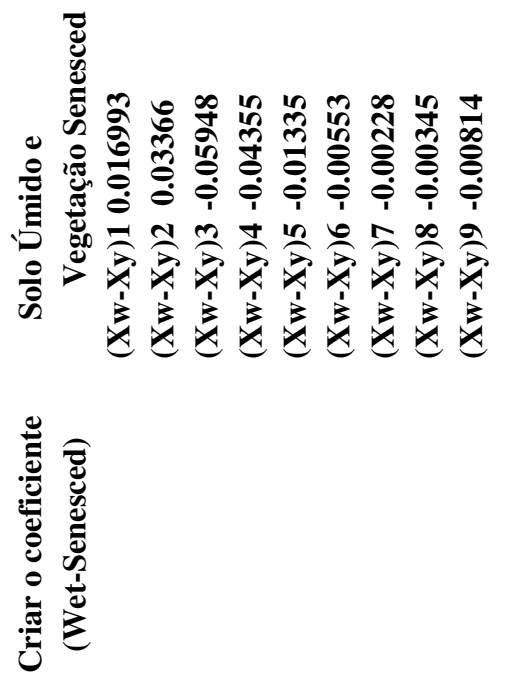
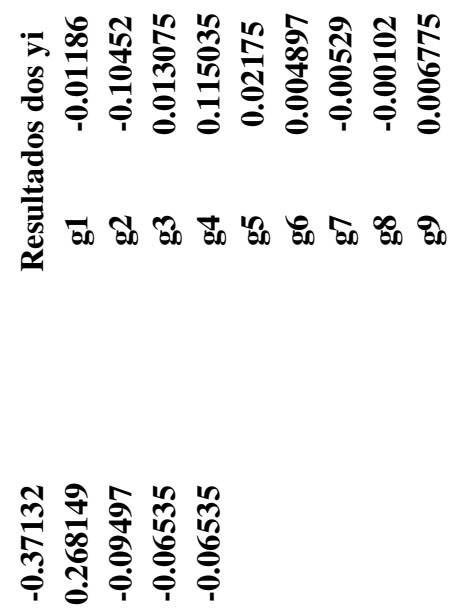

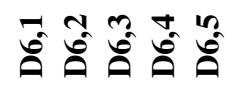

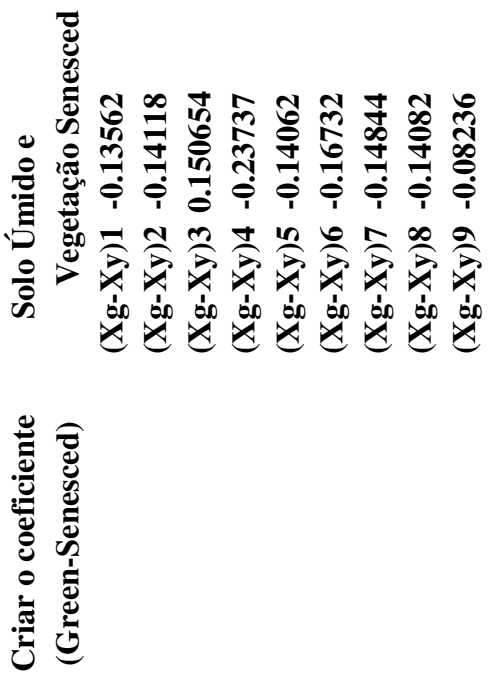



Fator de

Normalização

$\mathbf{G}=$

0.319497
Fator de

Normalização

$\mathbf{Y}=$ 0.063257
Fator de

Normalização

$\mathbf{G}=$ 2.16E-05
Coeficentes

para o Verde

$\mathrm{A2,1}=\quad \mathbf{- 0 . 0 4 4 8 3}$

$\mathrm{A} 2,2=\quad-0.10187$

$\mathrm{A} 2,3=\quad 0.949171$

$\mathrm{A} 2,4=\quad-0.14483$

$\mathrm{A} 2,5=\quad-0.11609$

$\mathrm{A} 2,6=\quad-0.20423$

$\mathrm{A} 2,7=\quad-\mathbf{0 . 0 7 3 5 1}$

$\mathrm{A2}, 8=\quad-0.07046$

$\mathrm{A} 2,9=\quad 0.012384$

\section{Coeficientes}

para o Amarelo

$\mathrm{A31}=\quad \mathbf{- 0 . 3 7 3 8 1}$

$\mathrm{A} 32=\quad-0.59508$

A33 $=\quad 0.07444$

$\mathrm{A} 34=\quad 0.65498$

$\mathrm{A} 35=\quad 0.212902$

$\mathrm{A} 36=\quad 0.154454$

$\mathrm{A} 37=\quad \mathbf{- 0 . 0 3 0 0 4}$

$\mathrm{A38}=\quad \mathbf{- 0 . 0 0 5 8 3}$

$\mathrm{A} 39=\quad \mathbf{0 . 0 3 8 5 7 5}$

Coeficientes

(Wet-Green)

$\begin{array}{lc}\text { A41 }= & -2.6 E-05 \\ \text { A42 }= & -0.64159 \\ \text { A43 }= & 0.080263 \\ \text { A44 }= & 0.706163 \\ \text { A45 }= & 0.229528 \\ \text { A46 }= & 0 \\ \text { A47 }= & -0.03237 \\ \text { A48 }= & -0.00627 \\ \text { A49 }= & 0.041591\end{array}$


Fator de Normalização

$G=\quad 0.057948$

Fator de

Normalização

$\mathbf{G}=$

0.158241
Coeficientes

(Wet-Senesced)

A51= -2.1E-05

$\mathrm{A52}=\quad-\mathbf{0 . 6 6 9 0 6}$

$\mathrm{A53}=\quad \mathbf{0 . 0 8 3 6 9 9}$

$\mathrm{A54}=\quad \mathbf{0 . 7 3 6 3 9 6}$

$\mathrm{A55}=\quad-3.5 \mathrm{E}-06$

$\mathrm{A} 56=\quad-2.6 \mathrm{E}-06$

$\mathrm{A57}=\quad \mathbf{- 0 . 0 3 3 9 3}$

$\mathrm{A58}=\quad \mathbf{- 0 . 0 0 6 5 4}$

$\mathrm{A59}=\quad \mathbf{0 . 0 4 3 3 7 1}$

\section{Coeficientes}

(Green-Senesced)

A61 = -0.07493

$\mathrm{A62}=\quad-\mathbf{0 . 6 6 0 4 9}$

A63 $=\quad 0.082626$

A64 $=\quad 0.726962$

A65 $=0.137446$

A66 $=\quad 0.030949$

$\mathrm{A67}=\quad-\mathbf{0 . 0 3 3 4 6}$

A68 $=\quad-0.00646$

A69 $=\quad 0.042815$ 


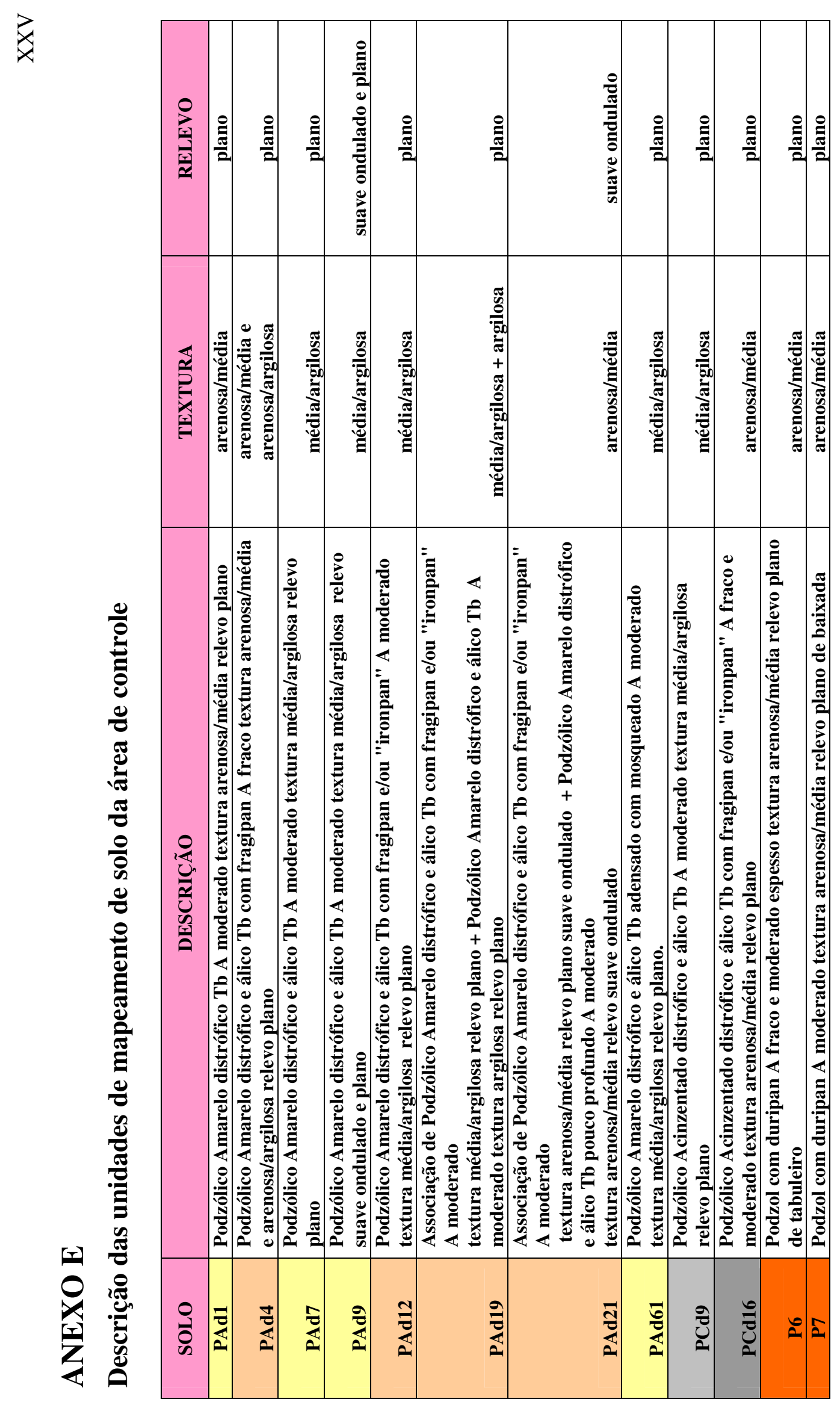




\section{ANEXO F}

Características gerais da imagem - Tabulação cruzada dos PI’s Nuvens_e_Sombras x Classes_solos (Área em pixels)

Plano-1: Nuvens_e_Sombras_Geral

$\begin{array}{lr}\text { \# linhas } & 488 \\ \text { \# colunas } & 497 \\ \text { \# pixels } & 242536\end{array}$

Resolução horizontal

Resolução vertical
1.000000

1.000000
Plano-2: Solos_Todas_Classes

\# linhas 488

\# colunas

497

\# pixels

242536

Resolução horizontal

Resolução vertical

1.000000

Plano-1 (nas linhas) : Nuvens_e_Sombras_Geral

Plano-2 (nas colunas): Solos_Todas_Classes

Número de pixels, área efetiva (livre de nuvens e sombras) e porcentagem em cada uma das unidades de solos com sombras e nuvens

Tabela F.1 - Área total, área efetiva e área com sombras e nuvens em cada unidade

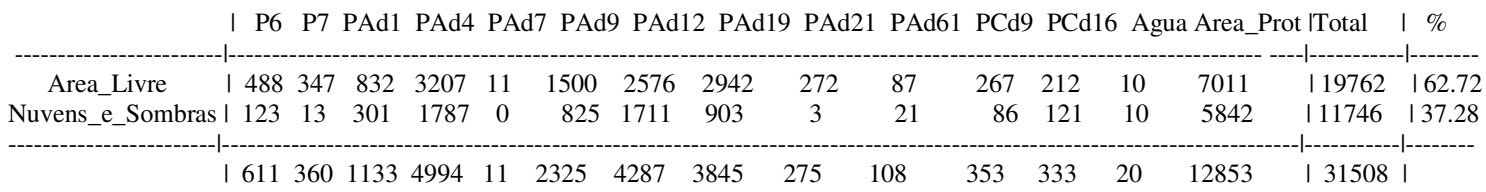

Tabela F.2 - Relação total e percentual de classes de solo efetiva (sem sombra) por área total do projeto

\begin{tabular}{|c|c|c|c|c|c|c|c|c|c|c|c|c|c|c|}
\hline & I P6 & P7 & PAd1 & PAd4 & PAd7 & PAd9 & PAd12 & PAd19 & $\operatorname{PAd} 21$ & PAd61 & PCd 9 & PCd16 & Agua & Area_Prot I Total \\
\hline Área_Projeto & । & 347 & 832 & 3207 & 11 & 1500 & 2576 & 2942 & 272 & 87 & 267 & 212 & 0 & 19762 \\
\hline$\%$ & 1.55 & 1.10 & 2.64 & 10.18 & 0.03 & 4.76 & 8.18 & 9.34 & 0.86 & 0.28 & 0.85 & 0.67 & 0.03 & 62.72 \\
\hline
\end{tabular}


Número de pixels por classes de solos reclassificação em áreas com sombras e nuvens e área efetiva (livre de nuvens e sombras)

Tabela F.3 - Total por projeto de áreas livres e com sombras e nuvens por classe de análise

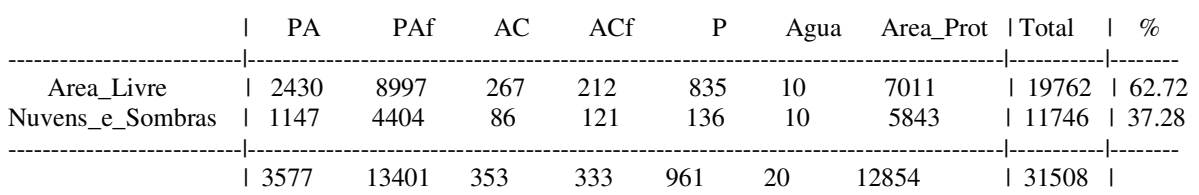

Tabela F.4 - Relação percentual de classes de análise por área total do projeto

\begin{tabular}{|c|c|c|c|c|c|c|c|c|}
\hline & I PA & PAf & $\mathrm{AC}$ & $\mathrm{ACf}$ & $\mathrm{P}$ & Agua & Area_Prot & | Total \\
\hline Área do Projeto & | 2430 & 8997 & 267 & 212 & 835 & 10 & 7011 & 19762 \\
\hline$\%$ & | 7.71 & 28.56 & 0.85 & 0.67 & 2.65 & 0.03 & 22.25 & | 62.72 \\
\hline
\end{tabular}

Tabela F.5 - Relação percentual de classes de análise por áreas livres

\begin{tabular}{|c|c|c|c|c|c|c|c|c|c|}
\hline & $\mid$ & PA & PAf & $\mathrm{AC}$ & $\mathrm{ACf}$ & $\mathrm{P}$ & Agua & Area_Prot & I Total \\
\hline Area_Livre & I & 2430 & 8997 & 267 & 212 & 835 & 10 & 7011 & | 19762 \\
\hline 9 & & 12.30 & 45.53 & 1.35 & 1.07 & 4.22 & 0.05 & 35.48 & I xxxxx \\
\hline
\end{tabular}




\section{Indice remissivo}

\begin{tabular}{|c|c|}
\hline Exatidão & $69,85,86,160,161,177$ \\
\hline exatidão do produto & $85,117,162$ \\
\hline exatidão do usuário & $86,117,161$ \\
\hline fatiamento & $134,139,140,147,148,156$, \\
\hline \multicolumn{2}{|l|}{$157,165,166$} \\
\hline fragipan & $109,110,111,115$ \\
\hline Gibsita & 38 \\
\hline Goetita & 39,40 \\
\hline Hematita & 39,40 \\
\hline histograma & $47,99,113,120,121,124,134$ \\
\hline
\end{tabular}

horizonte coeso $\quad, 1,6,93,110,146,162,166$

infravermelho médio $4,52,58,59,62,63,92$, $98,100,101,103,121,124,137,143,164$

infravermelho próximo $\quad 23,26,36,37,39,40,52$, $53,54,56,59,92,98,100,121,127,149,150$, $152,164,185$

linha do solo $\quad 36,58,59,149,150,152$ matéria orgânica $\quad 3,8,14,20,21,22,24,29$, $41,42,46,60,125,128,167,175$

Maxver $\quad, 74,75,76,81,82,119$

NDMI $\quad 5,56,61,62,89,98,103,152$, $154,155,156,157,165$

NDVI $\quad 5,33,34,53,55,56,57,58,59$, $60,61,62,89,98,102,103,104,152,154,156$, $157,165,184$

Podzol , 8, 110, 111, 117, 128, 142, 161, 162, 166 Podzólico $\quad 109,110,111,115,117,128$, 142, 145, 146, 151, 153, 154, 158, 161, 162, 166

Podzólico Acinzentado 110, 111, 115, 117, $128,142,145,146,151,153,154,158,162,166$ Podzólico Amarelo $\quad 109,110,111,115,117$, 142, 145, 146, 151, 153, 154, 158, 161, 162, 166 razão entre bandas $\quad 34,100,103,148$ reflectância $\quad 18,19,20,23,27,28,29,30,31$, $32,33,34,35,36,37,38,39,40,41,42,43,45$, $46,50,51,52,53,56,57,58,59,64,65,66,68$, 92, 97, 98, 100, 101, 106, 107, 121, 125, 126, 
$131,137,143,146,149,150,152,153,154$, $155,165,167,175,184,187$

resolução $\quad 17,18,23,24,25,26,28,36,37$, $41,61,70,79,80,83,94,95,98,100,102,164$, 167

SAVI $5,33,55,56,58,59,61,89,98,103$, $104,152,156,165,180$

solos $1,2,3,4,5,6,7,8,10,11,12,14,15,16$, $17,18,19,20,21,22,23,24,25,26,27,28,29$, $30,31,32,33,34,35,36,37,38,39,40,41,42$, $43,44,45,46,47,50,51,54,56,58,59,60,61$, $64,66,67,73,74,80,83,91,92,93,94,98,99$, 100, 101, 106, 107, 108, 109, 110, 113, 114, $115,116,117,125,127,128,129,133,135$, 136, 137, 138, 139, 141, 142, 143, 144, 145, $146,147,148,149,150,151,152,153,154$, $155,156,158,164,165,166,167,168,169$, $170,172,173,175,177,178,179,182,184$, $187,188,189,191$

Solos $\quad$, 6, 14, 17, 20, 31, 44, 115, 175, 176, 177, 188,192

Tabuleiros $\quad 1,2,3,4,6,7,8,9,12,15,91$, $164,169,181,182,188,189,191$
Tasseled Cap 5, 13, 34, 47, 53, 61, 62, 63, 65, 89, 95, 97, 98, 103, 104, 105, 106, 107, 108, $119,148,154,165,166,175,180$

textura $\quad 4,17,18,21,29,32,34,43,44,68$, $109,110,128,151,166$

Umidade $\quad 54,61,63,64,65,103,106,152$, $154,155,156,157,165$

umidade do solo $\quad 29,30,31,33,36,41,55,69$, 93, 140,141, 145, 146, 149, 153, 177, 185

vegetação $\quad 19,21,24,29,30,33,34,36,49$, $52,53,54,55,56,57,58,59,60,61,62,63,64$, $65,67,80,91,92,103,104,106,107,117,124$, 129, 133, 134, 135, 136, 137, 141, 142, 143, $144,145,148,149,150,151,152,153,155$, $165,168,177,179$

Verde $\quad 34,54,63,64,92,106,121,134$, $141,149,150,152,153,155$ 